\title{
Expression and Functional Analysis of Vsig1 Gene
}

\author{
Dissertation \\ zur Erlangung des Doktorgrades \\ der Mathematisch-Naturwissenschaftlichen Fakultäten \\ der Georg-August-Universität zu Göttingen
}

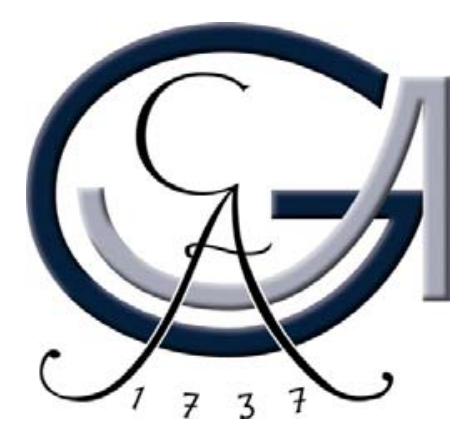

vorgelegt von

Odgerel Oidovsambuu

aus Ulaanbaatar, Mongolei

Göttingen, 2009 
D7

Referent:

Prof. Dr. W. Engel

Korreferentin:

Prof. Dr. S. Hoyer-Fender

Tag der mündlichen Prüfung: 


\section{ABBREVIATIONS}

ABI

APS

ATP

BAC

BCP

BLAST

bp

BSA

${ }^{\circ} \mathrm{C}$

cDNA

Cy3

dATP

dH2O

DAPI

dCTP

DMSO

DEPC

DNA

DNase

dNTP

dpc

dT

DTT

EDTA

EGL

ES

F

FCS

GAPDH
Applied Biosystem Instrument

Ammonium peroxodisulfate

Adenosintriphosphate

Bacterial Artificial Chromosome

1 -bromo-3 -chloropropane

Basic Local Alignment Tools

base pair

Bovine serum albumin

Degree Celsius

complementary DNA

indocarbocyanine

Desoxyriboadenosintnphosphate

distil Water

Diamidino-2-phenylindoledihydrochloride

Desoxyribocytosintriphosphate

Dimethyl sulfoxide

Diethylpyrocarbonate

Deoxyribonucleic acid

deoxyribonuclease

deoxynucleotidetriphosphate

day post coitus

deoxythymidinate

Dithiothreitol

Ethylene diamine tetraacetic acid

External granular layer

Embryonic stem

Filial generation

Fetal calf serum

Glyceraldehyde 3-phosphate dehydrogenase 
g

gm

HEPS

HPLC

hr(s)

IgG

IPTG

JL

$\mathrm{kb}$

LB

M

$\mathrm{Mb}$

ML

MoCo

MOCS

MOPS

mRNA

mg

$\mathrm{ml}$

$\mu \mathrm{l}$

um

$\min$

$\mathrm{NaAc}$

NBT

NCBI

Neo

ng

$\mathrm{nm}$

NTP

OD

ORF

PAC

PAGE

PAR1, 2 gravity

gram

N-(-hydroxymethyl)piperazin,N'-3-propansulfoneacid

High performance liquid chromatograpy

hour(s)IGL

Immunoglobulin G

Isopropyl-B-thiogalactopyranoside

Jackson Laboratory

kilobase

Luria-Bertrani

molarity

Mega base pair

Molecular layer

Molybdenum cofactor

Molybdenum cofactor synthesis step

3 - [N-Morpholino] -Propaneslilfate

messenger Ribonucleic acid

milligram

millileter

microliter

micrometer

minute

Sodium acetate

Nitro-blue tetrazolium

National Center for Biotechnology Information

Neomycin

nanogram

nanometer

Nucleotidetriphospate

Optimal density

Open Reading Frame

Bacteriophage PI Artificial Chromosome

Polyacrylamide Gel Electrophoresis

Fatty acyl-CoA reductase protein $(1,2)$ 


\begin{tabular}{|c|c|}
\hline PCR & Polymerase chain reaction \\
\hline $\mathrm{pH}$ & Preponderance of hydrogen ions \\
\hline pmol & picomol \\
\hline PBS & Phosphatebuffersaline \\
\hline PBT & Phosphatebuffersaline + Tween 20 \\
\hline PMSF & Phenylmethylsulfonyl fuoride \\
\hline RNA & Ribonucleic acid \\
\hline Rnase & Ribonuclease \\
\hline Rnasin & Ribonuclease inhibitor \\
\hline rpm & revolution per minute \\
\hline RT & Room temperature \\
\hline RT-PCR & Reverse transcriptase-PCR \\
\hline SDS & Sodium Dodecylsulfate \\
\hline SDS-PAGE & SDS-Polyacrylamide Gel Electrophoresis \\
\hline sec & second \\
\hline Tag & Thermus aquaticus \\
\hline TBE & Tris-Borate-EDTA-Elecrrophoresis buffer \\
\hline $\mathrm{TE}$ & Tris-EDTA buffer \\
\hline TEMED & Tetramethylethylene diamine \\
\hline Tris & Trihydroxymethylaminomethane \\
\hline $\mathrm{U}$ & Unit \\
\hline UV & Ultra violet \\
\hline $\mathrm{V}$ & Voltage \\
\hline $\mathrm{w} / \mathrm{v}$ & weight/volume \\
\hline X-Gal & 5-bromo-4-chloro-3-indolyl-fi-galactosidase \\
\hline
\end{tabular}

\section{Symbol of amino acids}
A Ala Alanine
B AA Asparagine or Asparatic acid
C Cys Cysteine
D Asp Asparatic acid
E Glu Glutamic acid 


$\begin{array}{lll}\text { F } & \text { Phe } & \text { Phenylalanine } \\ \text { G } & \text { Gly } & \text { Glycine } \\ \text { H } & \text { His } & \text { Histidine } \\ \text { I } & \text { He } & \text { Isoleucine } \\ \text { K } & \text { Lys } & \text { Lysine } \\ \text { L } & \text { Leu } & \text { Leucine } \\ \text { M } & \text { Met } & \text { Methionine } \\ \text { N } & \text { Asn } & \text { Asparagine } \\ \text { P } & \text { Pro } & \text { Proline } \\ \text { Q } & \text { Gin } & \text { Glutamine } \\ \text { R } & \text { Arg } & \text { Arginine } \\ \text { S } & \text { Ser } & \text { Serine } \\ \text { T } & \text { Thr } & \text { Threonine } \\ \text { V } & \text { Val } & \text { Valine } \\ \text { W } & \text { Trp } & \text { Tryptophan } \\ \text { Y } & \text { Tyr } & \text { Tyrosine } \\ \text { Z } & \text { Glx } & \text { Glutamine or Glutamic acid }\end{array}$

\section{Symbols of nucleic acids}
A Adenosine
C Cystidine
G Gaunosine
$\mathrm{T} \quad$ Tymidine
U Uridin 


\section{TABLE OF CONTENTS}

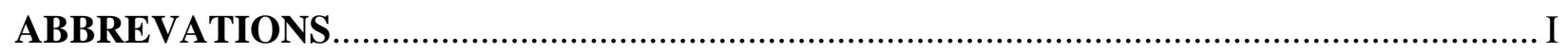

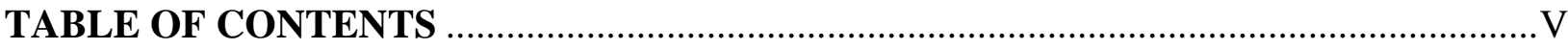

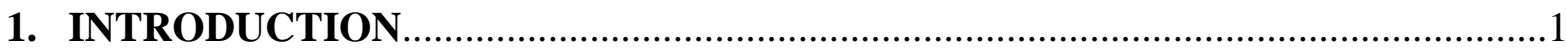

1.1 Structure of the stomach .............................................................................................

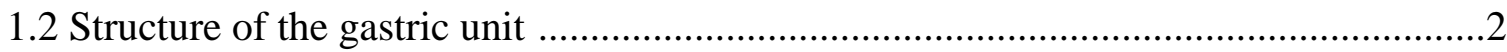

1.3 Stomach development in vertebrates .................................................................

1.4 Isolation of murine Vsig1 gene, a member of immunoglobulin superfamily ................8

1.5 Aims of the study .................................................................................................

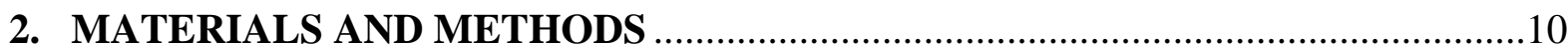

2.1 Materials ....................................................................................................10

2.1.1 Chemicals............................................................................................10

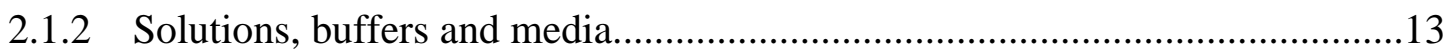

2.1.2.1 Agarose gel electrophoresis ....................................................................13

2.1.2.2 SDS-PAGE ...............................................................................13

2.1.2.3 Frequently used buffers and solutions .....................................................14

2.1.3 Laboratory materials ...................................................................................17

2.1.4 Sterilizations of solutions and equipments .....................................................17

2.1.5 Media, antibiotics and agar-plates ..................................................................18

2.1.5.1 Media for bacteria ..................................................................................18

2.1.5.2 Media for cell culture...............................................................................18

2.1.6 Antibiotics.................................................................................................19

2.1.7 IPTG/X-Gal plate................................................................................19

2.1.8 Bacterial strains.......................................................................................19

2.1.9 Eukaryotic strains...................................................................................19

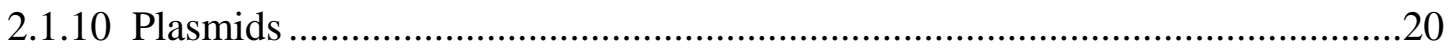

2.1.11 Synthetic oligonucleotides ..........................................................................20

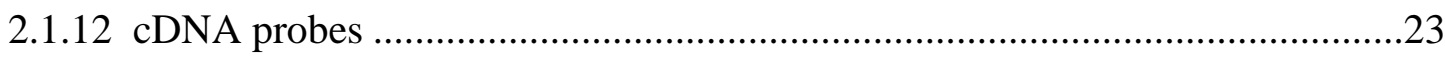

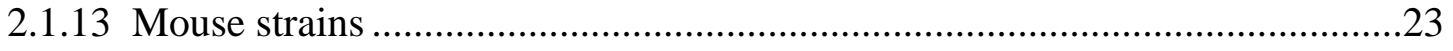




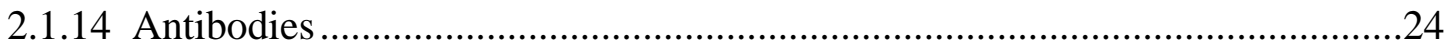

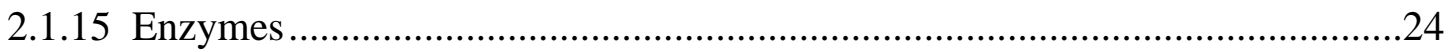

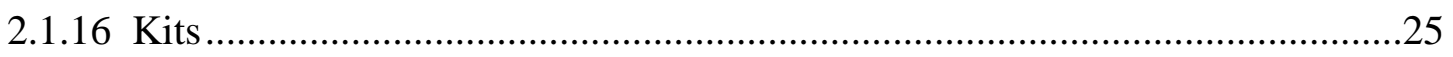

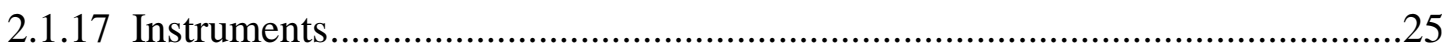

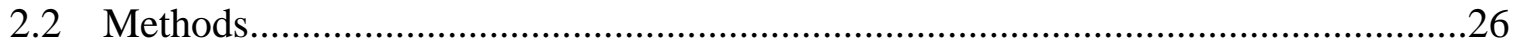

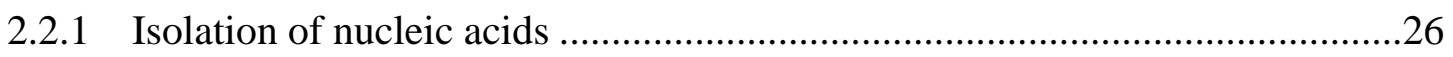

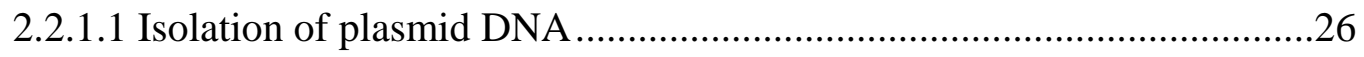

2.2.1.1.1 Small-scale isolation of plasmid DNA ..............................26

2.2.1.1.2 Large-scale preparation of plasmid DNA ...........................27

2.2.1.1.3 Endotoxin free preparation of plasmid DNA ......................27

2.2.1.2 Isolation of genomic DNA from tissue samples .................................28

2.2.1.3 Isolation of total RNA from tissue samples and cultured cells...............28

2.2.2 Determination of the nucleic acid concentration .......................................29

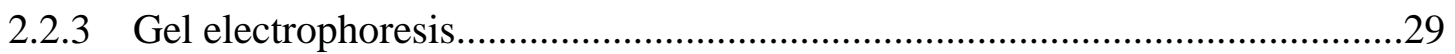

2.2.3.1 Agarose gel electrophoresis of DNA …...............................................30

2.2.3.2 Agarose gel electrophoresis of RNA …..............................................30

2.2.3.3 SDS-PAGE for the separation of proteins ..........................................30

2.2.4 Isolation of DNA fragments after agarose gel electrophoresis .......................31

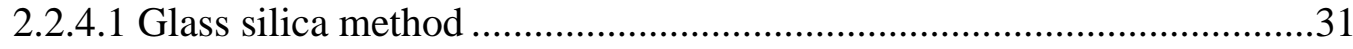

2.2.4.2 QIAquick gel extraction method.......................................................32

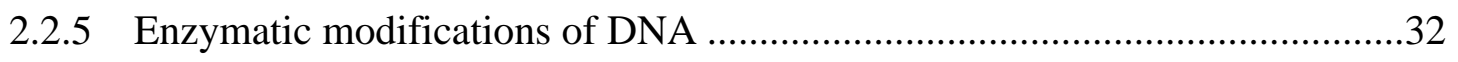

2.2.5.1 Restriction digestion of DNA …........................................................32

2.2.5.2 Ligation of DNA fragments ............................................................33

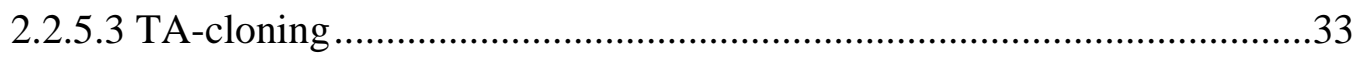

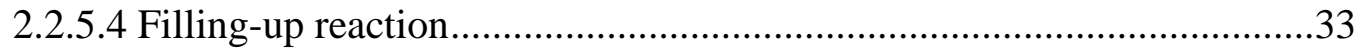

2.2.6 Preparation of competent E. Coli bacteria ..................................................34

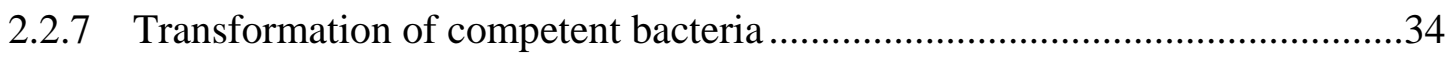

2.2.8 Polymerase Chain Reaction (PCR) .............................................................34

2.2.8.1 PCR amplification of DNA fragments..............................................35

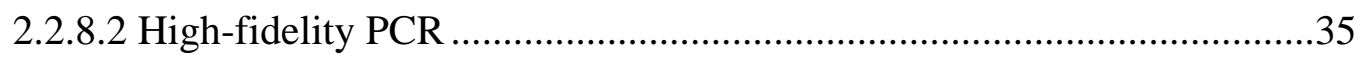

2.2.8.3 Reverse transcription PCR (RT-PCR) ...............................................36 
2.2.8.4 One-Step RT-PCR ..................................................................................

2.2.8.5 Quantative Real-Time PCR .....................................................................38

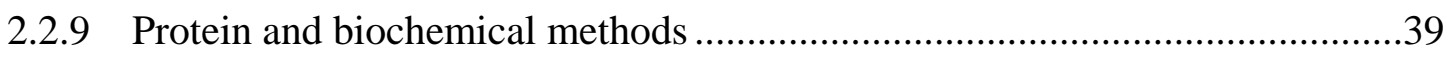

2.2.9.1 Isolation of total proteins from animal tissues .............................................39

2.2.9.2 Isolation of total proteins from cell culture................................................39

2.2.9.3 Determination of protein concentration .....................................................39

2.2.9.4 N-Glycosidase-F treatment of protein ......................................................40

2.2.10 Blotting techniques ...................................................................................40

2.2.10.1 Southern blotting of DNA to nitrocellulose filters ................................40

2.2.10.2 Northern blotting of RNA onto nitrocellulose filter ..............................41

2.2.10.3 Western blotting of protein onto PVDF membrane................................41

2.2.10.4 "Random Prime" method for generation of ${ }^{32}$ P-labeled DNA ..............42

2.2.10.5 5'-end radiolabeling of target DNA .......................................................42

2.2.11 Non-radioactive dye terminator cycle sequencing...........................................42

2.2.12 Hybridisation of nucleic acids ........................................................................

2.2.13 Generation of polyclonal antibody against fusion protein.................................43

2.2.13.1 Development of fusion protein using pET system.................................43

2.2.13.2 Purification of fusion protein using GST affinity column .....................44

2.2.13.3 Immunization of rabbit .......................................................................44

2.2.13.4 Purification of whole IgG from immunized rabbit serum ....................45

2.2.13.5 Purification of VSIG1 specific antibody...............................................45

2.2.13.5.1 Preparation of affinity column .................................................45

2.2.13.5.2 Affinity purification of VSIG1 specific antibody .................46

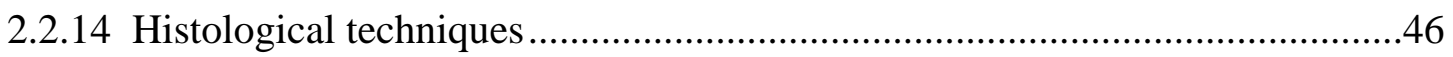

2.2.14.1 Tissue preparation for paraffin embedding ............................................46

2.2.14.2 Sections of paraffin block ...................................................................46

2.2.14.3 Hematoxylin-Eosin (HE) staining of the histological sections.............47

2.2.14.4 Immunohistochemistry ………………………....................................47

2.2.14.5 Immunocytochemistry ........................................................................

2.2.15 Establishment of stable transfected HepG2 cell line .......................................48

2.2.16 Cell culture assays on stable transfected HepG2 cell lines...............................48 
2.2.16.1 Cell-Cell adhesion assay by hanging drop method................................48

2.2.16.2 Cell migration assay...........................................................................49

2.2.17 Establishment of primary stomach cell culture..............................................49

2.2.18 Techniques for production of targeted mutant mice ..........................................50

2.2.18.1 Production of targeted embryonic stem cell clones ...............................50

2.2.18.1.1 Preperation of MEFs feeder layers .........................................50

2.2.18.1.2 Growth of ES cells on feeder layer .......................................51

2.2.18.1.3 Electroporation of ES cells ..................................................51

2.2.18.1.4 Growing ES cells for Southern blot analysis ........................52

2.2.18.2 Production of chimeras by injection of ES cells into blastocyst...........52

2.2.18.3 Detection of chimerism and mice breeding .........................................52

2.2.19 Software and Computer tools .........................................................................53

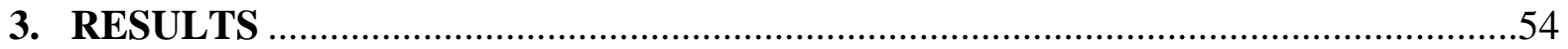

3.1 Isolation and characterization of Vsig1 cDNA …….............................................54

3.2 Analysis of amino acid sequence of murine VSIG1 .................................................57

3.3 Generation and purification of polyclonal anti-VSIG1 antibody ..............................59

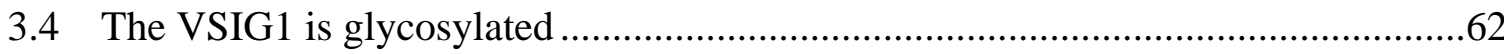

3.5 Expression pattern of murine Vsig1 gene ...............................................................63

3.5.1 Expression analysis of Vsig1 in different adult tissues ....................................63

3.5.2 The Vsig1 expression is restricted to glandular epithelium of stomach .........66

3.5.3 Cellular distribution of Vsig1 transcript and protein in adult stomach ............67

3.5.4 The Vsig1 gene is subjected to $\mathrm{X}$-inactivation ...............................................71

3.5.5 Expression pattern of Vsig1 during prenatal and postnatal developmental of stomach

3.5.6 Cellular distribution of VSIG1 protein in prenatal developmental stages of stomach

3.5.7 Expression analysis of Vsig1 in teratocarcinoma ............................................77

3.6 Functional analysis of Vsig1 ...............................................................................

3.6.1 Generation of conventional knockout mice ………….....................................78

3.6.1.1 Construction of Vsig1 targeting vector .....................................................78

3.6.1.1.1 Subcloning of the 5'-flanking region of the Vsig1 gene into the pPNT-1 vector 


\subsection{Subcloning of the 3'-flanking region of the gene} into pPNT-1 vector ........................................................78

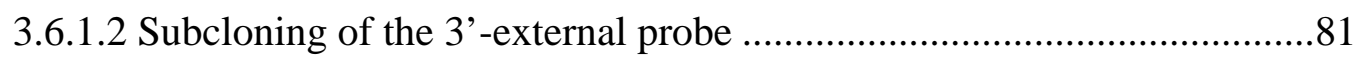

3.6.1.3 Electroporation of R1 ES-cells ....................................................81

3.6.1.4 Analysis of recombinant ES-cells ..................................................82

3.6.1.5 Generation of chimeric mice...............................................................83

3.6.1.6 Analysis of contribution of $129 / \mathrm{Sv}$ cells in testis of chimeric mice .......83

3.6.2 Transdifferentation of $V \operatorname{sig}^{-} / Y$ cells from stratified to cornified epithelium .84

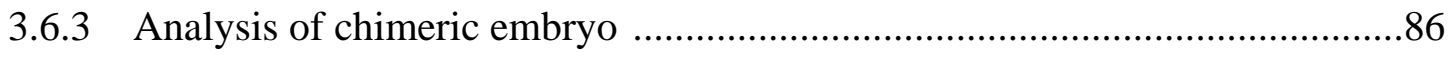

3.6.4 Generation of Vsig1 conditional knockout mice.........................................89

3.6.4.1 Generation of conditional targeting construct.......................................89

3.6.4.1.1 Subcloning of the 5'-flanking region of the Vsig1 gene into the pPNT-4 vector.

3.6.4.1.2 Subcloning of the 5'-flanking region of the Vsig1 gene into pPNT4 vector.

3.6.4.2 Subcloning of the 3'- and 5'-external probe .........................................93

3.6.4.3 Electroporation of R1 ES-cells ........................................................93

3.6.4.4 Analysis of recombinant ES cell clones.........................93

3.6.4.5 Generation and analysis of chimeric mice .........................97

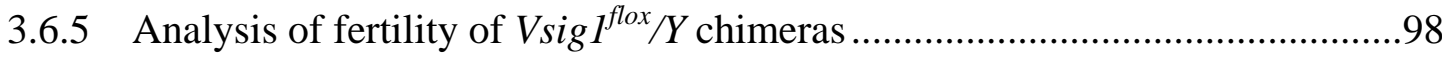

3.6.6 Expression analysis of Vsig1 in stomach of $V$ sig $1^{\text {flox }} / Y$ chimeric mouse.......105

3.6.7 Deletion of Pgk-Neo cassette in $V s i g 1^{\text {flox }} / Y$ ES cell ....................................106

3.7 Generation and characterization of Vsig1-EGFP transgenic mice ........................108

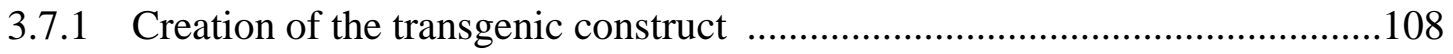

3.7.2 Transmission and expression analysis of the Vsig1-EGFP transgene ...........109

3.7.3 Determination of number of integration sites in the genomes of transgenic lines

3.7.4 Measurement of ratio of GFP-positive cells in transgenic stomach at different developmental stages

3.7.5 Cellular distribution of GFP-positive cells in stomach..............................117

3.7.6 Establishment and characterization of GFP-positive primary cell culture ....119 
3.7.7 Expression analysis for different marker genes in primary cell culture of stomach

3.8 Analysis of cell adhesion and cell migration in stable cell lines

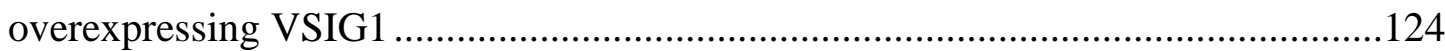

3.8.1 Generation of pcDNA-Vsig1 construct .........................................................124

3.8.2 Establishment of stable transfected cell lines ..................................................125

3.8.3 Analysis of cell-cell adhesion of stable cell line..........................................127

3.8.4 Analysis of migration properties of the stable cell line ..................................128

3.9 Expression analysis of human Vsig1 in gastric cancer tissues..................................130

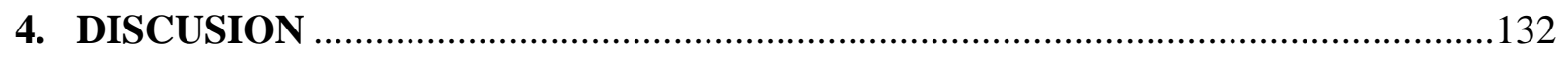

4.1 Summary of important results of the study ........................................................132

4.2 Overview of immunoglobulin superfamily..............................................................134

4.3 VSIG1 belongs to immunoglobulin superfamily ………………………………......135

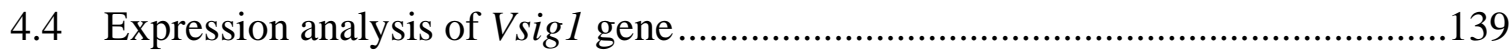

4.5 VSIG1 is a transmembrane protein localized on plasma membrane of glandular

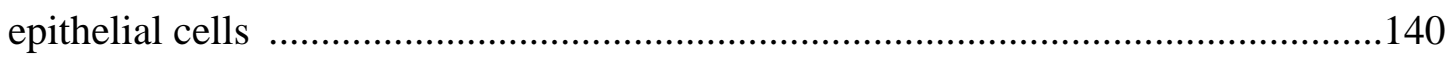

4.6 Isolation and characterization of stomach stem cell ................................................143

4.7 Functional analysis of Vsig1 in chimeric mice .......................................................146

4.8 Perspectives....................................................................................................151

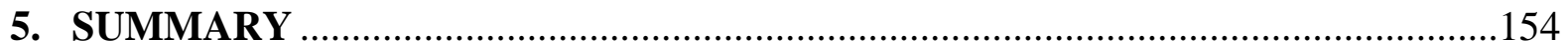

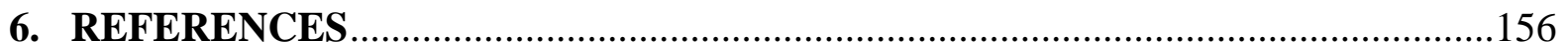

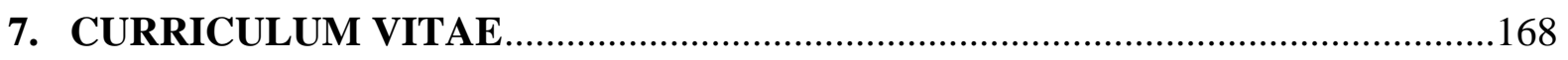

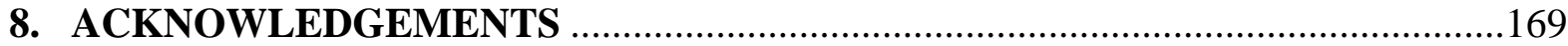




\section{INTRODUCTION}

\subsection{Structure of the stomach}

In most mammals, the stomach is a hollow muscular organ of the gastrointestinal tract, which is involved in the second phase of digestion following mastication. The stomach is localized between the oesophagus and the duodenumn in the space of the left anterior quadrant of the abdominal cavity, partly concealed by the left lateral lobe of the liver. The word stomach is derived from the Latin stomachus, which derives from the Greek word stomachos ( $\sigma \tau$ ó $\alpha \propto \chi \varsigma \varsigma)$. The words gastro- and gastric (meaning related to the stomach) are both derived from the Greek word gaster ( $\gamma \alpha \sigma \tau \eta \dot{\eta} \rho)$.

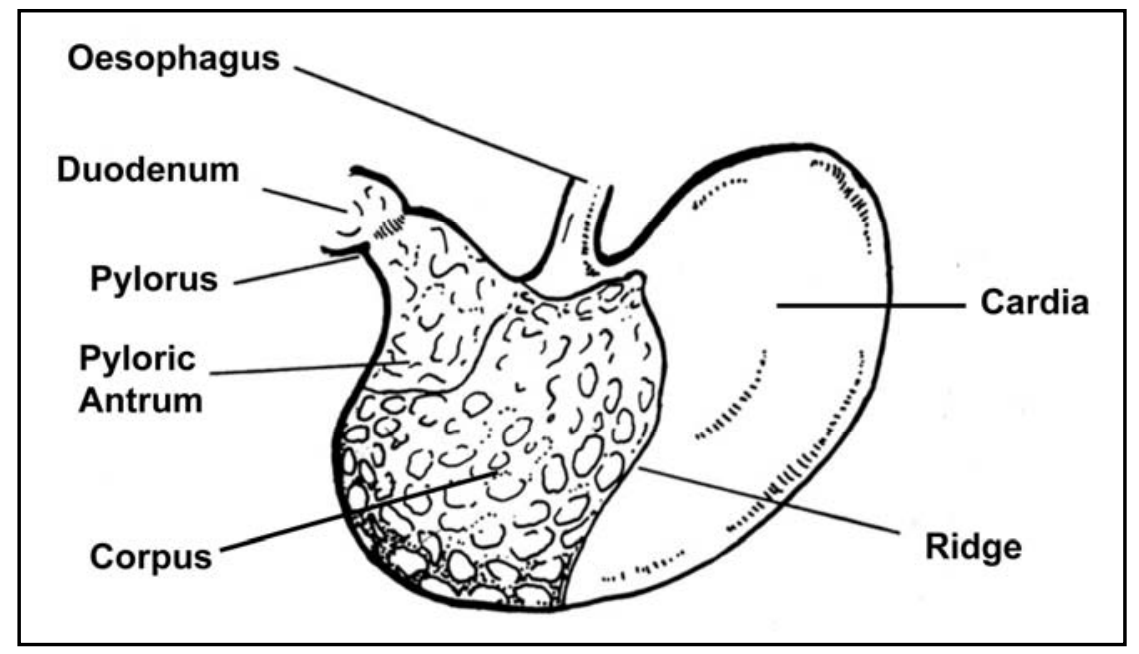

Figure 1.1 Schematic illustration of mouse stomach. (Coleman et al.,1966). According to the epithelial structure, the stomach can be subdivided into two main parts called as forestomach and glandular stomach. The glandular stomach contains corpus and antrum regions which are composed of monolayered glandular epithelium. The forestomach or cardia region is composed of polylayered squamous epithelium. Division of these two regions is visible grossly by the ridge. The pylorus marks the boundary between stomach and small intestine. 
The stomach has the following three basic functions. 1. Chemical and mechanical digestion of food 2. Killing of ingested pathogenic microorganisms 3. Holding food and release it at a constant rate (Raven and Johnson, 1993).

The stomach is a highly acidic environment due to hydrochloric acid production and secretion, which produces a luminal $\mathrm{pH}$ range usually between 1.5 and 2.5 depending on the food intake, time of the day and other factors. The adult mouse stomach can produce about 2.5 to $4 \mathrm{ml}$ of gastric acid per day with basal secretion levels being typically highest in the evening (Ogawa and Necheles, 1958).

\subsection{Structure of the gastric unit}

A murine stomach consists of two distinct parts, the forestomach and the glandular stomach. The forestomach is lined with a multilayer of squamous epithelium which shows cornification and it is almost identical to the oesophageal epithelium. The glandular stomach is lined with a monolayer of columnar epithelium, which forms gastric units (Fig. 1.1).

The term "gastric unit" (gastric gland) was introduced for first time by Plenck in 1932. He proposed that the epithelial cells lining the gastric lumen are organised as columnar shaped gastric unit, which represents the structural unit of stomach epithelium. Plenck has subdivided the gastric unit into four regions called as the pit, the isthmus, the neck and the base (Plenck, 1932). Totally 11 different cell types have been identified in gastric unit (Fig. 1.2 A). The cellular content of gastric unit varies in different regions of adult stomach. The proximal glandular stomach (fundus) has large gastric units with small pit regions, whereas the distal stomach (antrum) has small glands with large pit regions. Fundic glands are composed of parietal cells, endocrine cells and mucous neck cells, a cell type with uncertain function. Antral glands are exclusively composed of mucous and endocrine cell types (Karam and Leblond, 1993).

The glandular epithelium undergoes continuous renewal of its component cell lineages. Karam and Leblond (1992) combined radioactive thymidin labelling and electron microscopy analysis to examine the pathway of cell renewal in gastric unit of the glandular region of adult mice. The results of the analysis revealed that the multipotent stem cells of the glandular epithelium are residing in the isthmus region. There are three progenitor cell lineages, pre-pit, pure-neck and pre-parietal precursors, which become 
differentiated from multipotent stem cells. Within the gastric glands, migration of precursor cells is bidirectional from the isthmus region to form the gastric epithelium. Thus, the pre-pit precursor differentiation into mucus secreting pit cells moves upwards to the isthmus region, while the pre-neck precursors differentiate successively into pepsinogen producing neck cells and then zymogenic cells which migrate downwards to base region. In contrast, acid producing parietal cell precursors migrate to both directions of upward and downward (Fig 1.2 B). It is also considered that the antral gastric mucosa including the endocrine cells derive from a common stem cell located in the isthmus region (Karam and Leblond, 1995). The hormone secreting enteroendocrine cells are scattered in all four regions of gastric unit (Karam, 1999).

The precursor cell population makes up approximately 3\% of the gastric epithelium in adult mice. The lifespan of different gastric cells is different. The lifespan of differentiated pit, parietal and zymogenic cells averages 3, 54 and 194 days, respectively.

In the mouse, the gastric unit contains approximately 200 epithelial cells (Karam and Leblond, 1992). Experiments in $\mathrm{XX} \leftrightarrow \mathrm{XY}$ and $\mathrm{CH} 3 \leftrightarrow \mathrm{BALB} / \mathrm{C}$ chimeric mice have identified the presence of homotypic gastric glands derived from each of the parental strains (Thompson et al., 1990; Tatematsu et all., 1994). These results indicate that the gastric units in the mouse are colonally derived. In addition, an examination of the chromosomal complement of the gastrin-producing endocrine cells in the $\mathrm{XX} \leftrightarrow \mathrm{XY}$ chimeras demonstrated that these were or were not Y-positive, depending on whether the gland developed from a Y-containing clone or not. This indicates that at least the gastrin-secreting endocrine cells of the antrum are derived from a common stem cell. Experiments in $\mathrm{X}$-inactivation mosaic mice expressing the lacZ reporter gene investigating the clonality of gastric glands in the fundic and pyloric regions of developing mice demonstrated that while most glands are initially polyclonal with three or four stem cells per gland, they become monoclonal during the first six weeks of murine life (Nomura et al., 1998). 

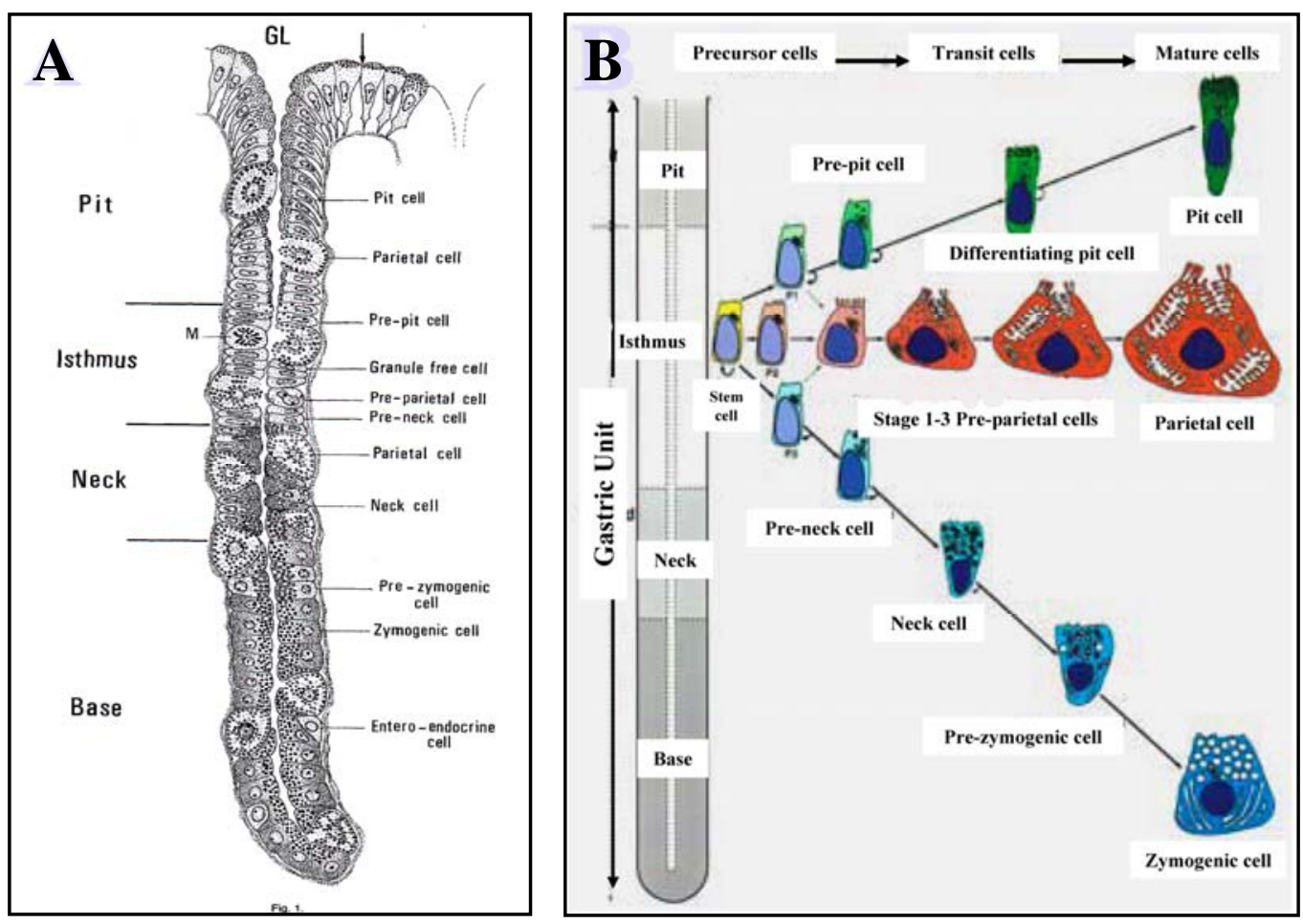

Figure 1.2 Schematic illustration of the gastric unit and cell differentiation fate in the gastric unit of the corpus region of stomach (Karam and Leblond, 1993 (A), 1999(B)). Drawing of a gastric unit from the corpus of the mouse stomach is shown (A). The gastric unit is divided into four regions listed at left side. The gastric unit contains 11 different cell types listed at right side. The pit region has pit cells, in which secretory granules accumulate at the apex, and also includes a few parietal cells. The isthmus region is characterized by the presence of four rather small cells including granule-free cells, pre-pit cells, pre-parietal cells and pre-neck cells. The neck region begins by the presence of the first neck cell, which is characterized by the pale secretory granules. The base region extends from the first zymogenic cell to the blind end of the unit. Also lightly stained enteroendocrine cells are included in the base region. The illustration-B shows cytodifferentation fate of the cells in the gastric unit. The stem cells (granule free cells in A) are located in the isthmus region which includes all precursor cells seen at the right. The stem cells give rise to three precursors: pre-pit cell precursors (P1), pre-parietal cell precursors (P2) and pre-neck cell precursors (P3), which evolves into pit, parietal and zymogenic cell lineages respectively. The straight arrows for pit and zymogenic cell lineages indicate the migration 
pathways. After their differentiation in the isthmus, parietal cells migrate in both directions.

\subsection{Stomach development in vertebrates}

After gastrulation of mouse embryo, the gastrointestinal tract develops from two germ layers, the endoderm and mesoderm, and it is innervated by cells derived from the third germ layer, the ectoderm. During development, the gut evolves from a simple tube that is morphologically homogenous to a highly complex organ that has distinct functional domains along the anterior -posterior and vertical (cross-sectional) axis and develops multiple accessory organs (Fig 1.3). Three different regions are normally recognized. The foregut forms oesophagus, stomach, proximal duodenum, thymus, thyroid, lung, pancreas and liver. The midgut forms most of the intestine. The hindgut forms the distal transverse colon, sigmoid and anorectum. The patterning mechanism along the vertical, horizontal axis and induction of growth of accessory organs all involve cross talk between the cells of endoderm and mesoderm.

The endodermal layer of gastrointestinal tube of E8.5 is still a histological uniform pseudostratified layer of cuboid epithelial cells. Despite its morphological uniformity, the endodermal layer is already patterned along the anterior-posterior (AP) axis at this point in development (Gordon and Hermiston, 1994; Wells and Melton, 1999).

Gastric mesenchyme is essential for survival of the epithelium in vitro, and tissuegrafting experiments have shown that a diffusible factor from the mesenchyme is critical for stomach epithelial development in the chicken (Koike and Yasugi, 1999). Recombination with forestomach mesenchyme did not change the fate of glandular epithelium and vice versa after E11.5 in the mouse (Fukamachi et al., 1979), suggesting that the primary specification of the gastric epithelium occurs before E11.5. In addition to this primary specification of the stomach, a secondary cell specification and glandular formation is required to form the mature stomach. Differentiation of the epithelium is first noted on day of E12.5. The epithelium of the forestomach begins to stratify on day of E13.5, and keratinisation is first noted on day E16.5. In the glandular stomach, the epithelium begins to stratify on day E12.5 and intra-epithelial vacuoles first appear on day 13.5. Primitive gastric glands are formed on day 15.5 (Fukamachi et al., 1979). Even differentiation of specific cell lineages and invaginations of epithelium to form glands begin already in the embryo, but mature glands are not formed until 
after birth. At birth, $90 \%$ of the cells in the rudimentary gastric units are precursor cells and this percentage is reduced to $20 \%$ in the first 7 days postnatally (P1-P7), when cellular differentiation occurs while gland size remains stable (Karam and Gordon, 1997). The second week after birth (P8-P14) is marked by an increase in the number of all cell types and glandular growth. Between P15 and P28, further cellular differentiation and glandular growth occur, and the cells in the glands are compartmentalized (Karam and Gordon, 1997).

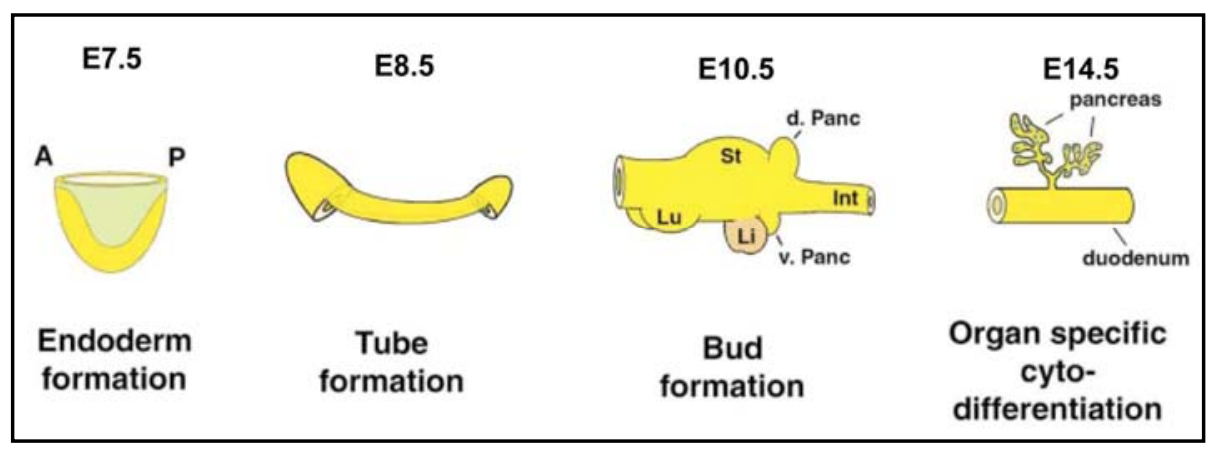

Figure 1.3 Stages of endoderm development (Wells et al., 1999). The illustration shows four stages of development of the gastrointestinal tract in mouse embryos (E7.5-E14.5). Embryonic endoderm is in yellow and the visceral (yolk sac) endoderm in light green. At the end of gastrulation (E7.5), the endoderm is a one cell-layer thick cup of approximately 500 cells, which covers the mesoderm and ectoderm of the embryo. Within 24 hrs (E8.5), a series of morphogenetic processes transforms the gut into a tube. The next step, the formation of organ buds, is seen in a E10.5 embryo, which has been stained for the pancreatic/duodenal marker $P d x 1$. In the lower panel, the schematized E10.5 gut tube shows the relative positions of organ buds (in the figure: lung-Lu, liver-Li, stomach-St, dorsal pancreatic bud-d.Panc, ventral pancreatic bud-v.Panc, and duodenum/intestine-Int). The E14.5 upper panel shows a dissected stomach, pancreas, and duodenum that have been stained for Pdx1 expression.

Many studies have revealed that the interactions of endodermal derived epithelium and mesodermal derived mesenchyme is crucial for cytodifferentation of stomach development. But still now the underlying molecular mechanisms are not well understood. Several epithelial and mesenchymal interactions have been implicated in 
the organogenesis of the stomach. For example, epithelial cell proliferation in the stomach and duodenum is increased in mice that lack the mesenchymal-specific forkhead transcription factor Fkh6 (Kaestner et al., 1997), and these mice have structural abnormalities of stomach, duodenum, and jejunum.

About 30 years ago, Fukumachi and his colleagues investigated the interactions between epithelial and mesenchymal tissues during development of the forestomach and the glandular stomach of fetal mice in vitro. They identified that stomach epithelium could not survive when cultivated alone, but its development was supported by the presence of homologous or heterologous mesenchyme. The developmental fate of the epithelium was affected by recombination with heterologous mesenchyme depending on the type of mesenchyme. The rate of keratinisation of the forestomach epithelium was significantly greater on recombination with homologous mesenchyme than on recombination with heterologous mesenchyme. Moreover, the rate of formation of glandular structures in the glandular stomach epithelium was significantly greater on recombination with 16.5-day stomach mesenchyme than on recombination with 14.5or 18.5-day stomach mesenchyme (Fukumachi et al., 1979). Also soon it was clearly shown that the squamous epithelium recombined with glandular mesenchyme has the ability of transdifferentation of glandular epithelium and ECPg (embryonic pepsinogen) expression (Mizuno and Yasugi, 1990). These results give us suggestion that the epithelial and mesenchymal interaction has a significant role for stomach cytodifferentation and the developmental fate of stomach epithelium could be characterized by molecular factors which are secreted from the mesenchymal tissues. BMP2 is one of the identified molecules, and it is secreted from mesenchyme, and responsible for epithelial differentiation (Narita et al., 2000). Bmp2/4 are members of a group of secreted growth factors, known as bone morphogenic proteins, which are involved in many inductive events during organogenesis, such as lung (Bellusci et al., 1996; Sakiyama et al., 2000) and tooth (Bei and Maas 1998, Tucker et al., 1998). In E46 chicken embryo, Bmp2 is expressed in mesenchyme of glandular stomach and lung mesenchyme (Narita et al., 2000). But Bmp2 is never expressed in the mesenchyme of forestomach or small intestine. It is found that, when Bmp2 is overexpressed in the mesenchyme of forestomach using retroviral constructs, the squamous epithelium of forestomach forms more glands and expressed ECPg (Embryonic pepsinogen). On the other hand, when the activity of the BMP2 is inhibited in mesenchyme of glandular stomach, the formation of glands and the expression of ECPg is completely inhibited. 
These results strongly suggest that BMP2 is a glandular mesenchymal factor that induces gland formation of epithelia and expression of ECPg in the epithelium (Narita et al., 2000).

Hedgehog signalling pathway plays a critical role for cytodifferentation of stomach epithelium. From early stomach development at E11.5 until after the onset of gastric epithelial cytodifferentiation at E15.5, Shh (Sonic hedgehog) is expressed at high levels in the forestomach and lower levels in the hindstomach, whereas Ihh (Indian hedgehog) is expressed in the hindstomach (Bitgood and McMahon, 1995). Ihh expression in the glandular stomach depends on FGP signalling as both $\mathrm{Fgfr}_{2} \mathrm{~b}^{-/-}$and $\mathrm{Fgf1}^{-/-}$mice have lack of expression of $I h h$ in the stomach (Spencer-Dene et al., 2006). When Shh is overexpressed throughout the whole glandular epithelium, there is neither gland development nor detectable Ihh expression in the epithelium. However, if SHH activity is inhibited by cyclopamine, the gland formation is stimulated and Ihh expression is upregulated (Fukuda et al., 2003). These results demonstrate that differentially expression of Shh and Ihh is necessary for stomach gland differentiation.

Other secreted factors, such as the Wnt, EGF (Epidermal Growth Factor) and the FGF (Fibroblast Growth Factor) are also important for stomach gland formation in both chicken and mouse embryo. Many Wnt genes and the genes of their corresponding receptors are expressed in the stomach region (Theodosiou and Tabin, 2003). Recently, it was reported that the Barx1, a homeodomain containing transcription factor, plays an important role for stomach gland formation by inhibiting the transient Wnt signalling (Kim et al., 2005). In the stomach of the Barx1 null mutant embryo, the glandular epithelial lining is infolded, disorganized and the stomach fails to develop a lumen. Importantly, $C d x 2$, which is normally expressed in the intestinal epithelium and controls its morphogenesis, is expressed ectopically in the defective epithelium of the stomach in the Barx1 mutant mouse. These results suggest that Barx1 regulates stomach epithelial differentiation via the control of Wnt signaling in mouse.

\subsection{Isolation of murine Vsig1 gene, a member of immunoglobulin superfamily}

The genome of mouse (mus musculus) has predicted 23768 genes (current ensemble database) and most of these genes are not yet studied. By 2006, approximately 3200 targeted knockout mouse lines had been registered on knockout mouse project database (Barbaric et al., 2007) and rest of the genes are waiting to be studied. 
The isolation of novel genes, which express differentially in organs, has a huge importance for understanding the molecular mechanism of development and function of a certain organ and tissue. Until now, the molecular mechanisms of stomach morphogenesis are unclear, so that identification and characterization of differentially expressed genes in stomach and molecular markers of stomach-specific cells are in great demand.

In our group, we are interested to isolate and characterize stomach-specific genes, which are involved in regulation of stomach development and function. In this context, we have used a subtractive cDNA hybridization method to isolate cDNA clones representing genes, which are expressed exclusively in stomach. The stomach cDNA was hybridized with abundant intestine and liver cDNA and subtractive cDNA fragments were cloned and sequenced (Göring, 2006). The 350-bp cDNA fragment of one clone $(S X)$ hybridized specifically in Northern blot analysis with a $2.7-\mathrm{kb}$ transcript in stomach RNA. No hybridization could be found in brain, liver and intestine. Alignment of the $S X$ cDNA and deduced amino acid sequences with the Genebank NCBI /EMBL database revealed that the deduced amino acid sequence of $S X$ is identical to that of VSIG1 protein, which belongs to the immunoglobulin family. Human and rat orthologues of Vsig1 were also identified in database.

\subsection{Aims of the study}

The aims and experimental approaches devised in this study can be placed in several categories, which are described below:

1. Expression analysis of Vsig1 gene during pre- and postnatal development of stomach.

2 Characterization of VSIG1 protein by biochemical and bioinformatic approaches.

3. Generation of murine VSIG1-specific polyclonal antibody.

4. Functional analysis of Vsig1 gene by generation and characterization of knockout mouse models.

5. Analysis of Vsig1 expressing cells using a transgenic mouse model, in which the EGFP is expressed under the control of Vsig1 promoter.

6. Establishing a stomach cell line

7. Investigating the effects of VSIG1-overexpression on cell adhesion and migration.

8. Generation of human VSIG1-specific polyclonal antibody.

9. Expression analysis of human Vsig1 in different types of gastric carcinoma 


\section{MATERIALS AND METHODS}

\subsection{Materials}

\subsubsection{Chemicals}

Acrylamide

Acetic acid

Agar

Agarose

Ammonium acetate

Ammonium persulfate

Ampicillin

Ampuwa

Bacto-tryptone

Bacto-Yeast-Extract

BCIP

bFGF

Bisacrylamide

Blocking powder

Bromophenol blue

BSA

Coomasie G-250

Choloroform

DAPI

Dextran sulfate

Diethyl pyrocarbonate (DEPC)

Dimethyl sulfoxid (DMSO)

Dithiothreitol

DNA Markers

dNTPs (100 mM)

Dye Terminator Mix

Ethanol

Ethidium bromide
Serva, Heidelberg

Merck, Darmstadt

Difco, Detroit, USA

GibcoBRL, Karlsruhe

Fluka, Neu Ulm

Sigma, Deisenhofen

Sigma, Deisenhofen

Fresenius, Bad Homburg

Difco, Detroit, USA

Difco, Detroit, USA

Boehringer, Mannheim

Boehringer Mannheim

Serva, Heidelberg

Boehringer, Mannheim

Sigma, Deisenhofen

Biomol, Hamburg

Sigma, Deisenhofen

Baker, Deventer, NL

Vector, Burfingame

Amersham, Freiburg

Carl-Roth, Karlsruhe

Merck, Darmstadt

Sigma, Deisenhofen

Invitrogen, Karlsruhe

Invitrogen, Karlsruhe

Applied Biosystems

Baker, Deventer, NL

Carl-Roth, Karlsruhe 
Ficoll 400

FCS

Formaldehyde

Formamide

Glutaraldehyde

Glycerol

Glycine

Goat serum

$\mathrm{HCl}$

$\mathrm{H}_{2} \mathrm{O}_{2}$

HEPES

Ionophore

IPTG

Isopropanol

IVF Medium

$\mathrm{KCl}$

Lambda DNA

Liquemin N 25000 (Heparin)

Methanol

$\mathrm{MgCl}_{2}$

MOPS

Methyl benzoat

$\beta$-Mercaptoethanol

Mineral oil

$\mathrm{NaCl}$

$\mathrm{Na}_{2} \mathrm{HPO}_{4}$

$\mathrm{NaH}_{2} \mathrm{PO}_{4}$

$\mathrm{NaHCO}_{3}$

$\mathrm{NaN}_{3}$

$\mathrm{NaOH}$

NBT

Orange G

Osmium tetraoxide

PBS
Amersham, Freiburg

Gibco/BRL, Karlsruhe

Gibco/BRL, Karlsruhe

Fluka, Neu Ulm

Sigma, Deisenhofen

Gibco/BRL, Karlsruhe

Biomol, Hamburg

Sigma, Deisenhofen

Merck, Darmstadt

Merck, Darmstadt

Merck, Darmstadt

A23187 Calbiochem

Carl-Roth, Karlsruhe

Merck, Darmstadt

Medicult, Berlin

Carl-Roth, Karlsruhe

Boehringer, Mannheim

Roche, Karlsruhe

Baker, Darmstadt

Carl-Roth, Karlsruhe

Merck, Darmstadt

Fulka, Neu Ulm

Serva, Heidelberg

Sigma, Deisenhofen

Carl-Roth, Karlsruhe

Carl-Roth, Karlsruhe

Carl-Roth, Karlsruhe

Carl-Roth, Karlsruhe

Carl-Roth, Karlsruhe

Carl-Roth, Karlsruhe

Boehringer, Mannheim

Sigma, Deisenhofen

Sigma, Deisenhofen

PAN, Aidenbach 
Phosphoric acid

Picric acid

Poly [dI-dC]

Phenol

Proteinase $\mathrm{K}$

Protein marker

Radioactive substances:

$[32 \alpha \mathrm{P}]-\mathrm{dCTP}$

Rediprimeтм II

RNase Inhibitor

RNA length standard

RNase away

Salmon sperms DNA

SDS

Select Peptone

Sodium acetate

Sodium citrate

TEMED

Triton X-100

Tris

Tween-20

X-Gal

Xylencyanol

Cell culture media
Merck, Darmstadt

Fluka, Neu Ulm

Amersham, Freiburg

Gibco/BRL, Eggenstein

Boehringer, Mannheim

Invitrogen, Karlsruhe

Amersham, Braunschweig

Amersham, Freiburg

Boehringer, Mannheim

Gibco/BRL, Eggenstein

Biomol, Hamburg

Sigma, Deisenhofen

Serva, Heidelberg

Gibco/BRL, Eggenstein

Carl-Roth, Karlsruhe

Carl-Roth, Karlsruhe

Serva, Heidelberg

Serva, Heidelberg

Carl-Roth, Karlsruhe

Sigma, Deisenhofen

Biomol, Hamburg

Bio-Rad, München

Gibco/BRL; PAN

All those chemicals which are not mentioned above were bought from either Merck, Darmstadt or Carl Roth, Karlsruhe. 


\subsubsection{Solutions, buffers and media}

\subsubsection{Agarose gel electrophoresis}

5x TBE buffer

$450 \mathrm{mM}$ Tris/HCL (pH7.5)

$450 \mathrm{mM}$ Boric acid

20 mM EDTA (pH 8.0)

Glycerol loading buffer -1

$10 \mathrm{mM}$ Tris/HCl (pH7.5)

$10 \mathrm{mM}$ EDTA (pH8)

0.025\% Bromophenol blue

$0.025 \%$ Xylenecyanol

$30 \%$ Glycerol

Glycerol loading buffer -II

$10 \mathrm{mM}$ Tris/ $\mathrm{HCl}(\mathrm{pH} 7.5)$

10 mM EDTA (pH 8)

$0.025 \%$ Orange G

$30 \%$ Glycerol

\subsubsection{SDS-PAGE}

$40 \%$ Acrylamide stock solution

$29.2 \%(\mathrm{w} / \mathrm{w})$ Acrylamide

$0.8 \%(\mathrm{w} / \mathrm{w})$ Bis-acrylamide

10\% Ammonium persulfate solution

in $\mathrm{H}_{2} \mathrm{O}$

Sample buffer (2X)

$0.5 \mathrm{M}$ Tris/ $\mathrm{HCl}(\mathrm{pH} \quad 6.8)$

$20 \%$ Glycerol

$4 \%$ SDS

10\% p-Mercaptoethanol 
Running buffer (5X)

$25 \mathrm{mM}$ Tris/ $\mathrm{HCl}(\mathrm{pH} 8.3)$

192 mM Glycin

$0.1 \%$ SDS

Stacking gel buffer (4X)

$0.5 \mathrm{mM}$ Tris/ $\mathrm{HCl}(\mathrm{pH} 6.8)$

$0.4 \%$ SDS

Separating gel buffer (4X)

1.5 M Tris/ $\mathrm{HCl}(\mathrm{pH} 8.3)$

$0.4 \%$

\subsubsection{Frequently used buffers and solutions}

Bouan fixative solution

Denaturation solution

Denhardt's solution (50X)

Depurinization solution

E-buffer (10X)

Elution buffer
15 volume of picric acid (in $\mathrm{H} 2 \mathrm{O}$ )

5 volumes Formaldehyde

1 volume Acetic acid

$1.5 \mathrm{M} \mathrm{NaCl}$

$0.5 \mathrm{M} \mathrm{NaOH}$

$1 \% \mathrm{BSA}$

1\% Polyvinylpyrrolidon

$1 \%$ Ficoll-400

$0.25 \mathrm{~N} \mathrm{HC} 1$

$300 \mathrm{mM} \mathrm{NaH}_{2} \mathrm{PO}_{4}$

50 mM EDTA (pH 8.0)

$1.5 \mathrm{M} \mathrm{NaCI}$

$20 \mathrm{mM}$ Tris/ $\mathrm{HCl}(\mathrm{pH} 7.5)$

$1 \mathrm{mM}$ EDTA 
Hybridisation solution I

Hybridisation solution II 5xSSC

Kinase buffer (IOX)

Ligation buffer (I0X)

Lysis buffer I

Lysis-buffer II

10 X MOPS Buffer
5X SSPE solution

5X Denhardt's solution

$0.1 \%$ SDS

5X Denhardt's solution

$10 \%$ Dextransulfate

$0.1 \%$ SDS

$100 \mathrm{mM}$ Tris/HCl (pH 7.4)

$100 \mathrm{mM} \mathrm{MgCb}$

100 mMDTT

$1 \mathrm{mM}$ ATP

$600 \mathrm{mM}$ Tris/HCl (pH7.5)

$80 \mathrm{mM} \mathrm{MgCl} 2$

$100 \mathrm{mM}$ DTT

$100 \mathrm{mM}$ Tris/HCl (pH 8.0)

$100 \mathrm{mM} \mathrm{NaCl}$

$100 \mathrm{mM}$ EDTA

$0.5 \%$ SDS

$100 \mathrm{mM}$ Tris/ $\mathrm{HCl}(\mathrm{pH} 8.0)$

5 mM EDTA

$200 \mathrm{mM} \mathrm{NaCl}$

$0.2 \% \mathrm{SDS}$

$100 \mu \mathrm{g} / \mathrm{ml}$ proteinase $\mathrm{K}$

$41.8 \mathrm{~g}$ MOPS

$16.6 \mathrm{ml} 3 \mathrm{M}$ Sodium acetate

$20 \mathrm{ml} 0.5 \mathrm{M}$ EDTA

in 1 liter of DEPC, adjust $\mathrm{pH}$ to 6.75 
Neutralisation solution

PBS buffer

PBT buffer

$\operatorname{SSC}(20 \mathrm{X})$

SSPE (20X)

Stop-Mix I

Stop-Mix II

TE-buffer

Washing solution I

Washing solution II
$1.5 \mathrm{M} \mathrm{NaCl}$

$1 \mathrm{M}$ Tris/HCL pH (pH 7.0)

$130 \mathrm{mM} \mathrm{NaCl}$

$7 \mathrm{mM} \mathrm{Na}_{3} \mathrm{HPO}_{4}$

$4 \mathrm{mM} \mathrm{NaH}_{2} \mathrm{HPO}_{4}$

$0.1 \%$ Tween-20 in PBS (IX)

$3 \mathrm{M} \mathrm{NaCl}$

$0.3 \mathrm{M} \mathrm{Na}_{3}$ citrate ( $\mathrm{pH} 7.0$ )

0.02 M EDTA

$0.2 \mathrm{M} \mathrm{NaH}_{2} \mathrm{PO}_{4}$

3.6 $\mathrm{M} \mathrm{NaCl}(\mathrm{pH} 7.0)$

95\% Formamide

20 mM EDTA (pH 8.0)

0.05\% Bromphenol blue

$0.05 \%$ Xylene cyanol

15\% Ficoll400

$200 \mathrm{mM}$ EDTA

$0.1 \%$ Orange $\mathrm{G}$

$10 \mathrm{mM}$ Tris/HCl (pH 8.0)

$1 \mathrm{mM}$ EDTA

2X SSC, $0.1 \%$ SDS

$0.2 \mathrm{X}$ SSC, $0.01 \% \mathrm{SDS}$ 


\subsubsection{Laboratory materials}

The laboratory materials, which are not listed here, were bought from Schütt and Krannich (Gottingen).

Whatman blotting paper

(GB 002, GB 003 and GB 004)

Cell culture flask

Culture slides

Dialysis hoses

Disposable filter Mirrisart NMI

Filter paper 0858

HPTLC Aluminum folio

HiTrap NHS activated column

Hybond C

Hybond N

Petri dishes

Pipette tips

Micro-centrifuge tubes

Transfection flask

X-ray films

Superfrost Slides
Schleicher and Schüll, Dassel

Greiner, Nurtingen

Falcon

Serva, Heidelberg

Sartorius, Gottingen

Schleicher and Schiill, Dassel

Merck, Darmstadt

Amersham, Braunschweig

Amersham, Braunschweig

Amersham, Braunschweig

Greiner, Nurtingen

Eppendorf, Hamburg

Eppendorf, Hamburg

Lab-Tek/Nalge, Nunc, IL, USA

Amersham, Braunschweig

Menzel, Glaser

\subsubsection{Sterilizations of solutions and equipments}

All solutions that are not heat sensitive were sterilised at $121^{\circ} \mathrm{C}, 10^{5} \mathrm{~Pa}$ for 60 min in an autoclave (Webeco, Bad Schwartau). Heat sensitive solutions were filtered through a disposable sterile filter ( 0.2 to $0.45 \mu \mathrm{rn}$ pore size). Plastic wares were autoclaved as above. Glasswares were sterilised overnight in an oven at $220^{\circ} \mathrm{C}$. 


\subsubsection{Media, antibiotics and agar-plates}

\subsubsection{Media for bacteria}

\begin{tabular}{|c|c|c|}
\hline \multirow[t]{3}{*}{ LB Medium ( $\mathrm{pH} 7.5)$ : } & $1 \%$ & Bacto-trypton \\
\hline & $0.5 \%$ & Yeast extracts \\
\hline & $1 \%$ & $\mathrm{NaCl}$ \\
\hline \multirow[t]{4}{*}{ LB-Agar: } & $1 \%$ & Bacto-trypton \\
\hline & $0.5 \%$ & Yeast extracts \\
\hline & $1 \%$ & $\mathrm{NaCl}$ \\
\hline & $1.5 \%$ & Agar \\
\hline
\end{tabular}

The LB medium was prepared with distilled water, autoclaved and stored at $4{ }^{\circ} \mathrm{C}$.

\subsubsection{Media for cell culture}

ES-cell medium:

HepG2 cell medium
DULBECCO's MEM (DMEM)

$0.1 \quad \mathrm{mM}$ non-essential amino acids

1 mM Sodium pyruvate

$10 \mu \mathrm{M}$ Mercaptoethanol

2 mM L-Glutamine

$20 \% \quad$ Fetal calf serum (FCS)

1000 U/ml Recombinant leukaemia inhibitory factor (LIF)

RPMI-1674 basic medium

$2 \mathrm{mM}$ L-Glutamine

$1 \% \quad$ Pen/Strp

$10 \% \quad$ FCS 
For long time storage of the cells in liquid nitrogen, the following freezing media were used:

ES cell - freezing medium:

$$
\begin{array}{ll}
30 \% & \text { ES cell medium } \\
50 \% & \text { FCS } \\
20 \% & \text { DMSO }
\end{array}
$$

\subsubsection{Antibiotics}

Stock solutions were prepared for the antibiotics. The stock solutions were then filtered through sterile disposable filters and stored at $-20^{\circ} \mathrm{C}$. When antibiotics were needed, in each case, it was added after the autoclaved medium has cooled down to a temperature lower than $55^{\circ} \mathrm{C}$.

$\begin{array}{llll} & \text { Master solution } & \text { Solvent } & \text { Final concentration } \\ \text { Ampiciliin } & 50 \mathrm{mg} / \mathrm{ml} & \mathrm{H}_{2} \mathrm{O} & 50 \mu \mathrm{g} / \mathrm{ml} \\ \text { Kanamycin } & 25 \mathrm{mg} / \mathrm{ml} & \mathrm{H}_{2} \mathrm{O} & 50 \mu \mathrm{g} / \mathrm{ml} \\ \mathrm{G} 418 & 40 \mathrm{mg} / \mathrm{ml} & \text { PBS } & 400 \mu \mathrm{g} / \mathrm{ml} \\ \text { Gancyclovir } & 100 \mathrm{mM} & \text { PBS } & 2 \mu \mathrm{M}\end{array}$

\subsubsection{IPTG / X-Gal plate}

LB-agar with $50 \mathrm{ng} / \mathrm{ml}$ ampicillin, $100 \mu \mathrm{M}$ IPTG and $0.4 \% \mathrm{X}-\mathrm{Gal}$ was poured into Petri dishes. The dishes were stored at $4^{\circ} \mathrm{C}$.

\subsubsection{Bacterial strains}
E. coli BL21DE3
(Novagen, Darmstadt,)
E. coli $\mathrm{DH} 5 \alpha$
(Invitrogen, Karlsruhe)
E. coli TB1
(NEB, Frankfurt am Main )

\subsubsection{Eukaryotic strains}

HepG2,

NIH3T3
ATTCC, Rockville, USA

Institute for Human Genetics, Göttingen

RI mouse embryonic stem cell line (Passage 11), Dr. A. Nagi, Toronto, Canada 


\subsubsection{Plasmids}

$\begin{array}{ll}\text { pBluesript SK (+/-) } & \text { (Stratagene, La Jolla, USA) } \\ \text { pBluesript KS (+/-) } & \text { (Stratagene, La Jolla, USA) } \\ \text { pGEM-T } & \text { (Promega, Wisconsin, USA) } \\ \text { pGEM-T Easy } & \text { (Promega, Wisconsin, USA) } \\ \text { pET21 } & \text { (Novagen, Darmstadt, Germany) } \\ \text { pMALc2x } & \text { (New England BioLab) } \\ \text { pEGFP1 } & \text { (Clontech, Heidelberg) } \\ \text { pPNT } & \text { (Prof. R. Mulligan, Children's Hospital, Boston, } \\ & \text { USA; modified by Prof H. Hahn, Institut für } \\ \text { pPNT4 } & \text { Humangenetik) } \\ \text { pZERO-2 } & \text { (Conrad et al., 2003) } \\ \text { PAC, Cosmid } & \text { (Invitrogen, Karlsruhe, Germany) }\end{array}$

\subsubsection{Synthetic oligonucleotides}

The synthetic oligonucleotide primers used in this study were obtained from Operon (Düsseldorf, Germany) and dissolved in water to a final concentration of $100 \mathrm{pmol} / \mu 1$.

SX-RTF1:

SX-RTR1:

SX-Probe1R1

SX-Probe2F1:

SX-Probe2R1:

SX-3ExtProbeF1:

SX-3ExtProbeR1:

MK219F1:

MK219R1:

SX-humNorthernR1:

SX-1humNorthernF1:

SX-Probe1F1:

SX-FuProF:

SX--FuProR:
5-AGTTGGGATCATCATCGGAG-3

5-GGTGTTTGCATTTTGGAAGG-3

5-AGGCTGTCGTTAAGGGGAAT-3

5-GGGAAATCTGGGTTGGTTCT-3

5-ATTGGCTCCTCCATTTCCTT-3

5-TTTTGGGAAGGTTGAGATGG-3

5-CCAGCCTGCATTCTATAGCC-3

5-CCACTGTGCGGCTACTGTAA-3

5-GAAGAATTCCTTTCCCTGCC-3

5-CAACGTGAAACCCCATCTCT-3

5-GCTGGTGGCCTAAGTACAGC-3

5-AAAGGGATGTGGAAACGATG-3

5-CCCCGAATTCGCCAGGAACAAAGTTAAATC-3

5-GGGGGTCGACCAAGACTGCTGTAGTAGTAG-3 
SX--FuProF2:

SX-FuProR2:

SX-NBF1:

SX-NBR1:

SA7F:

SA7R:

pET-R1:

pET-F1:

SX-Villin-RT-F1

SX-Villin-RT-R1

SX-Villin-F1

SX-Villin-R1

SX-Villin-F2

SX-Villin-R2

muSX-ORF-F2

muSX-ORF-R2

muSX-ORF-F1

muSX-ORF-R1

huSX-ORF-F1

huSX-ORF-R1

humGAPDH-R

humGAPDH-F

SX-huFuPro-F

SX-huFuPro-R

muSX-Seq1

muSX-Seq2

muSX-Seq3

muSX-Seq4

muSX-Seq5

SX-KO-Probe-F1

SX-KO-Probe-F2

SX-KO-Probe-F3

SX-KO-Probe-R1

SX-KO-Probe-R2
5-CCCCGGATCCGCCAGGAACAAAGTTAAATC-3

5-GGGGAAGCTTTTACAAGACTGCTGTAGTAGTAG-3

5-GGTGTTTGCATTTTGGAAGG-3

5-CTCCGATGATGATCCCAACT-3

5-ATCCTTTGAGAGGTGGGGTT-3

5-TGGCAAACACATGAGGACAT-3

5-TGCTAGTTATAGCGGT-3

5-CGAACGCCAGTGGACA-3

5-CACTGCTCTCACATGCTTTCTCC-3

5-CATACTGACCTGACCTGCAAGGC-3

5-GTACCATAGTCCTAGTCATGCGC-3

5-CTCGAATATGCCTATGCATCGGA-3

5-AGAAAGGATCATCATCAAAGCCGG-3

5-GGTCTTTGAATTGCCCAATAGCTG-3

5-CCCGGATCCTTCGGACTGGCACCTGCT-3

5-GGGCTCGAGGTGGGAATTGCCATACTA-3

5-CCCGGATCCATGATGGTGTTTGCATTT-3

5-GGGCTCGAGCCTTAACTGTATCCTCTCC-3

5-CCCGGATCCATGGTGTTCGCATTTTGG-3

5-GGGCTCGAGCCTTAACCACTCCCTTTTC-3

5-ATGGCATGAACTGTGGTCATGAGTCC-3

5-TGCCATCAATGACCCCTTCATTGACC-3

5-CCGGATCCAGAAATTCTAAGACCATCGC-3

5-CCAAGCTTCTCCTGAGTAGGCTTTGGCT-3

5-AGCAGACAGTGGAATTTACA-3

5-AAAGAAAGTTTCAACACGGC-3

5-AAATCCCAGCACAGAACTTG-3

5-CACCTGAGGCAGAGATTCAA-3

5-GGACGCCATCAGCTGAATT-3

5-CCATGTATGTGACTAACTGCCTA-3

5-GCCCCCAATAAGGAAGTATGTT-3

5-TGTCAGTGTCATTGAAAAGCAGT-3

5-CAGTTGTATGGTTTCTCTGCTC-3

5-CACACAACAGACACAATCCATG-3 


\begin{tabular}{|c|c|}
\hline SX-KO-Probe-R3 & 5-ACACTGAAAAGTTTGAACTCCCA-3 \\
\hline SX-EGFP-F1 & 5-GATGAAGGACCCTGGATTTGCT-3 \\
\hline SX-EGFP-R1 & 5-TGTAGTTGCCGTCGTCCTTGAA-3 \\
\hline SX-EGFP-F2 & 5-GGAAAGTGTTACTGGAAATGTCC-3 \\
\hline SX-EGFP-R2 & 5-AAGTCGATGCCCTTCAGCTCGA-3 \\
\hline SX-EGFP-F3 & 5-AAGAAGTCGTGCTGCTTCCAT-3 \\
\hline SX-EGFP-F4 & 5-TATATCAAGGGGACACACCC-3 \\
\hline SX-EGFP-R4 & 5-ATGAACTTCAGGGTCAGCTT-3 \\
\hline T7-pGEMT & 5-AATACGACTCACTATAGGGCGAATTGG-3 \\
\hline SP6-pGEMT & 5-TTAGGTGACACTATAGAATACTCAAGC-3 \\
\hline SX-ECF & 5-CCCCCGGATCCGGTCAGGTCAGTATGGTGCAAG-3 \\
\hline SX-ECR & 5-CCCCCTCGAGACCAAAGCTCCGATGATGATCC-3 \\
\hline ST-F1 & 5-GATCTTCCTTTATACACAAGTCATAGC-3 \\
\hline ST-R1 & 5-GTGTACAGAACTTAGGTGTTTAATTG-3 \\
\hline SX-KO-F4 & 5-CAACCATATACTCAGCTTTGCC-3 \\
\hline SX-KO-F3 & 5-CTGTGCGCTAATCAGGAAGATG-3 \\
\hline SX-KO-R3 & 5-AGGGCAAATGAGGCACTAACC-3 \\
\hline SX-Neo-F3 & 5-TGGATGTGGAATGTGTGCGAG-3 \\
\hline SX-KO-R2 & 5-TATCCTTTCAGTCCCTCTGTCC-3 \\
\hline SX-Cond-Probe-F1 & 5-GGCTATTGAAGACTCTTGCTG-3 \\
\hline SX-Cond-Probe-R1 & 5-CCACTACCCATATGCTGACTC-3 \\
\hline SX-Cond-Probe-F2 & 5-CTCTCCATGCCAACTCATGGAG-3 \\
\hline SX-Cond-Probe-R2 & 5-CCAATTTTCTGAGGAACCGCC-3 \\
\hline Villin-Probe-F2 & 5- GTCTTGTGCATGCTAAGCAAGC-3 \\
\hline Villin-Probe-R2 & 5-GTGTCAAAGTGGAAGGACAGC-3 \\
\hline Villin-Probe-F1 & 5-GGTGAGGGAGAGTGCTGCTTTC-3 \\
\hline Villin-Probe-R1 & 5-CTAGAGAGTGAGCTCAGGACAG-3 \\
\hline SX-FuPro-ORF-F & 5-GGGGGATCCCAAGCGACTTTCAGCATGATGG-3 \\
\hline SX-FuPro-ORF-R & 5-GGGCTCGAGCCACACAGATGATAACAGCAGC-3 \\
\hline SX-FuPro-C-R & 5-GGGCTCGAGGGGAATTGCCATACTAAATGCC-3 \\
\hline SX-FuPro-C-F & 5-GGGGGATCCGCTGCTGTTATCATCTGTGTGG-3 \\
\hline SX-Condprobe-5armF1 & 5-CCCCCAGAAAGCTTGCCTTGG-3 \\
\hline SX-Condprobe-5armR1 & 5-GGCCCAGCCCATTGTGGATGT-3 \\
\hline SX-Condprobe-5armF2 & 5-CCCATGCAGGCTCTATGCATC-3 \\
\hline
\end{tabular}




\begin{tabular}{ll} 
SX-Condprobe-5armR2 & 5-CTAACCTGGGTGGTCAGTGAG-3 \\
SX-EGFP-Probe-F1 & 5-GTAAACGGCCACAAGTTCAGCG-3 \\
SX-EGFP-Probe-R1 & 5-CACCTTGATGCCGTTCTTCTGC-3 \\
SX-EGFP-RT-F1 & 5-GTTCAGAGAGAACTCAGTGCCC-3 \\
SX-EGFP-RT-F2 & 5-GGCCTCTTTGCTTGGTGATGCC-3 \\
SX-EGFP-RT-R1 & 5-CGCTGAACTTGTGGCCGTTTAC-3 \\
SX-Cyto-F1 & 5-CATGGACCCTCATGATAATTTTGT-3 \\
SX-Cyto-R1 & 5-CAGTTTAAGATCAGAAAGACCTTC-3 \\
SX-Cyto-F2 & 5-GCGTGGAAATATTCTTATTGGTAG-3 \\
SX-Cyto-R2 & 5-AGAGTAACATTAGATCCAACAGTC-3 \\
PELO-RT-F2 & 5-GGGTAACAGGCGCAGAAAACAG-3 \\
PELO-RT-R2 & 5-AGCGTGAAGCCAGCTTCAGAAC-3 \\
SX-FRT-Seq-F1 & 5-GAGATTTTTAGCCTGGGACTGGTA-3 \\
SX-FRT-Seq-R1 & 5-TACCGGTGGATGTGGAATGTTTG-3 \\
SX-FRT-Seq-F2 & 5-GCATCGCATTGTCTGAGTAGGTG-3 \\
SX-FRT-Seq-R2 & 5-TACACACGACTTAAAAGTGCACCC-3 \\
SX-FRT-Seq-F3 & 5-CTCACTGATCGAATAGTCAAACC-3 \\
SX-Cre-F & 5-GGACCGGTCGCCACATGCCCAAGAAGAAGAGG-3 \\
SX-Cre-R & 5-GGGCGGCCGCCTAATCGCCATCTTCCAGCAGGC-3 \\
SX-D2Mit94-F & 5-GGCTTCGACCCTGGTTTTAG-3 \\
SX-D2Mit94-R & 5-TGAAAGTTCAGATGACCACACG-3 \\
& \\
\hline
\end{tabular}

\subsubsection{2 cDNA probes}

$h E F-1$ cDNA

$V$ sigl cDNA

$\beta$-actin cDNA

EGFP cDNA

\subsubsection{Mouse strains}

Mice strains C57BL/6J, 129/Sv, and NMRI were initially ordered from Charles River Laboratories, Wilmington, USA and further inbred in Animal facility of Institute of Human Genetics, Goettingen. 


\subsubsection{Antibodies}

Mouse monoclonal anti $\alpha$-tubulin, goat anti-rabbit-IgG conjugated with alkaline phosphatase, goat anti-rabbit-IgG conjugated with HRP, goat anti-rabbit-IgG conjugated with FITC, and sheep anti-rabbit-IgG conjugated with Cy3, antibodies were purchased from Sigma (Deisenhofen, Germany). Goat polyclonal anti-GATA4 and mouse monoclonal anti-Apg1 antibodies were purchased from Santa-Cruz Biotechnology Inc (Santa Cruz, USA). Mouse monoclonal anti-Cytokeratin5/6 was purchased from Dako (Denmark, Glostrup) and mouse monoclonal anti- $\mathrm{H}^{+} / \mathrm{K}^{+}$ATPase was purchased from Acris Antibodies (Hiddenhausen, Germany).

\subsubsection{Enzymes}

Restriction enzymes (with supplied buffers)

(Invitrogen, NEB)

Collangenase (grade II)

(Sigma, Deisenhofen)

Dispase II (grade II)

(Roche, Basel)

Klenow Fragment

(Invitrogen, Karlsruhe)

N-Glycosidase-F

(Roche, Basel)

Proteinase K.

(Carl-Roth, Karlsruhe)

Platinum Taq polymerase

(Invitrogen, Karlsruhe)

RNase A

(Qiagen, Hilden)

RNase H

(Invitrogen, Karlsruhe)

RNase inhibitor

(Invitrogen, Karlsruhe)

Superscript-II

(Invitrogen, Karlsruhe)

Taq polymerase (Immolase)

(BioLine, Luckenwalde)

T4 polynucleotide Kinase

(NEB, Frankfurt am Main)

T4 DNA ligase

(Promega, Mahhhein)

Tyripsin

(Invitrogen, Karlsruhe) 


\subsubsection{Kits}

Advantage-HF2 PCR kit

(Clontech, Heidelberg)

BigDye Terminator Cycle

(Applied Biosystems)

Sequencing Ready Reaction Kit

(Amersham, Pharmacia)

DYEnamic ET-Terminator mix

(Amersham Pharmacia)

Endo Free Plasmid Maxi Kit

GST-Bind kit

(Qiagen, Hilden)

JETsorb Gel Extraction Kit

JETstar Plasmid MIDI Kit

Large Construct Plasmid Kit

MabTrap IgG Purification Kit

Megaprime DNA Labeling Kit

Maxi Plasmid Kit

Mega Plasmid Kit

(Novagen, Darmstadt)

(Genomed, Löhne)

(Genomed, Löhne)

(Qiagen, Hilden)

(Amersham Pharmacia)

(Amersham Pharmacia)

(Qiagen, Hilden)

(Qiagen, Hilden)

Mini Plasmid Kit

(Qiagen, Hilden)

PCR Purification Kit

(Qiagen, Hilden)

pET fusion protein system

QIAquick Gel Extraction Kit

RNA Easy Kit

Rcdiprime $^{\mathrm{TM}}$ II Random Prime

(Novagen, Darmstadt)

(Qiagen, Hilden)

Qiagen, Hilden)

labeling System

(Amersham Pharmacia

\subsubsection{Instruments}

ABI PRISM 377 DNA Sequencer

(Applied Biosystem)

ABI 3100 Genetic Analyzer

(Applied Biosystem)

Microscope BX60

(Olympus, Tokyo)

GeneAmp PCR System 9600

Microtiterpiate-Photometer

(Perkin Elmer)

(BioRad, Hercules)

Molecular Imager FX

(BioRad, Hercules)

Phosphoimager Screen

Semi-Dry-Blot Fast Blot

Spectrophotometer Ultraspec 3000

(Kodak, Rochester, NY)

(Biometra, Göttingen)

(Amersham, Pharmacia)

Speed Vac concentrator SVC $100 \mathrm{H}$

(Thermo-Scientific) 
Thermomixer 5436

Turboblotter ${ }^{\mathrm{TM}}$

UVStratalinker ${ }^{\mathrm{TM}} 1800$

Video-Doc Illumination system

X-Ray Automatic Processor Curix 60

CASA system
(Eppendorf, Hamburg)

(Schleicher \& Schull)

(Stratagene, la Jolla, CA)

(Heroiab, Heidelberg)

(Agfa, Mortsel)

(Hamilton Thome Research)

\subsection{Methods}

\subsubsection{Isolation of nucleic acids}

\subsubsection{Isolation of plasmid DNA}

(Sambrook et al., 1989)

\subsection{Small-scale isolation of plasmid DNA}

A single E.coli colony was inoculated in $5 \mathrm{mi}$ of LB medium with the appropriate antibiotic and incubated in a shaker for $16 \mathrm{hrs}$ at $37^{\circ} \mathrm{C}$ with a speed of $160 \mathrm{rpm} .1 \mathrm{ml}$ of this saturated culture was used for making glycerol stock and rest of the culture was centrifuged at $5000 \mathrm{xg}$ for $15 \mathrm{~min}$. The pellet was resuspended in $200 \mu \mathrm{l}$ of solution P1 The bacterial cells were lysed with $200 \mu 1$ of P2 solution and than neutralised with $200 \mu 1$ of solution P3. The precipitated solution was incubated on ice for $15 \mathrm{~min}$, and centrifuged at $13000 \mathrm{xg}$ at $4{ }^{\circ} \mathrm{C}$. The supernatant was transferred into a new tube, and $1 \mathrm{ml}$ of $100 \%$ ethanol was added to precipitate the DNA. It was then stored in ice for $15 \mathrm{~min}$, centrifuged at full speed for $15 \mathrm{~min}$, and finally the pellet was washed with $70 \%$ ethanol and after air-drying dissolved in $50 \mu \mathrm{l}$ of TE buffer (adapted from Birnboim and Doly, 1979).

$\begin{array}{lll}\text { P1 } & 50 \mathrm{mM} & \text { Tris/HCl, }(\mathrm{pH} \mathrm{8.0)} \\ & 10 \mathrm{mM} & \text { EDTA } \\ & 100 \mu \mathrm{g} / \mathrm{ml} & \text { RNase A } \\ & & \\ \text { P2 } & 200 \mathrm{mM} & \mathrm{NaOH} \\ & 1 \% & \text { SDS } \\ \text { P3 } & 3 \mathrm{mM} & \text { Potassium acetate, }(\mathrm{pH} \mathrm{5.5)}\end{array}$




\subsection{Large-scale preparation of plasmid DNA}

A single clone was inoculated in $2 \mathrm{ml} \mathrm{LB}$ medium with appropriate antibiotic as a pre-culture for $8 \mathrm{hrs}$ in $37^{\circ} \mathrm{C}$ shaker. In $100 \mathrm{ml} \mathrm{LB}$ medium with appropriate antibiotic, this pre-culture was added in a dilution of $1 / 100$ fold and incubated overnight at $37^{\circ} \mathrm{C}$ with shaking. The saturated culture was centrifuged at $6000 \mathrm{xg}$ for $15 \mathrm{~min}$. The pellet was resuspended in $5 \mathrm{ml}$ of solution PI and cells were lysed with P2 and P3 as described above. The precipitated solution was centrifuged at 20000xg for $30 \mathrm{~min}$ at $4^{\circ} \mathrm{C}$. Meanwhile, the column (Qiagen-tip) that was provided with the midi preparation kit was equilibrated with $10 \mathrm{ml}$ of QBT solution. After centrifugation, the lysate was poured into this equilibrated column to allow the DNA to bind with the resin present in the bed of the column. The column was then washed twice with $10 \mathrm{ml}$ of solution QC. Finally, the DNA was eluted with $5 \mathrm{ml}$ of QF solution. To precipitate the DNA, $3.5 \mathrm{ml}$ of isopropanol was added and mixed thoroughly and centrifuged at $14000 \mathrm{xg}$ for $30 \mathrm{~min}$ at $4^{\circ} \mathrm{C}$. The DNA pellet was washed with $70 \%$ ethanol and dissolved in $100 \mu 1$ of TE buffer.

QBT

$$
\begin{aligned}
750 \mathrm{mM} & \text { Sodium chloride } \\
50 \mathrm{mM} & \text { MOPS (pH 7.0) } \\
15 \% & \text { Ethanol } \\
0.5 \% & \text { Triton X-100 }
\end{aligned}
$$

QC

$\begin{aligned} 1 \mathrm{mM} & \text { Sodium chloride } \\ 50 \mathrm{mM} & \text { MOPS (pH 7.0) } \\ 15 \% & \text { Ethanol }\end{aligned}$

QF

$\begin{array}{ll}1.25 \mathrm{M} & \text { Sodium chloride } \\ 50 \mathrm{mM} & \text { Tris } / \mathrm{HCl}(\mathrm{pH} 8.5)\end{array}$

\subsubsection{Endotoxin free preparation of plasmid DNA}

Endotoxins, also known as lipopolysaccharides or LPS, are cell membrane components of Gram-negative bacteria (e.g., E.coli). During lysis of bacterial cells, endotoxin molecules are released from the outer membrane into the lysate. Endotoxins strongly influence the transfection efficiency of cultured cells like embryonic stem 
(ES). Increased endotoxin levels lead to sharply reduced transfection efficiencies. Endofree plasmid preparation kit integrates endotoxin removal into standard plasmid preparation procedure. The neutralised bacterial lysate was filtered through a QIA filter cartridge (provided in kit) and incubated on ice with a specific Endotoxin Removal buffer. The endotoxin removal buffer prevents LPS molecules from binding to the resin in the columns (QIAGEN-tips), thus allowing purification of DNA containing less than 0.1 endotoxin units per $\mu$ g plasmid DNA.

\subsubsection{Isolation of genomic DNA from tissue samples}

(Laird et al., 1991)

Lysis buffer I:

$$
\begin{aligned}
& 100 \mathrm{mM} \text { Tris/HCl (pH 8.0) } \\
& 100 \mathrm{mM} \mathrm{NaCl} \\
& 100 \mathrm{mM} \text { EDTA } 0.5 \% \text { SDS }
\end{aligned}
$$

The method employed was the same as that of Laird et al. (1991). $0.5 \mathrm{~cm}$ of the tail from a mouse was incubated in $600 \mu \mathrm{l}$ of lysis buffer containing $35 \mu 1$ of proteinase-K $(10 \mu \mathrm{g} / \mu \mathrm{l})$ at $55^{\circ} \mathrm{C}$ overnight in Thermomixer 5436. To the tissue lysate, $300 \mu \mathrm{l}$ of phenol and $300 \mu \mathrm{l}$ of chlorophorm-isoamil alcohol mix (24:1) were added, mixed by inverting several times, and centrifuged at $8000 \mathrm{xg}$ for $5 \mathrm{~min}$ at room temperature. After transferring the upper aqueous layer into a new tube, the same procedure was repeated, first with 1:1 ratio of phenol and chloroform and then with chloroform. Finally, the DNA was precipitated with 0.7 volume of isopropanol, washed with $70 \%$ ethanol, and dissolved in 50-100 $\mu 1$ of double distilled water (Ampuwa) and incubated at $60^{\circ} \mathrm{C}$ for $15 \mathrm{~min}$.

\subsubsection{Isolation of total RNA from tissue samples and cultured cells}

Total RNA isolation reagent is an improved version of the single-step method for total RNA isolation. The composition of reagent includes phenol and guanidine thiocyanate in a mono-phase solution. 100-200 mg of tissue sample was homogenised in 1-2 $\mathrm{ml}$ of TRJ Reagent by using a glass-teflon homogeniser. The sample volume should not exceed $10 \%$ of the volume of reagent used for the homogenisation. To isolate total RNA from cultured cells, $350 \mu$ of reagent was added to the petri dish (6 $\mathrm{cm}$ diameter). Cells were homogenised with a rubber slick and the lysate was 
transferred into a microcentrifuge tube. The homogenate was incubated at $4{ }^{\circ} \mathrm{C}$ for 5 min to permit the complete dissociation of nucleoprotein complexes. Then, $0.2 \mathrm{ml}$ of chloroform was added, mixed vigorously, and stored at $4^{\circ} \mathrm{C}$ for $10 \mathrm{~min}$. After centrifugating at $12000 \mathrm{xg}$ for $15 \mathrm{~min}$ at $4{ }^{\circ} \mathrm{C}$, the colourless upper aqueous phase was transferred into a new tube. The RNA was precipitated by adding $0.5 \mathrm{ml}$ of isopropanol. Finally, the pellet was washed twice with $75 \%$ ethanol and dissolved in $80-100 \mu 1$ of DEPC- $\mathrm{H}_{2} \mathrm{O}$.

\subsubsection{Determination of the nucleic acid concentration}

The concentration of nucleic acids was determined spectrophotometrically by measuring absorption of the samples at $260 \mathrm{~nm}$. The quality of nucleic acids i.e. contamination with salt and protein was checked by the measurements at 230, 280, and $320 \mathrm{~nm}$. The concentration was calculated according to the formula:

$$
\begin{aligned}
& \text { C }-(\text { E } 260-E \text { 320)fc } \\
& C=\text { concentration of sample }(\mu \mathrm{g} / \mu \mathrm{l}) \\
& \text { E } 260=\text { ratio of extinction at } 260 \mathrm{ran} \\
& \text { E } 320=\text { ratio of extinction at } 320 \mathrm{~nm} \\
& \mathrm{f}=\text { dilution factor } \\
& \mathrm{c}=\text { concentration (standard) } / \text { absorption (standard) } \\
& \text { for double stranded DNA : c }=0.05 \mu \mathrm{g} / \mu 1 \\
& \text { for RNA }: \mathrm{c}=0.04 \mu \mathrm{g} / \mu 1 \\
& \text { for single stranded DNA : } \mathrm{c}=0.03 \mu \mathrm{g} / \mu 1
\end{aligned}
$$

\subsubsection{Gel electrophoresis}

Gel electrophoresis is the technique by which mixtures of charged macromolecules, especially nucleic acids and proteins, are separated in an electrical field according to their mobility which is directly proportional to macromolecule's charge to mass ratio. 


\subsubsection{Agarose gel electrophoresis of DNA}

Agarose gels are used to electrophorese nucleic acid molecules from as small as 50 bases to more than $50-\mathrm{kb}$, depending on the concentration of the agarose and the precise nature of the applied electrical field (constant or pulse). Usually, $1 \mathrm{~g}$ of agarose was added in $100 \mathrm{ml}$ of $0.5 \mathrm{x}$ TBE buffer and boiled in the microwave to dissolve the agarose, then cooled down to about $60^{\circ} \mathrm{C}$ before adding $3 \mu$ of ethidium bromide $(10 \mathrm{mg} / \mathrm{ml})$. This $1 \%$ agarose gel was poured into a horizontal gel chamber.

\subsubsection{Agarose gel electrophoresis of RNA}

(Hodge, 1994)

Single-stranded RNA molecules often have complementary regions that can form secondary structures. Therefore, RNA was run on a denaturing agarose gel that contained formaldehyde, and before loading, the RNA was pre-treated with formaldehyde and formamide to denature the secondary structure of RNA. $1.25 \mathrm{~g}$ of agarose was added in $100 \mathrm{ml}$ of 1x MOPS Buffer and dissolved by heating in microwave. After cooling it to about $50^{\circ} \mathrm{C}, 25 \mathrm{ml}$ of formaldehyde $(37 \%)$ was added, stirred and poured into a horizontal gel chamber.

RNA samples were treated as follows:

10 - $20 \mu \mathrm{g}$ RNA

$2 \mu l 10 x$ MOPS Buffer

$3 \mu \mathrm{l}$ Formaldehyde

$8 \mu$ Formamide $(40 \%)$

$1.5 \mu$ Ethidium bromide

Samples were denatured at $65^{\circ} \mathrm{C}$ for $10 \mathrm{~min}$ and chilled on ice before loading into the gel. The gel was run at $40 \mathrm{~V}$ at $4^{\circ} \mathrm{C}$ for about $12 \mathrm{hrs}$.

\subsubsection{SDS-PAGE for the separation of proteins}

(Laemmli, 1970)

SDS gel electrophoresis is a method for separating proteins within a sample for analysis and molecular weight determination. The proteins are denatured and rendered monomeric by boiling in the presence of reducing agents (P-mercaptoethanol or dithiotheitol) and negatively charged detergent (SDS). The proteins, which normally differ according to their charges, are all coated with the SDS molecules, which are 
negatively charged. Hence, all the proteins in the sample become negatively charged and achieve constant charge to mass ratio. In this way, the separation is according to the size of the proteins. A SDS-PAGE consists of two gels; Firstly, a 10-12\% separating gel was poured. In order to achieve a smooth boundary between separating and stacking gel, the separating gel was covered with a layer of water. After polymerisation of the separating gel, a $4 \%$ stacking gel was poured over it. The samples were boiled in sample buffer for $10 \mathrm{~min}$ at $95^{\circ} \mathrm{C}$ before loading into the gel. The gel was run at $15 \mathrm{~mA}$ for $1 \mathrm{hr}$ and then at a constant current of $30 \mathrm{~mA}$.

\begin{tabular}{|c|c|c|c|}
\hline$\underline{\text { Separation gel }}$ & & $15 \%$ & $7 \%$ \\
\hline Tris/HCL pH8.8 & $2 \mathrm{M}$ & $3.87 \mathrm{ml}$ & $3.87 \mathrm{ml}$ \\
\hline Acrylamid/Bisacrylamid & $30 \%$ & $8.90 \mathrm{ml}$ & $4.00 \mathrm{ml}$ \\
\hline SDS & $10 \%$ & $178 \mathrm{ml}$ & $178 \mathrm{ml}$ \\
\hline $\mathrm{dH}_{2} \mathrm{O}$ & & $2.033 \mathrm{ml}$ & $9.03 \mathrm{ml}$ \\
\hline TEMED & $5 \%$ & $40 \mu 1$ & $145 \mu 1$ \\
\hline APS & $5 \%$ & $40 \mu \mathrm{l}$ & $145 \mu 1$ \\
\hline
\end{tabular}

\section{Collection gel}

$\begin{array}{lcc}\text { Tris/HCL pH6.8 } & 1 \mathrm{M} & 2.25 \mathrm{ml} \\ \text { Acrylamid/bisacrylamid } & 30 \% & 4.20 \mathrm{ml} \\ \text { SDS } & 10 \% & 25 \mu \mathrm{l} \\ \text { TEMED } & 5 \% & 400 \mu \mathrm{l} \\ \text { APS } & 5 \% & 400 \mu l \\ \mathrm{dH}_{2} \mathrm{O} & & 17.8 \mathrm{ml}\end{array}$

\subsubsection{Isolation of DNA fragments after agarose gel electrophoresis}

\subsubsection{Glass silica method}

(Vogelstein and Gillespie, 1979)

For the isolation of DNA fragments which are more that 8-kb in length from agarose gels, the QIAEXII gel extraction kit (QIAGEN) was used. The principle of this method depends on the binding capacity of DNA to silica in high salt concentrations and elution in low salt solutions. After separation of DNA on an agarose gel, the DNA fragment to be isolated was excised with a razor blade and weighed. 3 volumes of 
QBT solution was added and melted at $55^{\circ} \mathrm{C}$. Depending on the DNA amount, required amount of silica glass-milk, which is an aqueous suspension of silica matrix, was added and the tube was incubated at $55^{\circ} \mathrm{C}$ for 10 min with shaking. After centrifuging it at full speed for $30 \mathrm{sec}$, the pellet was washed 2 times with PE buffer and allowed to dry at room temperature. For elution of DNA, the pellet was resuspended in $30 \mu \mathrm{l}$ of distilled water and incubated at room temperature for $10 \mathrm{~min}$ with continuous shaking. After the final centrifugation at $14000 \mathrm{xg}$ for $1 \mathrm{~min}$, the supernatant containing the DNA was transferred into a new tube.

\subsubsection{QIAquick gel extraction method}

This method is designed to extract and purify DNA of 70 bp to 10 kilobase pairs $(\mathrm{kb})$ in length from agarose gels. Up to $400 \mu \mathrm{g}$ agarose can be processed per spin column. The principle of this method depends on selective binding of DNA to uniquely designed silica-gel membrane. To the excised DNA fragment from agarose, 3 volumes of QG buffer was added and incubated at $50^{\circ} \mathrm{C}$ for $10 \mathrm{~min}$. After the gel slice was dissolved completely, it was applied over a QiAquick column and centrifuged for $1 \mathrm{~min}$. The flow through was discarded and the column was washed with $0.75 \mathrm{ml}$ of PE buffer. After drying the column, it was placed into a fresh microcentrifuge tube. To elute DNA, $50 \mu \mathrm{l}$ of EB buffer was applied to the centre of the QIAquick membrane and centrifuged for $1 \mathrm{~min}$.

\subsubsection{Enzymatic modifications of DNA}

\subsubsection{Restriction digestion of DNA}

Restriction enzyme digestions were performed by incubating double-stranded DNA with an appropriate amount of restriction enzyme in its respective buffer as recommended by the supplier, and at the optimal temperature for the specific enzyme. Standard digestions include 2-10 U enzyme per microgram of DNA. These reactions were usually incubated for 1-3 hrs to ensure complete digestion at the optimal temperature for enzyme activity, which was typically $37^{\circ} \mathrm{C}$. For genomic DNA digestion, the reaction solution was incubated overnight at $37^{\circ} \mathrm{C}$. 


\title{
2.2.5.2 Ligation of DNA fragments
}

The ligation of an insert DNA into a vector (digested with appropriate restriction enzyme) was carried out in the following reaction mix:

\author{
30 ng vector DNA (digested) \\ 50-100 ng insert DNA (1:3, vector: insert ratio) \\ $1 \mu 1$ ligation buffer (10x) \\ $1 \mu \mathrm{l}$ T4DNA ligase $(5 \mathrm{U} / \mu \mathrm{l})$ \\ in a total volume of $10 \mu 1$
}

Blunt-end ligations were carried out at $16^{\circ} \mathrm{C}$ for overnight, whereas overhang-end ligations were carried out at room temperature for 2-4 hrs.

\subsubsection{TA-Cloning}

(Clark, 1988; Hu, 1993)

Tag polymerase and other DNA polymerases have a terminal transferase activity that results in the non-template addition of a single nucleotide to the 3'-ends of PCR products. In the presence of all 4 dNTPs, the dATP is preferentially added. This terminal transferase activity is the basis of the TA- cloning strategy. For cloning of PCR products, pGEM-T Easy vector system that has 5'-T overhangs was used. The followings were mixed:

$$
\begin{aligned}
& 50 \mathrm{ng} \text { of pGEM-T Easy Vector } \\
& \text { PCR product (1:3, vector to insert ratio) } \\
& 1 \mu 1 \text { of T4 DNA Ligase } 10 \mathrm{X} \text { buffer } \\
& 1 \mu 1 \text { of T4 DNA Ligase } \\
& \text { in a total volume of } 10 \mu \mathrm{l}
\end{aligned}
$$

The content was mixed by pipetting and the reaction was incubated overnight at $16^{\circ} \mathrm{C}$.

\subsubsection{Filling-up reaction}

(Costa and Weiner, 1994)

0.1-4 $\mu \mathrm{g}$ of digested DNA was mixed with $0.05 \mathrm{mM}$ dNTPs and 1-5 U of Klenow fragment with reaction buffer in a total volume of $50 \mu 1$. The reaction was incubated at $37^{\circ} \mathrm{C}$ for $15 \mathrm{~min}$, and then stopped by heating at $75^{\circ} \mathrm{C}$ for $10 \mathrm{~min}$. 


\subsubsection{Preparation of competent $E$. Coli bacteria}

(Dagert and Ehrlich, 1979)

The competent bacterial cells are generated by a physical cell wall modification that facilitates DNA uptake. LB medium $(100 \mathrm{ml})$ was inoculated with a single colony of E.coli (strain DH5a) and the culture was grown at $37^{\circ} \mathrm{C}$ to $\mathrm{OD} 600=0.6$. Bacteria were centrifuged $\left(10 \mathrm{~min}, 4^{\circ} \mathrm{C}, 3000 \mathrm{xg}\right)$ and the pellet was resuspended in $50 \mathrm{ml}$ of sterile $50 \mathrm{mM} \mathrm{RbCl}$ solution $\left(4^{\circ} \mathrm{C}\right)$ and incubated on ice for $30 \mathrm{~min}$. The suspension of bacteria was centrifuged $\left(10 \mathrm{~min}, 4^{\circ} \mathrm{C}, 3000 \mathrm{xg}\right)$ and the pellet was resuspended in 10 $\mathrm{ml}$ of sterile $50 \mathrm{mM} \mathrm{CaCl}_{2}\left(4^{\circ} \mathrm{C}\right)$ with $15 \%$ glycerol. The mixture was dispensed into aliquots of $50 \mu \mathrm{l}$ and stored at $-80^{\circ} \mathrm{C}$. Mostly, competent DH5 $\alpha$ were purchased from Invitrogen.

\subsubsection{Transformation of competent bacteria}

(Ausubel et al., 1994)

Transformation of the bacteria was done by gently mixing one aliquot of competent bacteria (50 $\mu 1)$ with $10 \mu \mathrm{l}$ of ligation reaction. After incubation for $30 \mathrm{~min}$ on ice, bacteria were heat shocked for $45 \mathrm{sec}$ at $40^{\circ} \mathrm{C}$, cooled down for 2 min on ice. After adding $600 \mu \mathrm{l}$ of LB medium, bacteria were incubated at $37^{\circ} \mathrm{C}, 200 \mathrm{rpm}$ for $1 \mathrm{hr}$ to allow recovery of heat shocked bacteria and were plated out on LB-agar plates containing appropriate antibiotic $(50 \mu \mathrm{g} / \mathrm{mI})$ and whenever required, $1 \mathrm{mM} \mathrm{IPTG}$ and X-Gal $40 \mathrm{mg} / \mathrm{ml}$ (X-Gal for "Blue-White" selection).

\subsubsection{Polymerase Chain Reaction (PCR)}

Without a doubt, the polymerase chain reaction (PCR) represents the single most important technique in the field of molecular biology. It is a very sensitive and powerful technique (Saiki et al., 1988) that is widely used for the exponential amplification of specific DNA sequences in vitro by using sequence specific synthetic oligonucleotides (primers). The general principle of PCR starts from a pair of oligonucleotide primers that are designed so that a forward or sense primer directs the synthesis of DNA towards a reverse or antisense primer, and vice versa. During the PCR, the Taq DNA polymerase (Chien et al., 1976) catalyses the synthesis of a new DNA strand that is complementary to a template DNA from the 5' to $3^{\prime}$ direction by a 
primer extension reaction, resulting in the production of the DNA region flanked by the two primers. It allows the rapid and unlimited amplification of specific nucleic acid sequences that may be present at very low concentrations in very complex mixtures.

\subsubsection{PCR amplification of DNA fragments}

The amplification cycles were performed in an automatic thermocycler. The PCR reaction contains in general, the following substances:

$$
\begin{aligned}
& 10 \text { ng DNA } \\
& 1 \mu \mathrm{l} \text { forward primer }(10 \mathrm{pmol}) \\
& 1 \mu \mathrm{l} \text { reverse primer }(10 \mathrm{pmol}) \\
& 0,8 \mu \mathrm{l} 10 \mathrm{mM} \text { dNTPs } \\
& 2.5 \mu \mathrm{l} 10 \mathrm{X} \text { PCR buffer } \\
& 1 \mu \mathrm{l} 50 \mathrm{mM} \mathrm{MgCl} 2 \\
& 0.5 \mu \mathrm{l} \text { Taq DNA Polymerase }(5 \mathrm{U} / \mu \mathrm{l}) \\
& \quad \text { Up to } 25 \mu \mathrm{dH}_{2} \mathrm{O}
\end{aligned}
$$

The reaction mixture was placed in a $200 \mu 1$ reaction tube and placed in thermocycler. A standard PCR program is shown here:

$\begin{array}{llr}\text { Initial denaturation } & 95^{\circ} \mathrm{C} & 5 \mathrm{~min} \\ \text { Denaturation } & 94^{\circ} \mathrm{C} & 1 \mathrm{~min} \\ \text { Annealing } & 58^{\circ} \mathrm{C} & 1 \mathrm{~min} \\ \text { Elongation } & 72^{\circ} \mathrm{C} & 1 \mathrm{~min} \\ \text { Final extension } & 72^{\circ} \mathrm{C} & 10 \mathrm{~min}\end{array}$

\subsubsection{High-fidelity PCR}

To amplify genomic templates with exceptionally high fidelity, Advantage -HF 2 PCR kit (CLONTECH) was used. The fidelity of Advantage ${ }^{\circledR}-H F 2$ was normalized by the company, CLONTECH (Table 2.1). The high level of fidelity delivered by the Advantage"-HF 2 system increases confidence in sequence derived from PCR products and is beneficial in a variety of PCR applications, including expression 
studies of amplified full-length cDNAs, generation of cDNA libraries, and analysis of homologous genes amplified with degenerate primers.

$\begin{array}{ll}\text { Enzyme } & \text { Error rate }^{a} \text { (per 100 kb) } \\ \text { Taq } & 66^{\mathrm{b}} \\ \text { Advantage }{ }^{\circledR}-2 & 24 \\ \text { Advanlage*-HF 2 } & 2.3\end{array}$

${ }^{a}$ determined with individual clones after 25 PCR cycles

${ }^{\mathrm{b}}$ agrees with published data (Ling et al., 1991; Cariello et al., 1991)

The following reagents are mixed.

$1 \mu 1$ DNA (300-500 ng)

I $\mu \mathrm{l}$ Forward primer $(10 \mathrm{pmol} / \mu \mathrm{l})$

$1 \mu 1$ Reverse primer $(10 \mathrm{pmol} / \mu \mathrm{l})$

$2.5 \mu 110 \mathrm{mM} d \mathrm{NTPs}$

$2.5 \mu 1$ 10X PCR buffer

$0.5 \mu 150 X$ Advantage-HF 2 Polymerase Mix

Up to $25 \mu \mathrm{ld} \mathrm{H}_{2} \mathrm{O}$

The mixture was subjected to the following program in the thermocycler:

$\begin{array}{cr}\text { Initial Denaturation } & 94^{\circ} \mathrm{C} \text { for } 5 \mathrm{~min} \\ \text { Denaturation } & 94^{\circ} \mathrm{C} \text { for } 1 \mathrm{~min} \\ \text { Annealing } & 58^{\circ} \mathrm{C} \text { for } 1 \mathrm{~min} \\ \text { Extension } & 72^{\circ} \mathrm{C} \text { for } 1 \mathrm{~min} \\ \text { Final Extension } & 72^{\circ} \mathrm{C} \text { for } 10 \mathrm{~min}\end{array}$

\subsubsection{Reverse transcription PCR (RT-PCR)}

RT-PCR generates cDNA fragments from RNA templates and is very useful to determine the expression of genes in specific tissues or in different development stages. $1-5 \mu \mathrm{g}$ of total RNA was mixed with $1 \mu \mathrm{l}$ of oligo (dT) primer $(10 \mathrm{pmol} / \mu \mathrm{l})$ in a total volume of $12 \mu \mathrm{l}$. To avoid the possible secondary structure of the RNA, which might interfere with the synthesis, the mixture was heated to $70^{\circ} \mathrm{C}$ for $10 \mathrm{~min}$, 
and then quickly chilled on ice. After a brief centrifugation, the followings were added to the mixture:

$$
\begin{aligned}
& 4 \mu 15 x \text { First strand buffer } \\
& 2 \mu 10.1 \text { MDT } \\
& 1 \mu 110 \text { mMdNTPs } \\
& 1 \mu 1 \text { Rnase inhibitor }(10 \mathrm{U} / \mu \mathrm{l})
\end{aligned}
$$

The content of the tube was mixed gently and incubated at $42^{\circ} \mathrm{C}$ for $2 \mathrm{~min}$. Then, $1 \mu \mathrm{l}$ of reverse transcriptase enzyme (Superscript II) was added and further incubated at $42^{\circ} \mathrm{C}$ for $50 \mathrm{~min}$ for the first strand cDNA synthesis. Next, the reaction was inactivated by heating at $70^{\circ} \mathrm{C}$ for $15 \mathrm{~min}$. One $\mu 1$ of the first strand reaction was used for the PCR reaction (as described above).

\title{
2.2.8.4 One-Step RT-PCR
}

To obtain specific RT-PCR products, the QIAGEN OneStep RT-PCR kit was employed which contains optimized components that allow both reverse transcription and PCR amplification to take place in what is commonly referred to as a "one-step" reaction.

\author{
Per reaction: \\ $5 \mu 1$ of 5X QIAGEN OneStep RT-PCR buffer \\ $1 \mu 1$ of dNTP mix (containing $10 \mathrm{mM}$ of each $\mathrm{dNTP}$ ) \\ $1 \mu \mathrm{l}$ of Forward primer (10 pmol) \\ $1 \mu 1$ of Reverse primer (10 pmol) \\ $1 \mu 1$ of Qiagen OneStep RT-PCR Enzyme Mix \\ $1 \mu 1$ of RNA (about 1 ng) \\ RNAase free $\mathrm{dH}_{2} \mathrm{O}$ up to $25 \mu$ of total volume
}

After adding of total RNA isolated from mouse tissues was added to $24 \mu 1$ of prepared Master mix in a PCR tube, the sample was placed in the thermal cycler and the RTPCR program run according to the user manual. After the amplification step, the sample was checked on an agarose gel.

Thermal cycler conditions: 


$\begin{array}{llr}\text { Reverse transcription: } & 30 \mathrm{~min} & 50{ }^{\circ} \mathrm{C} \\ \text { Initial PCR activation step: } & 15 \mathrm{~min} & 95{ }^{\circ} \mathrm{C} \\ 35 \text { cycles } & & \\ \text { Denaturation: } & 30 \mathrm{sec} & 94{ }^{\circ} \mathrm{C} \\ \text { Annealing: } & 40 \mathrm{sec} & 56-60 \mathrm{X} \\ & (\text { depending on primers) } \\ \text { Extension: } & 1 \text { min } & 72{ }^{\circ} \mathrm{C}\end{array}$

\subsubsection{Quantative Real-Time PCR}

DNA was isolated from transgenic mice tails by the method described above (2.2.1.3) and quantified by spectrophotometer (OD260). Serial dilutions of sample and standard DNA's were made with buffer AE (Qiagen, Hilden). Standard DNA was serially diluted at $20,10,5,2.5$ and $1.25 \mathrm{ng} / \mu \mathrm{l}$ for the generation of standard curve, while each sample DNA (transgenic mouse) was used at a concentration of $10 \mathrm{ng} / \mu \mathrm{l}$. Primers were designed accordingly to generate the amplicons $<150 \mathrm{bp}$, enhancing the efficiency of PCR amplification. Real-time quantitative PCR was performed using double stranded DNA binding dye Syber Green PCR Master mix (Applied Biosystems) in an ABI GeneAmp 7000 Sequence Detection System. Each reaction was run in triplicate and the melting curves were constructed by using the Dissociation Curves Software (Applied Biosystems), to ensure that only a single product was amplified. Pelota gene (GenBank, NM_134058) primers (Pelo-RTF1 and Pelo-RTR1 (2.1.11)) were used for the normalization of each DNA sample measured for transgenic integration sites. Quantitative real-time PCR reactions of DNA specimens and standards were conducted in a total volume of $10 \mu 1$ with $5 \mu 1$ of 1 x Syber Green Master Mix, 2.5 $\mu 1$ of each forward and reverse primer in a final concentration of $1 \mu \mathrm{M}$ and $2.5 \mu 1$ of DNA. Thermal cycler parameters were $2 \mathrm{~min}$ at $50^{\circ} \mathrm{C}, 10 \mathrm{~min}$ at $95^{\circ} \mathrm{C}$ and 40 cycles involving denaturation at $95^{\circ} \mathrm{C}$ for $15 \mathrm{sec}$ and annealing/extension at $58^{\circ} \mathrm{C}$ for $1 \mathrm{~min}$. When the temperature reached the $T m(\mathrm{Tm}=87 \mathrm{oC})$ of the probes, a rapid loss of fluorescence was observed between the two adjacently bound probes. The negative derivative of fluorescence was plotted versus the temperature to define the templatespecific melting curves. Standard curves of the threshold cycle number versus the log number of copies of genes were generated for transgenic integration sites and were used to extrapolate the number of integration sites of transgene. 


\subsubsection{Protein and biochemical methods}

\subsubsection{Isolation of total proteins from animal tissues}

$100 \mathrm{mg}$ of tissue was homogenized in $500 \mu \mathrm{l}$ of RIPA buffer (PIERCE), by a Teflon-glass headed pestle. The cell membrane was destroyed by sonication with Branson ultra-Sonifier. The sonified samples were boiled for 10 minutes and subsequently centrifuged at $8000 \mathrm{xg}$ for $10 \mathrm{~min}$. The supernatant containing total proteins was taken and aliquoted in e-cups. The total protein samples were frozen in $20^{\circ} \mathrm{C}$ and the stock samples were stored at $-80^{\circ} \mathrm{C}$ for long time storage.

\subsubsection{Isolation of total proteins from cell culture}

(Deryckere et al, 1994)

$$
\begin{aligned}
& \text { Lysis buffer A: } \quad 10 \text { mM HEPES, (pH 7.9) } \\
& 1.5 \mathrm{mM} \mathrm{MgCl}_{2} \\
& 10 \mathrm{mM} \mathrm{KCl} \\
& 0.05 \% \text { Nonidet P-40 } \\
& 0.5 \mathrm{mM} \text { phenylmethylsulphonyl fluoride (PMSF) }
\end{aligned}
$$

$5 \times 10^{6}$ cells $/ \mathrm{ml}$ were harvested and washed with cold phosphate buffered saline, and resuspended in $50 \mu \mathrm{l}$ of lysis buffer $\mathrm{A}$. The cells were incubated at $4^{\circ} \mathrm{C}$ with shaking for $20 \mathrm{~min}$. After incubation, the cell membrane was destroyed by sonication with Branson ultra-Sonifier and followed by centrifugation at $8000 \mathrm{xg}$ for $10 \mathrm{~min}$ at $4^{\circ} \mathrm{C}$. The supernatant containing total proteins was taken and aliquoted in e-cups. The extracted total protein samples were frozen in $-20^{\circ} \mathrm{C}$ and the stock samples were stored at $-80^{\circ} \mathrm{C}$ for long time storage.

\subsubsection{Determination of protein concentration}

(Bradford, 1976)

To determine the protein concentration, Bio-Rad protein assay was employed which is a dye-binding assay based on the differential colour change of a dye in response to various concentrations of protein. The assay is based on the observation that the absorbance maximum for an acidic solution of Coomasie Blue G-250 shifts from 494 to $595 \mathrm{~nm}$ when the binding to protein occurs. The BSA stock solution of 1 $\mu \mathrm{g} / \mathrm{ml}$ was diluted in order to obtain standard dilutions in range of $10 \mu \mathrm{g} / \mathrm{ml}$ to 100 
$\mu \mathrm{g} / \mathrm{ml}$. The Bio-Rad's color reagent was diluted 1:5 with $\mathrm{H}_{2} \mathrm{O}$, and filtered through 0.45 um filters. In a 96-well microtiter plate, $20 \mu \mathrm{l}$ of each standard dilution and the samples to be measured were pipetted with $280 \mu \mathrm{l}$ of the color reagent. The absorption of the colour reaction was measured at $595 \mathrm{~nm}$ in a microplate reader (Microplate Reader 450, Bio-Rad).

\subsubsection{N-Glycosidase-F treatment of protein}

Total cell proteins were extracted from stomach using phosphate buffer. $400 \mu \mathrm{g}$ of proteins were treated with $\mathrm{N}$-glycosidase F enzyme (Roche) at a final concentration for $0.05 \mathrm{U} / \mu 1$ at $4{ }^{\circ} \mathrm{C}$ for overnight according to suppliers manual. SDS sample buffer with DDT (final concentration $25 \mathrm{mM}$ ) was added to the enzyme treated protein sample followed immediately by boiling for $10 \mathrm{~min}$ and $40 \mu \mathrm{g}$ denaturated proteins were loaded on Nu-Page SDS-PAGE (Invitrogen) and also equal amount of non-treated proteins were loaded parallely.

\subsubsection{Blotting techniques}

\subsubsection{Southern blotting of DNA to nitrocellulose filters}

(Southern, 1975)

In Southern blotting, the transfer of denatured DNA from agarose gels to nitrocellulose membrane is achieved by capillary flow. 20X SSC buffer, in which nucleic acids are highly soluble, is drawn up through the gel into the nitrocellulose membrane, taking with it the single-stranded DNA that becomes immobilized in the membrane matrix. After electrophoresis of DNA, the gel was treated with $0.25 \mathrm{M}$ $\mathrm{HC} 1$ for depurination. It was followed by denaturation solution for $30 \mathrm{~min}$ and $45 \mathrm{~min}$ in neutralization solution. The transfer of the DNA to the nitrocellulose membrane was done in a Turbo-Blot-apparatus (Sehleieher \& Schuell, Dassel). About 20 Whatman filter papers (GB 003) were layered on a Stack Tray followed by 4 Whatman filter papers (GB 002) and 1 Whatman filter paper GB 002 soaked with $2 \mathrm{X}$ SSC. The equilibrated nitrocellulose filter that was also soaked with $2 \mathrm{X}$ SSC was laid on the top. The agarose gel, which was treated as described above, was placed on the filter and was covered with 3 Whatman filter papers GB 002 soaked with 2X SSC. The buffer tray was placed and filled with 20X SSC. Finally a wick, which was soaked with 20X SSC, and the wick cover were put on the top of the blot. The transfer 
was carried out for overnight. Finally, after disassembling of the blot, the filter was washed briefly in 2X SSC and the DNA was fixed onto the filter by either baking it at $80^{\circ} \mathrm{C}$ for $2 \mathrm{hrs}$ or by UV-crosslinking in UV Stratalmker 1800.

\subsubsection{Northern blotting of RNA onto nitrocellulose filter}

For the transfer of RNA onto a nitrocellulose filter, the same procedure as described above (2.2.10.1) was performed. In this case, however, the gel does not need to be denatured, but was transferred directly onto the filter.

\subsubsection{Western blotting of protein onto PVDF membrane}

(Gershoni and Palade, 1982)

$\begin{array}{ll}\text { Anode I buffer } & \begin{array}{l}0.3 \mathrm{M} \text { Tris/HCl, }(\mathrm{pH} \text { 10.4) } \\ 20 \% \text { Methanol }\end{array} \\ & 25 \mathrm{mM} \text { Tris/HCl, }(\mathrm{pH} 10.4) \\ \text { Anode II buffer } & 20 \% \mathrm{Methanol} \\ & 40 \mathrm{mM} \text { e-Aminocaproic acid } \\ \text { Cathode buffer } & 25 \mathrm{mM} \text { Tris/HCl, }(\mathrm{pH} 9.4) \\ & 20 \% \text { Methanol }\end{array}$

After the electrophoresis of proteins on a SDS-PAGE, the gel and the PVDF membrane, which was cut at the size of the gel, was first moistened with methanol and then equilibrated in anode II buffer. Six pieces of GB004 Whatman filter paper were also cut at the size of the gel. Two pieces of filter papers were soaked in anode buffer I and one paper in anode II buffer. First, the papers soaked with anode 1 buffer were placed on semi dry transfer machine's lower plate and than papers soaked with anode II buffer were placed over it. The equilibrated membrane was placed over them and then the gel was placed avoiding any air bubbles. Another three Whatman paper soaked with cathode buffer was placed over to complete the sandwich model. The upper plate was placed over this sandwich and the transfer was carried out at 3.5 $\mathrm{mA} / \mathrm{cm}^{2}$ for $1 \mathrm{hr}$. 


\subsubsection{4 "Random Prime" method for generation of ${ }^{32}$ P-labeled DNA}

(Denhardt, 1966; Feinberg and Vogelstein, 1989)

Rediprime $^{\mathrm{TM}}$ II Random Prime Labeling System (Amersham Pharmacia) was used for labeling of DNA probes. The method depends on the random priming principle developed by Feinberg and Vogelstein (1989). The reaction mix contained dATP, dGTP, dTTP, Klenow fragment (4-8 U) and random oligodeoxyribonucleotides. Firstly, 25-50 ng of DNA were denatured in a total volume of $46 \mu 1$ at boiling water for $10 \mathrm{~min}$ and quick chilled in ice for $5 \mathrm{~min}$. After pipetting the denatured probe in Rediprime II Random Prime Labeling System cup, $4 \mu 1$ of $\left[\gamma^{32} \mathrm{P}\right]$ $\mathrm{dCTP}(3000 \mathrm{Ci} / \mathrm{mmol})$ was added to the reaction mixture. The labelling reaction was carried out at $37^{\circ} \mathrm{C}$ for $1 \mathrm{hr}$. The labelled probe was purified from unincorporated $[\gamma-$ ${ }^{32} \mathrm{P}$ ] dCTP by using microspin columns (Amersham Pharmacia).

\subsubsection{5'-end radiolabeling of target DNA}

For labeling of both 5 -ends of nucleotides, $\left[\gamma-{ }^{32} \mathrm{P}\right] \mathrm{dCTP}$ and polynucleotide kinase were used. The following was mixed in a sterile microcentrifuge tube:

$\begin{array}{lc}\text { Dephosphorylated DNA-5-ends } & 20 \text { pmol } \\ \text { 10X kinase buffer } & 5 \mu l \\ \text { T4 polynucleotide kinase }(5-10 \text { units } / \mu \mathrm{l}) & 1 \mu \mathrm{l} \\ {\left[\gamma-{ }^{32} \mathrm{P}\right] \mathrm{CTP}(3000 \mathrm{Ci} / \mathrm{mmol})} & 5 \mu \mathrm{l} \\ \text { TE buffer } & \text { to } 50 \mu \mathrm{l}\end{array}$

Then, the labeling reaction was carried out at $37^{\circ} \mathrm{C}$ for $1 \mathrm{hr}$. The labelled probe was purified from unincorporated $[\gamma-32 \mathrm{P}]$ ATP by using microspin $\mathrm{G}-25$ columns (Amersham Pharmacia).

\subsubsection{Non-radioactive dye terminator cycle sequencing}

Non-radioactive sequencing was performed with the Dye Terminator Cycle Sequencing-Kit (ABI PRISM). The reaction products were analysed with automatic sequencing equipment, namely 377 DNA Sequencer (ABI PRISM). For the sequencing reaction, four different dyes labeled dideoxy-nucleotides were used (Sanger et al., 1977). The reaction was carried out in a total volume of $10 \mu 1$ containing $1 \mu 1$ plasmid DNA or $100-200$ ng purified PCR products, 10 pmol primer and $4 \mu 1$ 
reaction mix (contains dNTPs, dideoxy dye terminators and Taq DNA polymerase). Elongation and chain termination take place during the following program in a thermocycler: 4 min denaturation followed by 25 cycles at $95^{\circ} \mathrm{C}, 30 \mathrm{sec} ; 55^{\circ} \mathrm{C}, 15 \mathrm{sec}$, annealing; $60^{\circ} \mathrm{C}, 4 \mathrm{~min}$, elongation. After the sequencing reaction, the DNA was precipitated with $1 / 10$ volume $3 \mathrm{M}$ sodium acetate and 2.5 volume $100 \%$ ethanol and washed in $70 \%$ ethanol. The pellet was dissolved in $4 \mu 1$ of loading buffer, denatured at $95^{\circ} \mathrm{C}$ for $3 \mathrm{~min}$, and finally loaded into the sequence gel.

\subsubsection{Hybridisation of nucleic acids}

(Denhardt, 1966)

The membrane to be hybridised was equilibrated in 2x SSC and transferred to a hybridisation bottle. After adding $10 \mathrm{ml}$ of hybridisation solution and sheared salmon DNA, the membrane was incubated for $2 \mathrm{hrs}$ in the hybridization oven at an appropriate temperature, which was usually $65^{\circ} \mathrm{C}$. Then, the labelled probe was denatured at $95^{\circ} \mathrm{C}$ for 10 min, quick chilled, and added to the hybridisation solution. The hybridisation was carried out overnight in the oven. Next day, the filter was washed for 10 min with $2 x \mathrm{SSC}$ at room temperature. Finally, it was washed with $0.2 \mathrm{x}$ SSC containing $0.1 \%$ SDS at the hybridisation temperature. After drying the filter, it was sealed in Saran wrap and exposed to autoradiography overnight at $-80^{\circ} \mathrm{C}$ or to Phosphoimager screen for $1-4 \mathrm{hrs}$. The film was developed in X-Ray Automatic Processor Curix 60 or screen was scanned in Phosphoimager. For quantification of detected bands, the program Quntity One (Bio-Rad) was used.

\subsubsection{Generation of polyclonal antibody against fusion protein}

\subsubsection{Development of fusion protein using pET system}

189-bp Vsig1 cDNA fragment was amplified by RT- PCR using FuProF2 and FuProR2 primers. Then the PCR product subcloned into pGEMT-easy vector and transformed into DH5 $\alpha$ cell (Invitrogen). The Hind3/BamH1 cDNA fragment was isolated from the pGEMT-easy vector and cloned into pET41a vector and the resulted construct was transformed into DH5 $\alpha$ cell. The plasmid DNA of pET41-Vsigl construct transformed into competent cell BL21DE3 (Novagen). Transformed cells were cultivated on LB-kanamycin plate at $37^{\circ} \mathrm{C}$ for overnight. 8 individual clones were cultivated in $5 \mathrm{ml}$ of $\mathrm{LB}+$ kanamycin medium at $37^{\circ} \mathrm{C}$ with shaking for overnight. 
After $16 \mathrm{hrs}$, IPTG was added in each of cultivation up to $1 \mathrm{mM}$ concentration. After 3 hrs, cells were harvested by table centrifuge (at $5 \mathrm{rpm}$, for $10 \mathrm{~min}$ ) for analyse of fusion protein. Thus, the best clone giving high yield of fusion protein was selected for further large scale fusion protein purification.

\subsubsection{Purification of fusion protein using GST affinity column}

1 liter of bacterial culture was prepared for purification of the fusion protein. The cells were harvested by centrifugation at $4000 \mathrm{X} \mathrm{g}$ for 20 minutes. And supernatants were discarded. The cells were resuspended in $50 \mathrm{ml}$ of ice cold resuspension buffer (from the kit). The resuspended cell sample was sonicated for disruption of bacterial cells. Then the cell lysate was centrifuged at $39,000 \times \mathrm{g}$ for 20 min to remove the cell debris. The supernatant was followed into new falcon tube and filtrated though a 0.45 micron membrane to prevent clogging of the resin (syringe-end filters are convenient for this purpose). GST-Bind Resin was gently mixed by inversion until completely suspended. Using a wide-mouth pipette, $4 \mathrm{ml}$ of GST-BindResin was transferred to the small polypropylene columns (Novagen) and allowed to settle down by gravitation force. The prepared affinity column was washed with 5 volumes of GST Bind/Wash Buffer for calibration. The GST-Bind/Wash Buffer was allowed to drain to the top of the column bed and the prepared fusion protein extract was loaded through the column. The loading of fusion protein extract through the column was repeated three times for efficient binding. The final flow-through fraction was collected on ice and stored in -20C for further analysis. The column was washed with $20 \mathrm{ml}$ of 1X GST Bind/Wash Buffer. At the end, the affinity bounded proteins were eluted with $7 \mathrm{ml}$ of $1 \mathrm{X}$ GST Elution Buffer.

\subsubsection{Immunization of rabbit}

For immunization, two rabbits were injected with a denatured and native GSTVSIG1 fusion protein samples, respectively. Denatured GST-VSIG1 fusion proteins were prepared by mixing with 1\% SDS, 5mM DTT and boiled for 10 minutes. $500 \mathrm{mg}$ (total volume $500 \mathrm{ml}$ ) of denatured and native fusion proteins were mixed $500 \mathrm{ml}$ of Freund's complete adjuvant, respectively (final total volume $1 \mathrm{ml}$ ). Before the first injection of the rabbits, approximately $10 \mathrm{ml}$ of blood was bled from each rabbit for zero-control. Next boost injections were performed in 21 days interval with $500 \mathrm{mg}$ 
of denatured and native fusion proteins mixed with Freund's incomplete adjuvant. After 21 days of 3-rd boost injections, the rabbits were sacrificed and the entire blood was collected. The serum was isolated from blood sample by centrifugation at $2000 \mathrm{~g}$ for 10 minutes at $4^{\circ} \mathrm{C}$.

\subsubsection{Purification of whole IgG from immunized rabbit serum}

The whole IgG was purified using MAbTrap antibody purification kit (Amersham). The serum sample was centrifuged at $10000 \mathrm{x} \mathrm{g}$ for 10 minutes to remove cells and debris. The supernatant was filtrated through a $0.45 \mu \mathrm{m}$ filter. Before application, the HiTrap Protein G-HP column and buffers were warmed to 37C. The column was equilibrated with $5 \mathrm{ml}$ distilled water, and followed by $3 \mathrm{ml}$ diluted binding buffer. Serum sample was applied through the column by syringe in slowly pumping. After applying of serum, the column was washed with 5-10 ml diluted binding buffer until no material appears in the eluent. After washing, the column was eluted with 3-5 $\mathrm{ml}$ diluted elution buffer. The eluted fractions were collected into $1.5 \mathrm{ml}$ tubes containing neutralization buffer and stored at $-20 \mathrm{C}$.

\subsubsection{Purification of VSIG1 specific antibody}

\subsection{Preparation of affinity column}

To prepare affinity column for purification of VSIG1 antibody, Affi-Gel 10 (BioRad) active ester agarose was used. Affi-Gel 10 is N-hydroxysuccinimide ester crosslinked to agarose gel beads which is capable to bind covalently with ligands containing free alkyl or amino groups. $3 \mathrm{ml}(1 \mathrm{mg} / \mathrm{ml})$ of GST-VSIG1 fusion protein was dialyzed against 5 liter of MOPS buffer (100mM MOPS, pH 7.5) for $24 \mathrm{hrs}$ at $4^{\circ} \mathrm{C}$ to remove Tris derived from elution buffer. $3 \mathrm{ml}$ of Affi-Gel 10 was washed three times with $9 \mathrm{ml}$ of cold dionized water. Dialyzed $4 \mathrm{ml}$ fusion protein was added to the washed Affi-Gel 10 pellet and the sample was incubated by rotating at $4{ }^{\circ} \mathrm{C}$ for 4 hours for coupling. After coupling, $100 \mu \mathrm{l}$ of $1 \mathrm{M}$ ethanolamine-HCL ( $\mathrm{pH} 8.0$ ) was added to the coupling samples and incubated for further $1 \mathrm{hr}$ for blocking. After blocking, the sample was centrifuged at $1000 \mathrm{~g}$ for $5 \mathrm{~min}$ and the supernatant was removed for analyzing of binding efficiency (by Goomassie staining) comparing to non coupled 
fusion protein sample. The pellet was washed 2 times with MOPS buffer and settled into the column.

\subsection{Affinity purification of VSIG1 specific antibody}

The prepared affinity column was washed with $10 \mathrm{ml}$ of PBS two times. Approximately $3 \mathrm{ml}$ of anti-serum was applied to the column and followed by slowly dropping. The follow through was collected and the running was repeated at least 5 times. After last running, the column was washed with $10 \mathrm{ml}$ PBS two times to remove residual serum materials. The column was eluted with $10 \mathrm{ml}$ of elution buffer (100 mM of glycine-HCL pH 2.4, $150 \mathrm{mM} \mathrm{NaCl} .1 \mathrm{ml}$ of elution fractions were collected separately and neutralized directly by adding $200 \mu \mathrm{l}$ of $1 \mathrm{M}$ Tris-HCL (pH 8.0). The elution fractions from 2-5 contain highest concentration of affinity purified antibody.

\subsubsection{Histological techniques}

\subsubsection{Tissue preparation for paraffin embedding}

The freshly prepared tissues were fixed in Bouin's solution or $4 \%$ paraformaldehyde in PBS for 24 - $72 \mathrm{hrs}$ to prevent the alterations in the cellular structure. The tissue to be embedded in paraffin should be free of water. The dehydration process was accomplished by passing the tissue through a series of increasing alcohol concentrations. For this purpose, the tissue was incubated in $50 \%$, $70 \%, 80 \%, 90 \%, 96 \%$ and $100 \%$ ethanol for at least $1 \mathrm{hr}$ at RT. Then tissue was incubated in $100 \%$ xylol overnight. Further, tissue was incubated in 1:1 mixture of xylol/paraffin at $65^{\circ} \mathrm{C}$ for overnight. Then tissue was incubated in $100 \%$ paraffin for several days, during that time, the paraffin solutions were regularly changed to remove completely the xylol. Finally, the tissue was placed in embedding mould and melted paraffin was poured into the mould to form a block. The block was allowed to cool and was then ready for sectioning or stored at $4{ }^{\circ} \mathrm{C}$.

\subsubsection{Sections of paraffin block}

The paraffin blocks were pre-cut to the optimal size and clamped into the microtome (Leica). The cut-thickness of the paraffin embedded was for $3-7 \mu \mathrm{m}$. The sections were floated on $40^{\circ} \mathrm{C}$ water to allow actual spread and subsequently put onto 
Superfrost slides. A fine brush was used to transfer the sections to slides. Slides were then dried at $45^{\circ} \mathrm{C}$ and incubated in $80^{\circ} \mathrm{C}$ for about 15 min to get rid off excess of paraffin. Slides were then stored at RT for further analysis.

\subsubsection{Hematoxylin-Eosin (HE) staining of the histological sections}

The stored slides with the paraffin sections were stained by the incubating the slides three times in histoclear (Xylol) for $3 \mathrm{~min}$ and in 100\%, 96\%, 80\%, 70\% and 50\% ethanol each for $2 \mathrm{~min}$. After washing with tap water for $1 \mathrm{~min}$, the sections were stained for $10 \mathrm{~min}$ in Harris hematoxylin. The slides were then rinsed in running tap water for 5-10 min, and then dipped quickly in acid-alcohol for several times to differentiate the nuclear blue signal. Then the slides were rinsed in tap water. After the hematoxylin staining, the slides were incubated in eosin for $5 \mathrm{~min}$, and then washed in $90 \%$ ethanol several times. Finally the slides were incubated in 100\% ethanol for $2 \mathrm{~min}$ and in xylol for 3 min for dehydration.

\subsubsection{Immunohistochemistry}

Slides with paraffin sections were incubated in $100 \%$ xylol to remove the paraffin and the sections were subsequently rehydrated by incubation in serially diluted ethanol in water. After rehydration, the slides were washed with PBS for $5 \mathrm{~min}$, and blocked with $10 \%$ of appropriate serum in PBS with $0.1 \%$ Tween-20 for $1 \mathrm{hr}$ at RT. Then slides were incubated with primary antibodies at 1:250 dilutions for 18-20 hrs at $4{ }^{\circ} \mathrm{C}$ in humidified chamber with PBS containing $2 \%$ serum and $0.1 \%$ Tween-20. The slides were then washed 3 times for 5 min with PBS and the protein was detected by incubating with respective FITC conjugated secondary goat anti-rabbit IgG at a dilution of 1:500 in PBS for 2 hrs. Sections were finally washed with PBS twice for $10 \mathrm{~min}$, mounted in Vecta-Shield mounting medium and DAPI. Images were taken using fluorescence microscope.

\subsubsection{Immunocytochemistry}

First, the culture media was removed from the cells in microscopical chambers or dishes and were rinsed with PBS. After that $1 \mathrm{ml} 4 \%$ PFA (made fresh) per chamber/dish was added and incubated for $3 \mathrm{~min}$ at RT for fixing the cells. Then, the cells were washed 3 times with PBS and permeabilized by adding $1 \mathrm{ml}$ buffer / plate 
containing $0.01 \%$ of Triton-X in PBS. The permeabilization was carried out for $15 \mathrm{~min}$ at RT. After permeabilization, the cells were washed with PBS three times for $5 \mathrm{~min}$.

Then, cells were incubated with the respective diluted primary antibody in a buffer containing PBS and $2 \%$ FBS for overnight at $4{ }^{\circ} \mathrm{C}$. Next day, the cells were washed with PBS three times for 5 min and then, incubated with the secondary antibody in the same buffer applied for primary, for $4 \mathrm{hrs}$ at RT. Before microscopical analysis the cells were washed 3 times with PBS and mounted with DAPI (Vector, Burfingame).

\subsubsection{Establishment of stable transfected HepG2 cell line.}

Approximately $4 \times 10^{5}$ of the HepG2 cells were plated on a well of 6-well plate, and cultured overnight in $1 \mathrm{ml}$ medium containing $10 \%$ FKS and $1 \%$ penicillin/streptomycin at $37^{\circ} \mathrm{C}$ and $5 \% \mathrm{CO}_{2} .6 \mu \mathrm{g}$ of DNA construct was diluted with the OPTIM-MEM medium containing no serum or antibiotics to a total volume of $50 \mu$. $10 \mu \mathrm{l}$ of Lipofectamin (Invitrogen) was diluted with OPTIM-MEM medium to a total volume of $50 \mu \mathrm{l}$. These two solution was mixed and incubated at RT for $30 \mathrm{~min}$ to allow complex formation. After $30 \mathrm{~min}$ incubation, $100 \mu \mathrm{l}$ of the mixed solution was added carefully to the growing cells which are covered with $1 \mathrm{ml}$ of growth medium. The cells were incubated for $3 \mathrm{hr}$ at $37^{\circ} \mathrm{C}$ and $5 \% \mathrm{CO}_{2}$. Medium containing the DNA complex were removed from the cells by gentle aspiration and cells were washed 2 times with PBS. Fresh medium was added and incubated for $48 \mathrm{hrs}$ to allow for gene expression. After $48 \mathrm{hrs}$, cells were selected in medium containing $600 \mu \mathrm{g} / \mathrm{ml}$ neomycin for 2 weeks. Stable transfected cells were grown as single clonies, and these clonies were picked up by pipetting with sterile tips under the microscopy and transferred to a well of 96 well plate. The selected clonies were maintained thereafter on medium with $200 \mu \mathrm{g} / \mathrm{ml}$ neomycin and subjected to expression analysis.

\subsubsection{Cell culture assays on stable transfected HepG2 cell lines}

\subsubsection{Cell-Cell adhession assay by hanging drop method}

Stable transfected cells were trypsinized and the numbers of cells were identified by counting with Neubauer's counting chamber. Approximately 500 single cells from the VSIG1-overexpressing cell line and control transfected cell line were incubated in 5 separate hanging drops respectively in water jacketed incubator. Every one hour, one 
hanging drop from each line was taken and the cells were resuspended by pipeting 5 times. Then total particle numbers in each drop were counted directly in Neubauer's counting chamber. Single cell, two cells or multi cell aggregations were counted as single particle. After counting the total particle numbers of all hanging drops, the changing dynamic of total particle numbers were plotted on a graph.

\subsubsection{Cell migration assay}

Cell migration assay was performed based on the healing speed of scratched wound in stable transfected HepG2 monolayer cells. The cells of stable transfected HepG2 line were grown at $90-100 \%$ confluence to form a monolayer in $10 \mathrm{~cm}^{2}$ culture dishes. By using a p200 pipet, a scratch of the cell monolayer was created in each clone. After drawing the scratch, the cells were washed two times with PBS and further incubated. The first images of the scratched wound were photographed just after washing with PBS, and further images were photographed after $12 \mathrm{hrs}, 24 \mathrm{hrs}$ and 48 hrs. The images acquired for each sample were further analyzed quantitatively by using computing software.

The migration rate of the cell was determined by measuring the distance between two leading edge of the scratched wound. If the cell migration is faster, the distance between two edges of the scratched wound will be faster. If the cell migration is slower, then the edges will be closed slowly. Using "Soft Imaging System" software (Olympus), in each certain time interval (12 hrs, $24 \mathrm{hrs}$, and $48 \mathrm{hrs}$ ), the distances between two edges of healing wound were measured 10 times randomly in selected fields of view and the mean values of the distance were identified for each clone.

\subsubsection{Establishment of primary stomach cell culture}

The whole stomach was dissected out carefully under the laminar flow and washed with PBS in room temperature. The stomach tissue was minced into small pieces with sterile mini scissors in $35 \mathrm{~mm}$ dish and the pieces were subsequently incubated in $1.5 \mathrm{ml}$ HBSS containing $1 \mathrm{mg} / \mathrm{ml}$ collagenase and $2 \mathrm{mg} / \mathrm{ml}$ dispase-II for 2 hrs. After 2 hrs, the stomach suspension was mixed with Paster pipette every 15 min for further 1-1.5 hrs and each time the single cell separation was controlled under the microscopy. After enough time incubation (3-4 hrs), the cell suspension was 
centrifuged at $1000 \mathrm{~g}$ for $5 \mathrm{~min}$. The supernatant was dissolved in pre-warmed trypsin solution and incubated for $5 \mathrm{~min}$. Trypsin digestion was stopped by adding $1 \mathrm{ml}$ FKS and the cell suspension was directly filtrated through the $70 \mu \mathrm{m}$ filter (BD Bioscience). Filtrated flow through containing the single cells was centrifuged at $1000 \mathrm{~g}$ for $5 \mathrm{~min}$ and the cell pellet was dissolved in appropriate amount of culture medium or PBS (in case of FACS). Stomach cells were plated on gelatine coated 6-well plate containing the ES-cell medium with LIF and incubated at $37^{\circ} \mathrm{C}$ in $5 \% \mathrm{CO}_{2}$ incubator for 10 days. After 10 days incubation, the cells were split by trypsinization and subjected for further experiments. From passage-2, long incubation (0.5-1.5 hrs) of dispase-II was more effective to disassociate the compactly aggregated cell clumps.

\subsubsection{Techniques for production of targeted mutant mice (Joyner, 2000)}

The discovery that cloned DNA introduced into cultured mouse embryonic stem cells can undergo homologous recombination at specific loci has revolutionized our ability to study gene function in vitro and in vivo. In theory, this technique will allow us to generate any type of mutation in any cloned gene. Over twenty years ago, pluripotent mouse embryonic stem cells (ES) derived from inner cell mass cells of mouse blastocysts were isolated and cultured (Martin, 1981; Evans and Kaufman, 1981) Genetic alterations introduced into ES cells in this way can be transmitted into the germline by producing mouse chimeras. Therefore, applying gene targeting technology to ES cells in culture gives the opportunity to alter and modify endogenous genes and study their functions in vivo.

\subsubsection{Production of targeted embryonic stem cell clones}

\subsection{Preparation of MEFs feeder layers}

A frozen vial of MEFs (mouse embryo fibroblasts) was quickly thawed at $37^{\circ} \mathrm{C}$ and transferred to $10 \mathrm{ml}$ EMFI medium. After centrifugation at $270 \mathrm{xg}$ for $5 \mathrm{~min}$, the cell pellet was gently resuspended in $10 \mathrm{ml}$ MEFs medium and plated on a $50 \mathrm{~mm}$ culture flask. Cells were incubated at $37^{\circ} \mathrm{C}$ in $5 \% \mathrm{CO} 2$. When the cells formed a confluent monolayer (three days), they were either trypsinized, transferred to five $150 \mathrm{~mm}$ dishes and grown until they formed confluent monolayer, or directly treated with mitomycin $\mathrm{C}$. To treat the MEFs with mitomycin $\mathrm{C}$, the medium was removed and $10 \mathrm{ml}$ fresh 
medium containing $100 \mu \mathrm{l}$ mitomycin $\mathrm{C}(1 \mathrm{mg} / \mathrm{ml})$ was added. After 2-3 hrs of incubation, the monolayer of cells was washed twice with $10 \mathrm{ml}$ PBS. The cells were then resuspended with $10 \mathrm{ml}$ medium and gentle pipetting dissolved any cell aggregates. The cells were centrifuged, resuspended in MEFs medium and plated onto dishes, which were treated with $0.1 \%$ gelatine for $30 \mathrm{~min}$. The feeder cells were allowed to attach by incubation overnight at $37^{\circ} \mathrm{C}, 5 \% \mathrm{CO}_{2}$ or used after $2 \mathrm{hrs}$ of incubation. Before adding ES cells on the feeder layer, the medium was changed to ES cell medium.

\subsection{Growth of ES cells on feeder layer}

One vial of frozen ES cells was quickly thawed at $37^{\circ} \mathrm{C}$ and cells were transferred to a $12 \mathrm{ml}$ tube containing $6 \mathrm{ml}$ ES cell medium. After centrifugation, the cell pellet was resuspended in $5 \mathrm{ml}$ ES cell medium and plated on $60 \mathrm{~mm}$ dishes containing MEFs at $37^{\circ} \mathrm{C}, 5 \% \mathrm{CO}_{2}$. Next day the medium was changed. The second day, cells were washed with PBS, treated with $2 \mathrm{ml}$ trypsin/EDTA at $37^{\circ} \mathrm{C}, 5 \% \mathrm{CO}_{2}$ for $5 \mathrm{~min}$. The cells were gently pipetted up and down to dissolve cell clumps, resuspended with $5 \mathrm{ml}$ ES medium and centrifuged. The cell pellet was resuspended in $10 \mathrm{ml}$ ES cell medium and distributed either to 5 or 6 dishes $(60 \mathrm{~mm})$, containing feeder layers or to 2 dishes (100 $\mathrm{mm}$ ) containing feeder layers. The cells were passaged every second day as described above.

\subsection{Electroporation of ES cells}

ES cells, which have grown for two days on $100 \mathrm{~mm}$ dishes, were trypsinized. The cell pellet was resuspended in $20 \mathrm{ml}$ PBS and centrifuged. The cell pellet was then resuspended in $1 \mathrm{ml}$ PBS. $0.8 \mathrm{ml}$ of cell suspension was mixed with $40 \mu \mathrm{g}$ of linearized DNA-construct and transferred into an electroporation cuvette. The electroporation was performed at $240 \mathrm{~V}, 500 \mu \mathrm{F}$ with the BIO RAD gene pulserTM. After electroporation, the cuvette was placed on ice for $20 \mathrm{~min}$. The cell suspension was transferred from cuvette into $20 \mathrm{ml}$ of ES cell medium and plated onto two $100 \mathrm{~mm}$ dishes containing feeder layers. The medium was changed every next day. Two days after the electroporation, the drugs for the selection were added (active G418 at $400 \mu \mathrm{g} / \mathrm{ml}$ and gancyclovir at $2 \mu \mathrm{M}$ ). The medium was changed every day. After about eight days of selection, drug resistant colonies have appeared and were ready for screening by Southern blot analysis. 


\subsection{Growing ES cells for Southern blot analysis}

The drug resistant colonies that were formed after about eight days of selection were picked with a drawn-out Pasteur pipette under a dissecting microscope. Each colony was transferred into a 24 well plate containing feeders and ES cell medium. After 2 days, the ES cells were trypsinized with $100 \mu \mathrm{l}$ trypsin for $5 \mathrm{~min}$ and resuspended in $500 \mu \mathrm{l}$ ES cell medium. Half of the cell suspension in each well was transferred to a well on two different 24 well plates, one gelatinised plate, and the other containing feeder cells (master plate). The gelatinised plate was used for preparing DNA and the master plate was kept frozen.

\subsubsection{Production of chimeras by injection of ES cells into blastocyst.}

The ability of mammalian embryos to incorporate foreign cells and develop as chimeras has been exploited for a variety of purposes including the perpetuation of mutations produced in embryonic stem (ES) cells by gene targeting, and the subsequent analysis of these mutations. The standard procedure is to inject 10-20 ES cells, which are recombinant for targeted locus, into the blastocoel cavity of recently cavitated blastocysts that have been recovered by flushing the uteri of day 4 pregnant mice (C57BL/6J). After injection, embryos are cultured for a short period (2-3 hrs) to allow re-expansion of the blastocoel cavity and then transferred to the uterine horns of day 3 CD1 pseudopregnant mice. Pseudopregnant females are obtained by mating 6-8 weeks old oestrous females with vasectomized males.

\subsubsection{Detection of chimerism and mice breeding.}

The most convenient and readily apparent genetic marker of chimerism is coat colour. Chimeric males (and sometimes females) are bred to wild-type mice to ascertain contribution of the ES cells to germline. Once a germline chimera has been identified, the first priority will be to obtain and maintain the targeted allele in living animals. The chimeras were bred with C57BL/6J and with $129 / \mathrm{Sv}$ mice to compare the phenotype in two different genetic backgrounds. 


\subsubsection{Software and Computer tools}

For the analysis of the nucleotide sequences, programs like BLAST, MEGABLAST and other programs from National Center for Biotechnology Information (NCBI) were used (www.ncbi.nlm.nih.gov). And for restriction analysis of DNA, NEBcutter V2.0 programm was used (http://tools.neb.com/NEBcutter2/index.php). Information about mouse alleles, phenotypes and strains were obtained from the Jackson Laboratory web page (www.informatics.jax.org). For multiple sequence alignment of peptide sequence, ClustalW2 (www.ebi.ac.uk/clustalw/) program was used. For basic calculations of molecular biological applications, ExPASy tools (www.expasy.org) and Promega's "Biomath" calculator (http://www.promega.com/biomath/) were employed. Mouse genome sequence and other analysis on mouse genes, transcript and putative proteins were downloaded from Celera discovery system (www.celera.com). 


\section{RESULTS}

\subsection{Isolation and characterization of Vsig1 cDNA}

To isolate cDNA clones representing genes which are exclusively expressed in stomach, a subtractive cDNA hybridization was performed (Göring, 2006). Total RNA was isolated from stomach and small intestine and reverse transcribed. Stomach "tester" and small intestine "driver" cDNAs were hybridized and the hybrid molecules were removed. The remaining not hybridized cDNA molecules represent genes that are expressed in the stomach "tester", but are downregulated in the intestine mRNA "driver". The not hybridized cDNA molecules were amplified by PCR and cloned into pGEMT-easy vector. A cDNA fragment of one clone $(S X)$ hybridized in Northern blot with a $2.7-\mathrm{kb}$ transcript in stomach RNA. No hybridization could be detected in RNA of other studied tissues (Fig. 3.1).

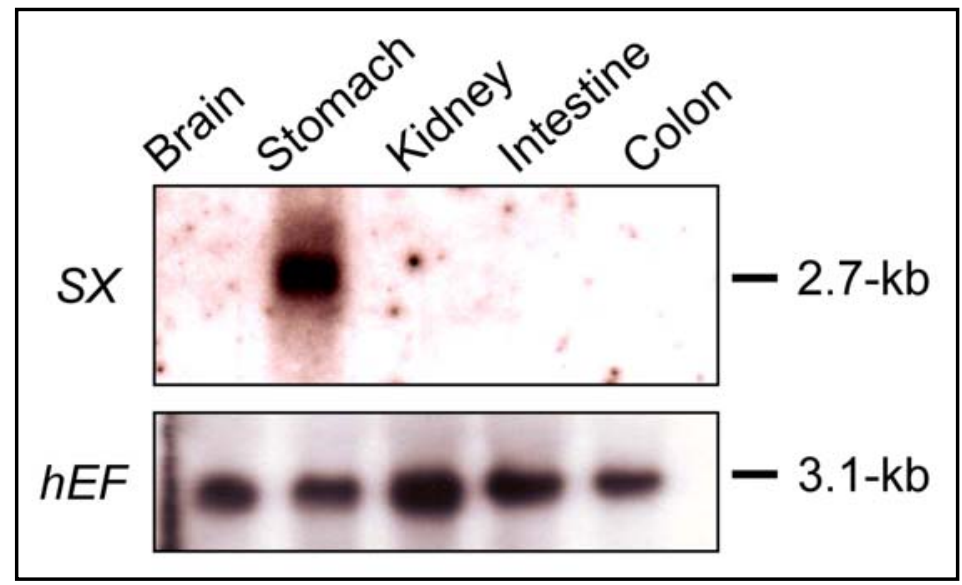

Figure 3.1 The cDNA fragment of the SX-clone was hybridized with a $2.7-\mathrm{kb}$ transcript which is expressed only in stomach. Integrity and variation of loaded RNA samples were checked by rehybridization with human elongation factor-2 $(h E F)$. The sizes of hybridization signals are indicated on the right.

A search of Genbank database revealed that the identified cDNA is identical to the sequence in 3' untranslated sequence of the Vsig1 gene. The Vsig1 gene is located on the $\mathrm{X}$ chromosome, contains 7 exons (Fig. 3.2) and encodes a novel member of the 
immunoglobulin superfamily. The Vsig1 gene is approximately 31-kb long. The length of 5-' and 3'-untranslated region is 56-bp and 906-bp, respectively. Translation start site ATG is located at position 57 to 59 and flanked by a sequence which is similar with the Kozak translation consensus sequence (CCG/ACC (ATG)G) (Kozak, 1989). The 3'-untranslated region of Vsig1 contains two polyadenylation sites (AATAAA), which are located at the positions 1426 and 2157 (Fig. 3.3).

The sequence of the cDNA fragment (SX) which was used for Northern blot hybridization is located between both of the predicted polyadenylation signals. Therefore, the probe only recognized the 2.7-kb transcript. To determine whether the Vsig1 gene transcribes two mRNA isoforms that are different in the length of the 3'-untranslated region, we have amplified a 500-bp cDNA fragment (probe-2). The probe-2 is located in the upstream sequence of the first poly-A signal and it was used for Northern blot hybridization with total RNA from brain, kidney, stomach and testis. The analysis revealed that the 500-bp cDNA recognizes a $2.7-\mathrm{kb}$ and a $1.4-\mathrm{kb}$ transcript in testis, and only a $2.7-\mathrm{kb}$ Vsig1 transcript in stomach (Fig. 3.4). These data demonstrate that Vsig1 transcribes two RNA isoforms, which are different in their length of 3'-untranslated region.

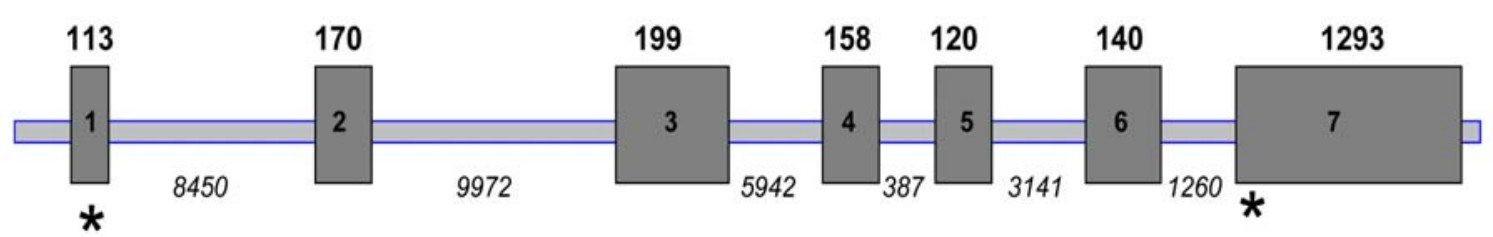

Figure 3.2 Schematic diagram of the exon-intron structure of the murine

Vsig1 gene. Positions of the translational start and stop codon sites are indicated by asterisks. Numbers on the top of the schematic diagram indicate the length of exons, and numbers on the bottom indicate length of the introns.

\section{cDNA sequence of murine Vsig1 gene}

1-gagcctagttcaggcagccttcggactggcacctgctgctccaagcgactttcagcatg-59

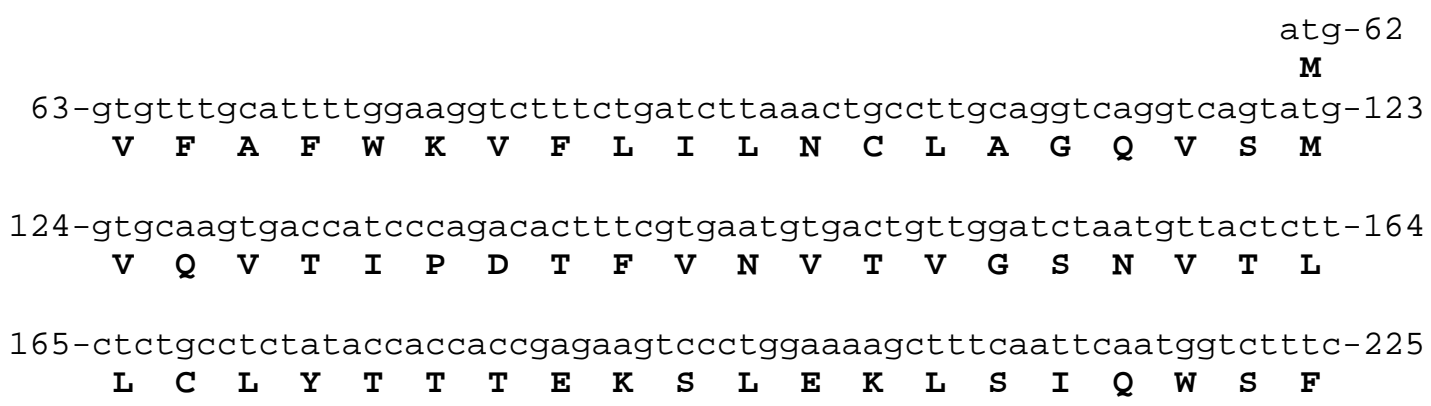


226 - ttccacaataaggaaatggaggagccaatatctatctactactctgaaggtggacaggct-266

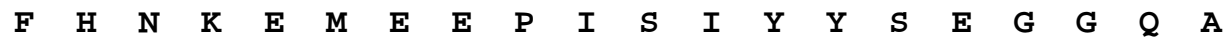

267 - tcagctattgggcaattcaaagaccgaataattggggctactaatcccggtaatgcatct-327 $\begin{array}{llllllllllllllllllll}\text { S } & A & \text { I } & G & \mathbf{Q} & \mathbf{F} & \text { K } & \text { D } & \mathbf{R} & \text { I } & \text { I } & G & \text { A } & \text { T } & \text { N } & \text { P } & G & \text { N } & \text { A } & \text { S }\end{array}$

328-atcaccatat tgcatatgcagccagcagacagtggaatt tacatctgtgatgtcaacaat-388 $\begin{array}{llllllllllllllllllll}\text { I } & \text { T } & \text { I } & \text { L } & \text { H } & \text { M } & \mathbf{Q} & \mathbf{P} & \text { A } & \text { D } & \text { S } & \text { G } & \text { I } & \text { Y } & \text { I } & \text { C } & \text { D } & \text { V } & \text { N } & \text { N }\end{array}$

389-cctccacattttgtgggcaaaaaccaaggcctccttgacgtcactgtct tagtcaaacct-449 $\begin{array}{lllllllllllllllllllll}\mathbf{P} & \mathbf{P} & \text { H } & \text { F } & \mathbf{V} & \mathbf{G} & \mathrm{K} & \mathbf{N} & \mathbf{Q} & \mathbf{G} & \mathbf{L} & \mathbf{L} & \mathbf{D} & \mathbf{V} & \mathbf{T} & \mathbf{V} & \mathbf{L} & \mathbf{V} & \mathrm{K} & \mathbf{P}\end{array}$

450 - tccaagcccttttgtaccatccaaggaagaccagaagcaggccatcctatt tccttgtct - 510 $\begin{array}{llllllllllllllllllll}\mathbf{S} & K & \mathbf{P} & \mathbf{F} & \mathbf{C} & \mathbf{T} & \mathbf{I} & \mathbf{Q} & \mathbf{G} & \mathbf{R} & \mathbf{P} & \mathbf{E} & \mathbf{A} & \mathbf{G} & \mathbf{H} & \mathbf{P} & \mathbf{I} & \mathbf{S} & \mathbf{L} & \mathbf{S}\end{array}$

511-tgcctttctgcctttggaacaccgtctcctttgtattactggtataacattgaggggaac-571 $\begin{array}{llllllllllllllllllll}C & L & S & A & F & G & T & P & S & P & L & Y & Y & W & Y & N & I & E & G & N\end{array}$

572 -accattgtgccagtaaaagaaagtttcaacacggccactggagttttagt tat tggaaat-632 $\begin{array}{llllllllllllllllllll}\mathbf{T} & \text { I } & \mathbf{V} & \mathbf{P} & \mathbf{V} & \mathbf{K} & \mathbf{E} & \mathbf{S} & \mathbf{F} & \mathbf{N} & \mathbf{T} & \mathbf{A} & \mathbf{T} & \mathbf{G} & \mathbf{V} & \mathbf{L} & \mathbf{V} & \mathbf{I} & \mathbf{G} & \mathbf{N}\end{array}$

633-ctaacaaattttgaacaaggttat taccagtgtactgccatcaacagtcttggcaatagt-693 $\begin{array}{llllllllllllllllllll}\mathbf{L} & \mathbf{T} & \mathbf{N} & \mathbf{F} & \mathbf{E} & \mathbf{Q} & \mathbf{G} & \mathbf{Y} & \mathbf{Y} & \mathbf{Q} & \mathbf{C} & \mathbf{T} & \text { A } & \text { I } & \text { N } & \text { S } & \text { L } & \text { G } & \text { N } & \text { S }\end{array}$

694 - tcctgtgaaat tgacttaacgtct tcacatccagaagttgggatcatcatcggagctttg-754

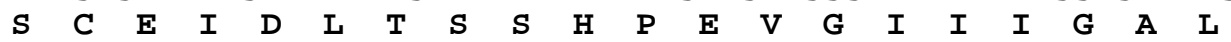

755 - gtcggtgccctgataggagctgctgttatcatctgtgtggtgtactt tgccaggaacaaa-815

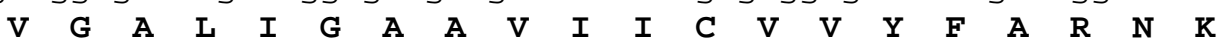

816 -gttaaatccaagcagcagaagaat taaat tccagcacagaact tgagccaatgacaaag-876 $\begin{array}{llllllllllllllllllll}\mathbf{V} & K & \mathbf{S} & K & \mathbf{Q} & \mathbf{Q} & \mathbf{K} & \mathbf{N} & \mathbf{L} & \mathbf{N} & \mathbf{S} & \mathbf{S} & \mathbf{T} & \mathbf{E} & \mathbf{L} & \mathbf{E} & \mathbf{P} & \mathbf{M} & \mathbf{T} & \mathbf{K}\end{array}$

877 -gtacaccatccccaacaaagtgaggcaatttcagctgatggcgtccagctagaaggaact - 937 $\begin{array}{llllllllllllllllllll}\mathbf{V} & \text { H } & \text { H } & \mathbf{P} & \mathbf{Q} & \mathbf{Q} & \text { S } & \text { E } & \text { A } & \text { I } & \text { S } & \text { A } & \text { D } & G & \text { V } & \mathbf{Q} & \text { L } & \text { E } & G & \text { T }\end{array}$

938-ctgccatcttccatccatgctggccacaacaccgaacctactactacagcagtcttggag-998 L $\begin{array}{llllllllllllllllllll}\mathbf{P} & \text { S } & \text { S } & \text { I } & \text { H } & \text { A } & \text { G } & \text { H } & \text { N } & \text { T } & \text { E } & \text { P } & \text { T } & \text { T } & \text { T } & \text { A } & \text { V } & \text { L } & \text { E }\end{array}$ 999-ccagaatatgagcctaatcctccactggaaactaccacacagcctgaccctgaaccagag-1059 $\begin{array}{llllllllllllllllllll}\mathbf{P} & E & \mathbf{Y} & \mathbf{E} & \mathbf{P} & \mathbf{N} & \mathbf{P} & \mathbf{P} & \mathbf{L} & \mathbf{E} & \mathbf{T} & \mathbf{T} & \mathbf{T} & \mathbf{Q} & \mathbf{P} & \mathbf{D} & \mathbf{P} & \mathbf{E} & \mathbf{P} & \mathbf{E}\end{array}$

1060-ggttcagtgccagtgctagcacctgaggcagagat tcaaccacacccagagctggacccg-1120 $\begin{array}{llllllllllllllllllll}G & S & V & P & V & L & A & P & E & A & E & I & Q & P & H & P & E & L & D & P\end{array}$

1121-gagactgagacagagcctgagcctgagcctgagcctaagcctgagcctgagccggaacct-1181 $\begin{array}{llllllllllllllllllll}E & T & E & T & E & P & E & P & E & P & E & P & K & P & E & P & E & P & E & P\end{array}$

1182 -gagcttgagcctgatcccagtctggagtaataattgagcctctgagcaaggcgggagag- 1242

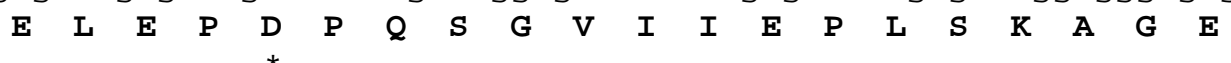
1243 -gatacagttaaggcataaataggcacggcatttagtatggcaattcccactaaagaaccc-1303 D $\quad \mathbf{T} \quad \mathbf{V} \quad \mathbf{K}$ A stop

1304 -at tcccggct tt taaaatt tggt tgact taaccagccccagtt tgtccgtccatcatagacaaccct catctatcaacgtattcat tccaaccat taatccaaaataaaaaa tcaaggcaactactgaagaaatgccgtg atttctgccttttagtatagggcttact taaaactgtactaatatgtaacataacaaaggccaaggccaagac acgtggtttatttctaatttacttggaagaatatttgcaaaagtatataacgcattttatagttatttttttg tcatggatcacctgtaaatatcataagatagggttaatttgattgaatattaattttatgattggttgtctttc ctgttcattttctttgtatttaccactgagaaaaagttggcaccattggcccataaattagaaaaaaataa tttcctccaaataagg tatgtatcaattggtacatataatt taaaactaagtaagtct tataatt tatcatat aggtctt taataaatcacctcagcgtgcaacatttgagcatagcatttttgtaactttttttttcactaccaa atagtgtacaagaaaacaatttagaataaaccttttctttggtgagcataaagtgttggtattggaggcgattc 
agagtaaacctttgactaagctatgatgttattactgtcggatgctatgtggttttggcaccagactgggatgg ttt tccagatgaacactttggtctactttagataatctaaactggccatttaaatactctgtattactgtgtct gtagtccatgttaatggaaatatcactct taaataaatgataagcagtaagt - 2177

Figure 3.3 Nucleotide sequence and deduced amino acid sequence of the Vsig1 cDNA. Numbering of nucleotides is assigned to both sides of the sequence. Nucleotides are numbered according to the presumed transcription start site. The translation stop codon is indicated by an asterisk. Polyadenylation signals are underlined. The sequence has been deposited in the gene bank database (GenBank accession number NP_084457)

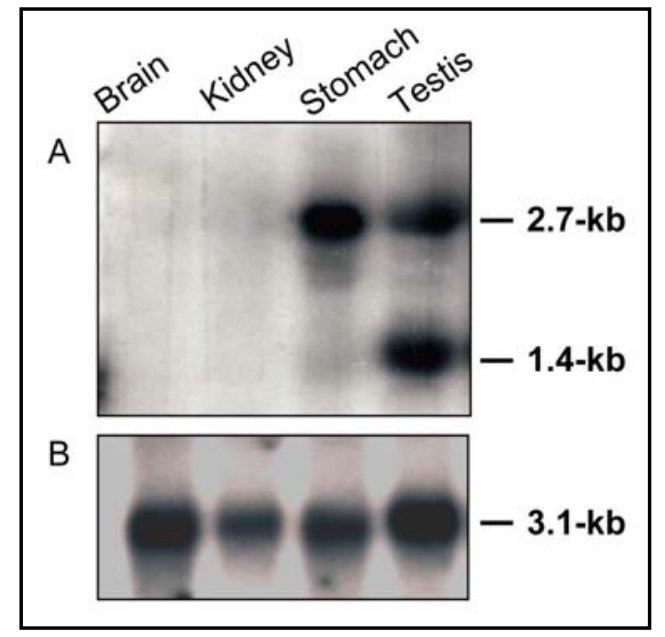

Figure 3.4 Transcription of Vsig1 produces two different isoforms of mRNA. In case of stomach, the probe-2 hybridizes with a $2.7-\mathrm{kb}$ transcript, and in case of testis, the probe- 2 hybridizes with a $2.7-\mathrm{kb}$ and a $1.4-\mathrm{kb}$ transcript (A). Integrity and variation of loaded RNA samples were checked by rehybridization with human elongation factor-2 ( $h E F)(B)$. The sizes of hybridization signals are indicated on the right.

\subsection{Analysis of amino acid sequence of murine VSIG1}

The Vsig cDNA sequence predicts a 407 amino acid protein (Fig. 3.5) A search in protein data bank (SWISS-PROT and NBRF-PIR) with the deduced amino acid sequence revealed only homology between the VSIG1 and members of the immunoglobulin-like family. The VSIG1 have an extracellular domain with two immunoglobulin-like domains at positions 29-139 and 154-220, a single transmembrane domain at position 237-259, and a short cytoplasmic tail at position 322-388 (Fig. 3.5A, B). A considerable homology between VSIG1 and members of the 
immunoglobulin superfamily exists in immunoglobulin-like domains (Ig-like domains) containing the sequence feature that define the immunoglobulin-like superfamily. Analysis of the hydropathy profile of the VSIG1 indicates that the protein contains two hydrophobic domains at positions 1-12 and 237-259. The hydrophobic domain at the $\mathrm{N}$-terminus is similar to that of other signal peptide sequences. The signal peptide of VSIG1 is comprised of 12 amino acids and contains 9 hydrophobic amino acids (Fig 3.5).

Further screening with the mouse sequence led to identification of the putative human and rat orthologues. The amino acid sequence of murine VSIG1 shows $73 \%$ and $87 \%$ homology with human and rat sequences respectively. The putative human and rat orthologues contain 2 extracellular Ig-like domains. The sequence within the extracellular domain (aa 1-129) reveals 96\% identity between mouse and human proteins. In contrast, the homology between mouse and human sequence in the cytoplasmic domain is decreased to $45 \%$.

A

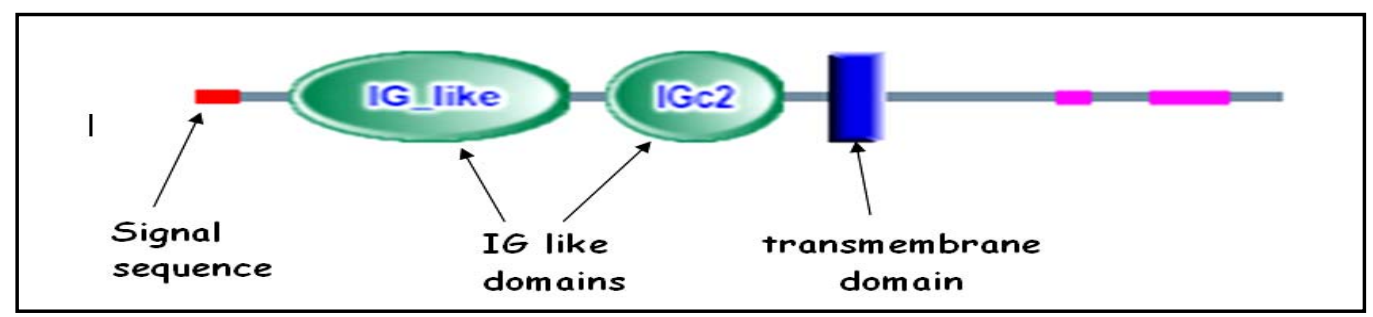

B

1 MVFAFWKVFLILNCLAGQVSMVQVTIPDTF VNVTVGSNVTLLCLYTTTEKSLEKLSIQWS 6 61 FFHNKEMEEPISIYYSEGGQASAIGQFKDRIIGATNPGNASITILHMQPADSGIYICDVN 120

121 NPPHFVGKNQGLLDVTVLVKPSKPFCTIQGRPEAGHPISLSCLSAFGTPSPLYYWYNIEG 180 181 NTIVPVKESFNTATGVLVIGNLTNFEQGYYQCTAINSLGNSSCEIDLTSSHPEVGШGA 240 241 RNKVKSKQQKNLNSSTELEPMTKVHHPQQSEAISADGVQLEG 300 301 TLPSSIHAGHNTEPTTTAVLEPEYEPNPPLETTTQPDPEPEGSVPVLAPEAEIQPHPELD 360 361 PETETEPEPE PEPKPEPEPEPELEPDPQSGVIIEPLSKAGEDTVKA

Figure 3.5 Predicted structure of murine VSIG1 protein. SMART on-line program displays that 5 predictable domains are existing in murine VSIG1 protein sequence. At the N-terminal region, a signal sequence (aa 1-12) is indicated by red color, two Ig-like domains (aa 29-139 and 154-220) are indicated by green color. The transmembrane domain (aa 237-259) is indicated 
by blue and the low complexity cytoplasmic domain (aa 322-388) is indicated by pink color.

The members of immunoglobulin superfamily are transmembrane proteins and most of these proteins are involved in cell-cell adhesion. These proteins are highly glycosylated through N- and O-glycosylation. Analysis of Vsig1 protein by Net-NGlyc program predicted the presence of six N-glycosylated sites in the extracellular domain of the murine VSIG1 protein sequence (Fig. 3.6).

1 - MVFAFWKVFLILNCLAGQVSMVQVTIPDTFVNVTVGSNVTLLCLYTTTEKSLEKLSIQWSFFHNKEM 68 -EEPISIYYSEGGQASAIGQFKDRI IGATNPGNASITI $\overline{L H M} Q P A D S G I Y I C D V N N P P H F V G K N Q G L L D$ 135 - VTVLVKPSKPFCTIQGRPEAGHPISLSCLSA FGTPSPLYYWYNIEGNTIVPVKESFNTATGVLVIGN 202 - LTNFEQGYYQCTAINSLGNSSCEIDLTSSHPEVGIIIGALVGALIGAAVIICVVYFARNKVKSKQQK 269 - $\overline{N L} N S S T E L E P M T K V H H P Q \overline{Q S E} A I S A D G V Q L E G T L P S S I H A G H N T E P T T T A V L E P E Y E P N P P L E T T T Q$ 336 - PDPEPEGSVPVLAPEAEIQPHPELDPETETEPEPEPEPKPEPEPEPELEPDPQSGVIIEPLSKAGED 403 - TVKA

Figure 3. 6 Presence of N-glycosylated sites in the protein sequence of murine Vsig1. The putative N-glycosylation sites are indicated by red-blue colors and underlined.

\subsection{Generation and purification of polyclonal anti-VSIG1 antibody}

To study the expression of VSIG1 protein and to determine the subcellular localisation, a VSIG1-specific polyclonal antibody was generated.

To generate a VSIG1-specific antibody, the VSIG1 protein sequence was compared to other protein sequences in database. This alignment revealed that the Ig-like domains in the extracellular segment of VSIG1 have high homology to that in other members of immunoglobulin superfamily, while the sequence of the cytoplasmic domain in VSIG1 did not show sequence homology to other proteins in database. Therefore, the sequence of cytoplasmic domain was used as antigen to generate a VSIG1-specific antibody.

To generate GST-VSIG1 fusion protein, a 189-bp of cDNA fragment encoding the sequence of cytoplasmic domain was amplified with primers SX-FuProF2 and SXFuProR2. The PCR fragment was cloned into prokaryotic expression vector pET41a and sequenced. After the induction of expression of GST-Vsig1 fusion protein, total protein was extracted from recombinant bacteria and electrophoresed on SDS-PAGE (Fig. 3.7) As shown in figure-3.7, expression of 42-kDa GST-VSIG1 was induced in recombinant 
bacteria (Fig. 3.7, lane-5) and the 42-kDa GST-VSIG1 fusion protein could not be detected in protein extract of uninduced recombinant bacteria (Fig. 3.7, lane-4).

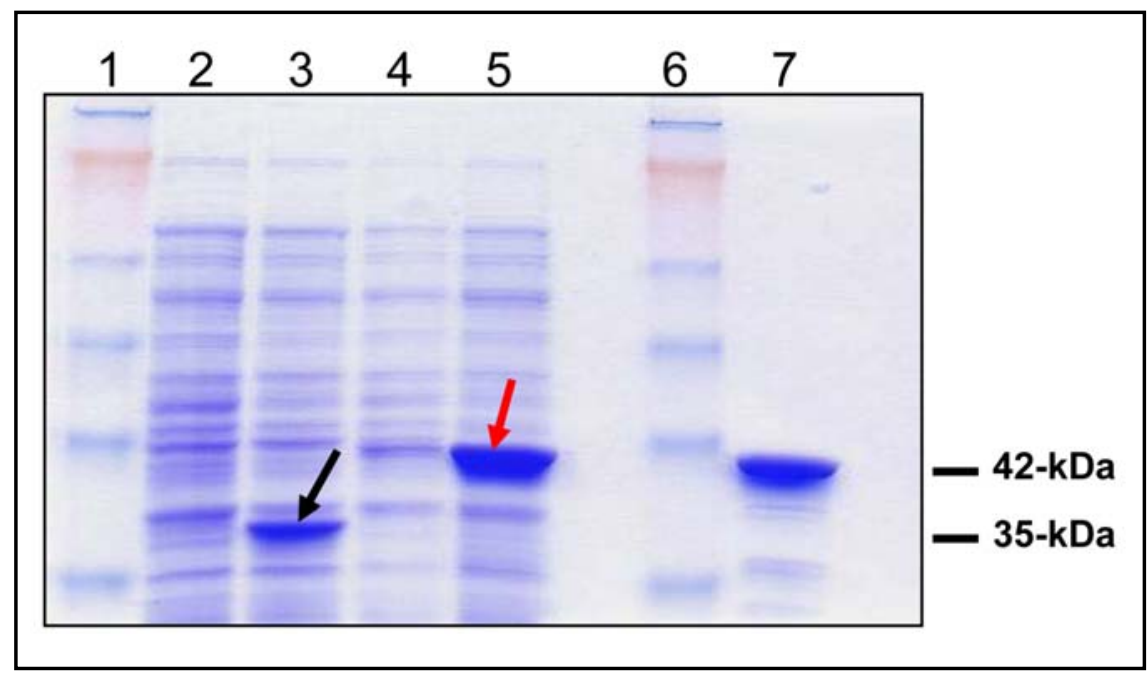

Figure 3.7 Expression of GST-VSIG1 fusion protein in BL21DE cells. After electrophoresis of proteins, the gel was incubated in Coomassie blue brilliant staining solution. Blue arrow indicates the induced GST protein (lane-3), which is lacking in the non-induced sample (lane-2). The red arrow indicates the induced GST-VSIG1 fusion protein (lane-5), which is lacking in the non-induced bacterial lysate (lane-4). After purification, only GST-VSIG1 fusion proteins are present in the eluted sample (lane-7).

The GST-VSIG1 fusion protein was purified from bacterial extract using glutathione sepharose column. $10 \mu \mathrm{l}$ of the purified fusion protein was separated on SDS-PAGE to check the purification of fusion protein (Fig. 3.7, lane-7). The purified fusion protein was then used for immunization of rabbits and subsequent affinity purification of the antibody. Two rabbits were immunised with approximately $100 \mu \mathrm{g}$ of purified fusion protein, which mixed with complete or incomplete Freund's adjuvant. The rabbits were subcutaneously injected for 3 times at the distance of 4 weeks. The rabbits were then sacrificed, and serum was isolated by centrifugation at $5000 \mathrm{xg}$ for $10 \mathrm{~min}$ at $4 \mathrm{C}$.

To check the immunoreactivity of antiserum, total cellular proteins were separated and blotted on a nitrocellulose membrane. The blotted membrane was incubated with crude antiserum in 1:100 dilutions. 


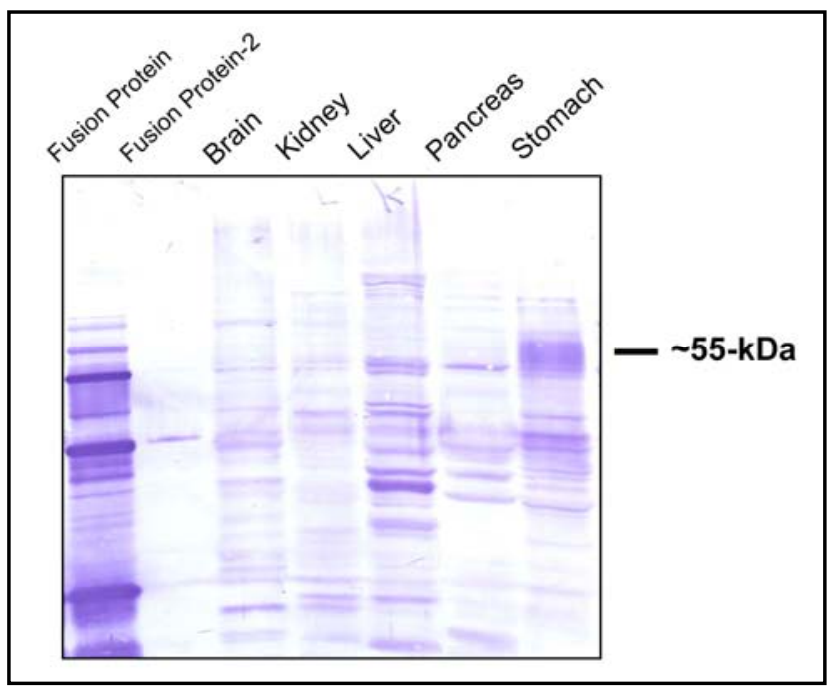

Figure 3.8 Western blot analysis with crude antiserum. Total proteins were extracted from brain, kidney, liver, pancreas and stomach. Non-purified (indicated as fusion protein) and purified fusion proteins (indicated as fusion protein-2) were loaded respectively. Antirabbit AP-conjugated IgG was used as secondary antibody.

As shown in figure 3.8, the crude antiserum did not recognise a specific protein in extracts of different tissues. To remove other proteins from polyclonal serum, IgG-purified antibody was isolated as described in Materials and Methods section and checked for specificity by Western blot analysis. As shown in figure 3.9A, the IgG polyclonal antibody specifically recognized a 42-kDa GST-VSIG1 fusion protein and a 55-kDa protein in stomach extract. No specific immunoreactive protein could be detected in extracts of other tissues.

To verify the specificity of the anti-VSIG1 polyclonal antibody, competition assay was performed. In this assay, VSIG1 antibody was incubated with GST-VSIG1 fusion protein. After 1 hour of incubation, the solution of competition assay was probed in Western blot containing protein extracts. As shown in figure 3.9B, the immunoreactivity of the $42-\mathrm{kDa}$ fusion protein and 55-kDa stomach protein are abolished in competition assay. This result indicates that the anti-VSIG1 antibody specifically recognizes a 55-kDa protein in stomach. 


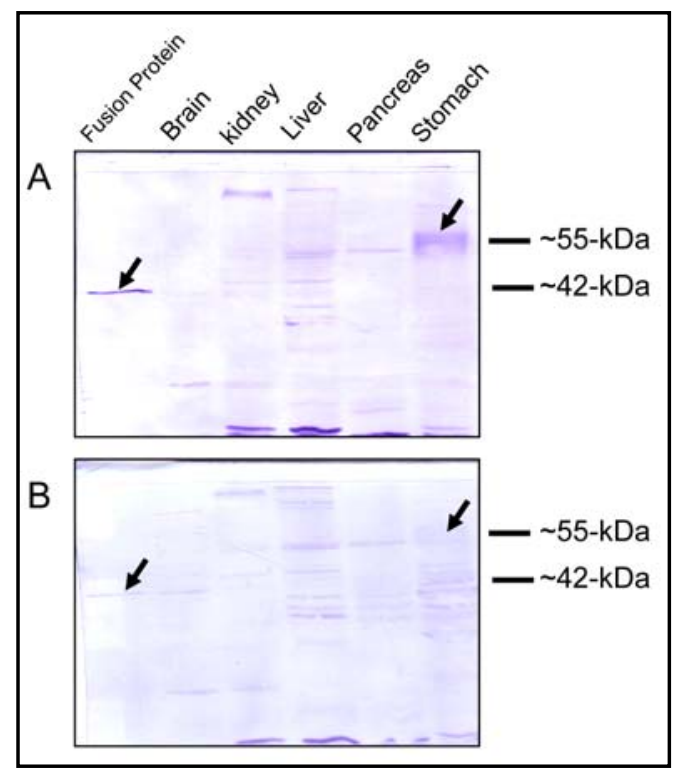

Figure 3.9 Competition assay to verify the specificity of Vsig1 antibody. (A) Western blot with protein extracts from brain, kidney, liver, pancreas, stomach and purified fusion protein probed with affinity purified polyclonal anti-VSIG1 antibody. The VSIG1 antibody recognizes the 55-kDa VSIG1 protein and 42-kDa GST-VSIG1 fusion protein. (B) In the competition assay, the immunoreactivity of the $55-\mathrm{kDa}$ stomach protein and the $42-\mathrm{kDa}$ fusion protein is abolished. This result indicates that the anti-VSIG1 antibody specifically recognizes the 55-kDa stomach protein and the 42-kDa GST-VSIG1 fusion protein.

To generate affinity purified antibody, GST-VSIG1 fusion protein was covalently coupled to Affi-Gel-10-active ester agarose beads and used for the purification of anti-VSIG1 antibody. The affinity-purified VSIG1 antibody was used in further experiments.

\subsection{The VSIG1 is glycosylated}

The affinity-purified VSIG1 antibody recognizes only a 55-kDa protein in stomach. The sequence analysis of VSIG1 predicted that the deduced protein has a molecular mass of $47-\mathrm{kDa}$ and its extracellular domain bears six NX(S/T) motifs for $N$-linked glycosylation. The difference between the observed molecular weight of VSIG1 in Western blot analysis and molecular mass of the amino acid sequence $(47-\mathrm{kDa})$ suggested that VSIG1 is glycosylated. To prove that, stomach lysate was enzymatically digested with Nglycosidase-F enzyme to release putative N-linked oligosaccharids. A sample of stomach protein was incubated without the enzyme as negative control. After overnight incubation, 
enzyme treated and untreated control samples were loaded on SDS-PAGE and blotted into a nitrocellulose membrane. Thereafter, a Western blot analysis was performed with antiVSIG1 antibody (Fig. 3.10).

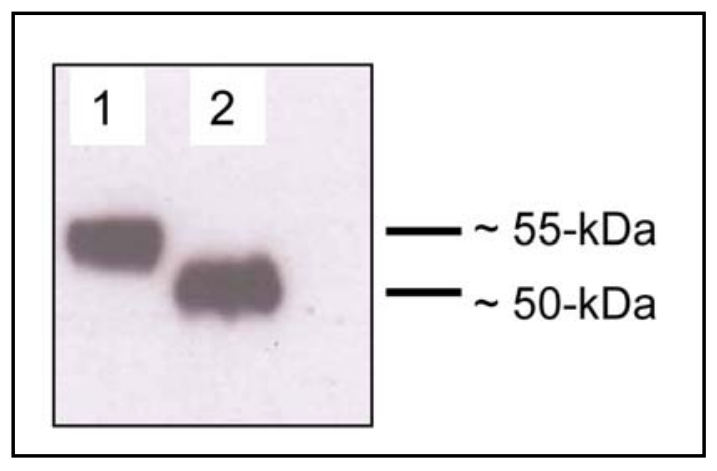

Figure 3.10 Western blot analysis of N-glycosidase-F treatment of VSIG1 protein. The enzyme treated protein sample (2) and the untreated control protein sample (1) were loaded on SDS-PAGE and subjected to Western blot analysis probed with anti-VSIG1 antibody. The approximate molecular mass of the detected proteins are shown on the right side by comparing with See-blue ${ }^{\mathrm{TM}}$ protein marker (Invitrogen).

The Western blot analysis revealed that the molecular mass of VSIG1 protein was shifted to $50-\mathrm{kDa}$ in $\mathrm{N}$-glycosidase-F-treated stomach lysate. In case of untreated protein sample, the molecular mass of VSIG1 was not shifted down. This result confirms that the $55-\mathrm{kDa}$ VSIG1 protein recognised by the antibody in stomach protein extract is N-glycosylated.

\subsection{Expression pattern of murine Vsig1 gene}

\subsubsection{Expression analysis of Vsig1 in different adult tissues}

To determine the expression of Vsig1 gene in different tissues of adult mouse, total RNA was extracted from brain, colon, heart, kidney, liver, lung, skeletal muscle, ovary, intestine, spleen, stomach and testis. $30 \mu \mathrm{g}$ of RNA from each tissue was size fractionated in a $0.8 \%$ agarose gel containing formaldehyde and transferred to nitrocellulose membranes. The Northern blot was hybridized with a ${ }^{32} \mathrm{P}-$ labeled murine Vsig1 cDNA fragment, which contained the sequence of the 3'-UTR (bp 1501-1940). 


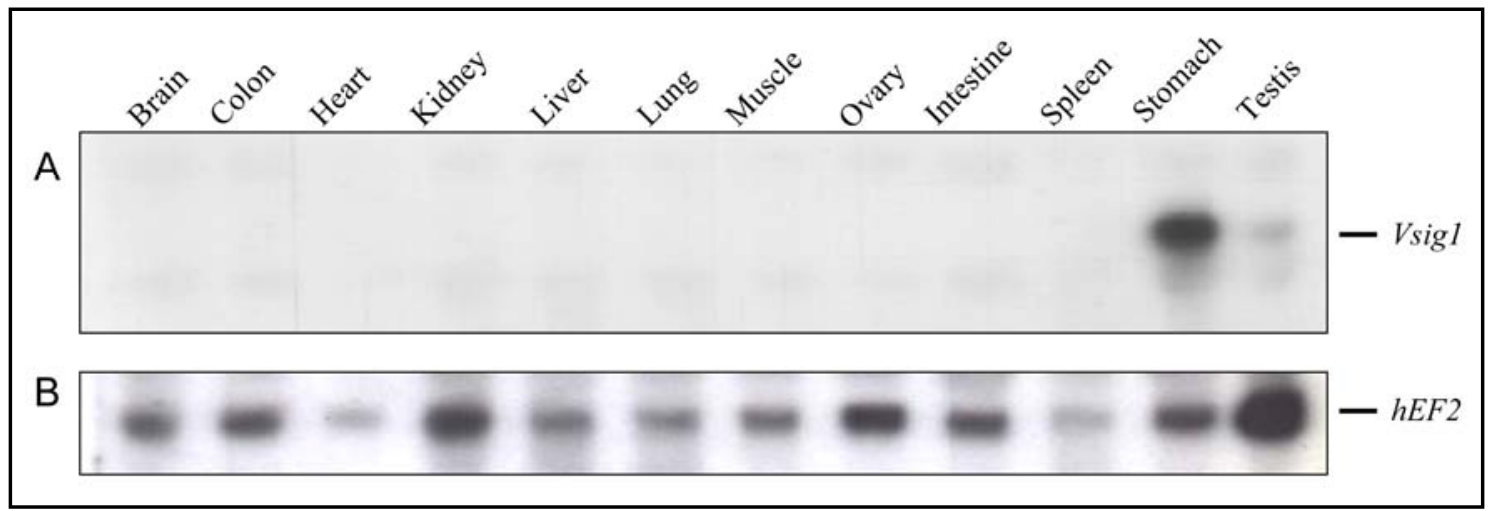

Figure 3.11 Expression analysis of murine Vsig1 gene in different organs.

Total RNA $(30 \mu \mathrm{g})$ was extracted from different tissues including brain colon, heart, kidney, liver, lung, ovary, skeletal muscle, intestine, spleen, stomach, and testis of adult mouse. Northern blot hybridization was probed with the Vsig1 cDNA fragmen(A). Integrity and variation of loaded RNA samples were checked by rehybridization with a probe for the human elongation factor-2 ( $h E F 2)(B)$.

Northern blot analysis demonstrated that the Vsig1 gene is abundantly expressed in stomach and slightly expressed in testis. No Vsig1 expression could be detected in other adult tissues tested (Fig. 3.11A). To check the integrity and equal amounts of RNA, the filter was rehybridized with a human elongation factor-2 (hEF) cDNA probe (Fig. 3.11B)

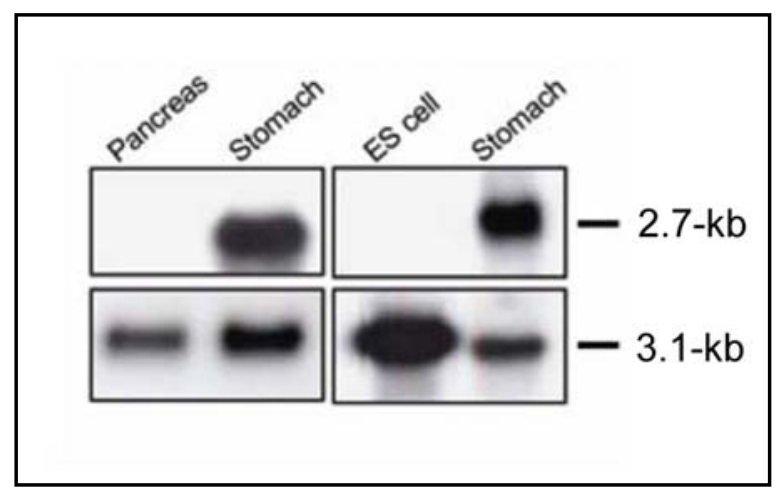

Figure 3.12 Expresion analysis of murine Vsig1 gene in pancreas, stomach and ES cells. Total RNA $(30 \mu \mathrm{g})$ was extracted from pancreas, ES cells and stomach. Northern blot hybridization was probed with the Vsig1 cDNA fragment. Integrity and equal loading of RNA was controlled by rehybridization with 
human elongation factor-2 probe ( $h E F$.) The sizes of hybridization signals are indicated on the right.

Further Northern blot analysis with RNA extracted from pancreas, ES cell and stomach revealed that the Vsig1 is not expressed in pancreas and ES cell (Fig. 3.12).

To analyze the expression of VSIG1 at the protein level, Western blot analysis was performed. Total cellular proteins were isolated from different tissues including brain, colon, heart, intestine, kidney, liver, pancreas, stomach and testis, electrophoresed on SDSPAGE and transferred onto a nitrocellulose membrane. The Western blot was performed with affinity purified anti-VSIG1 antibody. The anti-VSIG1 antibody recognises a 55-kDa protein only in protein extracts of stomach and testis (Fig. 3.13A). The expression level of the 55-kDa VSIG1 protein was higher in stomach than in testis. The membrane was subsequently stripped and probed with anti- $\alpha$-tubulin for monitoring the protein loading (Fig. 3.13B)

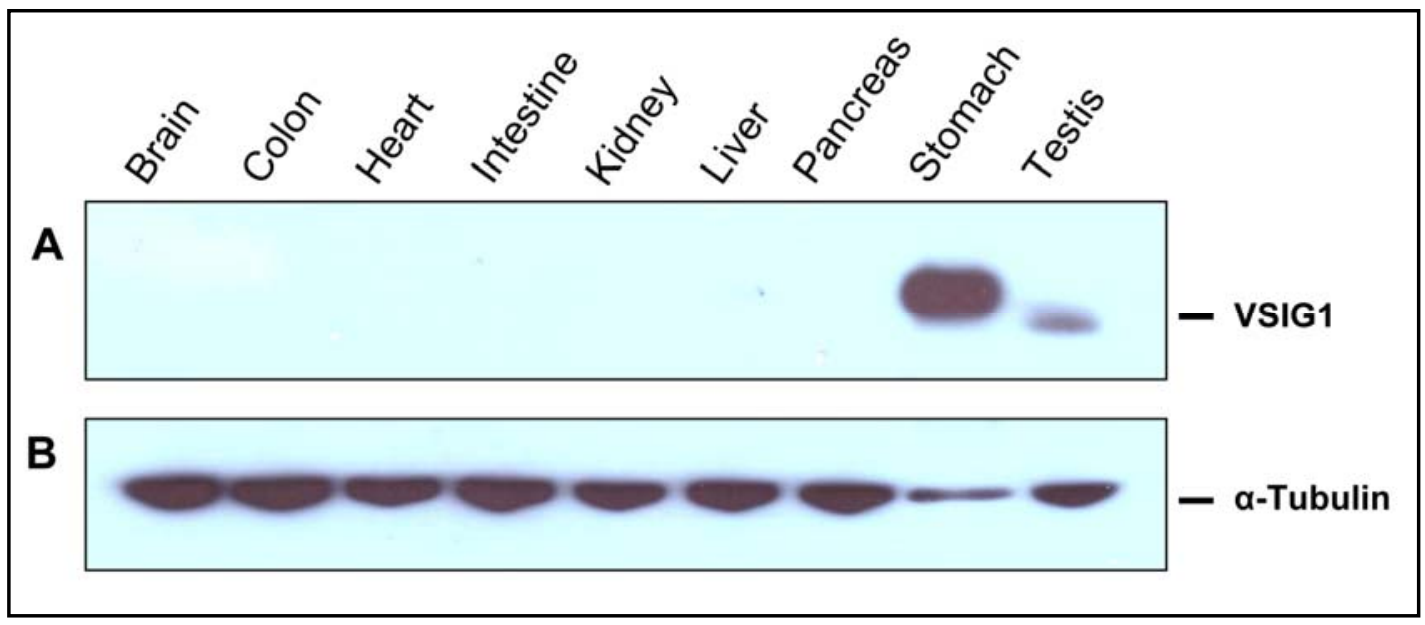

Figure 3.13 Expression of VSIG1 protein is restricted to stomach and testis. Affinity purified anti-VSIG1 antibody was used to probe the Western blot with protein extracted from different tissues. $\sim 55-\mathrm{kDa}$ VSIG1 protein was detected in stomach and testis (A). The membrane was stripped and subsequently probed with a monoclonal anti $\alpha$-tubulin antibody to monitor the loading (B). 
The Western blot analysis demonstrated that murine VSIG1 protein is highly expressed in stomach and slightly expressed in testis. No VSIG1 protein could be detected in other adult tissues tested (Fig. 3.13A).

\subsubsection{The Vsig1 expression is restricted to glandular epithelium of stomach}

According to the structure of epithelium, murine stomach is divided into 3 basic regions, which are called as cardia, corpus and antrum (Fig. 3.14). Corpus and antrum regions contain monolayered glandular epithelium, whereas the cardiac region contains multilayered squamous epithelium. The glandular epithelium in the corpus region (large and small curvature) consists of typical gastric units, which contain different cell types (Fig. 3.16). In contrast, the gastric units of the antrum region do not contain the acid producing parietal cells and pepsinogen producing zymogenic cells (Lee et al., 1985).

To determine the expression of Vsig1 in different regions of stomach, Northern blot with RNA extracted from oesophagus and different parts of stomach was hybridized with ${ }^{32} \mathrm{P}-$ labeled murine Vsig1 cDNA probe which is located in the 3'-untranslated region.

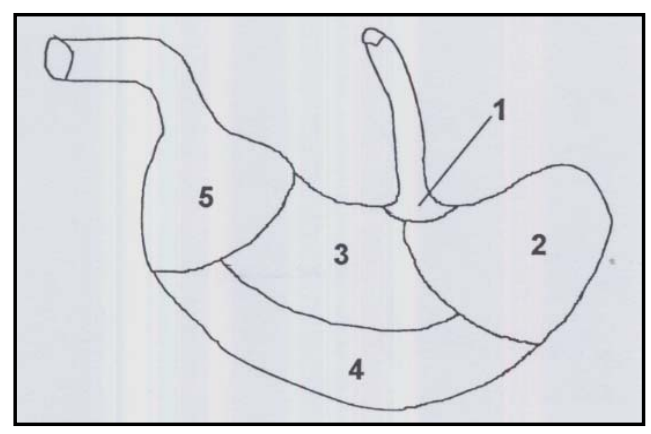

Figure 3.14 Schematic illustration of different parts of the murine stomach (including oesophagus). 1. Oesophagus 2. Cardiac region 3. Corpus (small curvature) 4. Corpus (large curvature) 5. Antrum 


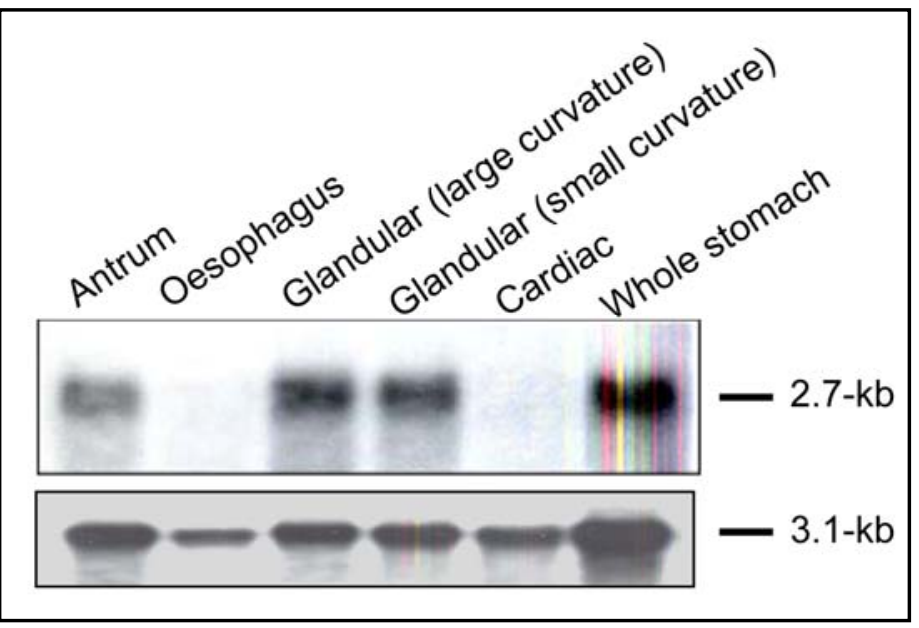

Figure 3.15 Expression of murine Vsig1 gene in different regions of adult mouse stomach. Total RNA $(30 \mu \mathrm{g})$ was extracted from different regions of stomach including cardiac region, corpus region (small curvature and large curvatur), and antrum region. The control rehybridization was performed with the human elongation factor-2 (hEF). The sizes of the hybridization signals are indicated on the right.

As shown in figure 3.15, the Vsig1 is expressed in corpus and antrum region of stomach. No VSig1 expression could be detected in oesophagus and cardiac region. This result demonstrates that the expression of Vsig1 is restricted to glandular epithelium of stomach.

\subsubsection{Cellular distribution of Vsig1 transcript and protein in adult stomach}

The functional unit of stomach is called as gastric unit (Fig. 3.16). The gastric unit can be subdivided into four regions: Pit, Isthmus, Neck and Base. Each gastric unit is composed of 11 different cell types (Karam and Leblond, 1992). All cells derive from the same population of stem cells in the isthmus region. Differentiation into different cell types occurs during the migration of the precursor cells (Hattori et al., 1974). The molecular mechanisms and factors that determine the cell-fate in the gastric unit are unknown. 


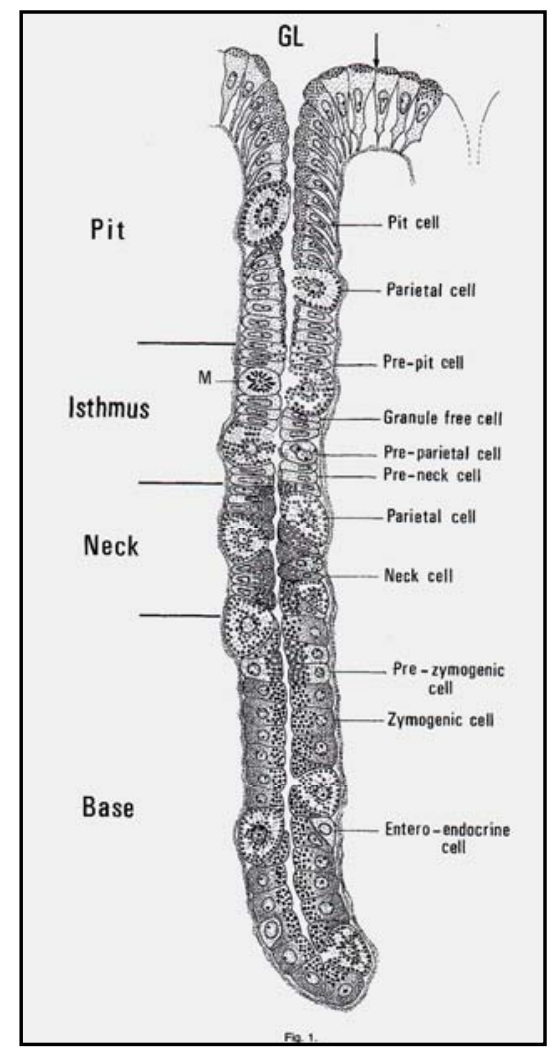

Figure 3.16 Schematic illustration of mouse gastric unit ( Karam and Leblond, 1992). The gastric unit of stomach contains 4 regions called as pit, isthmus, neck and base. Totally 11 different types of cells are included in a gastric unit. The gastric units of oxyntic (corpus) region contain short pit region whereas the gastric units of antrum region contain long pit region.

The expression pattern of Vsig1 in the gastric unit of adult stomach was identified by using a combination of in situ hybridization and immunohistochemistry. In situ hybridization on sections of adult stomach with DIG-labeled antisense probe revealed that Vsig1 mRNA is more prominent in the cells of isthmus and neck regions than in the base region. No Vsig1 expression could be detected in the Pit cells (Fig. 3.17A). Also expression of Vsig1 could not be detected in squamous epithelium (data not shown). In control experiments with DIG-labeled sense probe, no specific hybridization could be detected in cells of stomach (Fig. 17.B). 

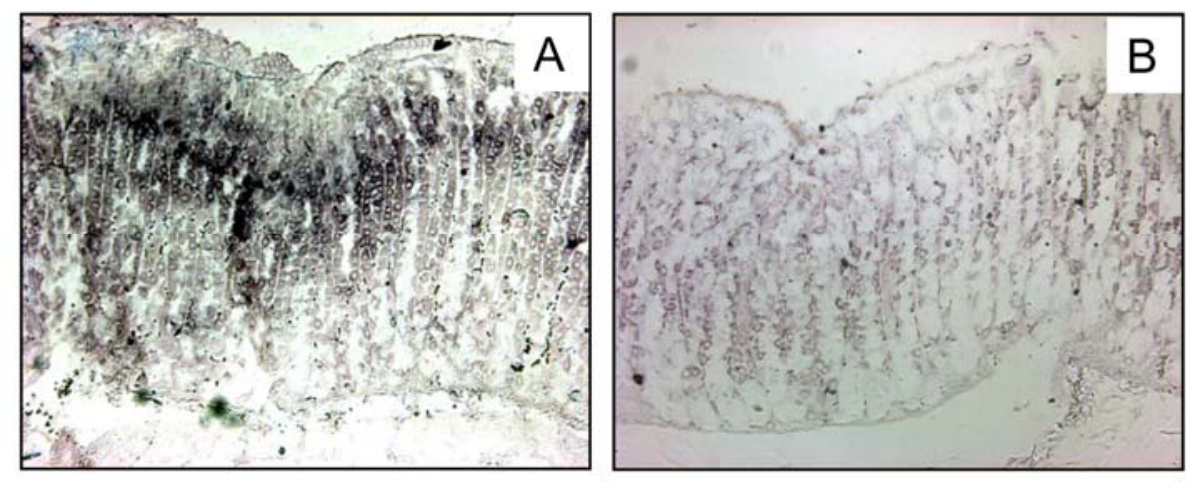

Figure 3.17 In-situ hybridization of Vsig1 mRNA in stomach section. DIGlabeled antisense probes hydridized with Vsig1 mRNA in isthmus and neck region of stomach (A). No hybridization could be observed by the sense probe (B). Optical magnification: $10 X$

Immunohistochemical staining in the sections of adult stomach with VSIG1 antibody revealed that the VSIG1 protein is present in cells of all regions of the gastric unit (Fig. 3.18A, C). The VSIG1 staining was most intense in the basolateral membrane of the Pit cells (Fig. 3.18B, D). These result suggest that Vsig1 mRNA is highly expressed in stem and progenitor cells locating in central region of gastric unit, and downregulated during the migration of progenitor cells through the up and down of the gastric unit. The highest intensity of VSIG1 protein and the absence of Vsig1 mRNA in Pit cells further suggest that the Vsig1 gene is expressed in progenitor cells and translation of VSIG1 occurs before the final differentiation of polarized Pit cells. Immunohistological staining revealed that the Vsig1 gene is not expressed in the squamous epithelial cells of stomach (Fig. 3.18E) 


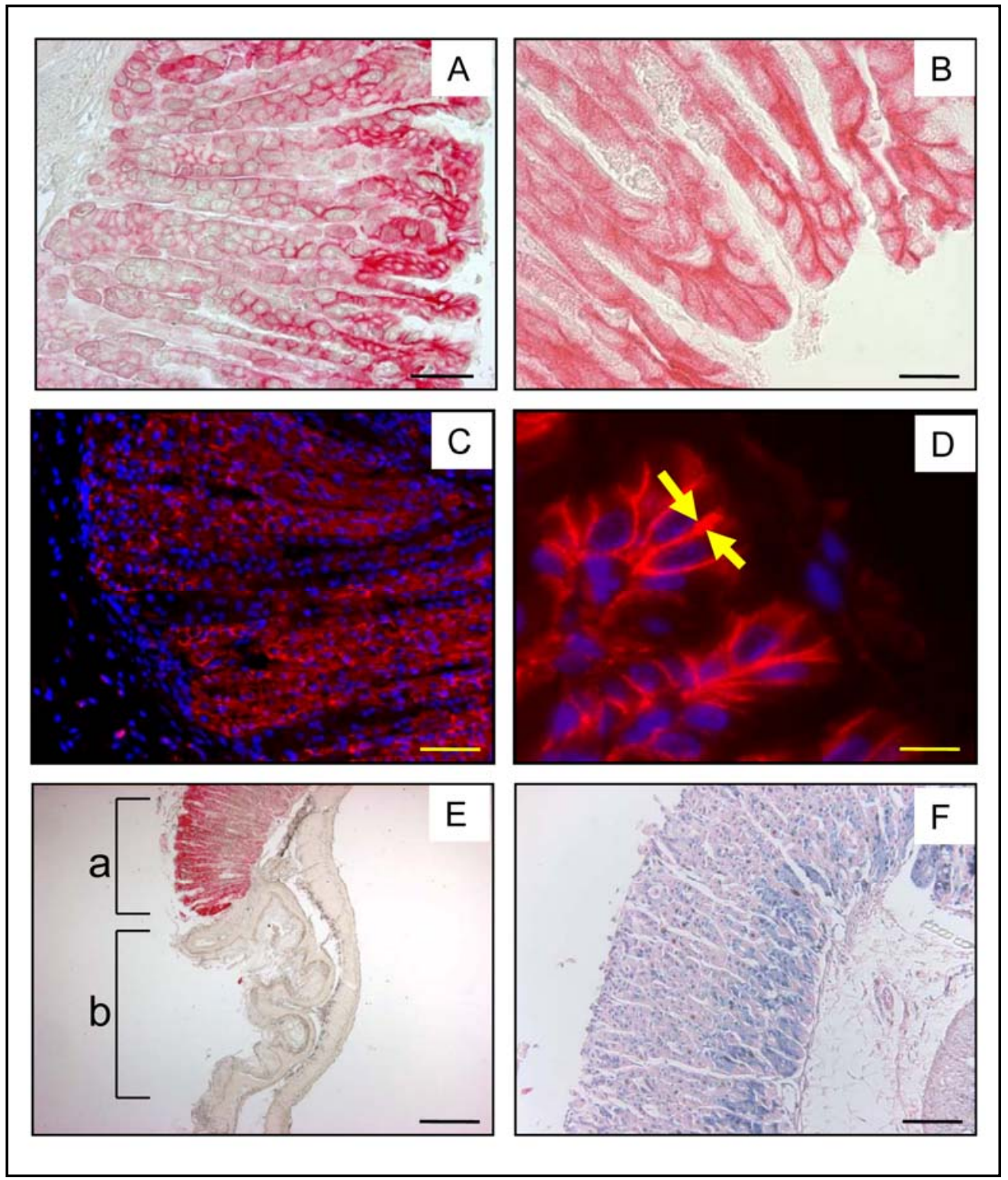

Figure 3.18 Cellular localization of VSIG1 protein in adult mouse stomach. Cross sections of adult stomach were stained with anti-VSIG1 antibody. Alkaline phosphatase $(\mathrm{A}, \mathrm{B})$ and $\mathrm{Cy} 3(\mathrm{C}, \mathrm{D})$ conjugated secondary antibodies were used. The VSIG1 protein is distributed in all cells of gastric unit. The high magnification micrographs show that the protein is localized on the lateral plasma membrane of the cells $(B, D)$. The nuclei were visualized by DAPI staining. The yellow arrows indicate the VSIG1 protein localization on the plasma membrane of Pit cells (D). VSIG1 protein distribution is restricted to glandular epithelium (a) and no expression of VSIG1 could be detected in squamous epithelium (b) (E). Glandular epithelium of stomach is stained by H\&E staining (F). Optical magnifications: $4 X$ in $E$; $10 X$ in $F$; $20 X$ in $A, C$; $60 X$ in $B, D$. 


\subsubsection{The Vsig1 gene is subjected to $\mathrm{X}$-inactivation}

The Vsig1 gene is localized in the $\mathrm{F} 1$ region of the murine $\mathrm{X}$ chromosome and the human orthologue is localized in the Xq22.3.

$\mathrm{X}$-inactivation is a process by which one of the two copies of the $\mathrm{X}$ chromosome in female is inactivated. As result, male and female have only one active $\mathrm{X}$-chromosome and $\mathrm{X}$ linked gene dosage compensation is realized. However, there are many X-linked genes, which escape X-inactivation. To determine whether the Vsig1 gene escapes from Xinactivation, Northern blot with RNA extracted from male and female stomach was hybridized with the Vsig1 cDNA probe (Fig. 3.19). The expression levels of Vsig1 in male and female stomach were quantified by Phospho-Image techniques (Bio-Rad) and normalized to $h E F-2$ expression level (Table 1).

\begin{tabular}{lccc} 
& $\begin{array}{c}\text { Density CNT/mm } \\
\text { Vsig1 }\end{array}$ & $\begin{array}{c}\text { Density CNT/mm } \\
\text { hEF }\end{array}$ & $\begin{array}{c}\text { Normalization } \\
\text { Value }\end{array}$ \\
\hline Female & 998640,9123 & 1221153,331 & 1,22 \\
Male & 913196,4402 & 1106024,209 & 1,21
\end{tabular}

Table 1 The results of signal density quantification (Phospho-Image system, Quantity-One software, Bio-Rad) The Phospho-image ${ }^{\mathrm{TM}}$ membrane was exposed with radioactive signals from Northern blot and each signal density was quantified respectively by Quantity-One ${ }^{\mathrm{TM}}$ program. Background subtraction method: Global

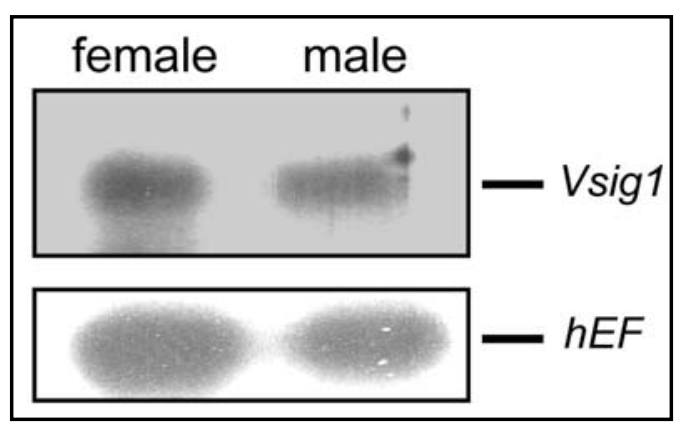

Figure 3.19 Northern blot analysis for $\mathbf{X}$ inactivation of Vsig1. Total RNA was extracted from male and female stomach and subjected to Northern blot hybridization using the Vsig1 cDNA probe. The control rehybridization was 
performed with the human elongation factor-2 (hEF). Each of the radioactive signals was quantified by Quantity-One ${ }^{\mathrm{TM}}$ program (Bio-Rad).

The final ratio of normalization quotations of female and male stomach is 1:1.1. This result shows that the expression level of Vsig1 gene in male and female stomach is not significantly different. Therefore the Vsig1 gene does not escape from X-inactivation.

\subsubsection{Expression pattern of Vsig1 during prenatal and postnatal development of stomach}

To evaluate the expression of Vsig1 during stomach development, Northern blots with RNA isolated from whole embryos of E8, E10, E11, E12 stages, and from stomachs of E14, E16, E18 embryos, and P1, P5, P10, P20, P30 and P60-day-old mice were hybridized with ${ }^{32}$ P-labeled Vsig1 cDNA probe (Fig. 3.20A). To check the integrity and equal amounts of RNA, the filter was rehybridized with a human elongation factor-2 ( $h E F$ ) cDNA probe (Fig. 3.20B)

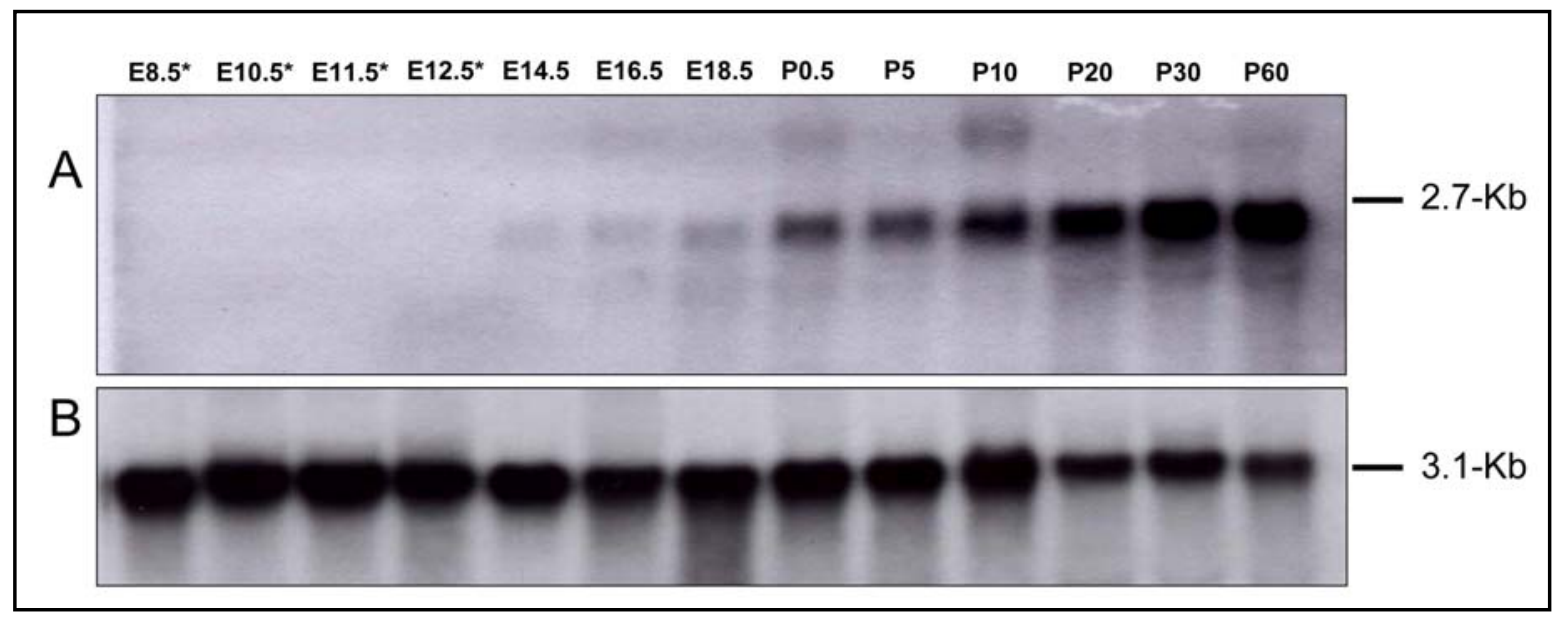

Figure 3.20 The expression of the murine Vsig1 gene during the prenatal and postnatal development of stomach. Total RNA was extracted from stomach in different prenatal and postnatal developmental stages (in case of E8.5, E10.5, E11,5 RNA was isolated from whole embryos) and hybridized with Vsig1 cDNA probe. The control rehybridization was performed with a human elongation factor-2 probe $(h E F)(B)$. The sizes of the hybridization signals are indicated on the right. 
The Northern blot analysis showed that the $2.7-\mathrm{kb}$ transcript was first detected in RNA of stomach at embryonic day 14.5 (E14.5). Thereafter, an increasing level of Vsig1 expression was observed through the pre- and postnatal developmental stages. No Vsig1 transcript could be detected in RNA isolated from whole embryos of E8.5 to E13.5 (Fig. 3.20A)

The inability to detect the Vsig1 transcript in RNA of whole embryos of E8-E12 by Northern blot suggests that Vsig1 gene could be expressed at low level in these embryonic stages. To determine whether the Vsig1 is expressed at low level in E8-E12, RT-PCR analysis was performed. The primers SX-RT-F1 and SX-RT-R1, which amplified a 210-bp of Vsig1 cDNA fragment were used. Total RNA was extracted from E8.5, E9.5, E10.5, E12.5 embryos and subjected to RT-PCR analysis (Fig. 3.21).

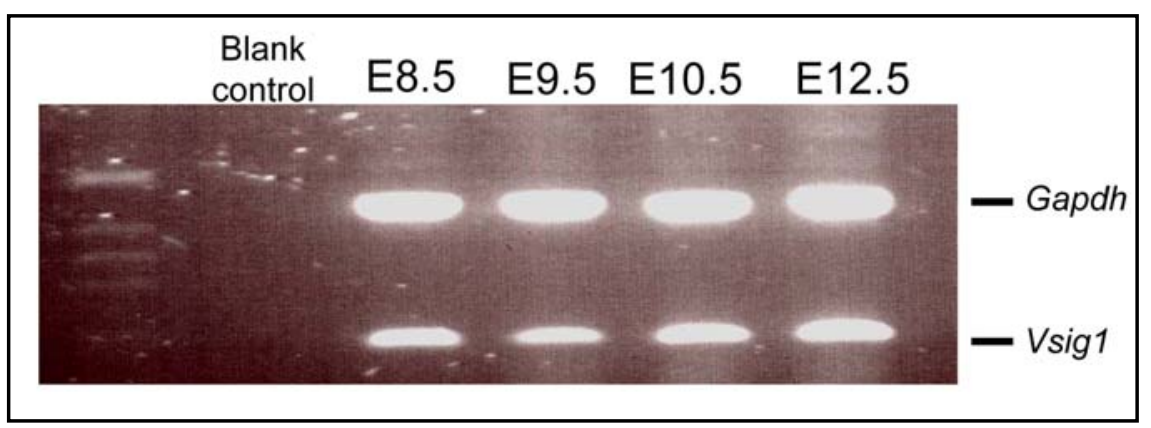

Figure 3.21 RT-PCR analysis of Vsig1 gene expression in E8.5, E9.5, E10.5 and E12.5 embryonic stages. RT-PCR amplified a 210-bp product of Vsig1 and a 450-bp product of Gapdh,, which served for control amplification. The blank control (the first lane) served to avoid master mix contamination.

The RT-PCR analysis shows that the Vsig1 gene is expressed at low level in E8.5, E9.5, E10.5 and E12.5 embryonic stages (Fig.3.21). The RNA quality was controlled by Gapdh expression. The identity of PCR products was verified by sequencing analysis.

\subsubsection{Cellular distribution of VSIG1 protein in prenatal developmental stages of stomach}

RT-PCR analysis revealed the expression of Vsig1 during embryonic developmental stages (Fig. 3.21). In the early stages of development, the origin of stomach is a simple primary gut, which comprises the endodermal epithelium and surrounding mesenchym. The development of mouse stomach begins by outgrowing of a certain place of the 
primary gut as a bulge around E10.5. At embryonic day 12.5 (E12.5) the stomach is lined with a simple, morphologically undifferentiated epithelial monolayer.

To determine the cellular distribution of VSIG1, embryos of 7.5, 8.5, 10.5, and 11.5 dayold-stages were isolated, fixed and embedded in paraffin. Serial sections were analyzed by immunohistochemistry with the anti-VSIG1 antibody. Detailed histological analysis did not reveal VSIG1-specific immunostaining in serial sections of different embryonic stages (Fig. 3.22).
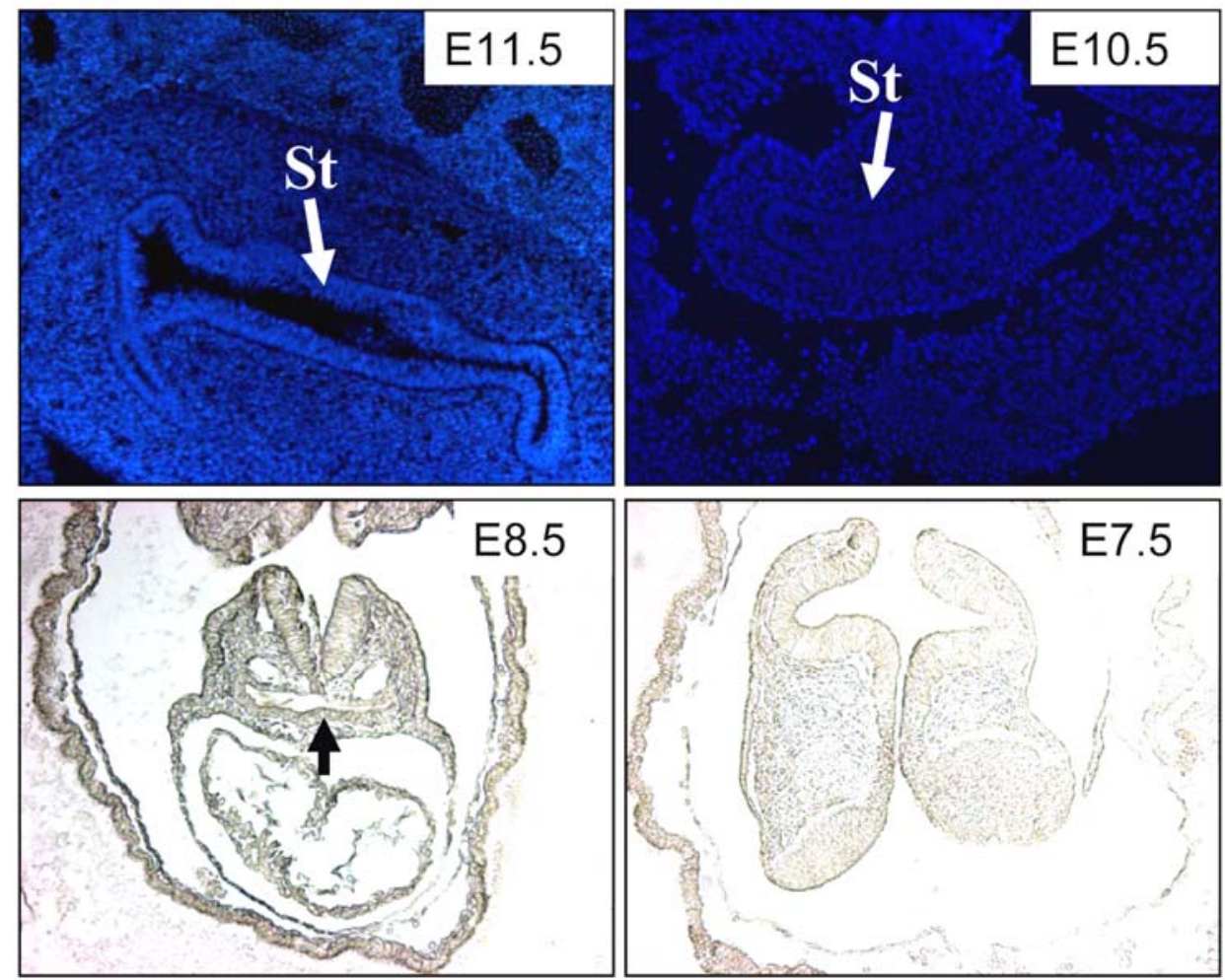

Figure 3. 22 Immunohistological analysis of VSIG1 protein distribution in embyronic developmental stages. In E10.5, E11.5, white arrows indicate the homogenous pseudoepithelium of primary gut which is the origin of glandular epithelium of stomach. DAPI staining was used to visualize the nuclei. In E8.5, black arrow indicates the endodermal layer, which develops into the primary gut. Optical magnification: $4 X$ in E7.5, E8.5; $10 X$ in E10.5, E11.5.

Immunohistochemical staining of sections through the stomach of E10.5 and E11.5 did not show VSIG1 specific immunostaining. These results suggest that Vsig1 is not expressed in early embryonic development (E7.5-E11.5). Furthermore, this result suggests that the Vsig1 is not expressed in undifferentiated epithelial monolayer of 
primary gut at embryonic day E10.5 and E11.5. At the embryonic day 13.5, the murine stomach contains a homogeneous pseudostratified epithelium that begins to differentiate along to the anterior and posterior plan into squamous epithelium in forestomach region (cardiac region) and stratified epithelium in the glandular region. To determine the expression profile of Vsig1 during the cytodifferentation of stomach epithelium, stomachs from E12.5, E13.5, E14.5 and E17.5 were isolated, fixed in 4\% paraformaldehyde and embedded in paraffin. Serial sections of stomach were then probed with VSIG1 antibody (Fig. 3.23). Only negligible staining could be discerned in the morphologically undifferentiated epithelium of E12.5 stomach (Fig. 3.23A, B). At E13.5 Vsig1 expression was detected in the glandular epithelium of posterior region of stomach, and no expression was detected in the epithelium of anterior region (Fig. 3.23C, D). In E14.5 and E17.5 stomach, much stronger expression of Vsig1 was observed in the primordial bud of the glandular epithelium. The VSIG1 is localized at the cell membrane. These results demonstrate that the expression of Vsig1 is restricted to the glandular epithelium during the embryonic development of stomach. Furthermore, the expression of Vsig1 in embryonic glandular epithelium, which mainly contains stem cells, suggests that the Vsig1 has an essential role in the proliferation of stomach stem cells and cytodifferentiation of glandular epithelium. 


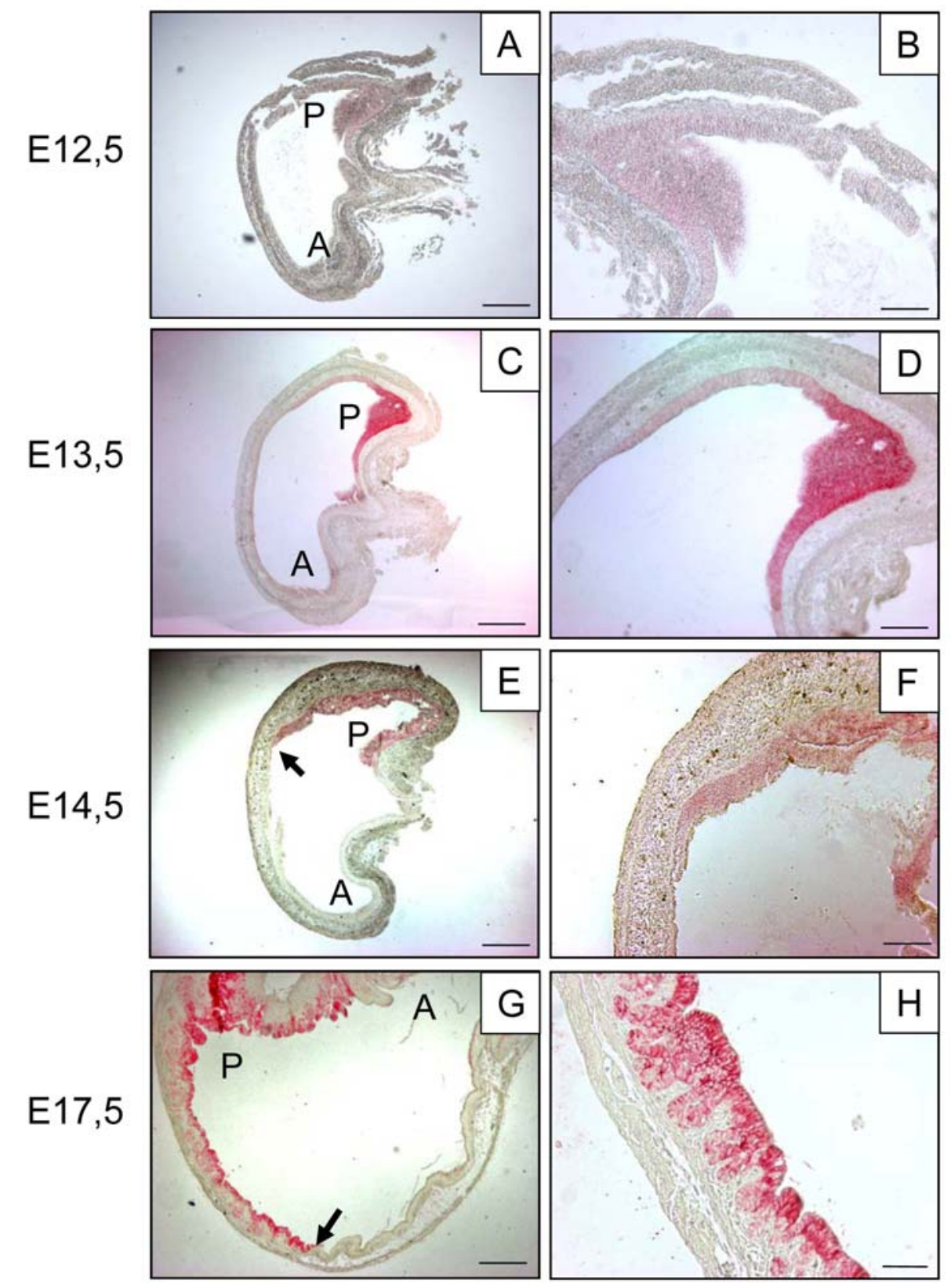

Figure 3.23 Immunohistochemical analysis of Vsig1 expression in embryonic stomach. In E12.5 and E13.5 VSIG1 expression is rather detected negligible in the accumulated cell population in primordial bud of posterior region, but the glandular epithelium is not developed in these stages (A, B, C, D). In E14.5 the epithelial differentiation makes the visible junction between anterior and posterior region (pointed by arrow) (E, F). In 17.5E, VSIG1 was found in the glandular epithelium of the posterior region, which is started to be invaginated $(\mathrm{F}, \mathrm{H})$. Optical magnifications: $4 X$ in $A, C, E, G ; 10 X$ in $B, D, F ; 20 X$ in $H$. 


\subsubsection{Expression analysis of Vsig1 in teratocarcinoma}

Teratocarcinoma is the classical stem cell tumor (Pierce, 1967). In other words, teratocarcinoma contains pluripotent stem cells as well as well organized tissues representing all three germ layers (Thomson et al., 1998). To determine the expression pattern of Vsig1 in teratocarcinoma, sections were done on teratocarcinoma, which has been isolated from Apg1-deficient mice (Held et al., 2006) and stained with anti-VSIG1 antibody (Fig. 3.24).
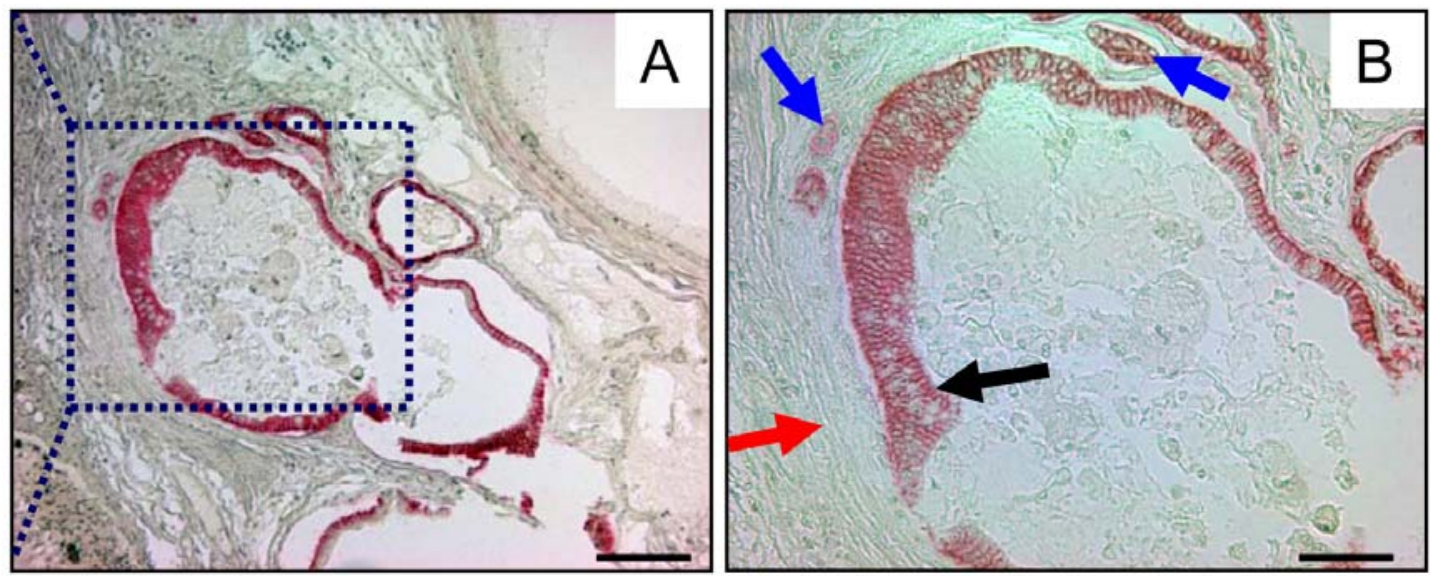

Figure 3.24 Vsig1 gene is expressed in teratocarcinoma. Immunohistochemical analysis showed that the Vsig1 gene is expressed in certain kinds of cells (indicated by black arrow in B) of teratocarcinoma. This VSIG1-positive tissue is attached to a tissue, which is morphologically similar to stomach mesenchymal tissue (indicated by red arrow in B). Optical magnifications: $4 X$ in A; $10 X$ in $B$.

Immunohistological analysis revealed that the VSIG1 is restricted to the plasma membrane of monolayered epithelial cells that line tubules in the teratocarcinoma tissues as well as patches of stem cells that may be differentiated later to monolayer of stratified epithelium (indicated by blue arrows in Fig. 3.24B). No VSIG1-specific staining was observed in other tissue types of teratocarcinoma, such as bone or muscle tissues (data not shown). 


\subsection{Functional analysis of Vsig1}

\subsubsection{Generation of conventional knockout mice}

To clarify the in vivo function of Vsigl, we have disrupted the X-linked Vsigl gene in XY ES cells using a replacement targeting strategy (Fig. 3.25). A 1.7-kb genomic fragment containing exon-1 was deleted and replaced by neomycin phosphotransferase gene cassette (Neo) under the control of phosphoglycerate kinase promoter. Exon-1 contains the translation initiation codon ATG. The expected targeting event would generate an allele that transcribes an untranslated Vsigl mRNA. Insertion of the negative selection marker, the Herpes simplex virus thymidine kinase (TK) gene in the targeting vector enabled us to use both positive and negative selection (Mansour et al., 1988).

\subsubsection{Construction of Vsig1 targeting vector}

\subsection{Subcloning of the 5 '-flanking region of the Vsig1 gene into the pPNT-1 vector}

Genomic 4.5-kb Xbal fragment containing the sequence of 5'-flanking region of the Vsigl was isolated from the cosmid clone (MPMGc121B114407Q2, RZPD) and cloned into the pZERO-2 ${ }^{\mathrm{TM}}$ vector. By clone hybridization screening of the cosmid sublibrary with the 500-bp probe located at the $5^{\prime}$ upstream region of exon-1, clones containing the 4.5-kb Xba1 fragment was picked up (clone-1 in Fig. 3.25). To generate the Vsig1 targeting construct, the 4.5-kb Xba fragment was isolated from clone-1 and subcloned in BamH1/EcoR1-digested pPNT-1 vector by blunt end ligation (clone-2 in Fig. 3.25).

\subsection{Subcloning of the 3'-flanking region of the gene into pPNT-1 vector}

The cosmid clone did not include the 3'- downstream region of exon-1. Therefore, a 2.9-kb Xho1/Not1 fragment containing a sequence of the intron-1 was amplified by PCR using high fidelity DNA polymerase enzyme with the primers SX3-ArmF1 and SX3-ArmR1 (Materials and Methods section) and cloned into the pGEMT-easy vector (clone-3 in Fig. 3.25). Cloned 2.9-kb Xho1/Not1 fragment was sequenced with vector specific T7, SP6 primers and internal primers. Finally the 2.9-kb Xho1/Not1 fragment was cloned into Xho1/Not1 digested clone-2 to produce clone-4 (Fig. 3.25). The targeting vector Vsig1-Neo- 
TK was subjected to multiple restriction analyses for verification of the construct (Fig. 3.26). The targeting vector was linearized at the unique NotI site present in the polylinker site before the transfection.

\section{Clone-1 (in pGEMT-easy vector)}

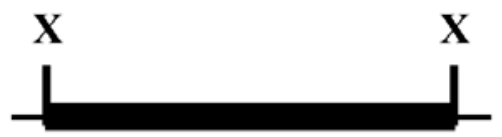

II. Clone-2 (in pPNT-1 vector)

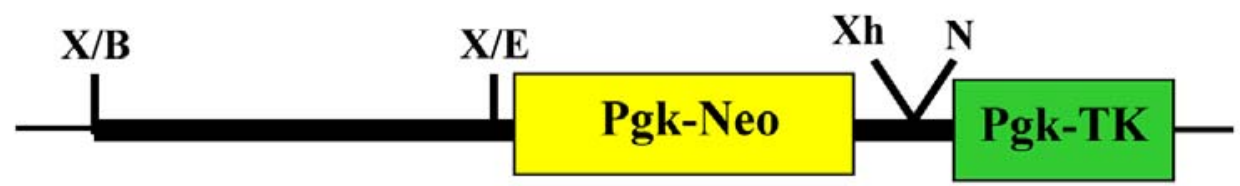

$\underline{\text { III. }}$

Clone-3 (in pGEMT-easy vector)

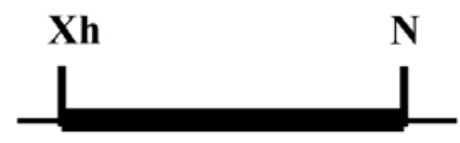

$\underline{\text { IV. Clone-3 Final targeting construct (in pPNT-1 vector) }}$

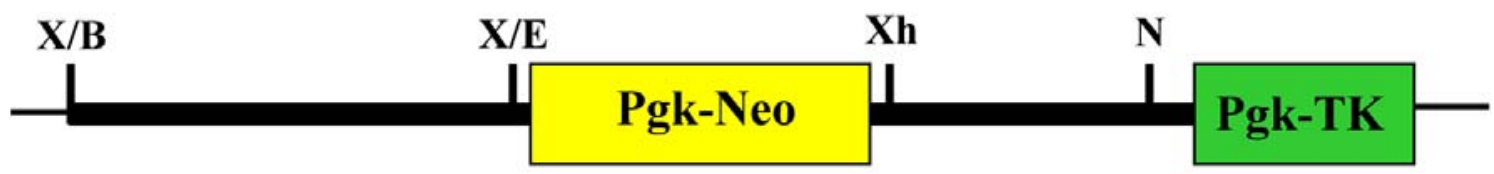

Continued to figure 3.25 


\section{Wild type Vsig1 allele}

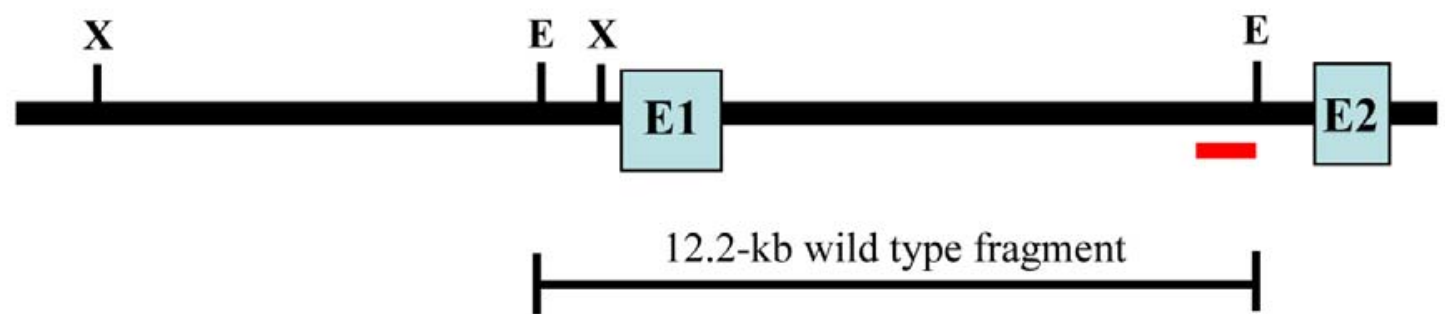

\section{Recombinant Vsig1 allele}

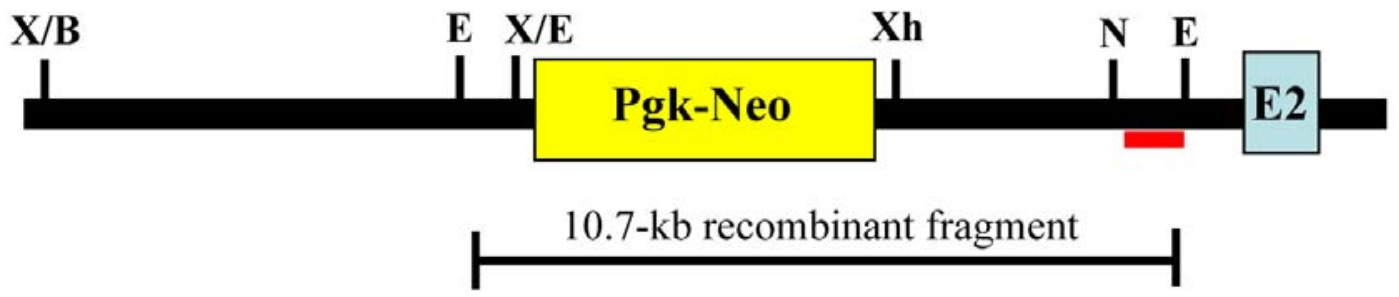

Figure 3.25 The schematic representations of subsequent cloning steps for the targeting construct are shown. The blue boxes represent exons of Vsig1 gene. The green box represents Thymidine kinase and the yellow box represents Neomycin cassette. The schematic representation of the wild-type allele and the recombinant allele is shown in illustration $\mathbf{V}$ and VI. The position of the 3'external probe for Southern blot screening is indicated by red rectangular (in $\mathbf{V}$ and VI). Genomic DNA was digested with EcoRI restriction enzyme for Southern blot screening with 3'-external probe.

In case of wild type, 3'-external probe detects a $12.2-\mathrm{kb}$ fragment, and in case of recombinant allele, the probe detects a $10.7-\mathrm{kb}$ fragment. The restriction site abbreviations are: X-XbaI; Xh-Xho; N-NotI; E-EcoR1. 

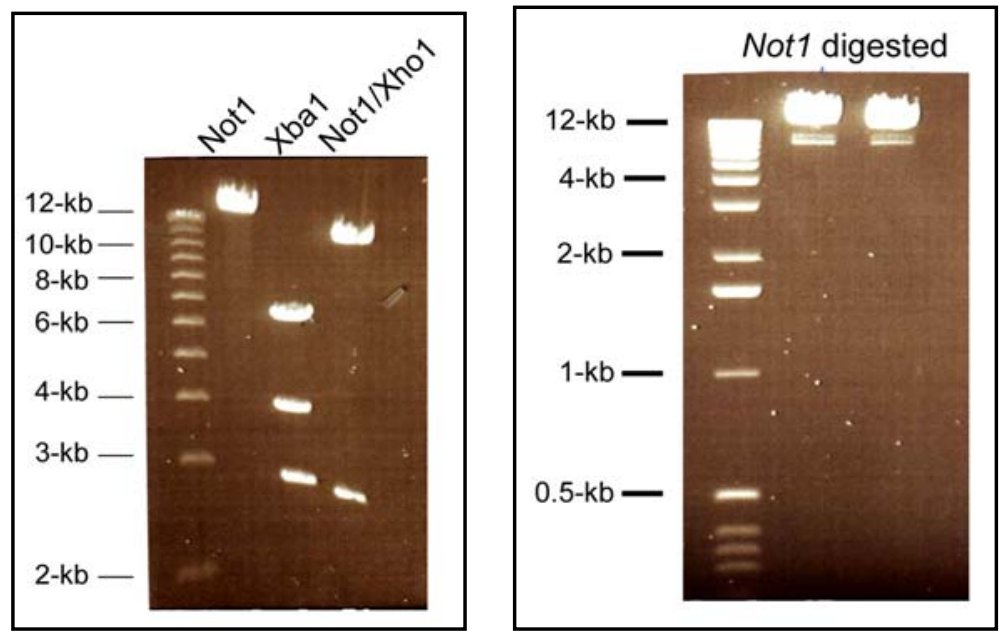

\section{Figure 3.26 Restriction analysis of the knockout construct with different} restriction enzymes. As expected, Not1 digestion of targeting construct gives only one band, which is $13.5-\mathrm{kb}, \mathrm{Xba}$ digestion gives three bands $(6.7-\mathrm{kb}, 4-\mathrm{kb}, 2.8-\mathrm{kb})$ and Not1, Xho1 double digestion gives 2 bands (11.8-kb, 2.7-kb)

\subsubsection{Subcloning of the 3'-external probe}

A $0.5-\mathrm{kb}$ fragment of the 3'-region of the Vsig1 gene (Fig. 3.25III) was amplified by PCR using the primers SX-3ExtProbeF1and SX-3ExtProbeR1. The PCR product was subcloned into the pGEM-T-easy vector and subsequently sequenced. Following the DNA digestion by EcoRI enzyme, the $0.5-\mathrm{kb}$ fragment was isolated from agarose gel and used as 3 '-external probe in Southern blot analysis for screening the recombinant ES-clones.

\subsubsection{Electroporation of R1 ES-cells}

ES cells were cultured in the culture medium (2.1.5.2). Confluent plates were washed in PBS buffer, trypsinized and the cells were suspended in the same buffer at $2 \times 10^{7}$ cells/ml. The plasmid DNA containing the targeting construct (pPNT-Vsig1) was purified using QIAGEN MaxiPrep kit (2.2.1.1.3) and linearized by NotI restriction enzyme before transfection. R1 ES cells were transfected by electroporation at $240 \mathrm{~V}$ and $500 \mu \mathrm{F}$ using a Bio-Rad Gene Pulser apparatus. The cells were plated onto nonselective medium in the presence of G418- resistant embryonic mouse fibroblasts. After 36 hrs, selection was 
applied using medium containing G418 at $400 \mu \mathrm{g} / \mathrm{ml}$ and gancyclovir at $2 \mu \mathrm{M}$. After 10 days of selection, 150 individual drug-resistant clones were picked into 24-well trays for freezing and isolation of DNA.

\subsubsection{Analysis of recombinant ES-cells}

To screen the recombinant ES-clones for homologous recombination events, genomic DNA was extracted from individual drug-resistant recombinant ES-clones and subjected to restriction digestion with EcoRI restriction enzyme. The complete digested DNAs were electrophoresed on a $0.8 \%$ agarose gel and transferred onto nitrocellulose membranes.

The $0.5-\mathrm{kb} 3$ '-external probe located in exon-2 (Fig. 3.25) was labeled with ${ }^{32} \mathrm{P}-\mathrm{dCTP}$ by random priming. Hybridization was carried out at $65^{\circ} \mathrm{C}$ overnight in Rapid-Hyb hybridization buffer containing denatured salmon sperm DNA $(100 \mu \mathrm{g} / \mathrm{ml})$. Membranes were washed twice at $65^{\circ} \mathrm{C}$ in a final stringency of $0.2 \mathrm{xSC} / 0.01 \% \mathrm{SDS}$.

According to the fact that the Vsig1 gene is a X-linked gene, and the used ES cells have a male genome, we expected that the 3'-external probe will recognize only the $12-\mathrm{kb} E c o R I$ fragment in wild type ES clones and the 10.7-kb EcoRI fragment in homologous recombinant Vsig1/Y ES clones (Fig. 3.25). Of the 150 colonies tested, one clone was found which showed the expected hybridization pattern (Fig. 3.27)

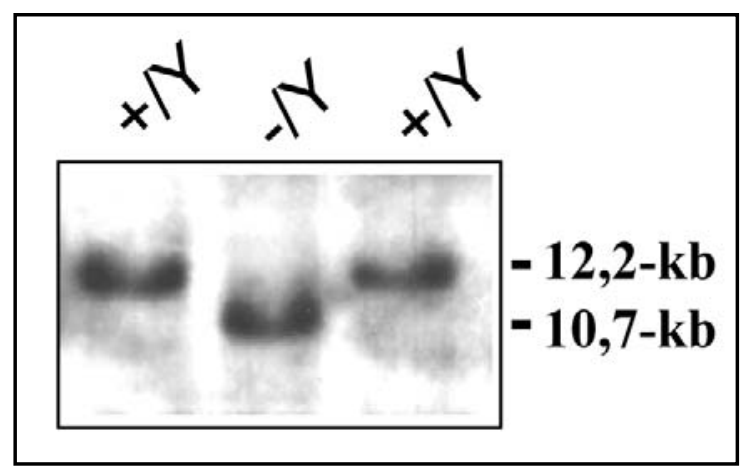

Figure 3.27 Southern blot analysis of ES clones by using the 3 '-external probe. Genomic DNA extracted from ES cell clones was digested with EcoRI. The 3'-external probe recognizes a 12.2-kb band in case of wild type and a 10.7$\mathrm{kb}$ band in case of recombination. 


\subsubsection{Generation of chimeric mice}

The recombinant ES cells were injected into 3.5-dpc blastocysts, which were derived from C57BL/6J mice. The blastocysts were retransferred into pseudopregnant CD1 mice to generate chimeric mice. This work was performed in the Max Planck Institute for experimental Medicine, Göttingen.

24 chimeric mice were generated by two independent injections of the recombinant ES clone. The chimeras were scored according to the coat colour. Both of the injections gave only low chimeric mice. 2 males with $40 \%, 2$ males with $30 \%, 2$ females $30 \%$ and 1 male with $15 \%$ chimerism were chosen for further experiments. Other animals showing only low chimerism (lower than 10\%) were not used for further experiments.

The mentioned chimeric mice were bred with $\mathrm{C} 57 \mathrm{BL} / 6 \mathrm{~J}$ mice to obtain $\mathrm{F} 1$ animals in respective background (C57BL/6J x $129 / \mathrm{Sv}$ ). One of the $40 \%$ chimeric mice died in the beginning of breeding, and therefore this mouse could not give any offspring. All of the other male and female chimeras did not transmit the targeted allele to their offspring and gave only C57BL/6J offspring (black haired offspring). The average litter size was not significantly different from that obtained from breeding $129 / \mathrm{Sv}$ males with C57BL/6J females.

\subsubsection{Analysis of contribution of 129/Sv cells in testis of chimeric mice.}

The low chimerism of the generated chimeras and the failure of the chimeras to give hemizygous progeny may be due either to the fact that Vsig1- deficient cells do not contribute efficiently for the development of different tissues, especially for the germ cells or a high contribution of Vsig1-nul cell leads to lethality of the chimeric embryos. To address these questions, we have sacrificed the chimeric mice and subjected different tissues to histological and molecular analysis.

We have performed PCR assay based on microsatellite polymorphisms to identify the presence of the 129/Sv (Vsig ${ }^{-/} / Y$ ) spermatozoa in the sperm samples which were isolated from cauda epididymis of different chimeras. The primers ST-F1 and ST-R1 amplified D10Mit180 microsatellite locus of mouse chromosome 10 and the PCR products are 134bp for the C57BL/6 genotype and 206-bp for 129/Sv genotype. 
As shown in figure 3.28, the presence of the $129 / \mathrm{Sv}\left(\operatorname{Vsig}^{-} / Y\right)$ spermatozoa as judged by the level of the amplified 129/Sv specific fragment was undetectable in all chimeric sperm samples (Fig. 3.28). These results and the expression of Vsig1 during early embryonic development which is detected by RT-PCR assay, lead us to suggest that a high contribution of Vsig1-null cells to the development of embryos causes lethality of the chimeric embryos.

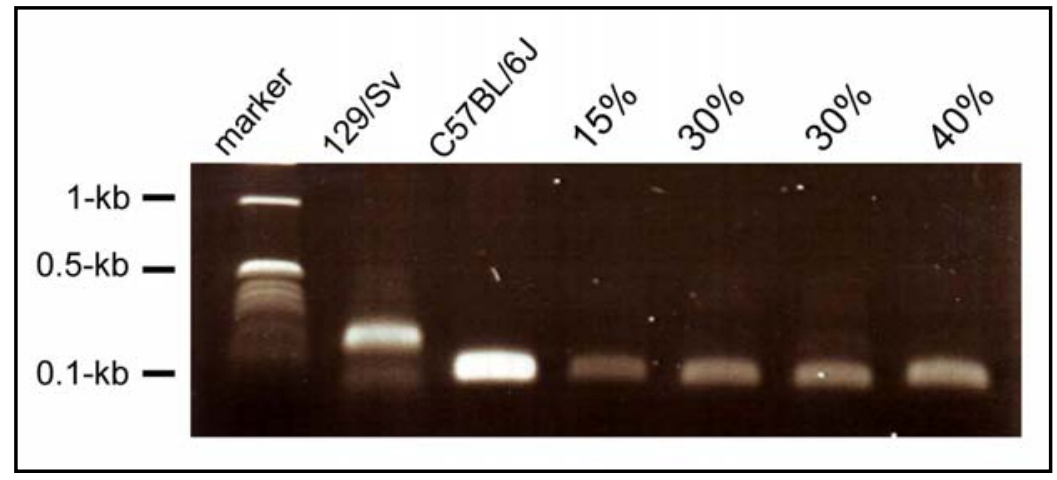

Figure 3.28 PCR assay using microsatellite specific primers was performed to determine the presence of $129 / \mathrm{Sv}$ spermatozoa in sperm samples of different chimeric mice. DNAs from wild type 129/Sv and C57BL/6J served as positive control. PCR amplifies a 134-bp product in case of C57BL/6 genotype and a 206-bp product in case of $129 / \mathrm{Sv}$ genotype.

\subsubsection{Transdifferentiation of $V$ sig1/Y cells from stratified to cornified epithelium}

Next, we analyzed the expression of Vsig1 in the $V \operatorname{sig} 1^{-} / Y-V \operatorname{sig} 1^{+} / Y$ chimeric mice. Stomachs from chimeric mice were isolated, fixed and embedded in paraffin wax. Serial sections of stomach tissues were prepared. Approximately 10 slides representing different regions of stomach were employed for immunostaining by incubation with VSIG1 specific antibody. The immunoreactivity was detected using alkaline phosphatase conjugated antirabbit secondary antibody.

We found that some parts of glandular epithelium in the corpus region of stomach contained Vsig1-negative cells (Fig. 3.29A). In contrast to the neighboring $V_{s i g l}^{+} / Y$ epithelium, the heterotypic Vsig1-deficient epithelium did not express $\mathrm{H}^{+} / \mathrm{K}^{+}$-ATPase P-subunit, which is a marker of the parietal cells in the glandular epithelium (Fig. 3.29C). H\&E staining revealed that Vsigl-deficient glandular epithelium was morphologically different from 
adjacent $\mathrm{Vsigl}^{+} / Y$ glandular epithelium and it had an atypical morphology of the cornified squamous epithelium, which is normally localized in the anterior stomach (Fig. 3.29E). Immunohistochemical analysis revealed that the cytokeratin-5 is highly expressed in the Vsig1-deficient epithelium as well as in the squamous epithelium of the anterior stomach (Fig. 3.29B, F). These results demonstrate

that the Vsig1-deficiency leads to transdifferentiation of the stratified (glandular) epithelium to cornified (squamous) epithelium.

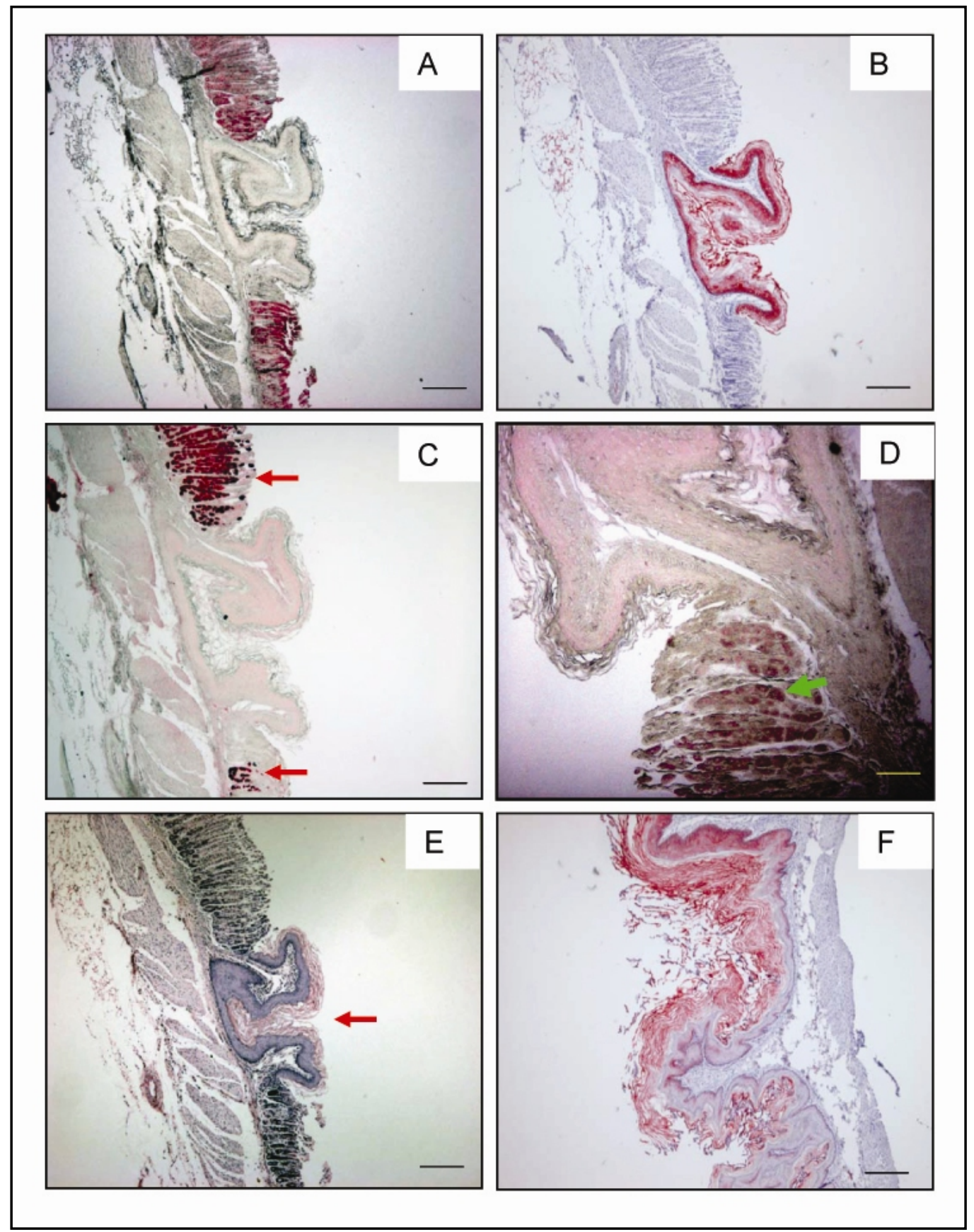


Figure 3.29 Immunohistochemical analysis of the stomachs from chimeric mice. Immunostaining on sections of chimeric stomach with VSIG1 antibody detects VSIG1-negative regions in glandular epithelium (A). Cytokeratin 5/6 is expressed in the VSIG1- negative region (B). Staining with anti $\mathrm{H}^{+} / \mathrm{K}^{+}$-ATPase antibody shows that the VSIG1-negative region has no parietal cells. Red arrows point to the parietal cells (C). Glandular epithelial marker GATA4 is not expressed in the VSIG1 negative region. The green arrow points to the GATA4 positive adjacent cells (D). H\&E staining shows histological structure of chimeric tissue. Red arrow indicates the VSIG1 negative region (E). The squamous epithelium of cardiac region was specifically stained with anti cytokeratin 5/6 antibody (F). Optical magnifications: $4 X$ in $A, B, C, E ; 10 X$ in $F, 20 X$ in $D$.

\subsubsection{Analysis of chimeric embryo}

The low chimerism of the $V \operatorname{sig} 1^{+} / Y-V \operatorname{sig} 1^{-} / Y$ chimeras lead us to suggest that high contribution of the Vsig1/Y cells in development of chimeric mice impairs the embryonic development. To address this question, we repeated the injection of blastocyst with Vsig1 $/ Y$ cells. The recombinant blastocysts were transferred into pseudopregnant females. Seven foster females were sacrified at day 16.5 of gestation and the uteri were dissected and 18 embryos were detected. Furthermore, we found also 7 dead (regressed) implanted sites in uterus which could account for resorption of embryos. Unfortunately, there was no embryonic materials in these implanted sites that could be used for genotyping of the dead embryos. The 18 embryos were dissected and stomachs were fixed for immunohistological studies. Head, liver, limbs and intestine were isolated from the 18 embryos and genomic DNA was extracted. PCR with microsatellite specific primers was performed to evaluate the contribution of the $129 / \mathrm{Sv}$ and C57B1/6J cells in the studied tissues. PCR analysis revealed that the $129 / \mathrm{Sv}$ cells are relatively high contributing to the development of liver and intestine of four chimeric embryos A2, B1, D1 and D2 (Fig. 3.30). 


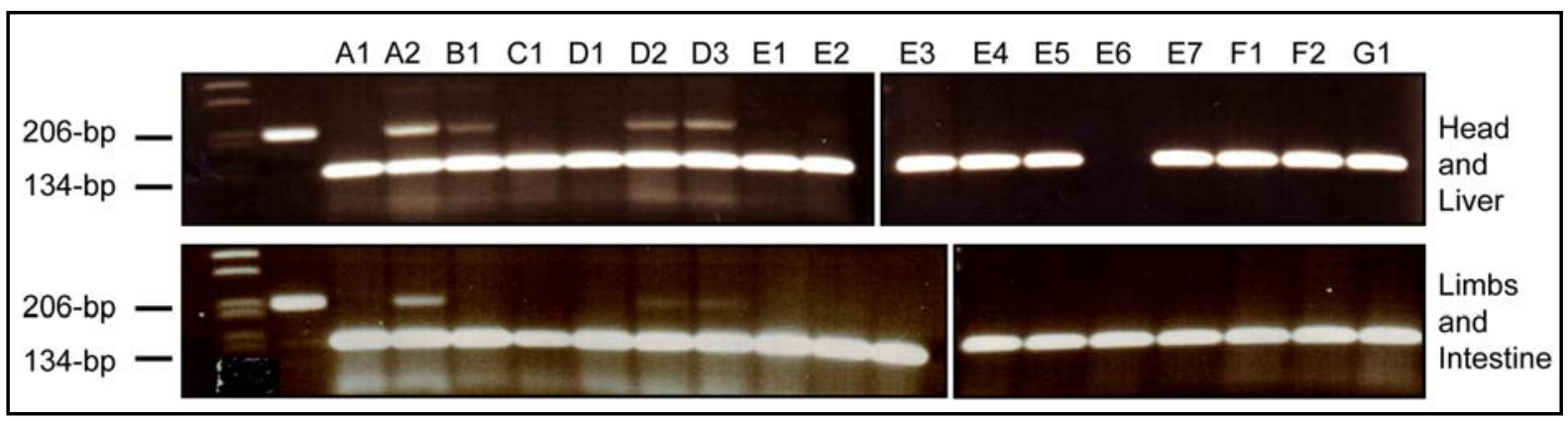

Figure 3.30 Embryo genotyping by PCR using microsatellite specific primers. DNAs from wild type 129/Sv (first lane) served as positive control. PCR amplified a 134-bp fragment for the C57BL/6 genotype and a 206-bp fragment for $129 / \mathrm{Sv}$ genotype. Each embryo is numbered with a combination of a block letter and a number, which indicates the foster mother and the embryo.

To determine the consequences of Vsig1-deficiency on the development of chimeric stomach, H\&E and immunohistological staining were performed on serial sections of stomach from 4 chimeric embryos (A2, B1, D1, and D2). Immunohistological staining with VSIG1 antibody revealed the presence of VSIG1-negative cells in a large region of glandular epithelium in stomach of chimeric embryo A2 (Fig. 3.31A). Also VSIG1negative small regions were found in glandular epithelium of other chimeric stomachs (data not shown). Histological analysis revealed that the development of glandular epithelium is impaired in VSIG1-negative region of posterior stomach while the glandular epithelium in VSIG1-positive region is well developed and primitive gastric units are formed (Fig. 3.31B). The histological appearance of VSIG1-negative epithelium in posterior stomach was similar to that in anterior stomach (Fig. 3.31D). To determine whether the Vsig1deficiency leads transdifferentation of epithelium in the VSIG1-negative region of posterior stomach to squamous epithelium, immunostaining with Cytokeratin-5/6 antibody was performed. As shown in figure 3.31 (C, D), the squamous epithelium marker Cytokeratin$5 / 6$ is not expressed in VSIG1-negative epithelium of posterior stomach. This result suggests that the complete transdifferentation of squamous epithelium is occurred during 
the pre- and postnatal developmental stages after E16.5 or the cytokeratin-5/6 is expressed only in $V \operatorname{sig} 1^{-1} Y$ cells of adult stomach.

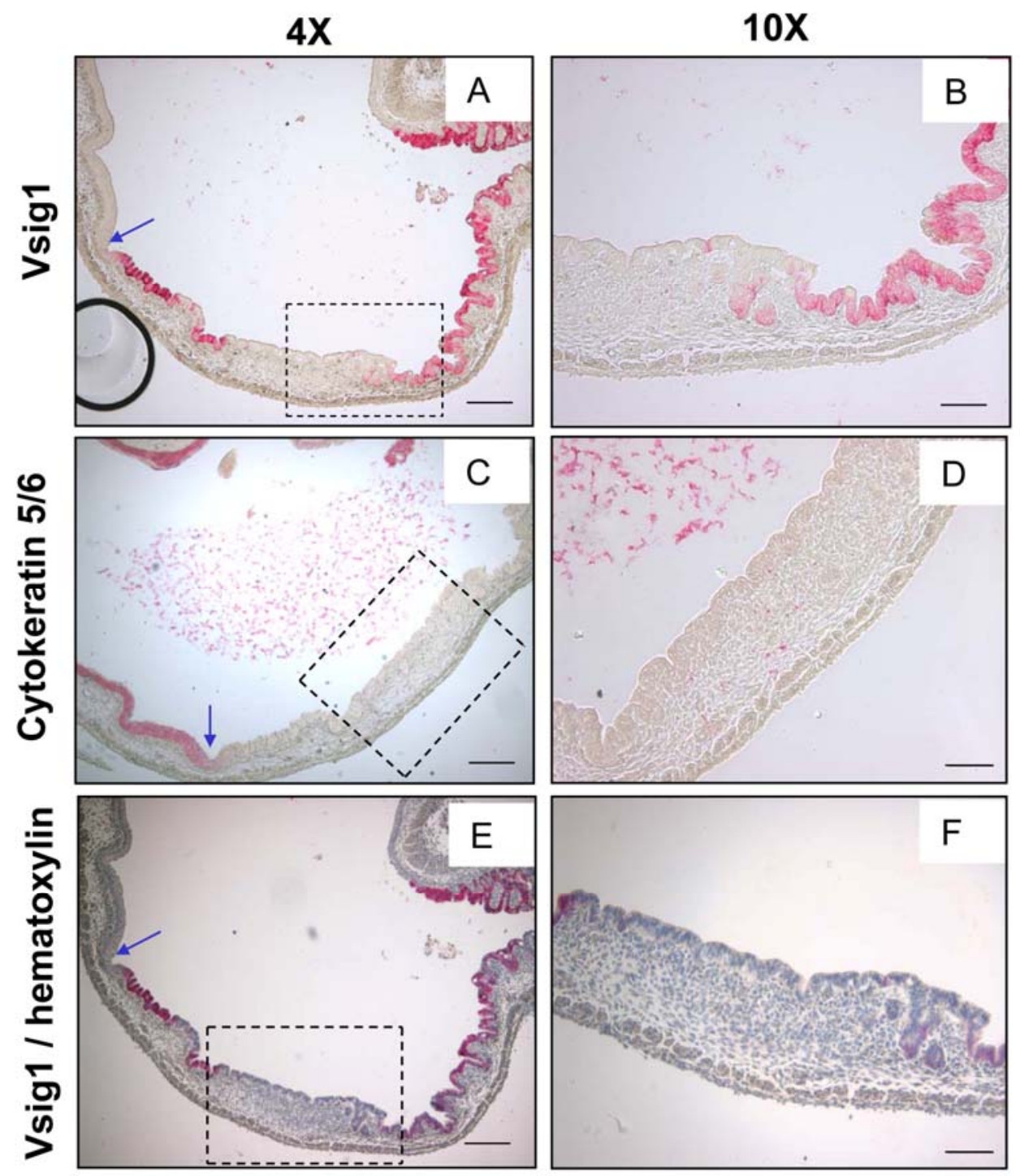

Figure 3.31 Immunohistochemical analysis of the stomachs from chimeric embryo A2. Immunostaining with anti-VSIG1 antibody detected VSIG1negative large region in glandular epithelium of posterior stomach (A, B). The blue arrow indicates the junction between glandular and squamous epithelium (A, C, E). Squamous epithelium marker Cytokeratin $5 / 6$ is not expressed in the VSIG1-negative cells $(\mathrm{C}, \mathrm{B})$ while the squamous epithelium has the expression (C). Immunostaining with VSIG1 antibody counterstained with hematoxylin staining to show histological structure of chimeric tissue. Optical magnifications: $4 X$ in $A, C, E ; 10 X$ in $B, D, F$. 


\subsubsection{Generation of Vsig1 conditional knockout mice}

Analysis of chimeric mice, which were generated by Vsig1 $/ Y$ ES cells suggests that Vsig1 has a vital role in early embryonic development, because chimeric mice with high contribution of $V \operatorname{sig} 1^{-} / Y$ cells are lethal. In order to identify the function of Vsig1 and to overcome the early lethality of the highly contributed chimeras, a Vsig1 conditional knockout construct was generated.

\subsubsection{Generation of conditional targeting construct}

\subsection{Subcloning of the 5'-flanking region of the Vsig1 gene into the pPNT4 vector}

In order to disrupt conditionally the Vsig1 gene in mouse, a conditional Vsig1 construct was designed in the pPNT4 vector (Conrad et al., 2003). In the conditional Vsig1 construct, exon-1 of Vsig1 gene was flanked with LoxP sites. The Pgk-Neo cassette, which is flanked with frt-elements was inserted in intron-1 for positive selection. Insertion of the herpes simplex virus thymidin kinase (TK) gene at the 3 '-end of the construct enabled us to use negative selection (Fig. 3.32).

The pPNT4 vector has 2 multicloning sites for subcloning of 5'- and 3'-arms of the construct which allow homologous recombination in transfected ES cells (Fig. 3.32). A 1$\mathrm{kb}$ genomic fragment containing exon-1 (including ATG) was amplified by PCR and cloned into pGEMT-easy vector and sequenced. The forward primer used for PCR amplification of the 1-kb fragment was designed to contain XbaI restriction site and the LoxP sequence, while the reverse primer contains the NotI restriction site. The 1-kb XbaI /NotI digested fragment was isolated from pGEMT-easy clone and cloned into XbaI /NotI digested pBluescript (SK+) vector (clone-1 in Fig. 3.32) .

The 4.5-kb Xbal genomic fragment containing the sequence of 5'-flanking region which is exactly located upstream of amplified XbaI/NotI fragment was isolated from the cosmid clone (MPMGc121B114407Q2, RZPD) and cloned into the pZERO ${ }^{\mathrm{TM}}$ -2 vector (clone-2, in Fig. 3.32). The XbaI 4.5kb genomic fragment was isolated from clone-2 and then cloned into clone-1 to generate clone-3 (Fig 3.32). The 5.5-kb 5'-arm was isolated from clone-3 by digestion with SalI/NotI and subcloned into SalI/NotI digested pPNT4 vector (clone-4 in Fig. 3.32). 


\subsection{Subcloning of the 3 ' flanking region Vsig1 gene into pPNT4 vector}

Southern blot analysis revealed that the cosmid clone (MPMGc121B114407Q2, RZPD) contained only the promoter region including the upstream sequence of exon- 1 . Therefore, the 2.9-kb NheI/Xho1 fragment containing a sequence of intron-1 was amplified by PCR with high fidelity DNA polymerase enzyme using the primers SX3-ArmF1 and SX3ArmR1, cloned into the pGEMT-easy vector (clone-5 in Fig. 3.32). The cloned 2.9-kb NheI/Xho1 fragment was sequenced with internal primers. The correctly sequenced 2.9-kb NheI/Xho1 fragment was cloned into NheI/Xho1-digested clone-4 to produce the final conditional targeting construct (clone-6 in Fig. 3.32).

The conditional targeting vector containing the 5.5-kb 5'-arm and 3-kb 3'-arm of Vsig1 was subjected to multiple restriction analyses for verification. The vector was linearized at the unique SalI site present in the polylinker site before transfection of the ES cells.

\section{WT allele of Vsiq1}

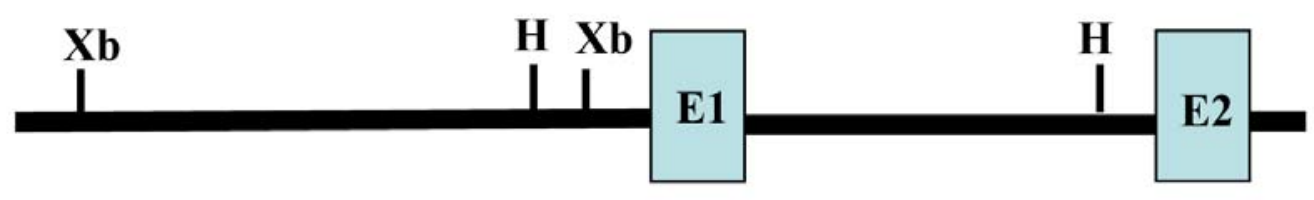

\section{Clone-1(in pBluescript SK+)}

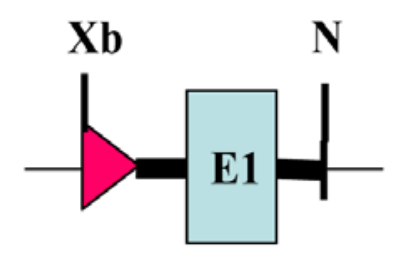

\section{Clone-2 (in pZERO-2)}

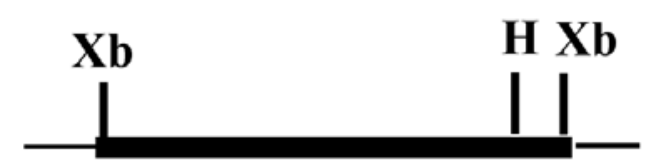

Continued to Figure 3.32 
$\underline{\text { IV Clone-3 (in pBluescript } S K+)}$

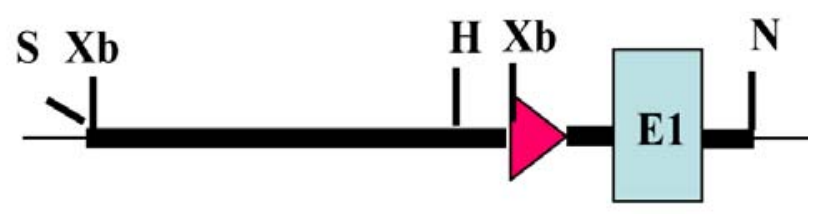

V. pPNT4 vector

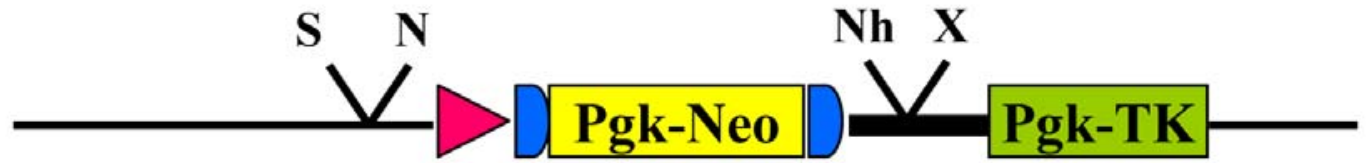

VI. Clone-4 (in pPNT4)

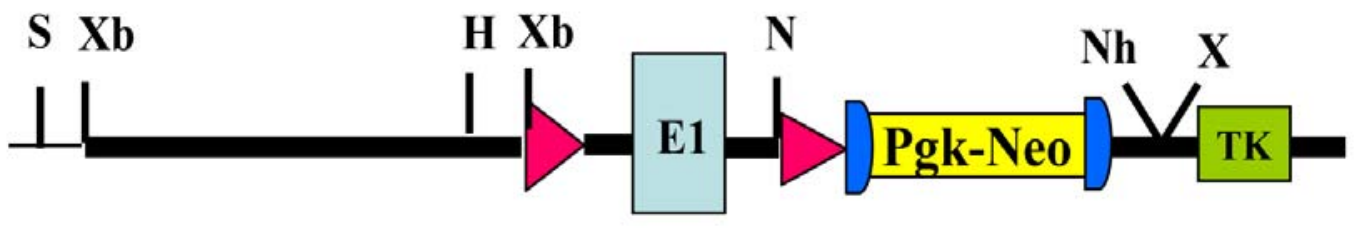

VII. Clone-5(in pGEM-T-easy)

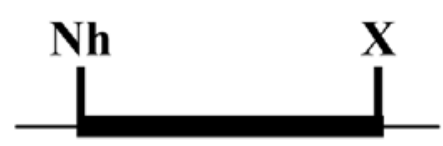

VIII. Clon- 6, final conditional targeting construc (in pPNT4)

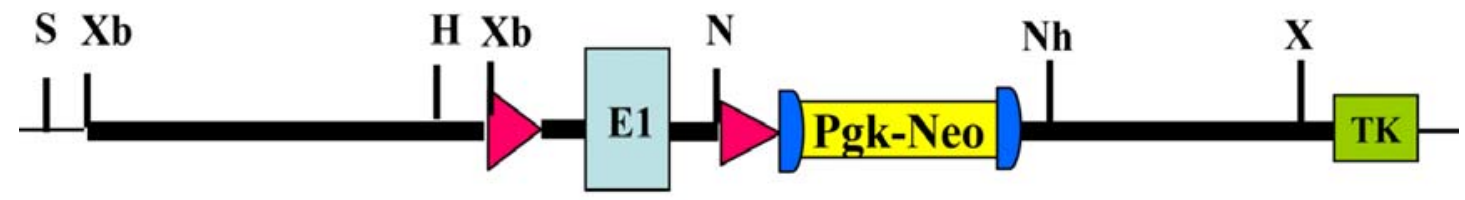

Continued to Figure 3.32 
IX. Recombinant allele (Vsiq1 $\left.{ }^{\text {flox }}\right)$

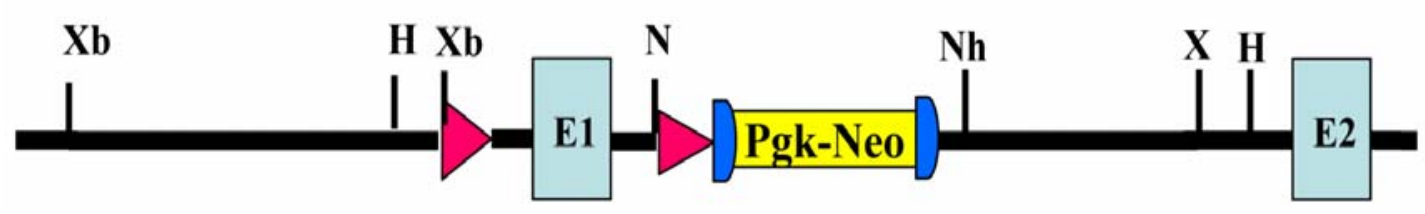

\section{$\underline{X}$. Neomycin cassette deleted allele (Neo-)}

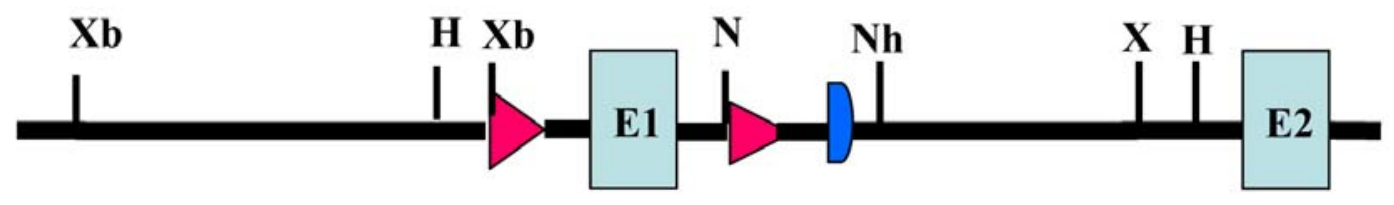

\section{Exon-1 deleted allele (Vsiq1')}

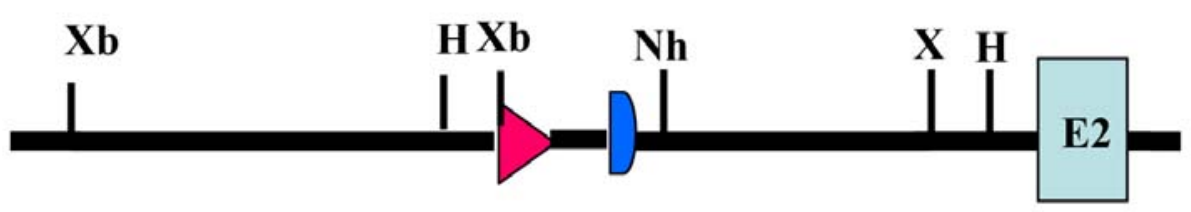

Figure 3.32 Construction of targeting vector and disruption of the Vsig1 gene.

The backbone of pPNT4 vector containing the Neo, Tk and LoxP cassettes was used for cloning the floxed Vsig1 construct (illustration V). The schematic representation of wild-type Vsig1 gene is shown first (illustration I) and the schematic representations of the subsequent cloning steps are shown (illustrations II-VIII). Red triangular stands for loxP sites and blue half rounds stand for frt sites. The violet rectangular stands for Thymidine kinase cassette and the yellow rectangular stands for Neomycin cassette. The recombinant allele including exon-1 produced after homologues recombination is shown in illustration IX. The neomycin cassette is floxed with yeast derived frt sequence which allows homologous recombination 
mediated by FRT recombinase resulting in the deletion of neomycin cassette. Schematic representation of the neomycin deleted allele is shown (illustration X). In the recombinant allele (illustration IX), the exon-1 is floxed with LoxP sites for homologous recombination mediated by Cre recombinase. Schematic representation of exon-1 deleted allele is shown in illustration XI. The restriction site abbreviations are: Xb-XbaI; X-Xho; N-NotI; Nh-NheI; H-Hind3; Bg-BglI,

\subsubsection{Subcloning of the 3 '- and 5'-external probes}

A $0.7-\mathrm{kb}$ genomic fragment located at the 3 '-region of the Vsig1 gene was amplified by PCR using the primers SX-3ExtProbeF1 and SX-3ExtProbeR1. The PCR product was subcloned into the pGEM-T Easy vector and subsequently sequenced. Following the DNA digestion by EcoRI enzyme, the $0.7-\mathrm{kb}$ fragment was isolated from agarose gel and used as probe for screening of recombinant ES-clones.

\subsubsection{Electroporation of R1 ES-cells}

Confluent plates of ES cell line RI were washed with PBS buffer, trypsinized and the cells were suspended in the same buffer at $2 \times 10^{7}$ cells $/ \mathrm{ml}$. The plasmid DNA containing the targeting construct (pPNT4-Vsig1) was purified using QIAGEN MaxiPrep kit (2.2.1.1.3) and linearized by SalI restriction enzyme before introducing into early passage R1 ES cells by electroporation at 240V and $500 \mu \mathrm{F}$ using a Bio-Rad Gene Pulser apparatus. The cells were plated onto nonselective medium in the presence of G418- resistant embryonic mouse fibroblasts. After 36 hrs, selection was applied using medium containing G418 at $400 \mu \mathrm{g} / \mathrm{ml}$ and gancyclovir at $2 \mu \mathrm{M}$. After 10 days of selection, 150 individual drug-resistant clones were picked into 24-well trays for freezing and isolation of DNA.

\subsubsection{Analysis of recombinant ES cell clones}

To screen the recombinant ESC-clones for homologous recombination events, genomic DNA was extracted from individual drug-resistant recombinant ESC-clones and subjected to restriction digestion with the HindIII restriction enzyme. The digested genomic DNAs were electrophoresed on a $0.8 \%$ agarose gel and transferred onto nitrocellulose membranes.

The 0.7-kb 3'-external probe located in exon-2 (Fig. 3.33C) was labeled with ${ }^{32} \mathrm{P}$-dCTP. Hybridization was carried out at $65^{\circ} \mathrm{C}$ overnight in Rapid-Hyb hybridization buffer 
containing denatured salmon sperm DNA $(100 \mu \mathrm{g} / \mathrm{ml})$. Membranes were washed twice at $65^{\circ} \mathrm{C}$ to final stringency of $0.2 \times \mathrm{SSC} / 0.01 \% \mathrm{SDS}$.

Vsig1 gene is localized on the $\mathrm{X}$ chromosome. Therefore, in each case of homologous and nonhomologous recombination event, only one genomic fragment is detectable. The 3'external probe should detect a 7.5-kb hybridization signal in case of wild type allele, and 9$\mathrm{kb}$ fragment in case of recombinant allele (Fig. 3.33B, C). Of the 150 colonies tested, 2 clones (clone-9 and clone-48) were found to have the floxed allele (Vsig1 $1^{\text {flox }} / Y$ ) (Fig.3.34A) To confirm that these two recombinant ES-cell clones had undergone correct homologous recombination at the 5'-junction, Southern blot with Nhe1 and BglI digested genomic DNA of two homologous recombinant clones (clone-9 and 48) and of the three non-homologous recombinant clones (clones-1, 8 and 47) were hybridized with the 5'-external probe (Fig. 3.34B). As expected for correct homologous recombination, the 5'-external probe only detected the 13.5-kb NheI-fragment and the 7-kb BglI-fragment. In case of nonhomologous recombination events, the 5'-external probe detected only the $15-\mathrm{kb}$ Nhefragment and the 9-kb BglI-fragment (Fig. 3.33D, E) and (Fig. 3.34B).

\section{Screening with 3'-external probe}

\section{$\underline{\text { I. Targeting vector }}$}

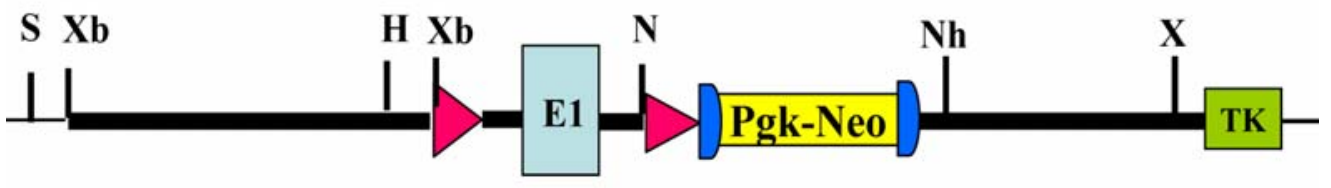

\section{WT allele $\left(\right.$ Vsig $\left.^{+}\right)$}

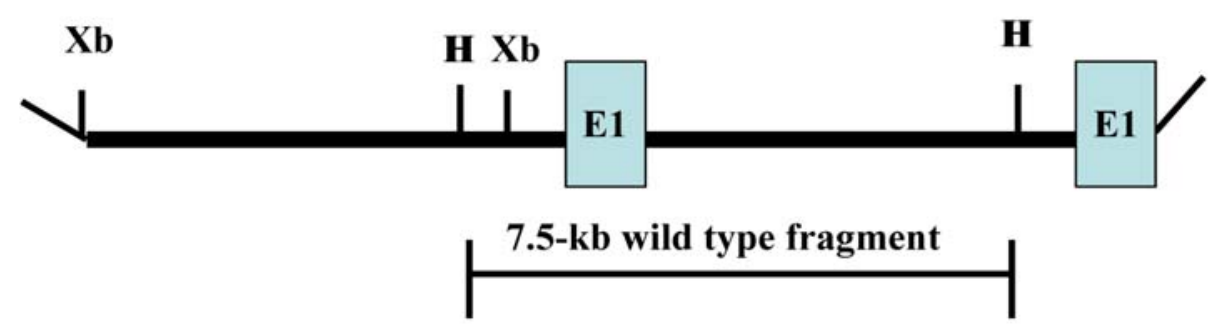

Continued to Figure 3.33 
III. Floxed allele (Vsig $\left.{ }^{\text {flox }}\right)$

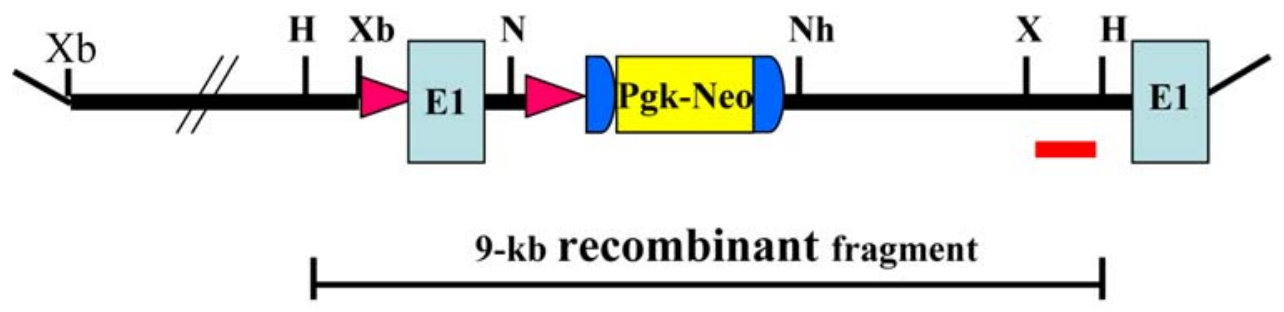

Verification with 5'- external probe

IV. WT allele $\left(\right.$ Vsig $\left.^{+}\right)$

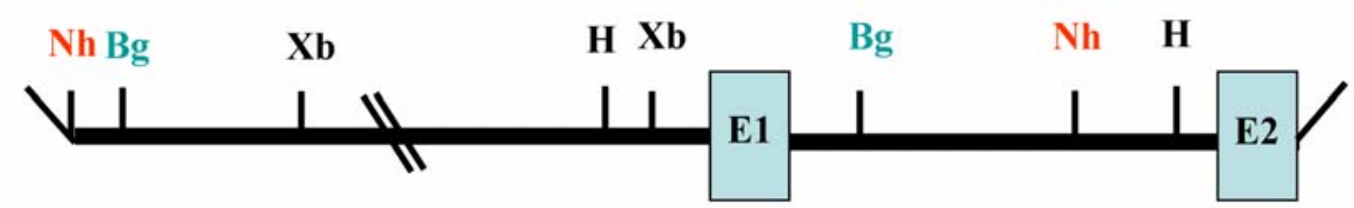

| 15-kb wt fragment (Nh)

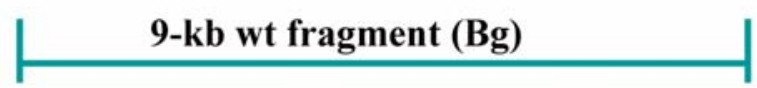

$\left.\underline{\text { V. Floxed allele (Vsig1 }}{ }^{\text {flox }}\right)$

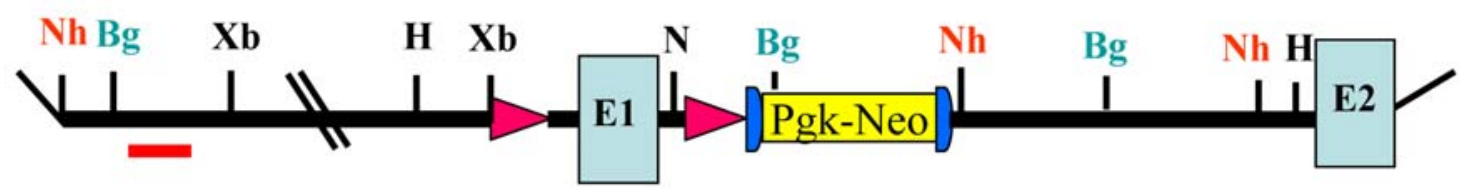

13.5-kb recombinant fragment $(\mathrm{Nh})$

7-kb recombinant fragment $(\mathrm{Bg})$

Figure 3.33 Schematic representation of Southern blot analysis of ES clones by using 3'-and 5'-external probes. Targeting vector is shown in illustration I. 
For screening with 3'-external probe, genomic DNA was digested with Hind3 (illustration II). In case of wild type allele, 3'-external probe recognizes a 7.5-kb fragment, and in case of floxed allele, the probe recognizes a 9-kb fragment (illustrations II, III). For verification by 5 '-external probe, the pre-identified clones were digested with NheI and BglI, respectively (illustration IV). By digestion with NheI, in case of wild type allele the $0.5-\mathrm{kb} 5$ '-external probe detects a $15-\mathrm{kb}$ fragment, and in case of floxed allele the probe detects a $13.5-\mathrm{kb}$ fragment (illustrations IV, V). By digestion with BglI, in case of wild type allele the 5'-external probe detects a 9-kb fragment, and in case of floxed allele the probe detects a 7-kb fragment (illustrations IV, V). Red triangular stands for loxP sites and blue half rounds stand for frt sites. The violet rectangular stands for Thymidine kinase cassette and the yellow rectangular stands for Neomycin cassette. The restriction site abbreviations are: Xb-XbaI; X-Xho; N-NotI; NhNheI; H-Hind3; Bg-BglI 

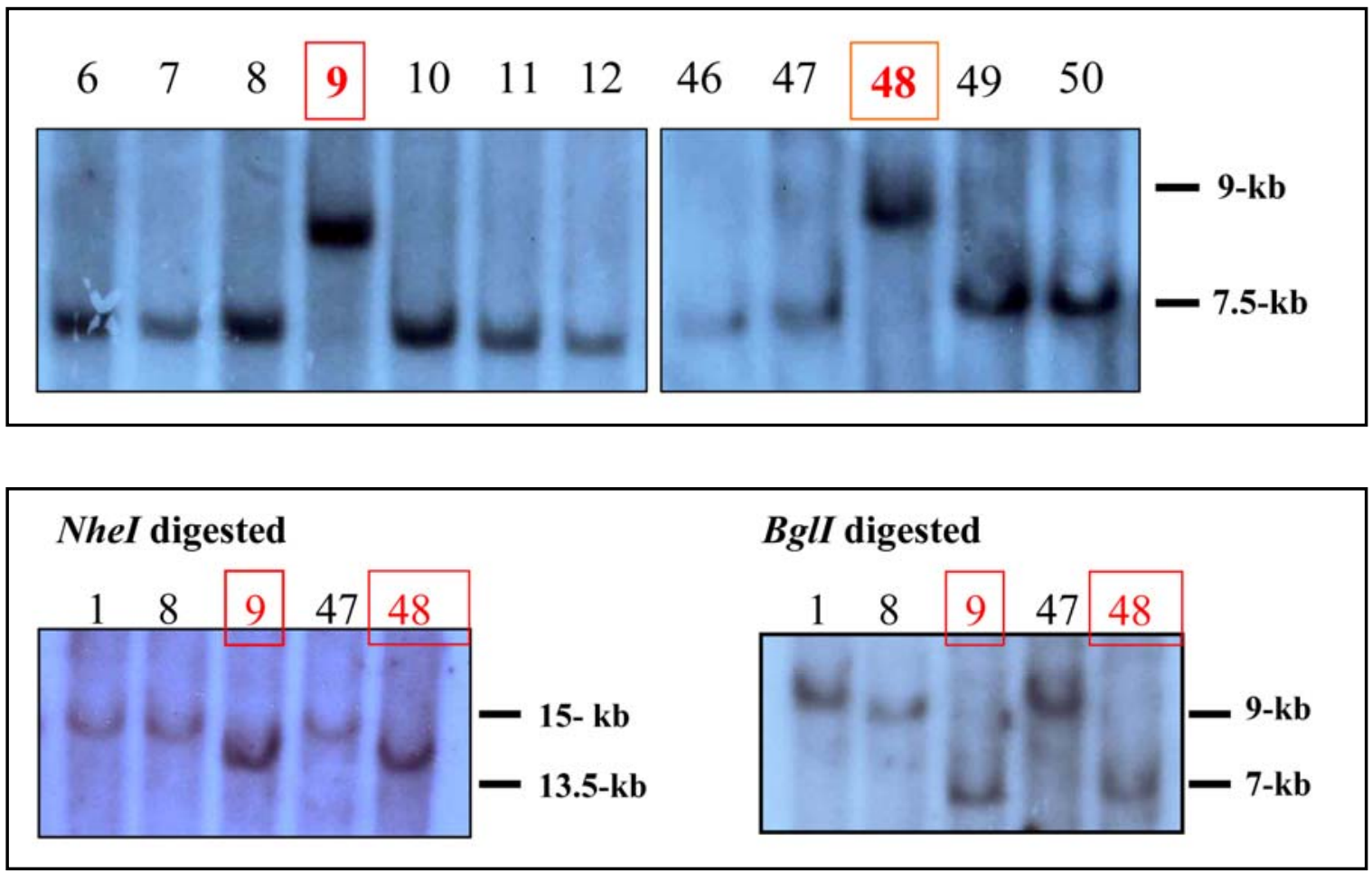

Figure 3.34 Southern blot analysis identified two recombinant ES cell clones using $3^{\prime}$ - and 5'- external probes. Clone 9 and clone 48 were found as recombinant clones by Southern blot screening with 3'-external probe, which detected a 9-kb fragment. The positive clones (clones 9 and 48) were verified by hybridization with 5'-external probe, which detected a $13.5-\mathrm{kb}$ recombinant fragment in case of NheI digestion and 7-kb recombinant fragment in case of BglI digestion, respectively (B).

\subsubsection{Generation and analysis of chimeric mice}

The recombinant ES cells of the clones 9 and 48 were injected into 3.5-dpc blastocysts derived from $\mathrm{C} 57 \mathrm{BL} / 6 \mathrm{~J}$ mice. The blastocysts were retransferred into pseudopregnant CD1 mice to generate the chimeric mice. This work was performed in the Max Planck Institute for experimental Medicine, Göttingen.

Injection of blastocysts with the recombinant ES cells gave totally 46 chimeras. According to the coat colour, the chimeric mice showed relatively high chimerism (ranged 10-15\%) were chosen for further experiments. 12 chimeras were bred with females and males of mouse strain C57BL/6J to generate F1 offspring (Table 3). 


\begin{tabular}{|c|c|c|c|}
\hline Line 9 & Date of Birth & Date of Breeding & Fertility \\
\hline CM-1 15\% & 28.10 .07 & 06.02 .2008 & infertile \\
\hline CM-2 $15 \%$ & 28.10 .07 & 06.02 .2008 & infertile \\
\hline CM-3 $15 \%$ & 28.10 .07 & 06.02 .2008 & fertile (only C57BL/6J) \\
\hline CM-4 15\% & 25.11 .07 & 06.02 .2008 & infertile \\
\hline CM-5 $15 \%$ & 25.11 .07 & 06.02 .2008 & infertile \\
\hline CM-6 $15 \%$ & 25.11 .07 & 06.02 .2008 & infertile \\
\hline CM-7 $10 \%$ & 25.11 .07 & 06.02 .2008 & fertile (only C57BL/6J) \\
\hline Line-48 & date of birth & date of breeding & Fertility \\
\hline CM-8 $15 \%$ & 06.02 .08 & 06.02 .2008 & infertile \\
\hline CM-9 $10 \%$ & 06.02 .08 & 06.02 .2008 & infertile \\
\hline CM-10 15\% & 12.02 .08 & 06.02 .2008 & infertile \\
\hline CM-11 15\% & 12.02 .08 & 06.02 .2008 & fertile (only $\mathrm{C} 57 \mathrm{BL} / 6 \mathrm{~J}$ ) \\
\hline CM-12 20\% (f) & 19.02 .08 & 06.02 .2008 & infertile \\
\hline
\end{tabular}

Table 3 Chimeric mice derived from line- 9 and line-48. From line-9, only two mice (CM-3, 15\% and CM-7, 10\%) gave offspring, which were all of C57BL/6J background. From line-48, only one mouse (CM-11, 15\%) gave offspring, which were also all C57BL/6J background. Rest of 9 ( 8 males and 1 female) mice from both lines were infertile. From these 8 infertile male mice, 5 mice had small testes, and 3 mice had normal sized testes.

\subsubsection{Analysis of the fertility of $\mathrm{Vsig}^{\text {flox }} / \mathrm{Y}$ chimeras}

Breeding of the $V \operatorname{sig} 1^{\text {flox }} / Y$ male chimeras with wild type females revealed that 9 of 12 chimeras $(75 \%)$ were completely infertile over 4 months of breeding. All offspring of the 3 fertile chimeric males had black coat. The infertile chimeras generated postcoital vaginal plugs in females, indicating that the infertile chimeras were capable of mating. To investigate the reproductive defects in infertile chimeric mice, testis and sperm were isolated from 8 infertile males. Anatomical examination revealed that Wolffian duct 
derivatives had differentiated normally into vas deferens, epididymis and accessory glands and testes were normally descended and no Mullerian duct derivatives were present. However, testes were significantly smaller in 5 chimeric males in comparison to wild type male mice. The other three chimeras had testes with normal size (Fig. 3.35).
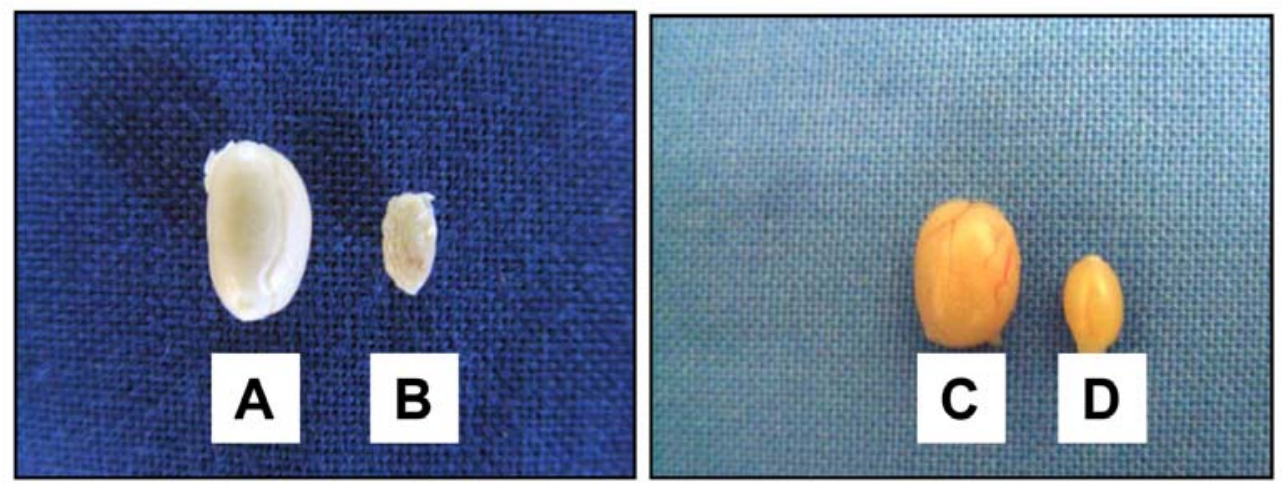

Figure 3.35 Phenotypic alteration of testes from chimeric mice. The testis B and D isolated from chimeric mice show significantly smaller size in comparison to the normal sized testes $\mathrm{A}$ and $\mathrm{C}$ isolated from other chimeric mice. All of the testes were isolated at 8 months of age.

Spermatozoa were collected from the cauda epididymis of chimeric mice with small testes (CM-1 in Table 4) and chimeric mice with normal testis (CM-2 in Table 4) and analyzed. The sperm number in epididymis of chimera CM-1 was significantly lower than that of wild type mice. Ratio of sperm with abnormal morphology was higher in CM-1 chimera. No differences in sperm number and morphology were found between CM-2 chimera and wild type. Sperm motility was analyzed by CEROS computer assisted semen analysis system. Results of these analysis revealed that the sperm motility of chimeras $\mathrm{CH}-1$ and $\mathrm{CH}-2$ was significantly slower than sperm of wild type. The main motility parameters VAP, VCL, and VSL were significantly impaired in both chimeric mice (Fig. 3.36). 


\begin{tabular}{|c|c|c|c|}
\hline Mice & $\begin{array}{c}\text { No of sperm in } \\
\text { cauda } \\
\text { epididymis } \\
\left(\mathbf{1 0}^{6}\right)\end{array}$ & $\begin{array}{c}\text { Mean } \\
\text { sperm } \\
\text { motility } \\
(\%)\end{array}$ & $\begin{array}{c}\text { No of } \\
\text { abnormal } \\
\text { sperm } \\
(\%)\end{array}$ \\
\hline $\begin{array}{c}\text { Control } \\
\text { WT }\end{array}$ & 1.5 & 58.6 & 2.4 \\
\hline CM-1 & 0.41 & 14.3 & 18.8 \\
\hline CM-2 & 1.08 & 51.3 & 3.5 \\
\hline
\end{tabular}

Table 4 Sperm parameter analysis for chimeric and wild type control mice.

The sperm from CM-1 chimeric mouse showed significantly different parametric values featuring reduced number of sperm, high level of abnormal spermatozoa and reduced motility.

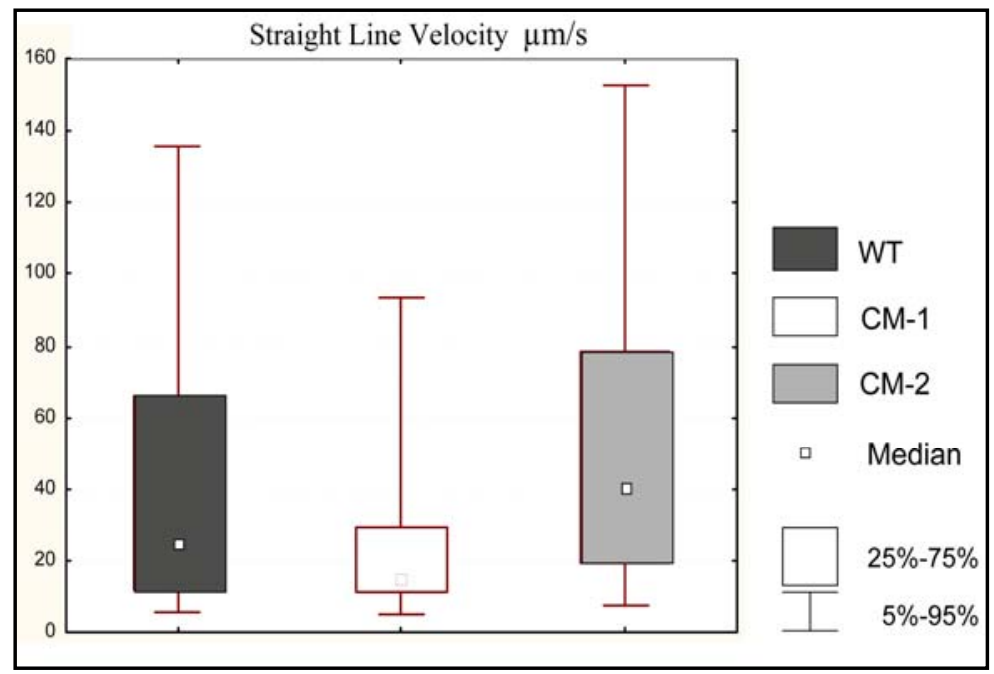

Figure 3.36 Quantified sperm motility by computer-assisted sperm analysis. Sperm of infertile chimeric mice -1 (CM-1) showed strongly reduced VSL (Straight Line Velocity) in comparison to spermatozoa of wild-type control mouse.

Examination of histological sections from both chimeras revealed that the testes of the chimeric mouse CM-1 had a range of unusual seminiferous tubule phenotypes that were not seen in controls. Testis of CM-1 chimera revealed a mixed atrophy type of damage showing seminiferous tubules with almost complete loss of spermatogenic cells (about 95\% of all tubules), other tubules with arrested spermatogenesis at primary spermatocytes and 
spermatids (Fig. 3.37A, B) . Tubules contained vacuoles and aggregates of cells accumulated in the lumen of tubules (Fig. 37C, D). Interestingly, the seminiferous tubules contained multilayered pretubular cells (2-3 layer) (Fig. 3.37C, D). Histological analysis of testes with normal size from infertile chimera (CM-2) showed normal spermatogenesis in all seminiferous tubules (Fig. 3.37E, F).
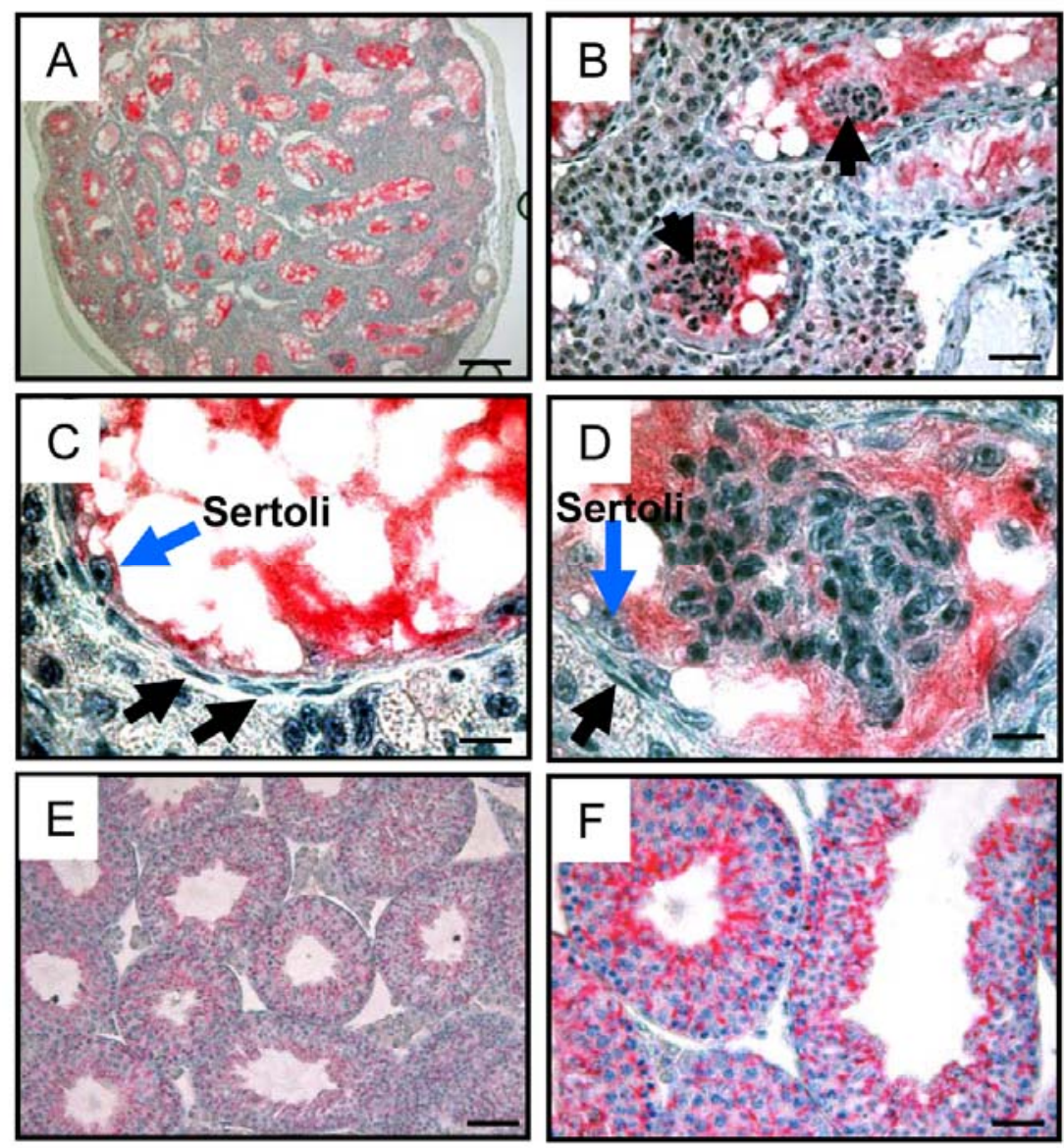

Figure 3.37 Histological analysis of testes of 8 months old infertile mice. Immunostainig with anti-VSIG1 antibody was counterstained with hematoxylin to visualize nuclei. The testes isolated from CM-1 show abnormality of histological structure featuring high proportion of interstitial cell population and degenerated seminiferous tubules with severe germ cell sloughing (A, B), vacuolated space (C), compact aggregated cells (D) in the lumen. Black arrows indicate the compactly aggregated cells in tubules (A, B) and multilayered pretubular cells (D). The blue arrows indicate the remaining Sertoli cells in degenerated tubules $(\mathrm{C}, \mathrm{D})$. The testes isolated from CM-2 show normal histological structure (E, F). Optical magnifications: $4 X$ in $A$; $10 X$ in $E ; 20 X$ in $B, F, 60 X$ in $C, D$. 
To investigate whether the testes of CM-1 has different types of germ cells, immunohistochemical analysis with anti-GCNA and anti-Apglantibody was performed. The nuclear GCNA protein is expressed in spermatogonia and primary spermatocytes, while the Apg1 is highly expressed in pachytene spermatocytes and spermatids. Results of this analysis demonstrated that anti-GCNA antibody stained the spermatogonia and primary spermatocytes, which are localized in 5\% of seminiferous tubules of chimeric testes of CM-1 (Fig. 3.38A, B). Similar results were also observed by immunostaining with anti-Apg1 antibody. Apg1-positive cells were only observed in 5\% of tubules (Fig. 3.38D, E). In contrast, no GCNA- and Apg1-positive germ cells were found in 95\% of the tubules of CM-1 chimeric testes (Fig. 3.38C, F).

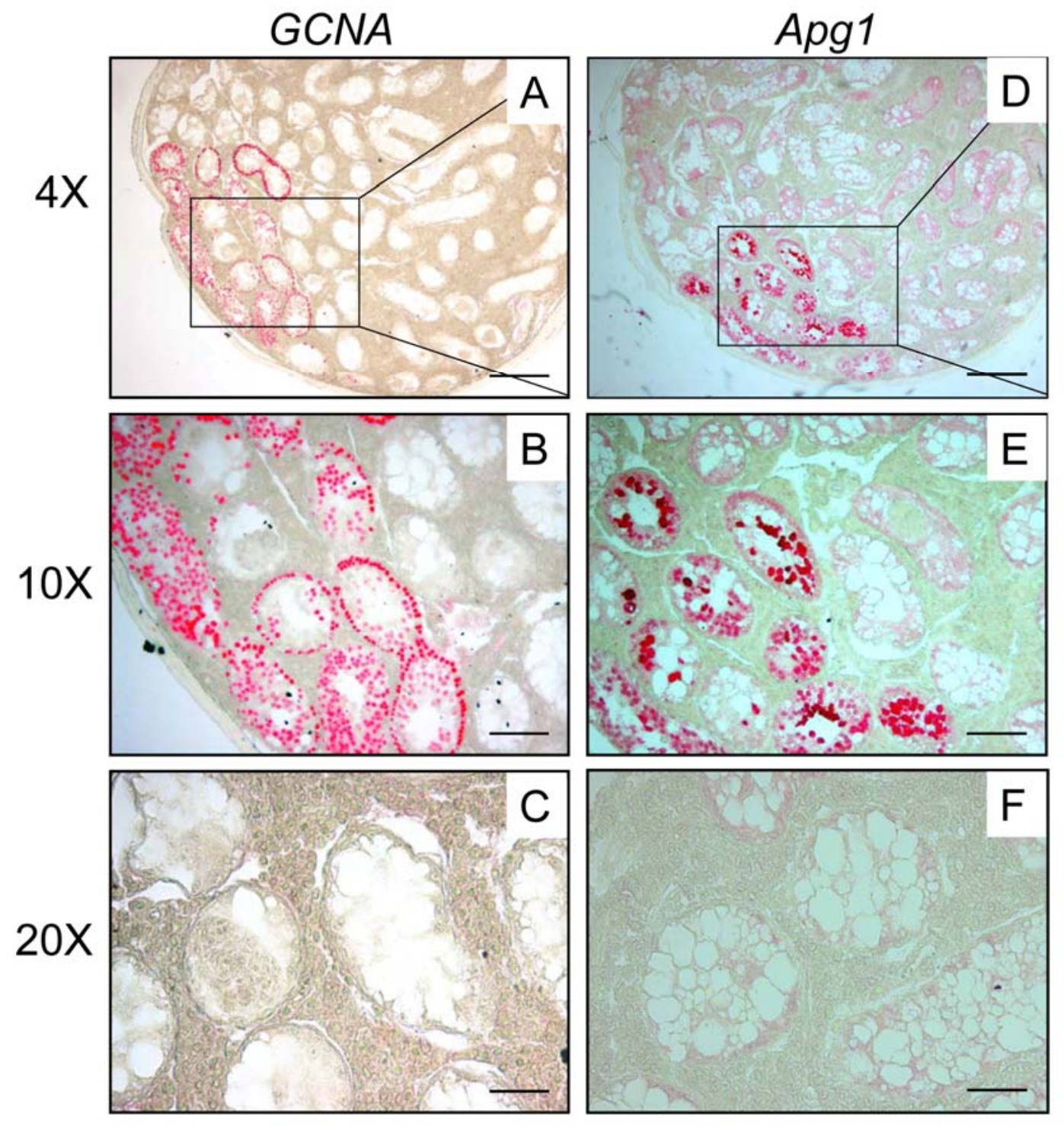

Figure 3.38 Impaired spermatogenesis in testes of CM-1 chimera. The immunostaining was performed with anti-GCNA antibody, which stains 
spermatogonia, primary spermatocytes, and anti-Apg1 antibody, which stains pachytene spermatocytes and post meiotic spermatids. The entire testis contains only a few number of seminiferous tubules, which have spermatogenic cells stained with GCNA and Apg1 (A, B, D, E). The morphologically altered tubules (95\%) contain only Sertoli cells, which are not stained with anti-GCNA (C) and anti-Apg1 (F). Optical magnifications: $4 X$ in A, D; 10X in B, E; 20X in C, F.

To determine the expression of Vsig1 in testis of chimeric mice, histological sections of testes from wild type, CM-1 and CM-2 chimeras were probed with anti-VSIG1 antibody. In seminiferous tubules of wild type testis, VSIG1 become confined to adhesion junctions between Sertoli-Sertoli (SSJ) and Sertoli-germ cell junctions (SGJ) (Fig. 3.39A). In small testes of CM-1 chimera, VSIG1 was found to be localized at the plasma membrane and in cytoplasm of Sertoli cells and also abundantly found in cellular materials of degenerated germ cells in the vacuolated tubules (Fig. 3.39B, C). No specific VSIG1 could be detected in aggregated cells, which are localized in the lumen of the vacuolated tubules (Fig. 3.39D). In testes with normal size of CM-2 chimera, VSIG1 is localized on the adhesion junctions of SSJ (Sertoli-Sertoli junction) and SGJ (Sertoli-germ cells junction) similar like that shown in wild type testis (Fig. 3.39F). Interestingly, in few tubules of CM-2 testis, VSIG1 is accumulated in the nucleus of round spermatocytes (Fig. 3.39G, H). 

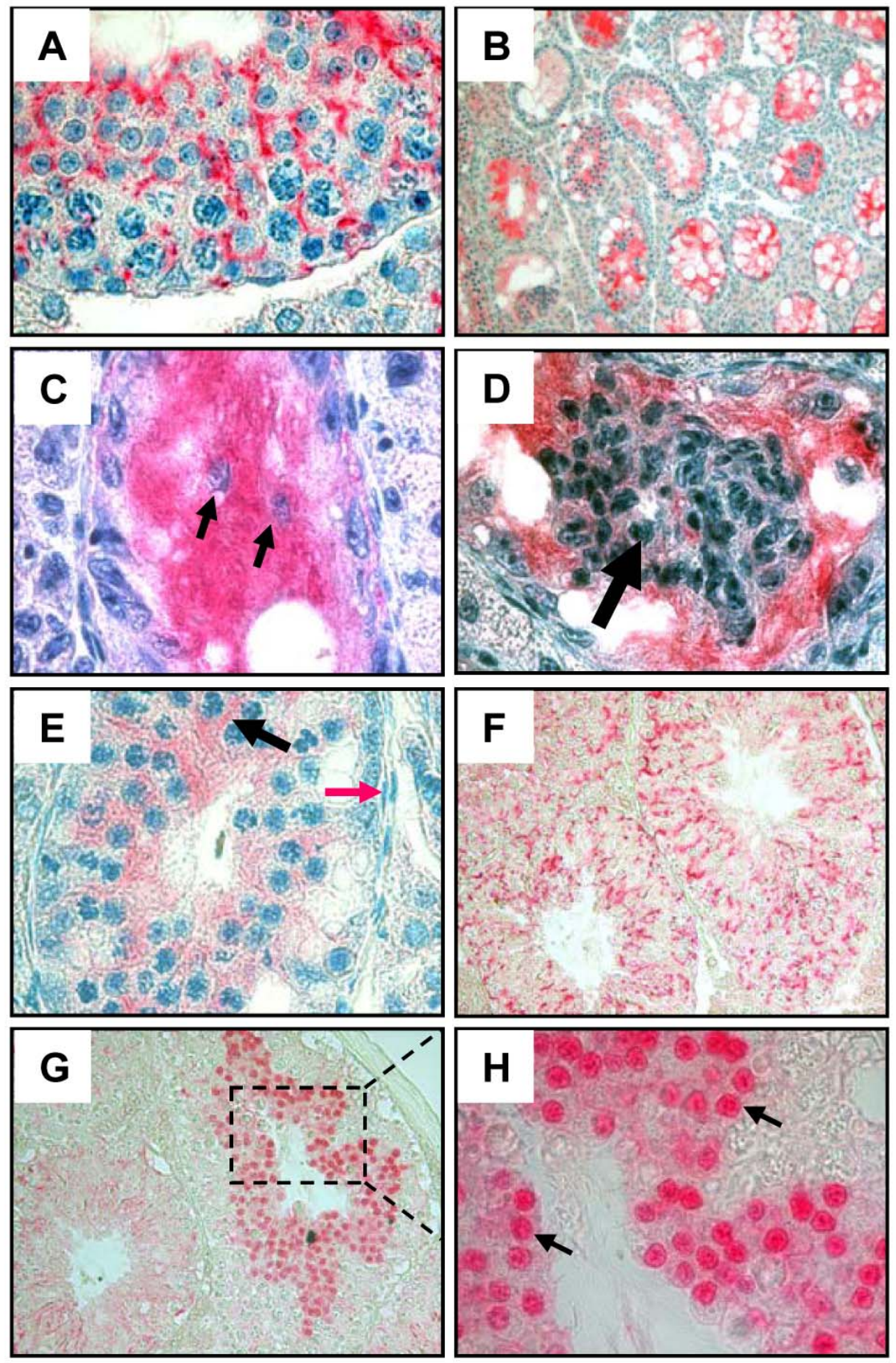

Figure 3.39 Immunohistological studies with VSIG1 antibody on CM-1 and

CM-2 testes. Immunostaining with VSIG1 antibody detects VSIG1 protein in junctions between SSJ (Sertoli-Sertoli junctions) and SGJ (Sertoli-germ cell junctions) in wild type testis (A). In small testis from CM-1, VSIG1 is localized in Sertoli cells in vacuolated tubules and also in cellular materials of degenerated germ cells (C), no specific signal could be detected in aggregated cells (indicated by black arrow) in the lumen (D). VSIG1 is detected in SSJ and SGJ in tubules with germ cells (E) Testis with normal size from CM-2 has specific staining with VSIG1 in SSJ and SGJ, similar to wild type testis $(\mathrm{F})$. But some tubules of CM-2 
testis have staining in the nuclei of round spermatocytes $(\mathrm{G}, \mathrm{H})$. Optical magnifications: $10 X$ in $B ; 20 X$ in $G, F, 60 X$ in $A, C, D, E, H$.

To determine the contribution of $V s i g 1^{\text {flox }} / Y$ cells in testes of chimeric mice CM-1 and CM2, we have performed a PCR assay based on microsatellite polymorphisms to evaluate the contribution of $129 / \mathrm{Sv}$ and C57BL/6J. As shown in figure 3.40, the ratio of $\operatorname{Vsig} 1^{\text {flox }} / Y$ cells as judged by the level of the amplified 129/Sv-specific fragment was higher than that of C57BL/6J-specific fragment in testis of both chimeras. These results suggest that the $V \operatorname{sig} 1^{\text {flox }} / Y$ cells are highly contributing in testis of infertile chimeras CM-1 and CM-2.

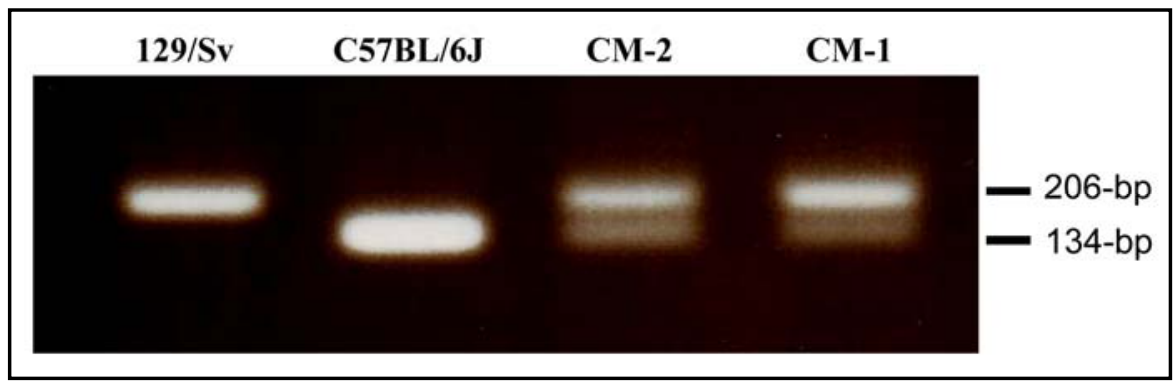

Figure 3.40 129/Sv cells are highly contributing in testicular development of chimeric mice (CM-1 and CM-2). Genomic DNA from wild type 129/Sv and C57BL/6J served as positive control. Strain specific PCR amplifies a 134-bp product in case of C57BL/6J background, and a 206-bp product in case of 129/Sv background.

\subsubsection{Expression analysis of Vsig1 in stomach of $V \operatorname{sig} 1^{\text {flox }} / Y$ chimeric mouse}

To determine whether the $V s i g 1^{\text {flox }} / Y$ allele disrupts the stomach development of chimeric mice CM-1 and CM-2, histological sections were stained with H\&E and VSIG1 antibody. Analysis of serial sections with H\&E revealed normal development of glandular epithelium in stomach of CM-1 (Fig. 3.41A, B) and CM-2 chimeras (Fig. 3.41C, D). The immunohistological analysis revealed that the Vsig1 is expressed in cells of glandular epithelium of both chimeric mice (Fig. 3.41). These results suggest that the contribution of $\operatorname{Vsig}^{\text {flox }} / Y$ cells do not disrupts the cytodifferentation of glandular epithelium. 


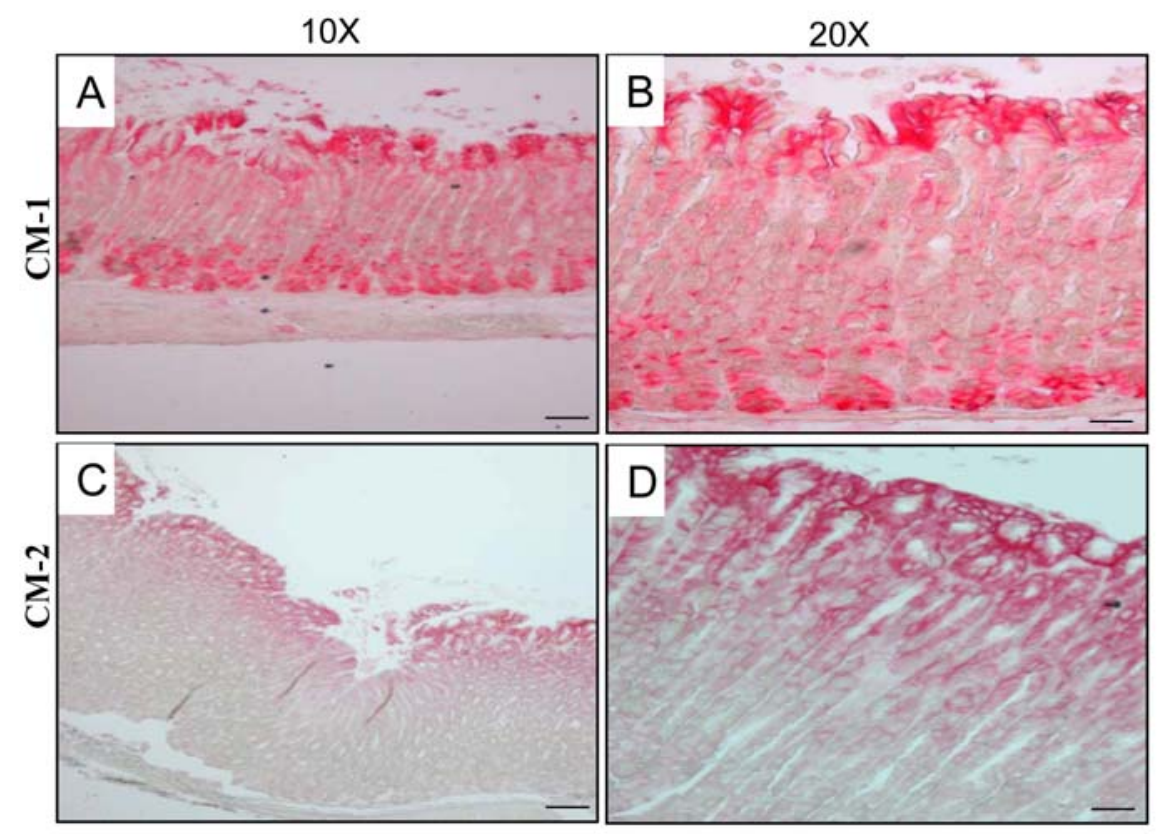

Figure 3.41 VSIG1-negative regions were not found in glandular epithelium of conditional chimeric mice stomachs. Immunostaining was performed with anti-VSIG1 antibody on serial sections of stomachs from chimeric mice CM-1 (A, B) and CM-2 (C, D). Optical magnifications: $10 X$ in A, C; $20 X$ in B, D.

\subsubsection{Deletion of Pgk-Neo cassette in $V s i g 1^{f l o x} / Y$ ES cell}

The low chimerism in the generated $V s i g 1^{+} / Y-V \operatorname{sig} 1^{\text {flox }} / Y$ chimeras lead us to suggest that the high contribution of the $V s i g^{\text {flox }} Y$ cells also impairs the embryonic development of chimeric mice. Several lines of evidence (Nagy et al., 1998) reveal that the insertion of Pgk-Neo cassette into an intron region of a gene can impair expression of floxed allele or lead to misexpression of neighboring genes. To avoid such an effect, the frt-flanked PgkNeo cassette was deleted in Vsig1 $1^{l o x} / Y$ ES cells by Flp recombinase-mediated vector (Fig. $3.42 \mathrm{~A}, \mathrm{~B}) . V \operatorname{sig} 1^{+} / Y$ cells of clone 9 and 48 were transient transfected with the pCAGGFlp vector which contains Flp recombinase under the control of $\beta$-actin promoter and puromycin resistant gene (Fig. 3.42C). After two days of selection with puromycin, cells were cultured for further 5 days with non selective medium. Single puromycin-resistant clones were treated with trypsin. Each clone was further cultured in replica with and without G-418 antibiotic. G-418-sensitive clones were selected and further analyzed for the deletion of the Pgk-Neo cassette. One (48-6) and three (9-4, 9-6 and 9-40) clones from transfection assays of ES-48 and ES-9 cells were identified by Southern blot and PCR analysis. 

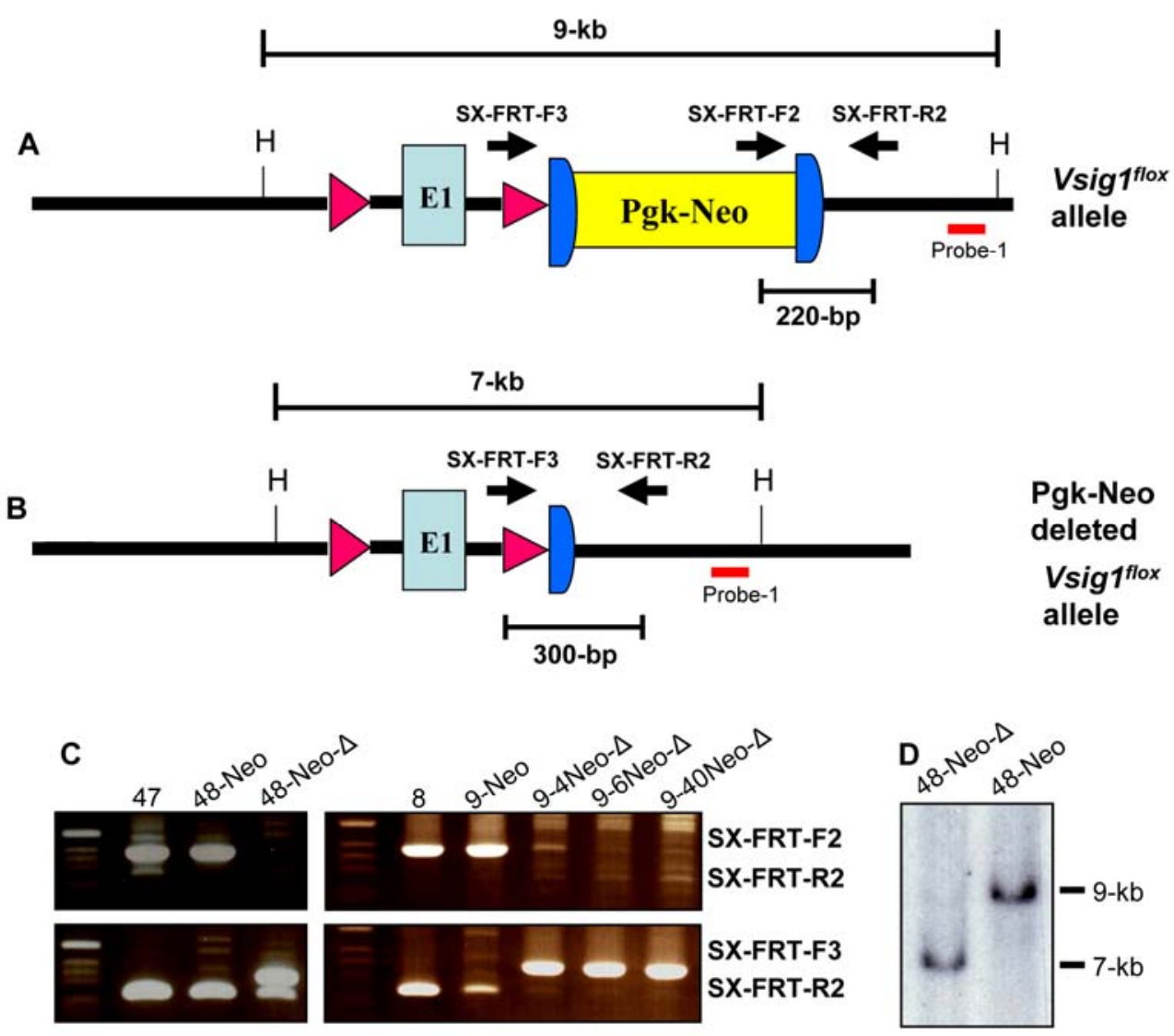

Figure 3.42 Deletion of Pgk-Neo cassette in Vsig1 ${ }^{l o x} / Y$ ES-cells. Schematic illlustration of floxed allele of Vsig1 with insertion of Pgk-Neo cassette in intron1 (A) Primers SX-FRT-F2 and SX-FRT-R2 amplified a 220-bp fragment which is overlapping with Neo and intron-1 sequence (A). After deletion of Pgk-Neo cassette, primers SX-FRT-F3 and SX-FRT-R2 are able to amplify a 300-bp intron fragment containing 34-bp Frt sequence. Southern blot analysis with 3'external fragment (indicated by red rectangular in A, B) revealed that Pgk-Neo cassette deletion in clone $48-\mathrm{Neo}-\Delta$ causes the reduction of the size of $9-\mathrm{kb}$ HindIII fragment to 7-kb (D). According to the illustration (A, B), PCR analysis revealed that Pgk-Neo cassette was deleted in $48-\mathrm{Neo}-\Delta, 9-4 \mathrm{Neo}-\Delta, 9-6 \mathrm{Neo}-\Delta$ and 9-40Neo- $\Delta$ clones (C). 
To confirm the correct recombination of the frt-flanked Pgk-Neo cassette, Southern blot with HindIII-digested DNA of clone 48-Neo and $48-\mathrm{Neo}^{\Delta}$ was hybridized with 3 '-external probe (probe-1 in Fig. 3.42A). As expected for correct recombination (Fig. 3.42 A, B), the external probe detected a 19-kb fragment of the Vsig1 $1^{\text {flox }}$ allele in DNA of clone $48-\mathrm{Neo}$ and a 7-kb fragment of Pgk-Neo recombinant allele in DNA of clone 48-Neo ${ }^{\Delta}$ (Fig. 3.42D) The cells of clones $48-\mathrm{Neo}^{\Delta}$ and $6-4-\mathrm{Neo}^{\Delta}$ were used for generation of chimeric mice. From 37 born mice, 9 chimeric mice were found. The chimerism of chimeras ranged between $5 \%-20 \%$. Breeding of 5 male chimeras (10-20\%) with females of mouse strain C57BL/6J showed that 2 chimeric males were fertile and sired only offspring with black coat. Other 3 chimeras were infertile over 2 months of breeding. These 3 chimeras are still in breeding till now.

\subsection{Generation and characterization of Vsig1-EGFP transgenic mice}

Expression analyses of Vsig1 demonstrate that Vsig1 gene expression begins in early embryonic stages of stomach development. This result suggests that Vsig1 gene could have crucial role for proliferation and differentiation of stomach epithelial cell. To make detailed analysis of Vsig1 expression and to isolate and characterize the Vsig1 expressing cells, we have generated a transgenic mouse model, in which the EGFP is expressed under the control of a 4.8-kb Vsig1 promoter region.

\subsubsection{Creation of the transgenic construct}

For construction of Vsig1-EGFP transgenic vector, pEGFP-1 vector was used. pEGFP-1 encodes a red shifted variant of enhanced green fluorescence protein (EGFP), which contains the double amino acid substitution of Phe-64 to Leu and Ser-65 to Thr. This mutant type of GFP is optimized for brighter fluorescence and higher expression in mammalian cells. (excitation maximum $=488 \mathrm{~nm}$ : emission maximum $=507 \mathrm{~nm}$ ). The vector contains Kozak consensus sequence between multi-cloning site and ATG of EGFP and also a 235-bp long SV40 polyadenylation signal after translation stop codon of EGFP. The 4.5-kb Xbal fragment containing the upstream sequence of exon-1 was isolated from the cosmid clone (MPMGc121B114407Q2, RZPD) and cloned into the XbaIdigested pBluescrip-SK(+) vector (clone-1). The 350-bp genomic fragment between the 4.5-kb XbaI fragment and translation start codon ATG of exon-1 was amplified by PCR 
using forward primer SX-EGFP-F2 and reverse primer SX-EGFP-R2. The forward and reverse primers contain the sequences of restriction sites of NotI and SstII, respectively. The PCR product was cloned into pGEMT-easy vector and sequenced (clone-2). Correct sequenced $350-$ bp fragment was isolated from clone-2 by digestion with NotI/SstII and subcloned into NotI/SstII digested clone-1 to produce clone-3. The 4.8-kb fragment was isolated from clone-3 by digestion with SalI/SstII and subcloned into the SalI/SstII digested pEGFP-1 vector (clone-4).

The final transgenic construct was checked by digestion with several restriction digestions and linearized with Pvu1 restriction site located on the backbone of pEGFP-1 vector. The fragment containing the Vsig1-EGFP transgenic allele was purified from ethidium bromide free agarose gel by using QIAEX-II gel extraction kit. The purified DNA fragment was dissolved in TE-buffer and sent to the Max-Plank-Institute for experimental Medicine (Göttingen) for pronuclear microinjections into fertilized mouse oocytes.

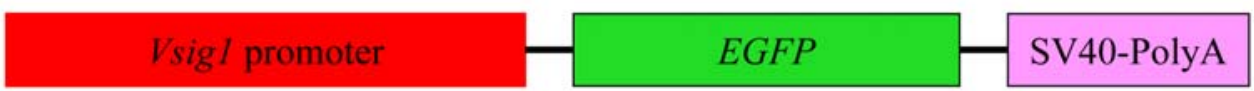

Figure 3.43 Schematic representation of the transgenic construct. The Vsig1EGFP construct contains the coding region of the EGFP gene (cDNA) under the control of a 4.8-kb Vsig1 promoter and SV40 polyadenylation signal (SV40).

\subsubsection{Transmission and expression analysis of the Vsig1-EGFP transgene}

After the transgenic constructs were microinjected into male pronuclei, the oocytes were transferred into the uteri of foster mothers. The founder mice were then screened for the presence of the transgene after 3 weeks of age by extraction of the genomic DNA from their tail biopsies. PCR analysis was performed using the primers SX-EGFP-RT-F1 and SX-EGFP-RT-R1 (Fig. 3.44).

Out of the 58 founders, 5 founders (around 8.9\%) were found to contain the integration of the transgene in the genome. The 5 founders were then bred with WT mice of FVB/N strain to check for transmission of the transgene in the F1 generation. Four of the founders (Lines Nr. 17, 46, 52 and 56) were found to transmit the transgene to their offspring. The average litter size of the Vsig1-EGFP founder breedings was around 10.6. 


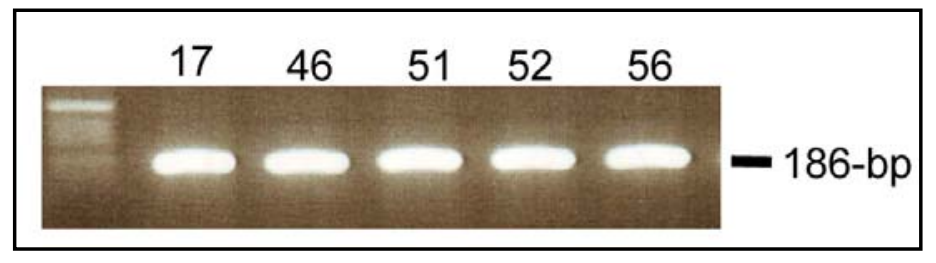

Figure 3.44 Genotyping PCR for Vsig1-EGFP transgenesis. Founders \#17, \#46, \#51, \#52 and \#56 were detected as Vsig1-EGFP positive founder mice by the genotyping PCR. PCR was carried out with primers SX-EGFP-RT-F1 and SX-EGFP-RT-R1 in following cycle temperature: $35 \mathrm{x}\left(94^{\circ} \mathrm{C}-30 \mathrm{~s} \_58^{\circ} \mathrm{C}-\right.$ $\left.30 \mathrm{~s} \_72^{\circ} \mathrm{C}-30 \mathrm{~s}\right)$.

From each transgenic line, one animal in F1 generation was sacrificed and used to track the GFP expression in whole mount tissues. Using fluorescence microscopy, strong GFP fluorescence was observed in the corpus region of stomach. The GFP fluorescence was restricted to spots in glandular region (Fig. 3.45) No other tissues including testis exhibited any GFP fluorescence. Such GFP fluorescence could not be detected in stomach of line \#17. Therefore, the transgenic line \#17 was eliminated. We have also examined the expression of EGFP in embryonic tissues at E17.5. GFP fluorescence was detected in stomach. These GFP signals were restricted to the corpus and antrum regions (Fig. 3.45).
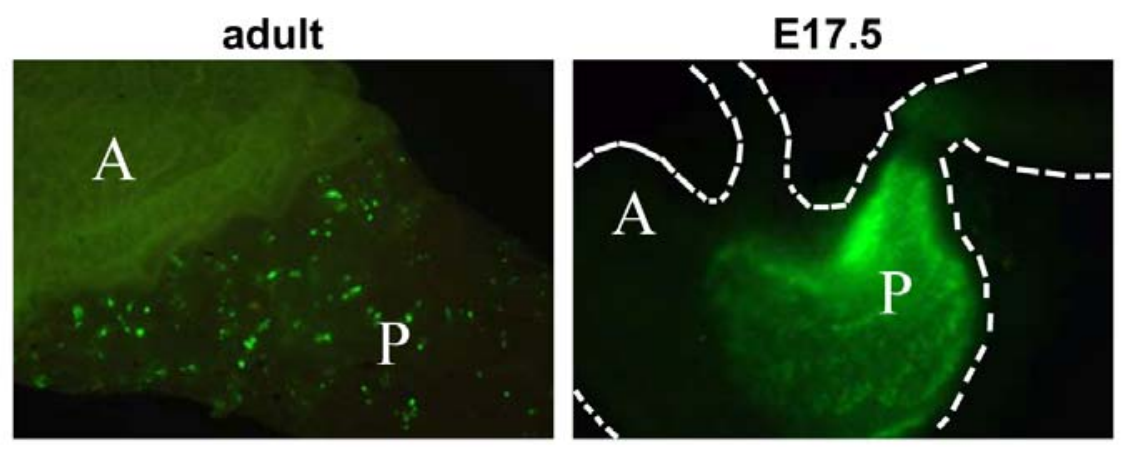

Figure 3.45 Direct GFP fluorescence from whole mount stomachs. Stomachs from adult stage and E17.5 were examined for direct GFP fluorescence. GFPpositive cells are distributed as spots in glandular epithelium of posterior stomach (P) of the adult mouse, and no GFP-positive cells were detected in anterior stomach (A). In case of E17.5, GFP-positive cells are distributed as denser in posterior stomach. Optical magnification: $4 X$ 
To check the level of transgenic expression in lines \#46, \#52 and \#56, total RNA was extracted from stomach and testes of transgenic animals of each line and subjected to Northern blot analysis. A 780-bp fragment of EGFP cDNA was isolated from pEGFP-1 vector by digestion with SmaI and BglI restriction enzymes and used as probe in the Northern blot hybridization.

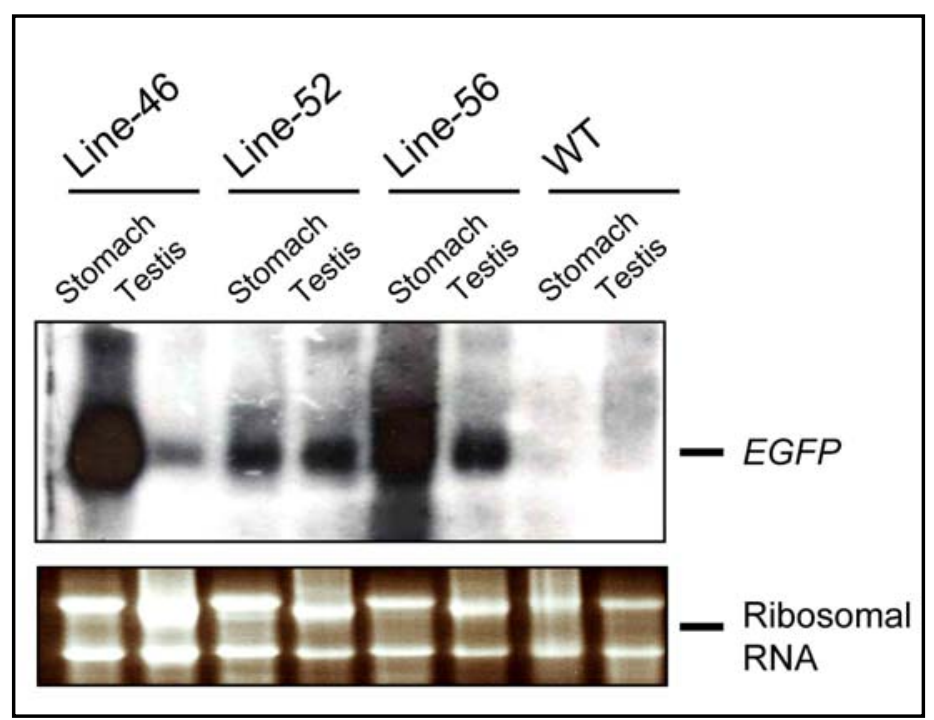

Figure 3.46 Transgenic expression is higher in line \#46 and line \#56 than in line\#51. Total RNA was extracted from stomach and testis from each transgenic line. RNAs from wild-type animals were loaded as negative control. Gel documentation picture displaying the $28 \mathrm{~s}$ and $18 \mathrm{~s}$ ribosomal RNAs indicates the integrity and equal loading of RNA.

Northern blot analysis demonstrated that the Vsig1-EGFP transgenic allele is highly expressed in stomach and testis of lines \#46 and \#56, while the expression was lower in line \#51. Extracted RNA from wild-type stomach and testis was used as negative control. (Fig. 3.46).

\subsubsection{Determination of number of integration sites in the genomes of transgenic lines}

Quantification of the integrated transgene in the genome of lines \#46 and \#56 was determined by Real-Time PCR analysis using the primers SX-EGFP-RT-F1 and SX-EGFPRT-R1 based on the segregation pattern of transgene through the offspring. DNA from the founders and their 10 positive offspring in F1 generation were subjected to the PCR assay. 
The DNA copies of the transgene as judged by level of amplified fragment were normalized to DNA copies of mouse Pelota gene. Analysis of Real-Time PCR results revealed that there is no statistically significant deviation in the line of normalized values (Table 5). This result indicates that the Vsig1-EGFP transgenic allele is not segregating through the offspring and only one integration site of the transgenic allele was in the genome of line\#56.

\begin{tabular}{|c|c|c|c|c|c|c|}
\hline \multirow{2}{*}{$\begin{array}{c}\text { Animals from } \\
\text { Line-56 }\end{array}$} & \multirow{2}{*}{ Alleles } & \multicolumn{3}{|c|}{ CT values } & \multirow{2}{*}{$\begin{array}{l}\text { Mean et } \\
\text { values }\end{array}$} & \multirow{2}{*}{$\begin{array}{c}\text { Normalization } \\
\text { values }\end{array}$} \\
\hline & & $25 \mathrm{ng}$ & $12.5 \mathrm{ng}$ & $6,25 \mathrm{ng}$ & & \\
\hline \multirow{2}{*}{ Founder } & Vsigl-EGFP & 16,18 & 16,96 & 17,84 & 16.99 & \multirow{2}{*}{0,819} \\
\hline & Pelota & 19,75 & 20,81 & 21,63 & 20.73 & \\
\hline \multirow[t]{2}{*}{ Offspring No 1} & Vsigl-EGFP & 16,69 & 17,27 & 18,33 & 17,43 & \multirow{2}{*}{0,813} \\
\hline & Pelota & 20,67 & 21,31 & 22,3 & 21,42 & \\
\hline \multirow{2}{*}{ Offspring No 7} & Vsig1-EGFP & 16,94 & 17,5 & 18,34 & 17.59 & \multirow{2}{*}{0,817} \\
\hline & Pelota & 20,69 & 21,34 & 22,51 & 21,51 & \\
\hline \multirow[t]{2}{*}{ Offspring No 8} & Vsigl-EGFP & 16,53 & 17,22 & 18,19 & 17,31 & \multirow{2}{*}{0,809} \\
\hline & Pelota & 20,09 & 21,59 & 22,46 & 21,38 & \\
\hline \multirow{2}{*}{ Offspring No 10} & Vsig1-EGFP & 16,82 & 17,64 & 18,51 & 17,65 & \multirow{2}{*}{0,816} \\
\hline & Pelota & 20,85 & 21,46 & 22,54 & 21,61 & \\
\hline \multirow{2}{*}{ Offspring No 11} & Vsig1-EGFP & 16,4 & 17,09 & 17,91 & 17,13 & \multirow{2}{*}{0,829} \\
\hline & Pelota & 19,77 & 20,53 & 21,7 & 20,66 & \\
\hline \multirow[t]{2}{*}{ Offspring No 49} & Vsigl-EGFP & 16,11 & 16,81 & 17,73 & 16,88 & \multirow{2}{*}{0,821} \\
\hline & Pelota & 19,63 & 20,44 & 21,58 & 20,55 & \\
\hline \multirow[t]{2}{*}{ Offspring No 50} & Vsigl-EGFP & 16,04 & 16,85 & 17,69 & 16,86 & \multirow{2}{*}{0.81} \\
\hline & Pelota & 20,15 & 20,71 & 21,55 & 20,8 & \\
\hline \multirow[t]{2}{*}{ Offspring No 53} & Vsigl-EGFP & 15,78 & 16,36 & 17,41 & 16,51 & \multirow{2}{*}{0.796} \\
\hline & Pelota & 19,9 & 20,78 & 21,54 & 20,74 & \\
\hline \multirow{2}{*}{ Offspring No 84} & Vsigl-EGFP & 15,17 & 15,89 & 16,65 & 15,9 & \multirow{2}{*}{0,824} \\
\hline & Pelota & 18,66 & 19,17 & 20,06 & 19,29 & \\
\hline \multirow[t]{2}{*}{ Offspring No 86} & Vsig1-EGFP & 15,92 & 16,43 & 17,21 & 16.52 & \multirow{2}{*}{0,803} \\
\hline & Pelota & 19,83 & 20,65 & 21,19 & 20,55 & \\
\hline
\end{tabular}

Table 5. Transgenic allele segregation analysis by Real Time PCR for line \#56.

The founder and 10 positive offspring from F1 generation were subjected for segregation analysis. For each animal, three serially diluted genomic DNA samples (25 ng, $12.5 \mathrm{ng}$ and $6.25 \mathrm{ng}$ ) were employed for Real Time PCR and the mean values were identified, respectively. The each normalization value was obtained by comparing of mean "ct" value of transgenic allele to mean "ct" value of endogenous Pelota allele.

To establish homozygous transgenic mice, 8 transgenic males and 7 transgenic females of F2 generation of line \#56 were intercrossed with wild-type animals and the offspring were genotyped by PCR. All offsprings from two males and one female parents were transgenic. These results suggest that the transgenic parents were homozygous for the transgenic allele. 
These homozygous parents were then intercrossed to establish the homozygous transgenic line.

\subsubsection{Measurement of ratio of GFP-positive cells in transgenic stomach at different developmental stages}

The transgenic mice could be used to identify and track Vsig1-EGFP cells, and especially can have an extended feasibility of separation of Vsig1-EGFP cells from other cell types by FACS (Fluorescence Activated Cell Sorting).

Stomach tissues from transgenic animals at E13.5, E15.5, E18.5, P0.5, P3.5, P10.5, P20.5 and P90 were enzymatically dissociated by collagenase and dispase as described in Materials and Methods section (2.2.17). In case of stomach from P90, only corpus and antrum regions were subjected for enzymatic digestion. In case of other developmental stages, whole stomach was subjected for digestion. Subsequently, the single cell suspension was applied for FACS analysis and the percentages of EGFP-positive cells were measured. Flow cytometric analysis revealed that the total cell suspension of adult stomach comprised approximately $0.78 \%$ EGFPpositive cells (Fig. 3.47). The percentage of GFP-positive cells was higher in embryonic stomach than that in stomach of postnatal stages. The GFP-positive cells constituted around $4.62 \%$ of the total cell suspension from whole stomach of E13.5. The percentage of GFPpositive cells was increased during prenatal developmental stages and reached at maximum level of $8.26 \%$ in cellular suspension of E18.5. But after birth, the percentage of GFP-positive cells was decreased rapidly by showing $5.31 \%, 3.94 \%, 1.09 \%$, and $0.78 \%$ in cellular suspensions of P3.5, P10.5, P20 and P90, respectively (Fig. 3.48, Table 6).

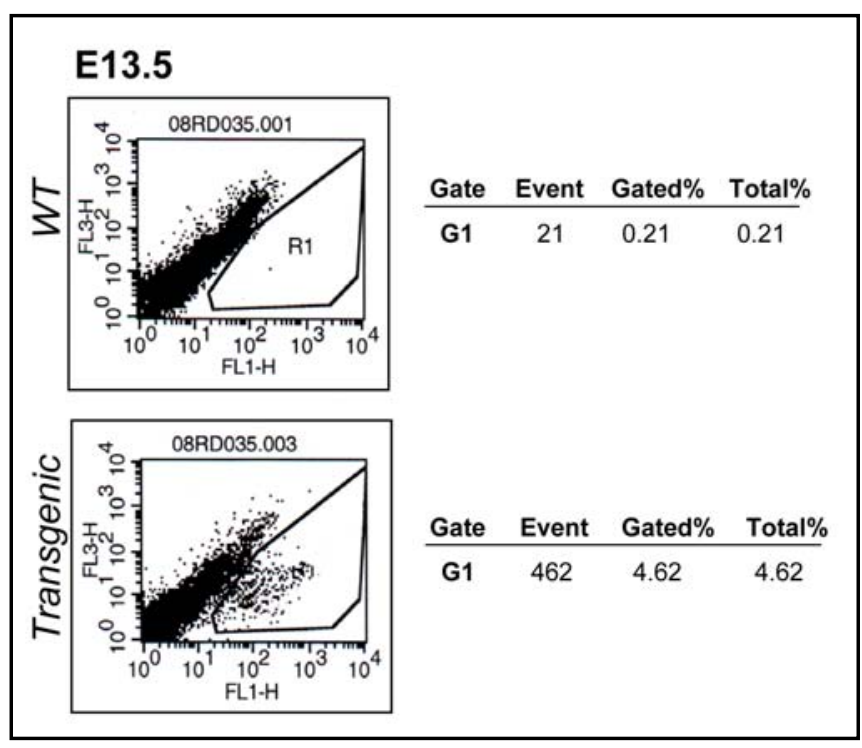



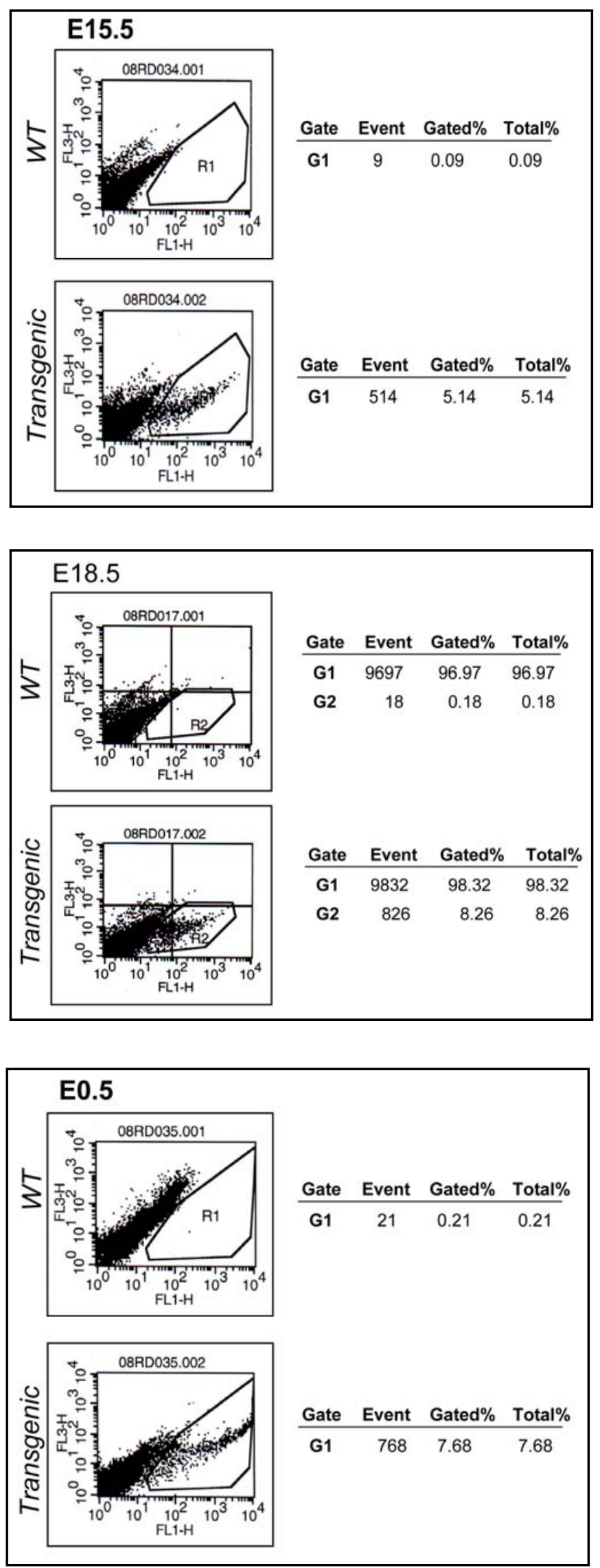

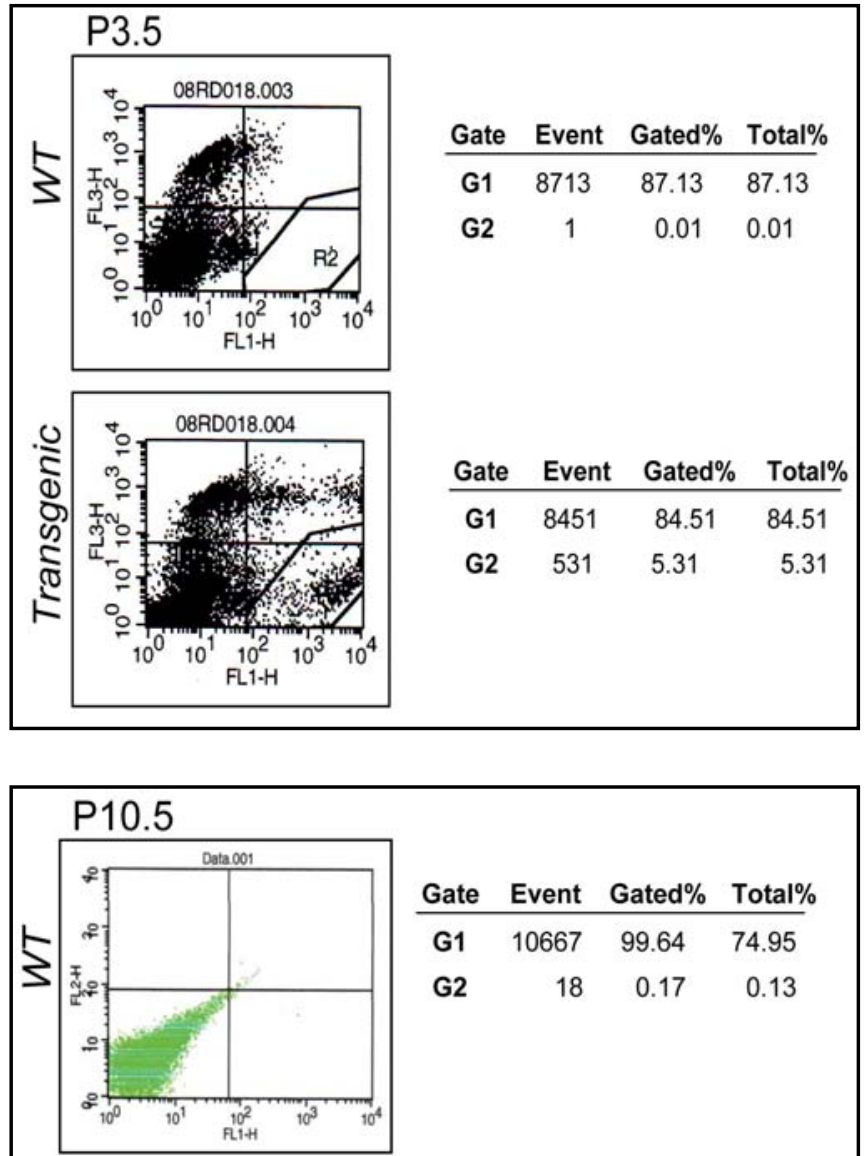

Gate Event Gated\% Total\%

$\begin{array}{llll}\text { G1 } & 10667 & 99.64 & 74.95\end{array}$

$\begin{array}{llll}\text { G2 } & 18 & 0.17 & 0.13\end{array}$

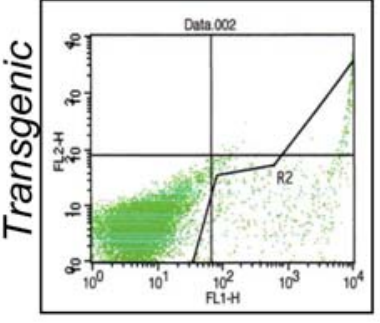

Gate Event Gated\% Total\%

$\begin{array}{lllll}\text { G1 } & 9923 & 94.99 & 76.31\end{array}$

$\begin{array}{llll}\text { G2 } & 412 & 3.94 & 3.17\end{array}$

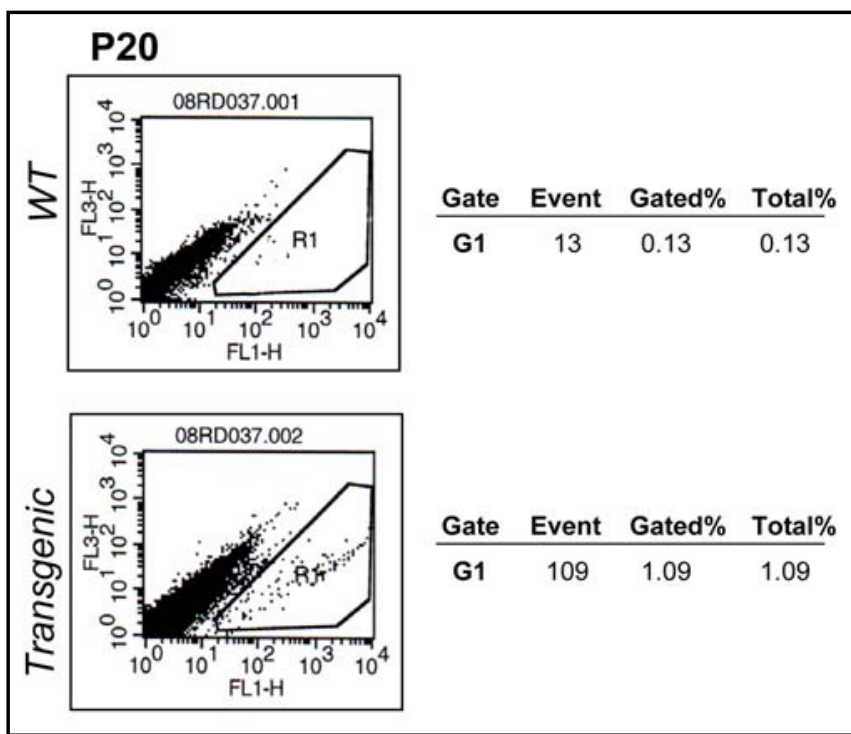




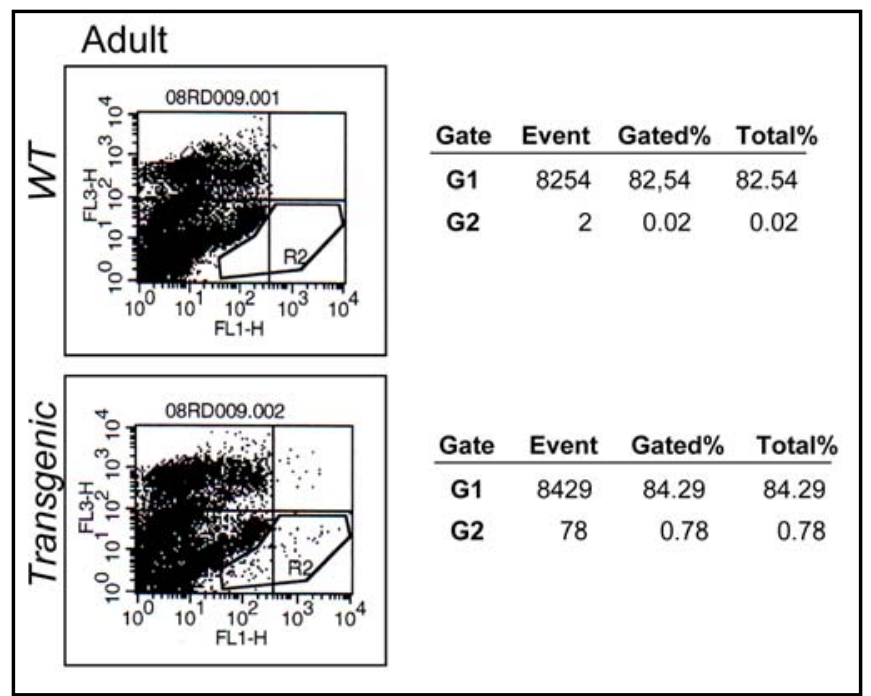

Fig 3.47 Fluorescence activated cell sorting (FACS) analysis of cell suspension from stomach of E13,5, E15.5, E18.5, P0.5, P3.5, P10.5, P20.5 and P90 transgenic mice from line \#56. In each case, wild type stomach cell suspension was used as negative control. G1: Non florescence cell population. G2: Distinct population of fluorescence cell.

\begin{tabular}{|c|c|c|c|c|c|c|c|l|}
\hline $\begin{array}{c}\text { Developmental } \\
\text { stages }\end{array}$ & $E 13.5$ & $E 15.5$ & $E 18.5$ & $P 0.5$ & $P 3.5$ & $P 10.5$ & $P 20.5$ & $\sim P 90$ \\
\hline $\begin{array}{c}\text { Percentage of } \\
\text { GFP positive cells }\end{array}$ & $4.62 \%$ & $5.14 \%$ & $8.26 \%$ & $7.68 \%$ & $5.31 \%$ & $\begin{array}{c}3.67 \\
( \pm 0.41)\end{array}$ & $1.09 \%$ & $0.78 \%$ \\
\hline
\end{tabular}

Table 6. Percentage of GFP-positive cells in stomach cell suspensions in the pre- and postnatal developmental stages. In case of $\mathrm{P} 10.5$, the analysis was repeated for 4 times and the margin of error was identified as $3.67 \pm 0.41$ in corresponding to $95 \%$ confidence interval by Student's " $t$ " distribution. 


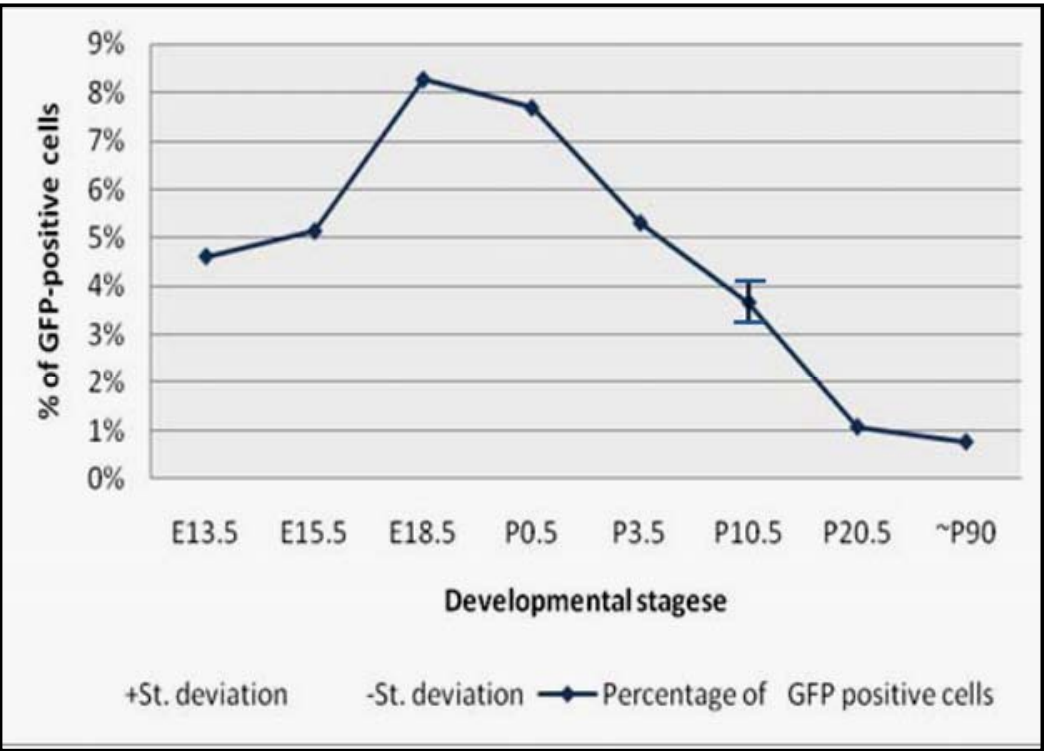

Figure 3.48 Significant reduction of GFP-positive cell number was observed during the developmental stages of stomach. $\mathrm{X}$-axis shows pre- and postnatal developmental stages, Y-axis shows the percentage of GFP-positive cells in stomach cell samples. In case of P10.5, FACS analysis was repeated 4 times to identify the standard deviation of percentage value of GFP-positive cells. By Student's " $t$ " distribution, the margin of error found as $3.67 \pm 0.41$ in corresponding to $95 \%$ confidence interval.

\subsubsection{Cellular distribution of GFP-positive cells in stomach}

In order to identify the cellular distribution of GFP-positive cells in stomach of adult transgenic mice, direct GFP fluorescence in stomach cryosections was analysed under the fluorescence microscope (Fig. 3.49). No specific GFP fluorescence could be detected in squamous epithelial cells of posterior stomach of transgenic animals. Strong GFP fluorescence was found in a few spots which are randomly distributed along the glandular epithelium (Fig. 3.49). These GFP fluorescence signals seem to be due to diffusion of GFP protein from cells. Cryosections of wild type stomach were examined as controls and GFPfluorescence could not be detected in cryosections (Fig. 3.49). 


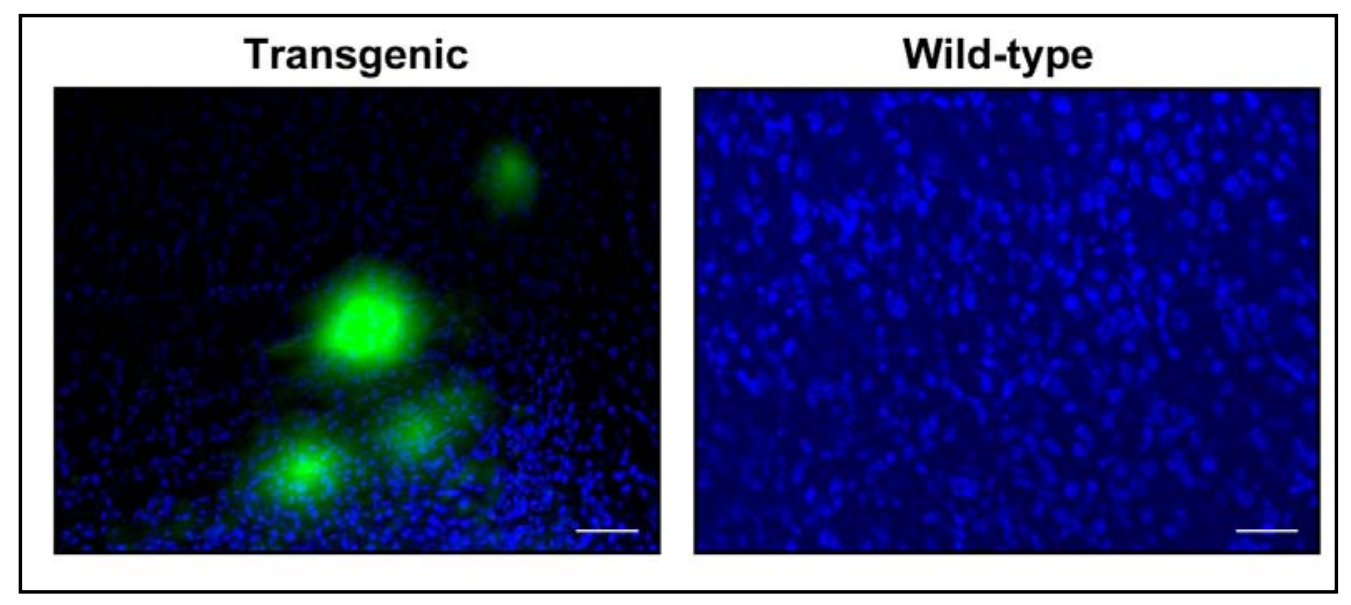

Figure 3.49 EGFP positive cells are not localized in every gland of stomach. Direct EGFP fluorescence (green fluorescence) of transgenic stomach sections was photographed. DAPI staining was used to visualize the nuclei. Optical magnification: $10 X$

To overcome the problem concerning the diffusion of GFP protein in the unfixed cryosections, transgenic stomach tissues were firstly fixed with 4\% paraformaldehyde for $15 \mathrm{~min}$ and then directly examined by fluorescence microscopy. No GFP fluorescence could be detected in fixed stomach sections of transgenic mice.

To detect the GFP-positive cells, stomach and testis from adult transgenic mice were fixed and embedded in paraffin. Immunostaining of histological sections was performed using mouse monoclonal anti-GFP antibody. Careful analysis of serial sections revealed that rare GFP positive cells were distributed widely spaced, randomly in glandular epithelium of antrum and corpus region. In the gastric unit, the localization of GFP-positive cells was not observed to be restricted to certain positions and the cells were rather localized at or upper the isthmus region. Morphologically, the GFP-positive cells were relatively small, oval or triangular shaped with large pale nuclei and they were localized as single or neighbouring 2-4 cell population (Fig. 3.50C). Most gastric glands did not appear to contain GFP-positive cells. Approximately, every 20 of the gastric unit of glandular stomach region had one unit, which contained GFP positive cells (Fig. 3.50C, D).

The FACS analysis showed that the percentage of GFP-positive cells is increased in stomach of embryo. To verify these results, serial sections of stomach from E18.5 were subjected to immunostaining with anti-GFP antibody. Immunohistological analysis revealed that large numbers of GFP-positive cells are located in the primordial bud of glandular epithelium. The GFP-positive cells were more accumulated in the antrum, while the number of these cells was decreased in epithelium of corpus region (Fig. 3.50A). 
Taken all together, the results of FACS and immunohistological analysis demonstrated that number of the GFP-positive cells are increased during prenatal developmental stages, but after birth the number of GFP-positive cells are decreased dramatically. The change in the number of GFP-positive cells during stomach development suggests that these cells are stem cells of glandular epithelium, because the percentage of stem cells in epithelium of embryonic stomach is higher than that in adult stomach.

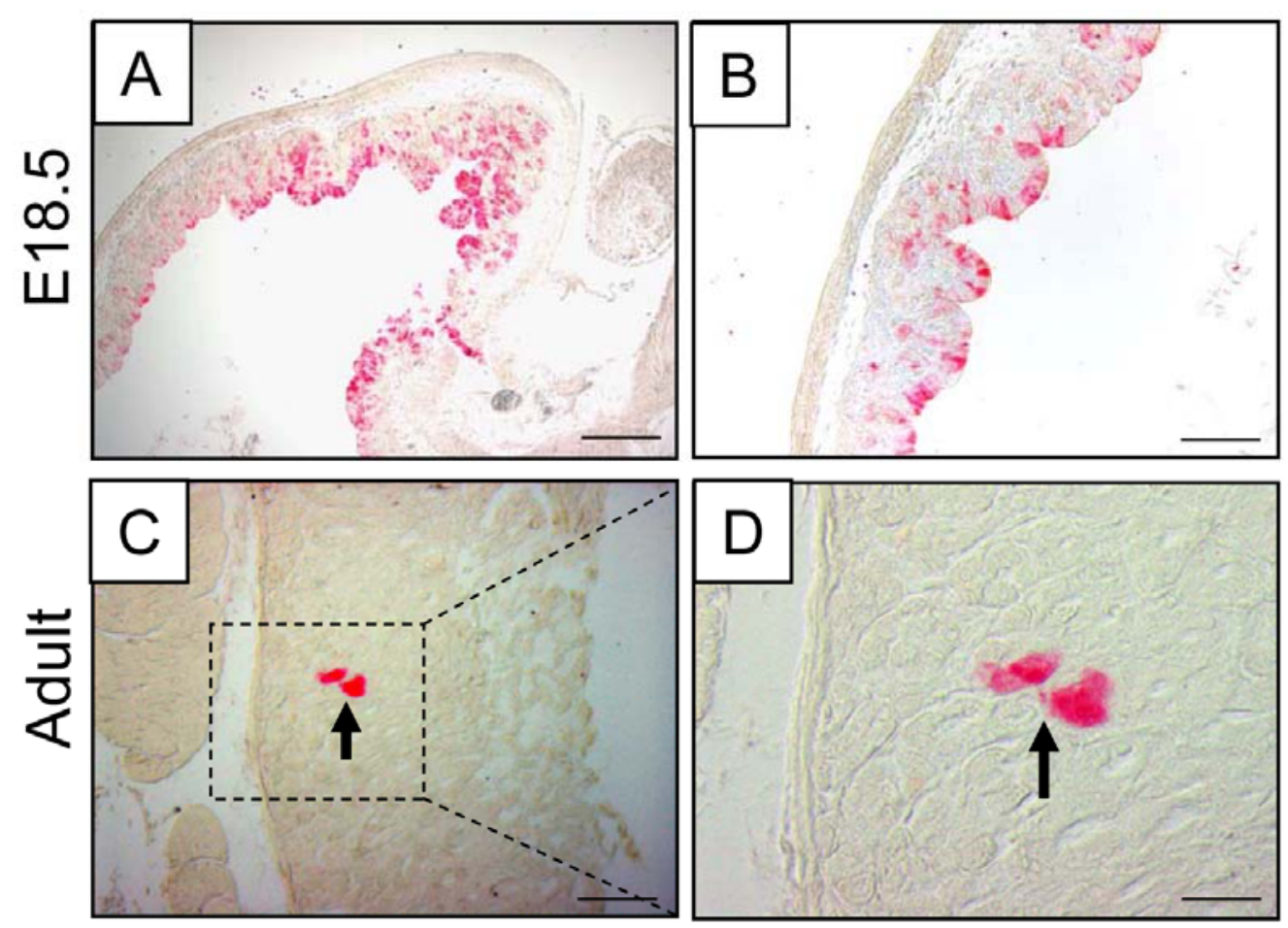

Figure 3.50 Immunohistological analysis of stomach from transgenic animals.

Stomach from E18.5 is shown (A, B). More positive cells are accumulated in pyloric antrum part of stomach (A). Corpus region of stomach is shown (B). Adult stomach $(C, D)$ has a few number of positive cells in comparison to embryonic stomach. APconjugated anti mouse IgG was used as secondary antibody. Optical magnification: Optical maghifications: $10 X$ in A, B, C; $60 X$ in D.

\subsubsection{Establishment and characterization of GFP-positive primary cell culture}

To determine the fate of the GFP-positive cells, GFP-positive cells were sorted from cell suspensions which were prepared from glandular stomach of transgenic mice in P10. Approximately, 20.000 GFP-positive cells were isolated by FACS-sorting and plated on mitomycin treated embryonic fibroblast layer in two wells of a 24-well plate. Cells were cultured with ES cell growing medium containing LIF. After $72 \mathrm{hrs}$ of culture, the medium 
was changed and the growing medium was changed every 4 days. The cells were passaged every 10 days.
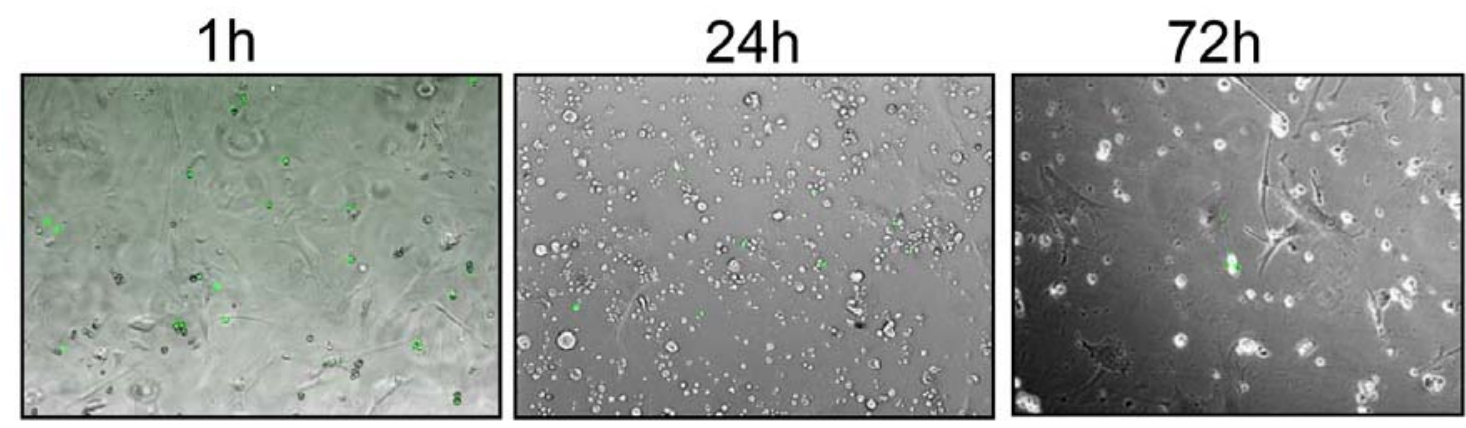

Figure 3.51 FACS sorted EGFP positive stomach cells during 72 hrs. The FACS sorted EGFP cells were plated on embryonic fibroblast feeder layer with ES cell growing medium. The fluorescence photomicrogpraphs of FACS sorted cell were taken after plating $1 \mathrm{hr}$, after $24 \mathrm{hrs}$, and after $72 \mathrm{hrs}$. The photomicrographs are overlapping with bright field and EGFP filter. Optical magnification: $10 X$

Examination of the cell cultures by fluorescence microscopy revealed that approximately $80 \%$ of plated cells were GFP-positive. However, the percentage of GFP-positive cells was dramatically decreased after $24 \mathrm{hrs}$ and no GFP-positive cells could be detected after $72 \mathrm{hrs}$ (Fig. 3.51). In another experiment, we plated the sorted GFP-positive cells on gelatine coated wells of a 24-well plate and cultured them with ES cell growing medium containing LIF. Similar to the results of the first experiment, no GFP-positive cells could be observed after 2 days of culture. This result suggests that the expression of EGFP is downregulated in cells during the culture or that the GFP-positive cells are not able to grow under the mentioned culture condition.

Sorted cells were grown during the first week of culture as layers over the feeder cells. Cells were dissociated to single cells with trypsin and plated into three gelatine coated wells of a 24-well plate (passage-1). After two days of culture, several cell clones were observed in cell culture of passage-1. These clones were increased in size during the culture. Treatment of clones with trypsin revealed that the trypsin is not able to dissociate the cell clones into single cells. However, mechanical dissociation of trypsinized cells by vigorous resuspension dissected the clones into several parts. These cells were then plated again on a gelatine coated plate (passage-2). We cultured these cells till passage-4. Due to the failure of dissociation of cell clones, we could not able to determine the proliferation rate of 
cultured cells. Collagenase and dispase treatment was not able to dissociate cell clones to single cells.

To determine whether stomach-derived cells in passage-4 represent stem cell characteristics, cells were cultured on slides, fixed with 4\% paraformaldehyde for $30 \mathrm{~min}$ and stained with rabbit anti-VSIG1 and mouse anti-GFP antibody. Other slides with stomach derived cells were used to determine the expression of alkaline phosphatase, a marker of pluripotent stem cells.
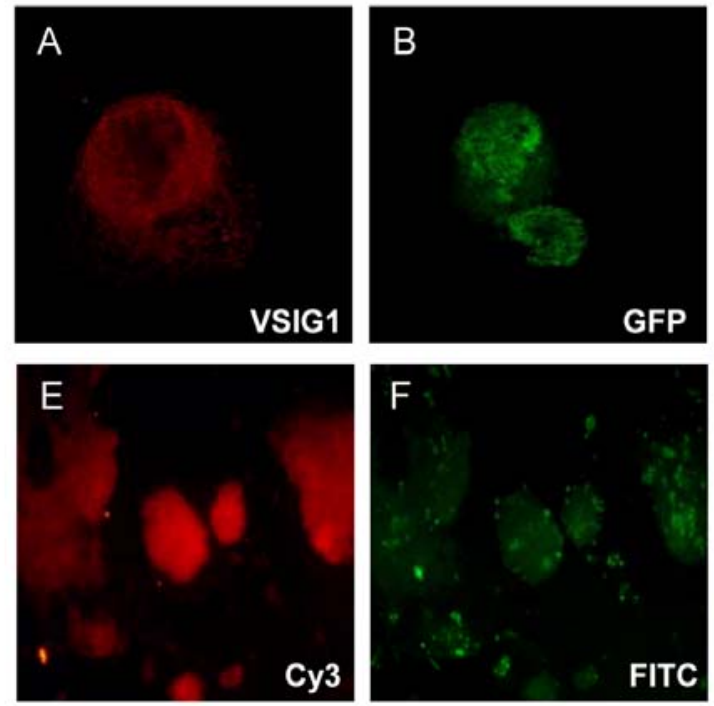
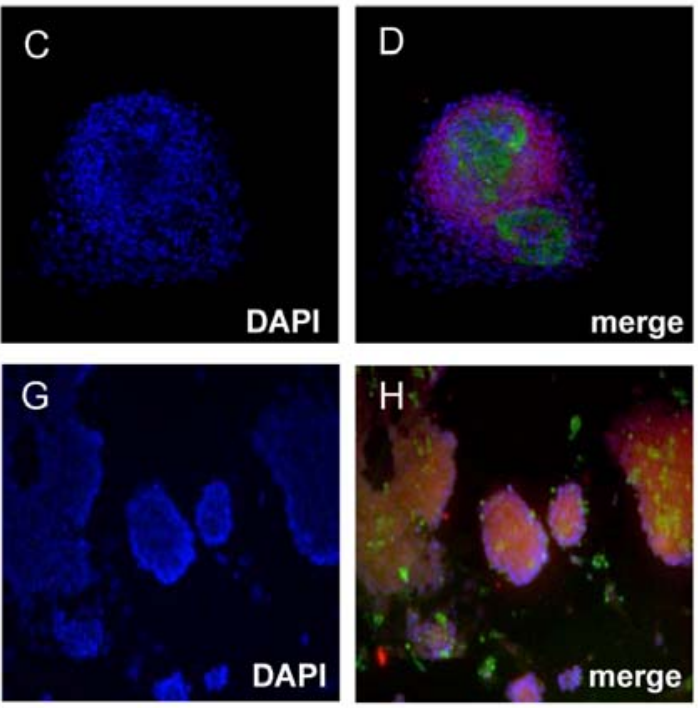

Figure 3.52 Stomach derived cell clumps were stained with anti-VSIG1 and anti-GFP. Confocal images show that the clumps were stained with anti-VSIG1 and anti-GFP antibodies (A-D). But the immunostaining without the first antibody shows that the stained clumps could have artificial signals due to unspecific staining by secondary antibody. Optical magnification: $10 \mathrm{X}$

As shown in figure $3.52 \mathrm{~B}$, cells locating in the centre of the clones were highly stained with anti-GFP antibody as compared to those located in the edge of clones. In contrast to that, VSIG1-stained cells were localized at the edge of clones while cells in the centre of clusters were VSIG1 negative (Fig. 3.52A). Co-localization of GFP and Vsig1 expressing cells revealed the presence of GFP and VSIG1 positive cells (Fig. 5.52D). To prove the specific staining of GFP and VSIG1 antibodies, the cell culture was stained only with the second antibodies as control (Fig. 3.52E-H). The immunostaining without first antibodies showed that some cells in the clones could have artificial signals due to unspecific staining by the secondary antibody (Fig. 3.52E-H) 
To determine the alkaline phosphatase activity in clones of passage-4, cells were subjected to alkaline phosphatase assay (AP-assay). For positive control, we used embryonic stem cells. As shown in figure 3.54A, ES cells have high AP-activity (blue staining). In contrast, clones of stomach-derived cells are not stained with AP (Fig. 3.53B)
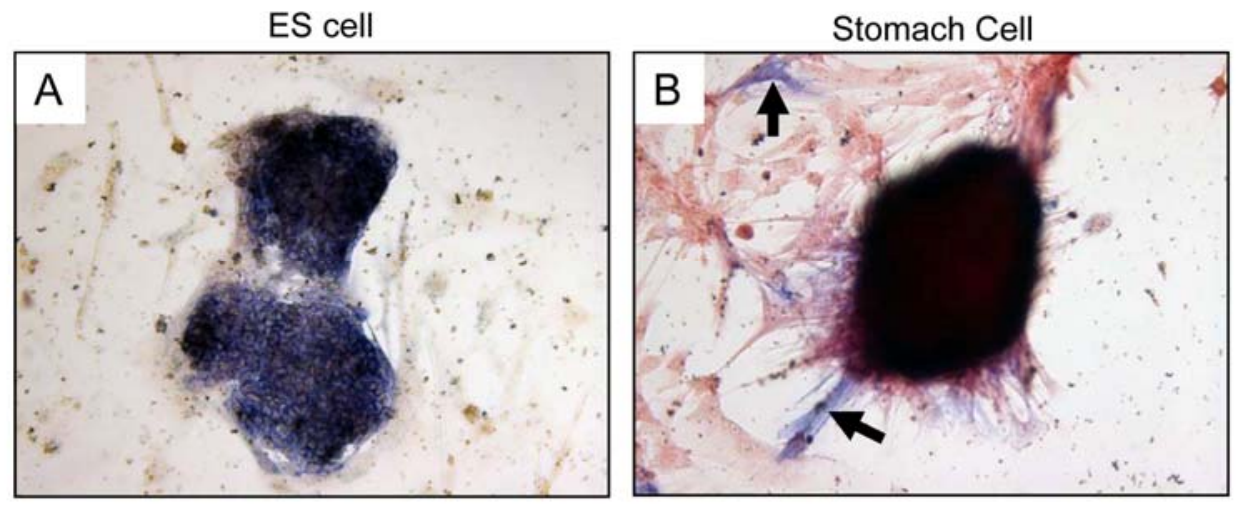

Figure 3.53 Alkaline phosphatase detection assay on stomach and ES cells. Blue color is indication of AP activity and the brown color is the indication of lack of activity of AP. The control ES cell clones show blue color which is the indication of alkaline phosphatase activity, whereas the stomach cell clones show brown color. But in stomach cell culture, some cells which are not aggregated also showed blue color (indicated by black arrow). Optical magnification: $10 X$

\subsubsection{Expression analysis for different marker genes in primary cell culture of stomach}

To determine the expression of pluripotency and endodermal stem cell markers in stomach-derived cell culture, RT-PCR analysis was performed. Total RNA was isolated from the cells of passage-4 (P4) and cDNAs were reverse transcribed using the poly-T primers. The ES cell-, stomach-, and brain-cDNAs were used as control. Specific primers for pluripotency genes Oct4, Sox2, Nanog, Rex-2, endodermal stem cell marker genes GATA-4, Lgr5, alpha-fetoprotein (Afp), and early epithelial expressing gene KRT1-18 were used in RT-PCR assay. PCR products were cloned into pGEMT-easy vector and sequenced. 


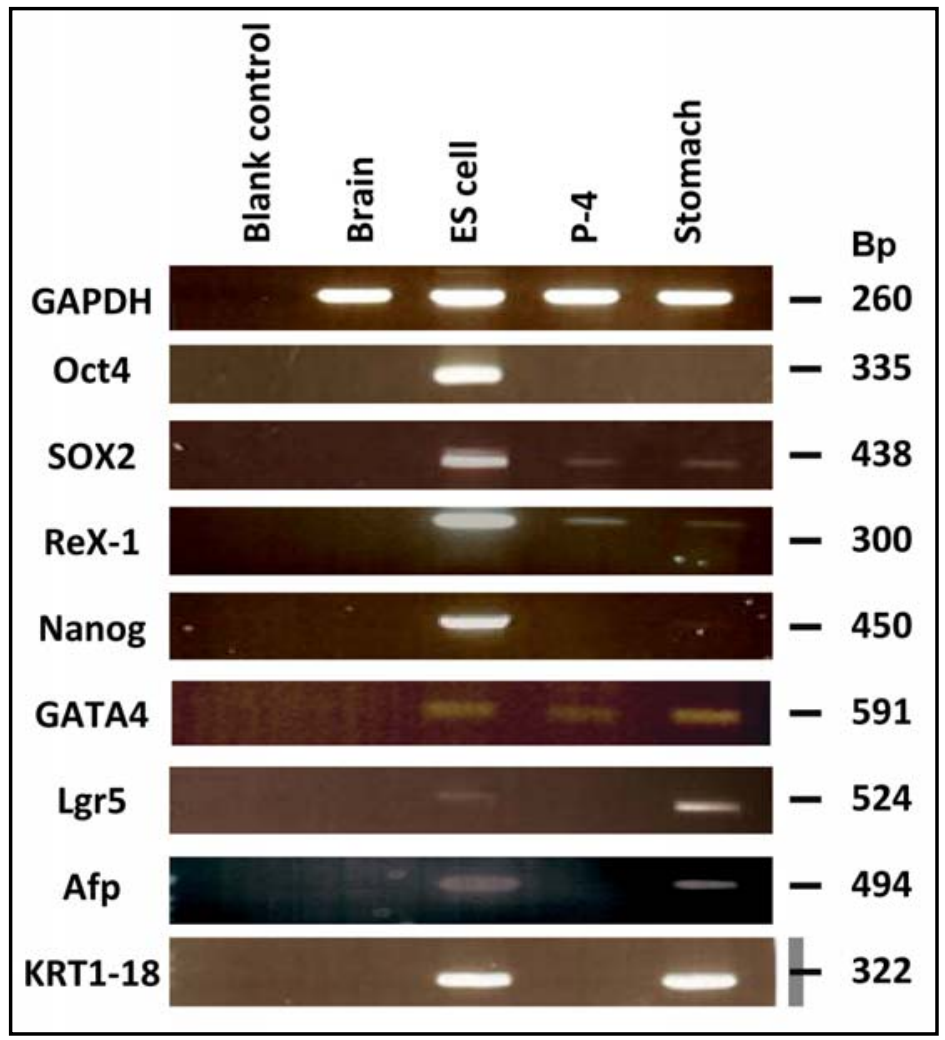

Figure 3.54 mRNA expression analysis of cultured stomach cells (P4) for different markers. RT-PCR was performed on cDNAs from brain, ES cells, passage-4 (P-4), stomach, and blank control. GAPDH primers were used for control amplification.

The RT-PCR analysis showed that pluripotent marker Oct4 and Nanog are not expressed in P-4 and stomach. Other pluripotent markers such as Sox2 and Rex1 are slightly expressed in cells of P-4 and stomach. In case of endodermal markers, only GATA4 expression was found in P4 and stomach, whereas Lgr5, Afp, and KRT expression was not found. In case of control ES cells, high expression of pluripotent markers was found. This result indicates that the stomach derived cultured cells do not express pluripotency markers and early epithelial cell markers. 


\subsection{Analysis of cell adhesion and cell migration in stable cell lines overexpressing VSIG1}

Members of immunoglobulin superfamily are cell-cell adhesion molecules. Some members have been shown to be localized at the tight junctions of epithelial and endothelial cells. Apart from linking cells to each other, cell adhesion molecules are critical in modulating signal transduction. Such functions are vital for regulation of cellular adhesion, proliferation, migration and differentiation. To determine the role of Vsig1 in cell-cell adhesion and migration, we have established a stable transfected cell line, in which the Vsig1 is overexpressed.

\subsubsection{Generation of $p c D N A-V s i g 1$ construct}

The coding sequence of Vsig1 was amplified using the primers SX-ORF-F2 and SXORF-R2 containing the sequence of HindIII and XhoI restriction sites, respectively. The 1178-bp amplified cDNA fragment was inserted into the HindIII and XhoI -digested pcDNA3.1(-)/myc-His-A vector. The cloned coding sequence of Vsig1 cDNA includes translation stop codon TAA sequence at the end of the sequence, therefore the resulting VSIG1 protein is not tagged with myc-tag (Fig. 3.55).

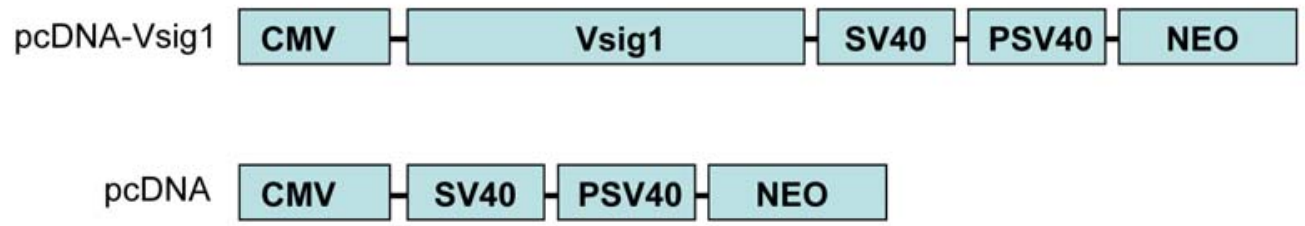

Figure 3.55 Schematic representation of fusion constructs used for transfection of HepG2 cells. The pcDNA-Vsig1 construct contains the coding region of Vsig1 gene (cDNA) under control of cytomegalovirus (CMV) promoter, SV40 polyadenylation signal (SV40) and neomycin resistance gene (NEO) under control of SV40 promoter (PSV40). The control plasmid contains all DNA sequences except Vsig1 cDNA (pcDNA). 


\subsubsection{Establishment of stable transfected cell lines}

To determine the overexpression of the pcDNA-Vsig1 recombinant allele, transient transfections of Hela and HepG2 cell lines with the constructs were firstly performed. Immunostaining of transient transfected cell lines with anti-VSIG1 antibody revealed that the VSIG1 is localized on the cell-cell adhesion (Fig. 3.56A) and on the focal adhesion sites (Fig. 3.56B). Slight staining was also detected in the cytoplasm.
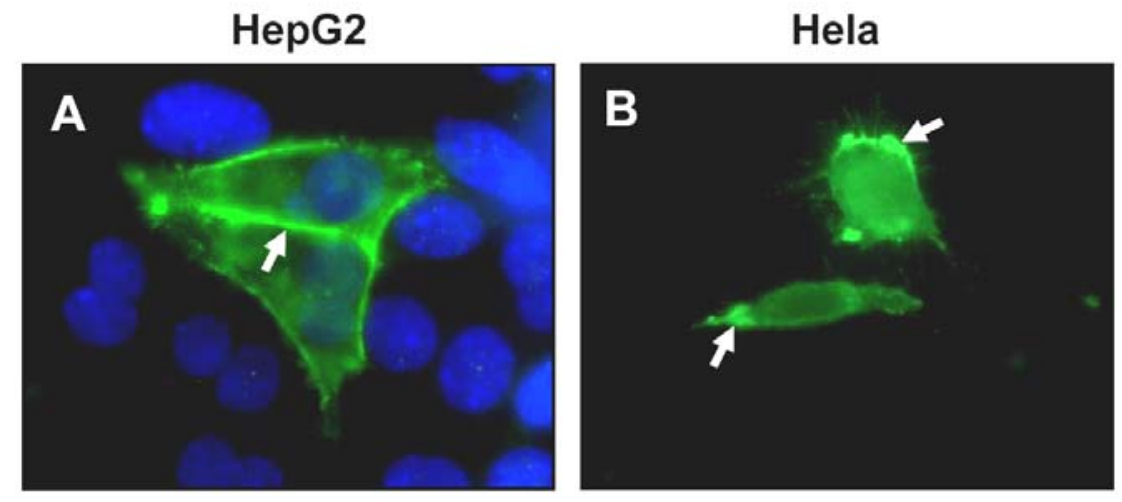

\section{Figure 3.56 Subcellular localization of VSIG1 in different cell lines.}

Transient transfected Hela and HepG2 cells were immunostained with VSIG1 antibody. The white arrow indicates the positive staining at cell-cell adhesion (A) of transient transfected HepG2 cells and at focal adhesion sites (B) of Hela cells. DAPI staining was used to visualize the nuclei. Optical magnification: $20 X$ in $B ; 20 X$ in $A$.

To generate Vsig1-stable transfected cell lines, we have transfected the HepG2 cell line with the pcDNA-Vsig1 construct and pcDNA vector as control. Two days after transfection, cells were trypsinized and plated into 6-well plates. Cells were cultured with growing medium containing $600 \mu \mathrm{g} / \mathrm{ml} \mathrm{G}-418$ for 10 days. G-418 resistant clones were picked up, trypsinized and platted each in a well of a 96-well plate. Repetition of the last steps enabled us to establish 10 recombinant pcDNA-Vsig1 and 2 recombinant pcDNA clones. To determine the overexpression of pcDNA-Vsig1 recombinant allele in stable transfected cell line, total protein was extracted from different stable cell lines and subjected to Western blot analysis with anti-VSIG1 antibody. Western blot analysis revealed that the pcDNA-Vsig1 is expressed in all established cell lines (Fig. 3.57). High level of expression was observed in clone-5. No expression of Vsig1 could be detected in control cell lines. 


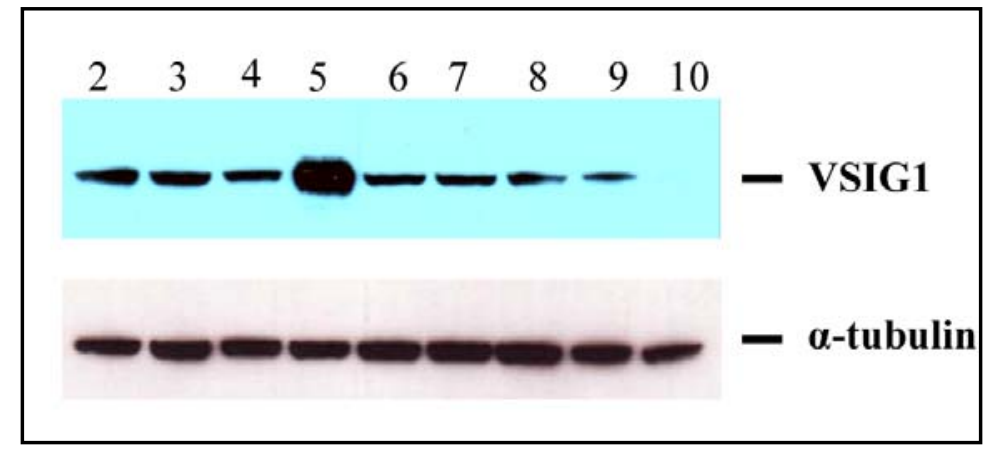

Figure 3.57 Expression of Vsig1 in stable transfected cell lines. Clone-5 shows highest expression level of VSIG1. Clone-10 represents the HepG2-pcDNA cell line which does not express VSIG1. Western blot with alpha-tubulin antibody was used for monitoring the protein loaded.

To determine the subcellular localization of VSIG1 in stable transfected cells, immunostaining with anti-VSIG1 antibody was performed on clone-5. Immunostaining revealed that the localization of VSIG1 is restricted to cell-cell adhesion (Fig. 3.58).
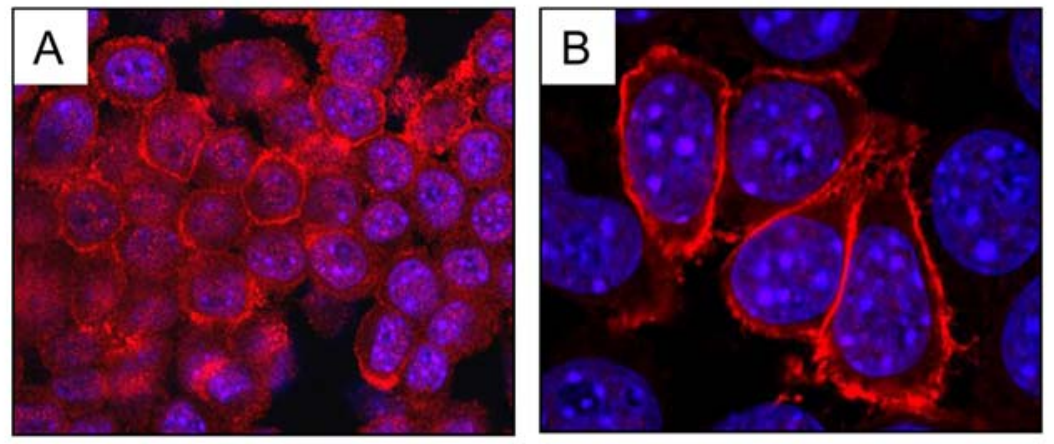

Figure 3.58 Subcellular localization of VSIG1 in stable transfected cell line of clone-5. Cells were fixed with paraformaldehyde and incubated with VSIG1 antibody (A). In high magnification image (B), it is shown that the VSIG1 is localized on the plasma membrane of cells. DAPI staining was used to visualize the nuclei. Optical magnifications: $20 X$ in $A ; 60 X$ in $B$.

The immunofluorescence staining revealed that as expected, the VSIG1 is localized on the plasma membrane of transfected cells, the most intense signals are on the membrane of two cell adhesions. 


\subsubsection{Analysis of cell-cell adhesion of stable cell line}

To check the role of VSIG1 in cell-cell adhesion, we performed adhesion assay by hanging drop method. Approximately 500 single cells from the VSIG1-overexpressing cell line (clone-5) and from control cell line (clone-10) were incubated in 5 separate hanging drops, respectively. Every one hour, one hanging drop from each line was taken and the cells were resuspended by pipeting 5 times. Then total particle numbers in each taken drop were counted directly in Neubauer's counting chamber.

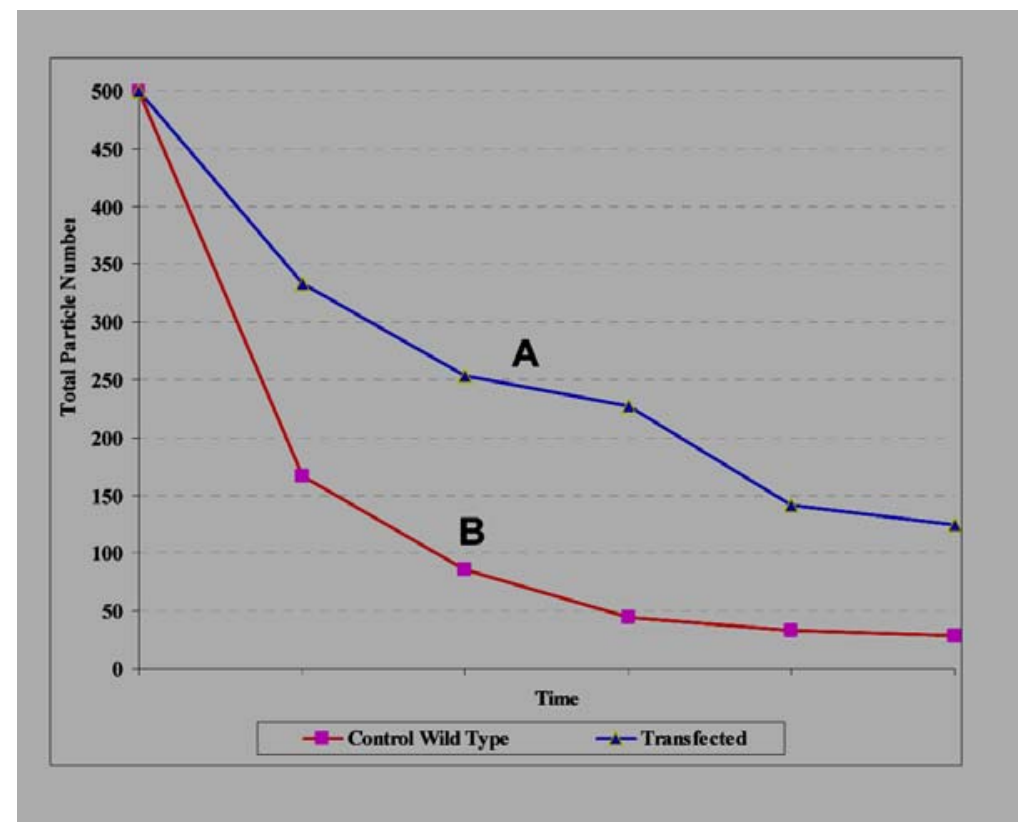

Figure 3.59 Aggregation characteristic of HepG2-pcDNA-Vsig1 (clone-5) and control HepG2-pcDNA (clone-10) lines. The Y-axis shows the total particle number and $\mathrm{X}$-axis shows the time interval. In case of clone-5 (A), the total particle numbers are reduced slowly in comparison to clone-10 (B), which has rapid reduction of total particle numbers.

The aggragation assay showed that the aggregation activity of VSIG1 expressing cells (clone-5) is weaker than those of control cell line which do not express VSIG1 (clone-10). The control cell line (clone-10) has approximately 2 times higher aggregation activity than the VSIG1 expressing cells (Fig. 3.59). This result indicates that the overexpression of VSIG1 in HepG2 cell decreases the adhesion of the cells. 


\subsubsection{Analysis of migration properties of the stable cell line}

Cell migration assay was performed, based on the healing speed of scratched wound in monolayer cells. The cells of clone-5 and clone-10 respectively were grown at $100 \%$ confluence to form a monolayer in $10 \mathrm{~cm}^{2}$ culture dishes. By using a p200 pipet, a scratch of the cell monolayer was created in each clone. After drawing the scratch, the cells were washed with PBS two times and further incubated. The first images of the scratched wound were photographed just after washing with PBS and further images were photographed after 12 hrs, 24 hrs and 48 hrs (Fig. 3.60). The images acquired for each sample were further analyzed quantitatively by using computing software.

The migration rate of the cells was determined by measuring the distance between two leading edges of the scratched wound. If the cell migration is faster, the distance between two edges of the scratched wound will be closed faster. If the cell migration is slower, then the edges will be closed slowly. Using "Soft Imaging System" software (Olympus), at each certain time interval (12 hrs, $24 \mathrm{hrs}$, and $48 \mathrm{hrs}$ ), the distances between two edges of healing wound were measured 10 times randomly in selected fields of view and the mean values of the distance were identified for each clone.

The wound healing assay showed that the cells of clone- 5 are able to migrate faster than clone-10. This result indicates that VSIG1 has a role in cell migration, and the overexpression of VSIG1 in HepG2 cell increases the cell migration property. 


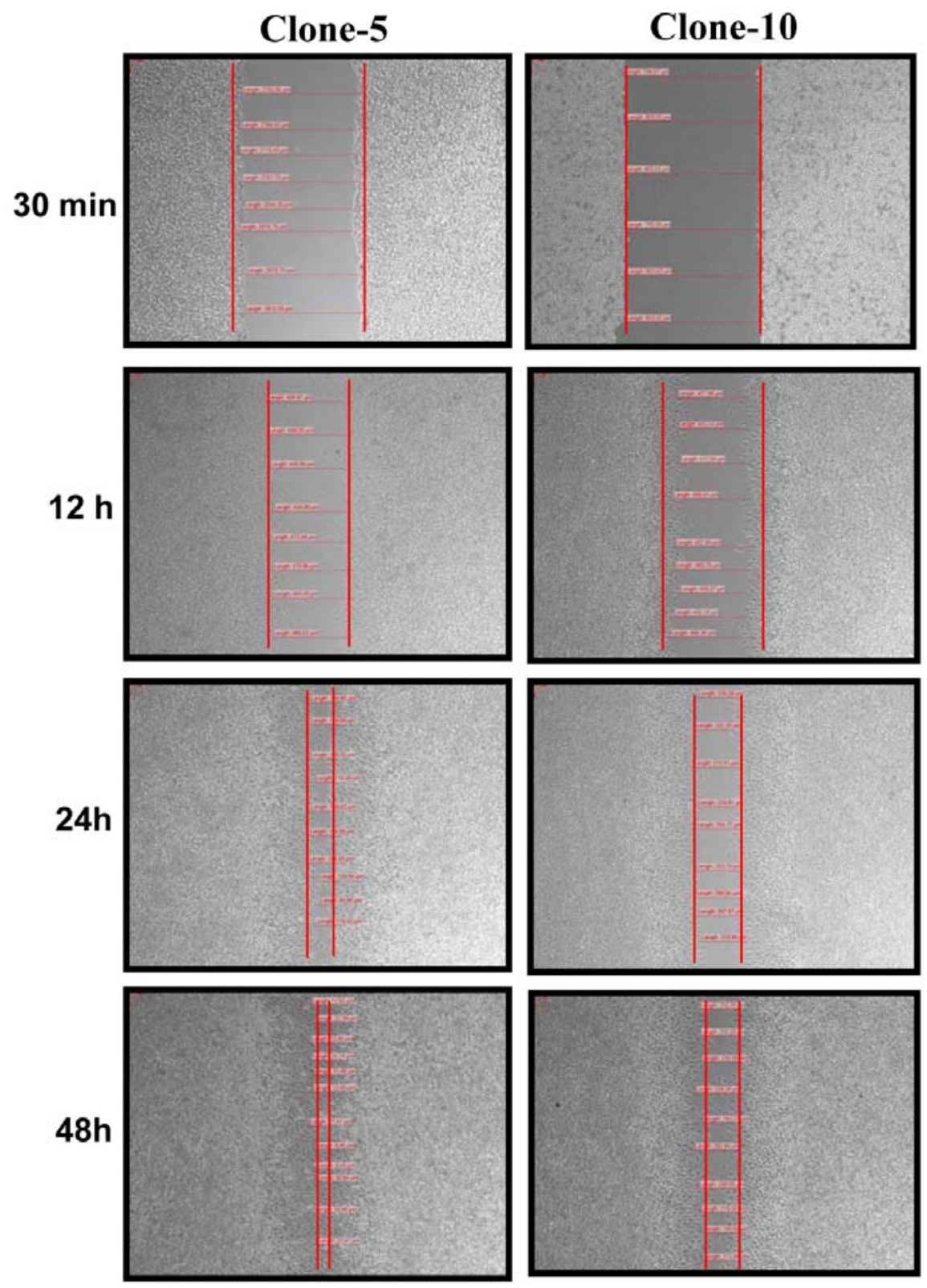

Figure 3.60 Analysis of cell migration of clone-5 and clone-10 by in vitro scratch assay. Images were acquired in time interval of $30 \mathrm{~min}, 12 \mathrm{hrs}, 24 \mathrm{hrs}$ and $48 \mathrm{hrs}$. The red lines were drawn to show approximate distance between two edges of wound. Optical magnificagion: $4 X$ 


\subsection{Expression analysis of human Vsig1 in gastric cancer tissues}

Stomach cancer is the fourth most common cancer worldwide and it is the second leading cause of cancer-related deaths after lung cancer. Most cases of gastric cancer $(85 \%)$ are adenocarcinomas that occur in the glandular epithelium of the stomach. Approximately $40 \%$ of cases of gastric cancer develop in the pyloric antrum, $40 \%$ develop in the corpus region and $15 \%$ develop in the cardiac region. In about $10 \%$ of cases, cancer develops in more than one part of the organ.

To study the expression of human VSIG1 protein in gastric cancer, polyclonal antibody against human VSIG1 was used. Anti-mouse VSIG1 antibody failed to detect the human VSIG1 in Western blot and immunostaining. To generate anti-human VSIG1-specific antibody, a 180-bp of cDNA fragment encoding the sequence of cytoplasmic domain was amplified with primers huSX-FuProF2 and huSX-FuProR2. The PCR fragment was cloned into prokaryotic expression vector pET41a and the construct was used to produce GSThuVSIG1 fusion protein. The human-VSIG1 specific antibody was produced as described in the section of generation of murine VSIG1 specific antibody.

There are two types of gastric carcinoma which are classified as intestinal and the diffused types. To identify VSIG1 expression in gastric carcinoma, immunohistological analysis with anti-VSIG1 antibody was performed on the sections of both types of the gastric carcinoma representing early, middle and late stages of tumor differentiation. (Fig.3.61). Immunohistological analysis revealed that human VSIG1 protein is strongly expressed in cell clusters containing poorly differentiated compact tumor cells in early stage of gastric carcinoma (Fig. 3.61A, D). In the middle stage of gastric carcinoma, reduced level of VSIG1 expression was observed only in some tumor cells (Fig, 3.61B, E) In contrast, no expression of VSIG1 was detected in well differentiated tumor cells of late stage of tumorgenesis (Fig. 3.61C, F). 


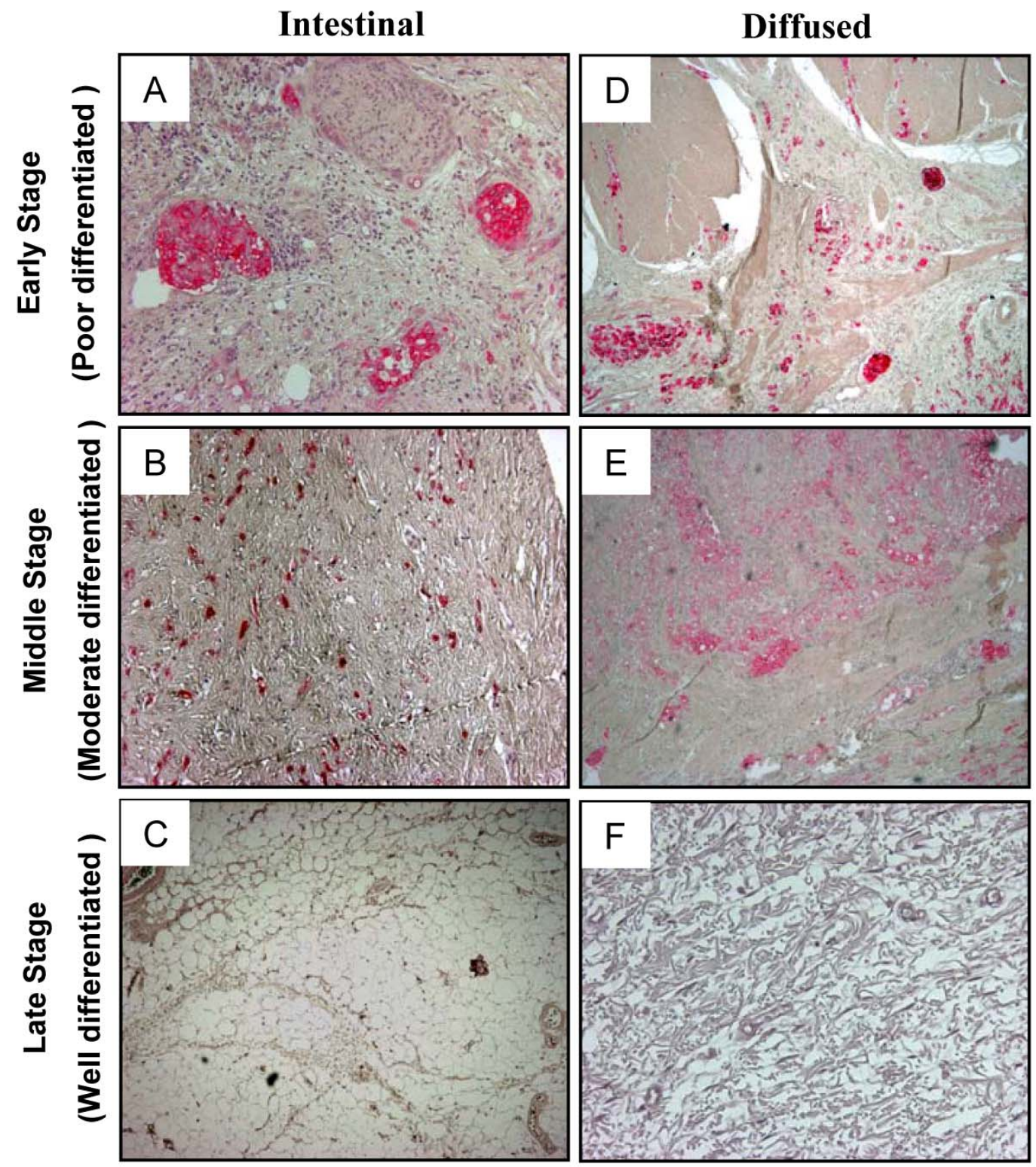

Figure 3.61 Expression of human VSIG1 in gastric carcinoma tissues.

VSIG1 protein expression was detected in poorly and moderately differentiated tumor cells, but not detected in well differentiated tumor cells. Optical magnification: $10 X$ 


\section{Discussion}

\subsection{Summary of important results of the study}

We have isolated and characterized a cDNA fragment of Vsigl gene, which is a novel member of immunoglobulin superfamily and localized on X-chromosome. Expression analysis revealed that the $2.7-\mathrm{kb}$ of $V$ sigl transcript is highly expressed in stomach, and 1.4-kb splice variant was detected in testis. No Vsigl transcript could be detected in other adult tissues. To determine the expression pattern and subcellular localization of VSIG1, a polyclonal anti-VSIG1 antibody has been generated and purified. The immunohistochemical analysis showed that VSIG1 is localized on plasma membrane of glandular epithelial cells of stomach, the staining was most intense in the basolateral membrane of the pit cells. Vsigl mRNA and protein were not found in squamous epithelial cells of forestomach. The analysis of Vsigl expression pattern during the pre- and postnatal developmental stages showed that Vsigl is expressed initially in E13.5 stomach. In E14.5 and E17.5 stomach, a much stronger expression of Vsigl was observed in primordial buds of the glandular gastric epithelium and the expression is maintained in the cells of gastric units through the whole lifespan. The temporal and spatial profile of $V$ sigl expression suggests a potential role in regulation of cytodifferentiation of stomach epithelium.

To study the role of VSIG1 in cell-cell adhesion and migration, we have established stable transfected HepG2 cell line, in which the VSIG1 is overexpressed. The VSIG1overexpressing cells showed reduced of cell-cell adhesion and increased migration properties.

To determine the function of Vsigl, a conventional Vsigl knockout construct has been generated and used for transfection of embryonic stem cells. One homologous recombinant $\mathrm{Ssigl}^{-} / Y$ clone has been identified and used for generation of chimeric mice. All 24 chimeric mice generated by injection of Vsig1-null cells into the blastocyst of mouse strain $\mathrm{C} 57 \mathrm{Bl} / 6 \mathrm{~J}$ had low chimerism and did not transmit the targeted allele to their offspring. Analysis of chimeric mice leads us to suggest that a high contribution of Vsig1-null cells in the development of embryos causes lethality of chimeric embryos. Immunohistochemical analysis of the stomachs from two adult chimeric mice revealed that the corpus region of stomach contains Vsigl-deficient epithelial cells. This Vsig1- 
deficient epithelium was morphologically similar to squamous epithelium and expressed Cytokeratin-5/6 which is the marker of squamous epithelium. These results demonstrate that the Vsigl-deficiency leads to transdifferentiate the glandular epithelium to the squamous epithelium.

To overcome the early embryonic lethality of chimeric mice possibly due to highly contributed $V$ sigl ${ }^{-} / Y$ cells, a conditional targeting vector has been constructed. In the conditional vector, exon-1 of Vsigl gene was flanked with LoxP sites. Two homologous recombinant ES cell clones were isolated and used to generate chimeric mice. All chimeric mice had also low chimerism and $75 \%$ of them were infertile. Analysis of sperm parameters from the infertile chimeras revealed that the infertile chimeras had reduced number of spermatozoa in caudal epididymis and impaired sperm motility. Histological analysis of testis from infertile chimeric mice revealed that the testis had seminiferous tubules with almost complete loss of spermatogenic cells (about 95\% of all tubules) (Fig. 3.37) and other tubules with arrested spermatogenesis at primary spermatocyte stage. Tubules contained vacuoles and aggregates of cells accumulating in the lumen of tubules. Interestingly, some tubules contained multilayered pretubular cells (2-3 layers). To investigate whether the chimeric testes has different types of germ cells, immunohistochemical analysis was performed with anti-GCNA and anti-Apg1 antibodies, which are markers for different spermatogenic cells. The immunohistochemical analysis could not detect any GCNAand Apg1-positive germ cells in the seminiferous tubules. The fertile chimeric mice $(25 \%)$ had low chimerism and did not transmitted the $V_{\text {sig }} I^{\text {flox }}$ allele to their offspring.

The expression of the Vsigl in stomach epithelium of early embryonic development (E13.5), lead us to suggest that the Vsigl is expressed in stem cells of stomach epithelium. To further determine the expression of Vsig1 in progenitors of stomach epithelium and to perform isolation and cultivation of stomach epithelial stem cell, we have generated Vsigl-EGFP transgenic mice. The Vsigl-EGFP transgenic allele contains the EGFP gene under the control of the 5'-region of the Vsig1 gene. Analysis of stomach from transgenic embryos at E18.5 revealed that the GFP fluorescence was restricted to the corpus and antrum regions. In contrast, the GFP fluorescence in stomach of adult transgenic mice was restricted to spots in glandular epithelium. Immunohistological analysis of stomach from E18.5 revealed that GFP-positive cells are distributed in cells of primordial gastric unit. Most of the gastric units in stomach of 
adult mice do not appear to contain GFP-positive cells. Approximately, every 20 of gastric unite in glandular region contained one or two GFP-positive cells.

Flow cytometric analysis showed that the percentage of GFP-positive cells increased during the prenatal developmental stages and reached to maximum level of $8.26 \%$ in cellular suspension of stomach from E18.5. After birth, the percentage of GFP-positive cell decreased rapidly to $0.78 \%$ in P90 stomach sample. To identify and characterize the stomach stem cells, we tried to establish a cell line from FACS sorted GFP-positive cells. Most GFP-positive cells did not become attached to the dish and even the few number of attached GFP-positive cells lost rapidly their green fluorescence after 24-hrs. The expression analysis of different stem cell marker genes was performed by RT-PCR on mRNA sample isolated from stomach primary cell culture $\left(4^{\text {th }}-\right.$ passage $)$. RT-PCR analysis showed that the stomach-derived cultured cells do not express pluripotency markers and early epithelial cell markers.

To study the expression of human VSIG1 protein in gastric cancer, a polyclonal antihuman VSIG1 antibody was generated and purified. Immunohistological analysis with anti-humanVSIG1 antibody was performed on the sections of gastric carcinoma representing early, middle and late stages of tumour differentiation. Immunohistological analysis revealed that human VSIG1 protein is strongly expressed in cell clusters containing poorly differentiated compact tumour cells in early stage of gastric carcinoma. In the middle stage of gastric carcinoma, reduced level of VSIG1 expression was observed only in some tumour cells and no expression of VSIG1 was detected in well differentiated tumour cells of late stage of tumorgenesis.

\subsection{Overview of immunoglobulin superfamily}

The immunoglobulin superfamily (IgSF) is a heterogeneous group of proteins containing a common fold, called the Ig-fold (domain), which is a sandwich of two $\beta$ sheets. The IgSF is one of the largest gene and protein families in vertebrates and represents 765 members in the human genome (Lander et al., 2001; Venter et al., 2001). The Ig-superfamily molecules are conserved through evolution and can be found in flies and worms, which are predicted to have 153 and 70 different Ig-like-domain-containing proteins, respectively (Rubin et al., 2000).

The members of the family can contain one or many Ig-domains, comprising two basic types: constant domain $(\mathrm{C})$ with seven $\beta$-strands and the variable domain $(\mathrm{V})$ with eight to ten $\beta$-srands. However, there are some Ig-domains that belong to different categories, 
in which the Ig-domain resembles IgV-domains in their amino acid composition, but are similar in size to IgC-domains. These are called IgC2 domains, while the standard $\operatorname{IgC}$ domains are called IgC1 domains (Halaby, 1998). The typical IgSF member is a type-I transmembrane glycoprotein. These proteins have a N-terminal extracellular region which contains one ore more Ig-like domains that are involved in molecular recognition and C-terminal cytoplasmic tail that functions in signalling pathway (Shinya-Suzu et al., 2002). The classifications of IgSF members are based on their common functional role (receptors, enzymes, antibiotic proteins etc) and their distribution in tissues (neuronal system, gastrointestinal tract, hematopoetic system, etc) or species (vertebrates and invertebrates, etc). The members of immunoglobulin superfamily have diverse functions, which are important for immunity, cell adhesion, signal transduction and enzymatic reaction.

\subsection{VSIG1 belongs to immunoglobulin superfamily}

Using subtractive cDNA hybridization method, we have isolated the cDNA fragment SX. A search of Genbank database revealed that the SX cDNA sequence corresponds to the Vsigl gene. Murine Vsig-1 gene is localized on the F1 region of $\mathrm{X}$ chromosome (in human, Xq22.3) and consists of 7 exons.

VSIG1 belongs to a subclass of the immunoglobulin subfamily of cell adhesion molecules, termed CTX/JAM family (Chretien et all., 1998; Aurrand -Lions et al., 2001; Ebnet et al., 2004). All members of the CTX/JAM subclass of immunoglobulin superfamily have homologous type-1 transmembrane proteins with an extracellular moiety consisting of one variable (V-type) and one constant (C2-type) immunoglobulin (Ig) domain, a single transmembrane domain and a cytoplasmic tail. The first identified member of the CTX/JAM subfamily was cortical thymocyte marker in Xenopus and was discovered in 1996 (Chretien et al., 1996). Other CTX/JAM subfamily members include A33 (Gpa33) (Heat et al., 1997), the junctional adhesion molecules JAM-1, -2, -3 (Ebnet et al., 2004), the endothelial cell-selective adhesion molecule ESAM (Hirata et al., 2001), the brain and testis specific immunoglobulin superfamily protein (BT-IgSF) (Suzu et al., 2002) and CAR-like membrane protein (Raschperger et al., 2004). Members of the CTX/JAM subclass are typically cell-cell adhesion molecules (Bazzoni et al., 2000; Hirata et al., 2001) and, in adult tissues, are predominantly localized to cellcell contacts between epithelial and endothelial cells. Like other members of CTX/JAM subfamily, the extracellular region of VSIG1 contains 2 Ig-like domains (V-and C2- 
type) and 6 sites of potential N-linked glycosylation. The predicted molecular weight of VSIG1 is $47-\mathrm{kDa}$, while the affinity purified VSIG1 antibody recognizes an approximately 55-kDa protein in stomach. Enzymatic digestion of stomach extract by $\mathrm{N}-$ Glycosidase-F enzyme which removes N-linked oligosaccharides, revealed the presence of large amounts of N-linked glycosyl residues in VSIG1. The genomic organization of the members of this subfamly is similar. All of CTX/JAM genes including Vsigl encompass 7 exons encoding the same structural regions of their respective proteins. The exon-1 encodes the 5'-untranslated region and a large portion of the signal sequence, exons- 2 and -3 encode the V-type Ig-like domain, exons- 4 and 5 encode the C2-type Ig-like domain, exon-6 encodes the transmembrane domain and a portion of cytoplasmic domain and exon-7 encodes the remaining cytoplasmic domain and the 3 '-untranslated region.

Members of the CTX/JAM family localize to the tight (TJ) and adhesion junctions (AJ) of epithelial and endothelial cells, and are believed to mediate cell-cell adhesion (Bazzoni et al., 2003). The tight junction is the most apical junction in vertebrate epithelial cells and is responsible for the stable separation of the apical and the basolateral membrane domains by forming a diffusion barrier in the plane of the membrane. This physical diffusion barrier is very important for the functional separation of different compartments in an organism by restricting the free diffusion of macromolecules across epithelial monolayers (Stevenson and Keon 1998; Cereijido et al., 1998; Fleming et al., 2000; Tsukita et al., 2001).

Comparison of the amino acid sequence of the mouse VSIG1 with that of human VSIG1 revealed that the sequence of the extracellular domain is $81 \%$ identical, whereas the cytoplasmic domain shows only $46 \%$ sequence identity. The C-terminal region of human and mouse VSIG1 protein contain glutamine-proline repeat sequences (EP).

Alignment of the amino acid sequences of VSIG1 and other members of CTX/JAM subfamily is shown in figure-4.1. The amino acid sequence of the VSIG1 is $31 \%, 27 \%$, $29 \%, 26 \%, 27 \%, 24 \%, 31 \%, 28 \%$ and $30 \%$ identical to CTX, JAM-1, -2, -3, ESAM, CAR, IgSF11, Gpa33 and CLMP, respectively. The multiple sequence analysis showed that the extracellular domain of the CTX/JAM subfamily proteins is conserved. In contrast, the cytoplasmic domain is the least conserved region of the protein (Fig. 4.1). 


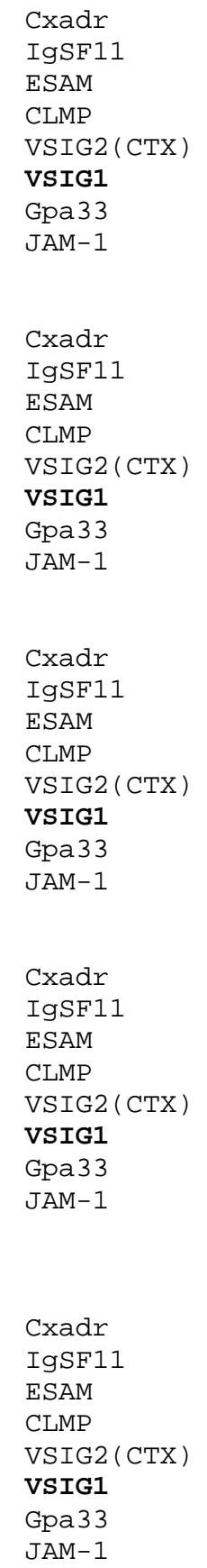

Cxadr

ESAM

CLMP

VSIG1

Gpa33

$$
\text { JAM-1 }
$$

Cxadr

IgSF11

ESAM

$\operatorname{VSIG} 2(\mathrm{CTX})$

GPa33

JAM-1

Cxadr

IgSF11

ESAM

CLMP

$\operatorname{VSIG2}(\mathrm{CTX})$

VSIG1

Gpa33

JAM-1
- - - - - - MAR - - LLCFVLLCGIADFTSGLSITTPEQRIEKAKGETAYLPCKFTLSP 47 - . - . - - MTRRRSAPASWLLVSLLGVATSLEVSESPGSVQVARGQTAVLPCAFSTSA 50 MILQAGTPETSLLRVLFLGLSTLAAFSRAQMELHVPPGLNKLEAVEGEEVVLPAWYTMAR 60 - . - - MSLFFLWLVSYYVGTLGTHTEIKRVAEEKVTLPCHHQLGL 40 - - - - - MAWPLVGAFLCGHLLGFVCLSGLAVEVTVPTEPLSVPKGKTAELSCSYKTSV 52 MMVFAFWKVFLILNCLAGQVSMVQVTIPDTFVNVTVGSNVTLLCLYTTTE 50 - . . - . - MLGKAGSVVWMFCAIWVAADALTVETTQDILRAARGRSVTLPCTYNTYV 49 - - - - MGTEGKAGRKLLFLFTSMILGSLVQGKGSVYTAQSDVQVPENESIKLTCTYSGFS 55 $+$

E - - DQGPLDIEWLISPSDNQ - IVDQVIILYSGDKIYDNYYPDLKGRVHFTSNDVKSGDAS 104 A - - LLN - LNVIWMVIPLSNA-NQPEQVILYQGGQMFDGALR-FHGRVGFTG - TMPATNVS 104 EESWSHPREVPILIWFLEQEGKEPNQVLSYINGVMTN - - - - KPGTALVHS - - ISSRNVS 113 P - - EKDTLDIEWLLTDNEGN - - - QKVVITYSSRHVYNNLTEEQKGRVAFAS - NFLAGDAS 94 G - - - DNFALEWSFVQPGKPISASVPVLYFTNGHLYPTGSKADRAILLHDP - - PTGGLAT 106 K- -SLEKLSIQWSFFHNKEM - -EEPISIYYSEGGQASAIGQFKDRIIGATN - - - PGNAS 102 S- - -DREGFIQWDKLLRSQT - - - ERVVTWNFVTKKYIYGNRYENRVRVSN-DAELSNAS 101 S - - - - - PRVEWKFVQGSTT - - - - ALVCYNSQITAP - - - - YADRVTFSS - - - - - - SG 92

$+$

$$
++
$$

INVTNLQLSDIGTYQCKVKKAPGVA - - NKKFLLT - - VLVKPSGTRCFVDGSEEIGNDF 158 IFINNTQLSDTGTYQCLVNNLPDRG - - GRNIGVTGLTVLVPPSAPQCQIQGSQDLGSDV 161 LRLGALQEGDSGTYRCSVNVQNDEGKSIGHSIKSIELKVLVPPAPPSCSLQGVPYVGTNV 173 LQIEPLKPSDEGRYTCKVKNS--..-- GRYVWSHVILKVLVRPSKPKCELEGEPTEGSDL 148 LKLTDLRPSDTGTYLCNVNNPPDFY - - TNGLGLINLTVLVPPSHPLCSQSGQTSVGGSA 163 ITILHMQPADSGIYICDVNNPPHFV - - -GKNQGLLDVTVLVKPSKPFCTIQGRPEAGHPI 159 ITIDQLTMDDNGTYECSVSLMSDQD---VNAKSRVRLLVLVPPSKPDCSIQGEMVIGNNI 158 ITFSSVTRKDNGEYTCMVSEEGGQN - - - -YGEVSIHLTVLVPPSKPTISVPSSVTIGNRA 148 $+$ $* * * *+$

KLKCEPKEGSLPLQFEWQKLS - - - - DSQTMP - - - - TPWLAEMTSPVISVKNASSEYSG 208 ILLCSSEEGIPRPTYLWEKLD - - - - NTLKLP - - - - PTATQDQVQGTVTIRNISALSSG 211 TLNCKSPRSKPTAQYQWERLA - - . - - PSSQVF - . - . - FGPALDAVRGSLKLTNLSIAMSG 223 TLQCESASGTKPIVYYWQRIREKEGEDEHLPP - - - -KSRIDYNNPGRVLLQNLTMASSG 203 ALGCRSSEGAPKPVYNWERLGS - - - - SPTPPP - - - - GSMVQDEVSGQLILTNLSLTSSG 214 SLSCLSAFGTPSPLYYWYNIEG - - - - NTIVP - - - -VKESFNTATGVLVIGNLTNFEQG 209 QLTCHSAEGSPSPQYSWKSYN- - - - AQNQQ - - - -RPLTQPVSGEPLLLKNISTETAG 207 VLTCSEHDGSPPSEYSWFKDGISMLTADAKKTRAFMNSSFTIDPKSGDLIFDPVTAFDSG 208 * * - + *

TYSCTVQNRVGSDQCMLRLDVVPPSNR-AGTIAGAVIG - - - TLLALVLIGAILFCCHRK 263 LYQCVASNAIGTSTCLLDLQVISPQPRSVGVIAGAVGTGAVLIVICLALISGAFFYWRSK 271 VYVCKAQNRVGFAKCNVTLDVMT - -GSKAAVVAGAVVG - - - TFVGLVLIAGLVLLYQRR 277 LYQCTAGNEAGKESCVVRVTVQY - -VQSIGMVAGAVTG - - - IVAGALLIFLLIWLLIRRK 258 TYRCVASNQMGSASCELNLSVTD - - - SSEGRVAGTLIG - - - -VLLGVLLLSVAAFCLIRF 267 YYQCTAINSLGNSSCEIDLTSSH - - -PEVGIIIGALVG - - - ALIGAAVIICVVYFARNK 262 YYICTSSNDVGIESCNITVAPRPP-SMNIALYAGIAGS- - -VFVALIIIGVIVYCCCCR 262 EYYCQAQNGYGTAMRSEAAHMDAVELNVGGIVAAVLVT-----LILLGLLIFGVWFAYSRG 264 $* * * *$ * $*$ - $\quad++$

RREEKYEKEVHH - - - DIREDVPPPKSRTSTARS - - - - - - - - - - - - - - 293 NKEE - EEEEIPN - - -EIREDDLPPKCSSAKAFHTEISSSENNTLTSSNTYNSRYWNNNPK 327 SKTL - - - EELAN - - - DIKEDAIAPRTLPWTKGSDTISKNGTLSSVTSARALR - - - - - - - 323 SKDRYEEEDRPN - - -EIREDAEAPRARLVKPSSSSSGSRSSRSGSSSTRSTG - - - - - - - - - 307 QKERKKEPKETYGGSDLREDATAP . . . . . . . . . . . . . . . . . . . 291 VKSKQQKNLNSSTELEPMTKVHHPQQSEAISADGVQLEGTLPSSIHAGHNTEPTTTAVLE 322 EKDDKDQDREDAR - PNRAAYQVPK- . YFERTKKGTAPG - _ _ _ 


Cxadr
IgSF11
ESAM
CLMP
VSIG2(CTX)
VSIG1
Gpa33
JAM-1

CXadr
IgSF11
ESAM
CLMP
VSIG2(CTX)
VSIG1
Gpa33
JAM-1

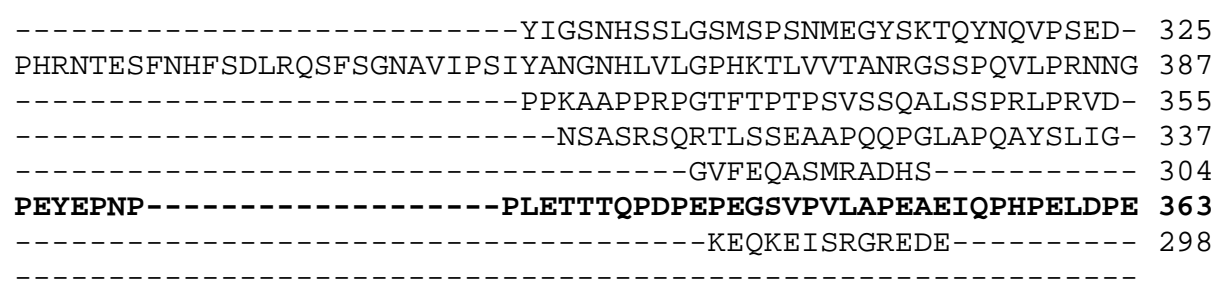

- FERAPQSPTLAPAKVAAPNLSRMGAVPVMIPAQSKDGSIV- - - 365 SVSRKPWPQHTHSYTVSQMTLERIGAVPVMVPAQSRAGSLV- - - 428

- - EPPPQAVSLTPGGVSSSALSRMGAVPVMVPAQSQAGSLV - - 394

- - - - PEVRGSEPKKVHHTTLTKAETTLSTTPSQSKAFQTV- - - 373

- - - - 328

TETEPEPEPEPKPEPEPEPELEPDPQSGVIIEPLSKAGEDTVKA 407

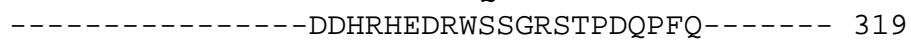

- . KKVIYSQPSTRSEGEFKQTSSFLV - - 300

Figure 4.1 Multiple sequence alignment of VSIG1 with the members of CTX/JAM

subfamily. ClustalW2 program displays the amino acid alignment of $8 \mathrm{CTX} / \mathrm{JAM}$ subfamily members. Underlined V-type, C2-type Ig-like domains and transmembrane domain show high homology. In contrast, the C-termal regions of the proteins are less homologous. Amino acid identities are shown below the alignments: *, identity; +, high similarity; -, similarity.

The evolutionary relationship of VSIG1 with other members of CTX/JAM subfamily was identified by multiple sequence analysis (Fig. 4.2). This analysis demonstrated that VSIG1 is more closely related to IgSF11, ESAM and CLMP molecules in CTX subfamily.

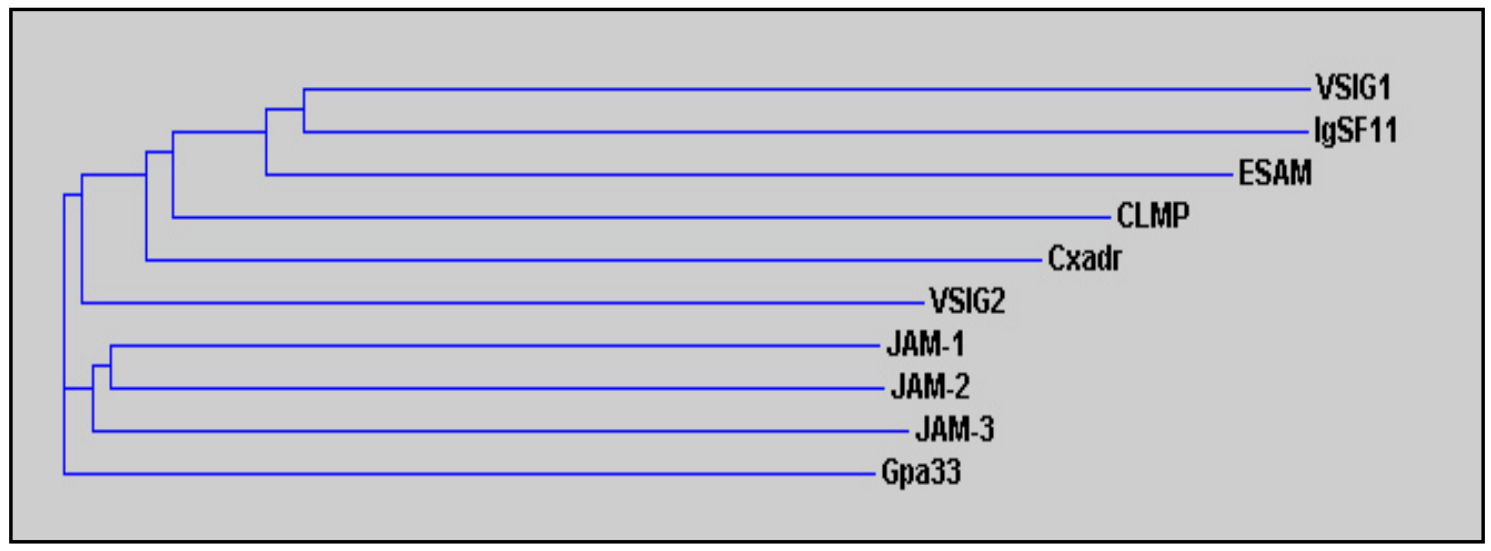

Figure. 4.2 Phylogenetic tree of CTX subfamily member proteins based on multiple sequence alignments. The members of CTX subfamily are compared by the program ClustalW2 and display as phylogenetic relationship tree. 


\subsection{Expression analysis of Vsig1 gene}

The majority of CTX/JAM family members (JAM-1, -2, -3, ESAM and CAR) do not exhibit tissue specific expression, but are expressed predominantly in endothelial cells, leukocytes and epithelium from various organs. (Bazzonni, 2003). BT-IgSF11 and GPA33 are the exception. BT-IgSF11 expression is restricted to brain and testis, while the GPA33 is expressed almost exclusively in mucosa of small and large intestine (Johnstone et al., 2000).

Tissue distribution of Vsigl gene expression in adult mouse was demonstrated by Northern blot and Western blot analysis. Northern blot analysis showed that an approximately 2.7-kb transcript is exclusively expressed in stomach and testis (Fig 3.11). Western blot analysis showed that a highly glycosylated, approximately 55-kDa protein is expressed in stomach and testis. The expression patterns of Vsigl at the mRNA and at the protein levels correlated well with each other.

A murine stomach consists of two distinct regions, the anterior and the posterior region. The anterior region (forestomach) is lined with a multilayer of squamous epithelium, which shows cornification and it is almost identical to the oesophageal epithelium. The posterior region of stomach is lined with a monolayer of columnar epithelium, which forms gastric units. The stomach posterior region can be subdivided into two regions: corpus and antrum, which are different as their unique features of gastric glands. The immunohistochemistry analysis shows that VSIG1 is specifically expressed only in glandular epithelium of posterior region of stomach. No VSIG1 expression could be detected in squamous epithelium in anterior stomach. The immunohistochemistry analysis detected the VSIG1 protein in the epithelium of posterior region of stomach of E13.5 and no VSIG1 was detected in the epithelium of anterior region. In E14.5 and E17.5 stomach, a much stronger expression of VSIGl was observed in primordial buds of the glandular gastric epithelium. Stomach differentiation begins in E10.5 from anterior region of primitive gastric tube by outgrowing of bud in E9.5-E10.5 (Fig. 1.2). In E12.5, presumptive forestomach and presumptive glandular stomach are composed of undifferentiated simple epithelial lining and surrounding undifferentiated mesenchymal cells. Cytodifferentiation of the gastric epithelium is initiated around E13.5. At E16.5, the epithelium of the forestomach is a squamous multilayer, whereas the epithelium of the glandular stomach is a monolayer of columnar cells that have formed primitive epithelial invaginations (Songyuang et al., 1997). The specific expression of VSIG1 in 
the glandular epithelium during early development of stomach suggests that VSIG1 plays a role in cytodifferentation of stomach epithelium.

Expression pattern of Vsigl is similar to that of Ihh (Indian hedgehog of (Bitgood et al., 1995). Ihh is expressed early in the anterior stomach and the expression depends on FGP (Fibroblast Growth Factor) signalling as both $\mathrm{Fg} f r 2 b^{-/-}$and $\mathrm{Fgfl}^{-/-}$mice have lack of expression of Ihh in the stomach (Spencer-Dene et al., 2006). In Ihh-deficient mice, the glandular stomach differentiation was failed and Shh (Sonic hedgehog) was upregulated in whole stomach region (Fukuda et al., 2003). These similar expression patterns suggest that Vsigl may have a role in hedgehog signalling pathways for stomach differentation characterized by differentially expression of Ihh and Shh.

The murine and human Vsigl gene is localized in the $\mathrm{F} 1$ region of the murine $\mathrm{X}$ chromosome and in human Xq22.3, respectively. Male and female genome have only one active X-chromosome. However, Lyon et al (1962) first time predicted that some $\mathrm{X}$-linked pseudoautosomal genes should escape from $\mathrm{X}$-inactivation for the $\mathrm{X}$ and $\mathrm{Y}$ chromosomes equivalent dosage and later Mohandas et al (1979) showed that Sts (steroid sulfatase $(\mathrm{Xp} 22.32))$ is the first clear example of $\mathrm{X}$-inactivation escaped gene. Now it is estimated that approximately $15-20 \%$ of $\mathrm{X}$-linked genes are escape $\mathrm{X}$ inactivation in human (Carrel et al., 1999) but in mouse, few number of genes escape in comparison to human (Disteche, 1995, 1999; Payer and Lee, 2008). This issue raises a question whether Vsigl escapes from X-inactivation. Northern blot analysis revealed that Vsigl gene does not escape from $\mathrm{X}$-inactivation, and the expression doage of Vsig 1 is identical in stomach of male and female. Most of the genes, which escape from Xinactivation, are localized on the pseudoautosomal region PAR1 and PAR2 (D'Esposito et al., 1996). Also some genes, which are localized somewhere outside of PAR1 and -2, were identified as escaped genes from X-inactivation. Most of these genes are multicopy genes, which are homologous with other autosomal genes (Carrel and Willard, 2005). The facts, that Vsigl is a single copy gene, and not localized on pseudoautosomal regions, give us a confirmation that Vsigl gene does not escape from $\mathrm{X}$-inactivation.

\subsection{VSIG1 is a transmembrane protein localized on plasma membrane of glandular epithelial cells}

The immunohistochemical analysis showed that VSIG1 protein is localised on the basolateral plasma membrane of the epithelial cells. The localization of VSIG1 to cellcell contacts suggested that VSIG1 plays diverse roles in cell-cell adhesion. 
Adhesion molecules play essential roles in the overall tissue organization and the proper physiological function of organs by establishing and organizing cell-cell contacts (Aurrand-Lions et al., 2000). Most of the members of CTX/JAM subfamily are junctional adhesion molecule localizing on the plasma membrane of the cell-cell adhesion (Ebnet et al., 2003).

Epithelial cells have distinct apical and basolateral membrane domains that differ in protein and lipid composition. These two domains are separated by tight junctions (TJs), where the certain leaflets of plasma membrane of adjacent cells appear as series of fusions, the so called TJ-strands (Tsukita et al., 2001). These fusion points restrict the free diffusion of lipids and integral membrane proteins between the two compartments (fence junction). Tjs, therefore, are crucial in the generation and maintains of cellular polarity in vertebrate endothelial and epithelial cells (Yeaman et al., 1999). Three types of tight junction proteins have identified so far. These are occludin, claudins (Furuse at al., 1998), and several immunoglobulin (Ig) subfamily members such as JAM-1, (Martin-Pudura et al., 1998; Ebnet et al., 2003), ESAM (Nasdala et al., 2002) and CAR (Cohen et al., 2001). Among these, occludin and claudins seem to form the molecular basis of tight junction strand, as antibodies against occludin exclusively label $\mathrm{Tj}$ strands (Saitou et al., 1997). To determine whether VSIG1 is localized to TJs and/or adhesion junction of the basolateral membrane, co-immunolocalization of VSIG1 and occludin and/or JAM-1 must be done.

The intercellular adhesion is mediated through interaction of adhesion molecules between two apposing cells. Several members of immunoglobulin superfamily are involved in the cell-cell adhesion. Nectins are cell adhesion proteins and belong to immunoglobulin superfamily. The extracellular regions of nectins homophilically and heterophilically interact in trans with each other; (Takahashi et al.,1999; SatohHorikawa et al., 2000; Reymond et al., 2001). Two nectin molecules at the surface of the same cell first form cis-dimers, followed by trans-interaction by the cis-dimers on apposing cells (Miyahara et al., 2000) (Fig. 4.3). When this trans-interaction occurs between two apposing cells, the cells adhere to each other (Fig. 4.3). In contrast to the nectins, the extracellular regions of cadherins only homophilically interact in trans with each other (Takeichi., 1995) (Fig 4.3). The trans-interaction between cadherin molecules is $\mathrm{Ca}^{2+}$-dependent, whereas that between nectin molecules is $\mathrm{Ca}^{2+}$ independent. 


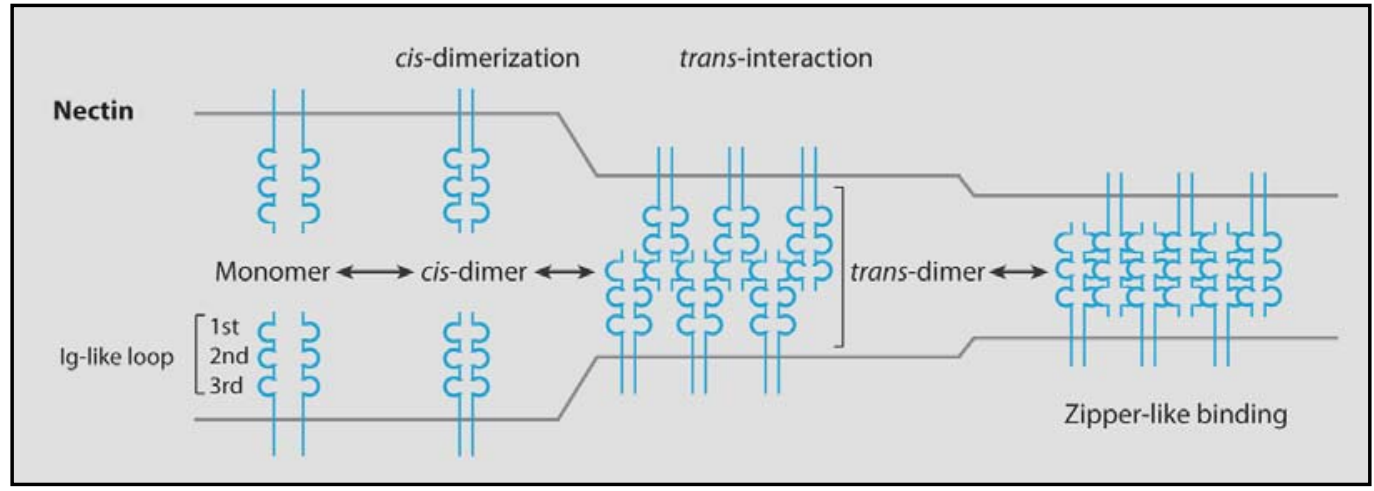

Figure 4.3 Schematic illustration of the cis- and trans-interactions of nectins (Takai et al., 2008). Two nectin molecules of the same plasma membrane first form cis-dimers and then form a trans-interaction by the cisdimers on apposing cells through each first Ig-like loop or in a zipper-like fashion with all three Ig-like loops.

To determine the role of Vsigl in cell-cell adhesion, we have established a stable transfected HepG2 cell line, in which the Vsigl is overexpressed. Immunohistochemical analysis revealad that the VSIG1 protein is localized at the plasma membrane of the stable transfected HepG2 cells. To check the role of VSIG1 in cell-cell adhesion, we performed adhesion assay. The adhesion assay showed that the aggregation activity of VSIG1-expressing cells is weaker than that of control cell line, which does not express VSIG1. These results reveal that the overexpression of VSIG1 in HepG2 cells decreases the cell adhesion. These results can be explained by several reasons.

The cell adhesion molecules make trans-interaction by homophilic and heterophilic manner. Some molecules make the trans-interaction by both of the manner and some molecules make it by only homophilic and heterophilic manner, respectively. The VSIG1 may mediate cell-cell adhesion by homophilic and heterophilic interaction. The homophilic interaction of VSIG1 $\leftrightarrow$ VSIG1 alone could not support the cell adhesion. Therefore, the absence of the heterotypic partner of VSIG1 in HepG1 cell line may be the cause for the low affinity of cell-cell adhesion. Similar results were obtained by the experiments on the Necl-5-overexpressing cell line (Aoki et a., 1997; Ikeda et al., 2003). The other possible explanation is that the cell-cell adhesion activity of VSIG1 is $\mathrm{Ca}^{2+}$ dependent. E-cadherin is one of the well characterized cell adhesion molecules and can 
be clear example of $\mathrm{Ca}^{2+}$-dependent cell-cell adhesion. Kitajima et al (1996) did experiments to check whether the E-cadherin mediated cell-cell aggregation is $\mathrm{Ca}^{2}$ dependent. They produced stable transfected hepatocytes, which overexpressed Ecadherin (PC12/tax). They did 2 parallel aggregation assays with the PC12/tax cell line. One assay was performed with medium containing $1 \mathrm{mM} \mathrm{CaCl}_{2}$ and another assay containing $1 \mathrm{mM}$ EDTA. The results of aggregation assay showed that PC12/tax cells are aggregating in the presence of $1 \mathrm{mM} \mathrm{CaCl}_{2}$, whereas the $1 \mathrm{mM}$ EDTA treated PC12/tax cells failed to aggregate (Kitajima et al., 1996). These findings revealed that the cell-cell adhesion mediated by E-cadherin is significantly dependent on the presence of $\mathrm{Ca}^{2+}$.

The third possible explanation is the absence of an interaction partner, which is interacting with intracellular domain of the VSIG1 in the HepG2 cell line. The Cterminal end of JAM-2 contains a PDZ binding domain, which is responsible for interacting with cytoplasmic interaction partners such as PAR-3, ZO-1 and ZO-2. JAM2-overexpressing $\mathrm{CHO}$ cell line can aggregate and grow as multilayer. Deletion of the PDZ binding domain disrupts the interaction of the JAM-2 protein with its cytoplasmic partners. Cells, which are overexpresing mutated JAM-2 have low affinity to aggregate and they grow as monolayer (Ebnet et al., 2003). This result indicates that the interaction of the intracellular domain of adhesion molecules with their interacting protein is crucial for cell-cell adhesion. Based on the above finding, it can be assumed that the absence of VSIG1-cytoplasmic partners in VSIG1-overexpressing HepG2 cell is one of the possible reasons for the low capacity of the VSIG1-overexpressing cells to aggregate.

\subsection{Isolation and characterization of stomach stem cell}

Northern blot and immunohistochemical analysis of Vsigl demonstrate that Vsig1 gene expression begins around E13.5 of stomach development. VSIG1 protein is detected in all cells of pseudostratified epithelium in that stage. There was no expression in mesenchymal layer. This highly specific expression in early stage of stomach development gives us a suggestion that Vsigl gene is expressed in stomach stem cells.

As described in above section, the stomach epithelium begins to differentiate in E13.5 and form two distinct types of epithelium. Stratified squamous epithelium is in anterior region and monolayered glandular epithelium is in posterior region. Even differentiation of specific cell lineages and invaginations of epithelium to form glands 
begin already in the embryo, but mature glands are not formed before birth. At birth, $90 \%$ of the cells in the rudimentary gastric units are precursor cells. The percentage of progenitor cells is reduced to $20 \%$ in the first 7 days postnatally (P1-P7), when cellular differentiation occurs (Karam and Gordon, 1997).

Existing reports on the localization of epithelial stem cells in gastric unit are somewhat controversial. Karam and Leblond (1992) combined radioactive thymidin labelling and electron microscopy analysis to identify cell types in the gastric unit of the glandular region of adult mice. They found out that the multipotent stem cells of the glandular epithelium are localized in the isthmus region. They also identified three progenitor cell lineages, pre-pit, pure-neck and pre-parietal precursors, which become differentiated from multipotent stem cells. It is also considered that the antral gastric mucosa, including the endocrine cells derived from a common stem cell located in the isthmus region (Karam and Leblond, 1995). Several studies have shown that stomach glands are homotypic, and thus, all of the different cells in one gland are clonally derived from the same parent progenitor cell (Thompson et al., 1990; Tatematsu et all., 1994). Other studies have shown that in the beginning of invagination, most glands are initially polyclonal with three or four stem cells per gland, and they become monoclonal during the first six weeks of murine life (Nomura et al., 1998).

Gastric stem or progenitor cells have not been well-characterized due to the lack of specific markers that permit their prospective recognition. Recently, Barker et al (2007) have used the cDNA probe of LGR5, which is an intestine stem cell marker, to localize the epithelial stem cells in gastric unit. The in-situ hybridization showed that epithelial stem cells are localized on the base of gastric unit similar to localization of epithelial stem cells in the base of intestinal crypt (Barker et al., 2007).

The high expression of Vsigl in glandular epithelium of embryonic stomach, which mainly contains epithelial stem and progenitor cells, suggest that VSIG1 could be useful as marker for isolation of the gastric epithelial stem cells. To isolate and characterize the epithelial stem cells of stomach, we have generated Vsigl-EGFP transgenic mice. Immunohistological studies revealed that the transgenic EGFP allele is expressed in most cells of glandular epithelium of stomach from embryos at E18.5. In adult stomach, no GFP-positive cells were detected in most gastric units. Approximately, every 20 gastric unit has only one unit which has one or two GFP-positive cells. This result demonstrates that the expression pattern of transgenic Vsigl-EGFP in embryonic stomach is similar to that of endogenous Vsigl gene. In contrast, the expression pattern 
of transgenic allele in adult stomach is different to that of endogenous $V$ sigl gene. It can be assumed that the 1.2-kb long 3'-untranslated region of Vsigl gene contains elements, which are responsible for stability of Vsigl mRNA in glandular epithelial of adult stomach. Such sequences are lacking in transgenic EGFP-mRNA. The results of many studies showed that the 3'-untranslated region of a gene influence the stability of its mRNA (Kakok et al., 2004; Ross, 1995; Adham et al., 2008). Shirneshan et al (2008) have generated a transgenic mouse Insl3-Ins, in which the human insulin gene is under the control of Leydig-cell specific gene (Ins13). They found that the expression of transgenic insulin mRNA was very low in Leydig cells. Replacement of 3'-untranslated region of insulin with that of Ins13 in the second transgenic allele resulted in a significantly higher transgene expression. These results suggest that the 3'-untranslated region of Insl3 contains elements, which are responsible for stability of transgenic transcript in Leydig cells (Shirneshan et al., 2008).

Alternative explanation came from our recent Northern blot analysis showing that Vsig1 gene transcribes $2.7-\mathrm{kb}$ and 2.0-kb mRNA isoforms in adult stomach. Both transcripts are different in the length of the 3'-untranslated regions and in the expression level. The 2.7-kb mRNA is highly expressed in adult stomach and contains 1.5-kb 3'-UTR, while the 2.0-kb mRNA is lowly expressed in adult stomach and contains 800-bp 3'-UTR, which is spliced at the first polyadenylation signal of the gene. Low expression level of the $2.0-\mathrm{kb}$ transcript in adult stomach suggest that this transcript is restricted to the epithelial stem cells similar to the transcript of the transgenic Vsigl-EGFP. Similar results were also observed from the characterization of the Villin-LacZ and Villin-EGFP transgenic lines, in which the reporter genes LacZ and EGFP are expressed under the control of Villin promoter (Qia et al., 2007). Immunohistochemical analysis of stomach section of adult transgenic mice showed that expression of reporter genes is restricted to a few epithelial cells in antrum of the stomach. Most glands did not appear to contain $\beta$ gal- or GFP-positive cells, when present; they commonly appeared as single cells in a single gastric unit. After treatment of the transgenic mice with interferon gamma (IFN$\gamma)$, Qia et al found that the gastric progenitor cells ( $\beta$-gal-positive cells) were greatly expanded in number and adjacent gastric gland often contained $\beta$-gal-positive cells. These data revealed that the gastric progenitor cells are normally quiescent, but that IFN- $\gamma$ induces their mitotic division.

To determine the percentage of GFP-positive cells in stomach during the pre- and postnatal developmental stages, flow cytometric analyses were performed. The GFP-positive cells 
constituted around $4.62 \%$ of the total cell suspension from whole stomach of E13.5. The percentage of GFP-positive cells increased during the prenatal developmental stages and reached at maximum level of $8.26 \%$ in cellular suspension of E18.5. After birth, the percentage of GFP-positive cells was decreased rapidly. This result is also consistent with the previous data about dynamics of stomach stem cell population according to developmental stages.

Establishing of primary cell culture, especially for epithelial stem cells of stomach is very important for characterization of stomach stem cell, studying gastric cancer and Helicobacter induced epithelial alteration. Successful establishment and characterization of stomach epithelial cell line have not yet been reported. Recently, Yang et al (2007) tried to isolate and characterise human epithelial stem cells of stomach. They used special medium (K-NAC) containing $5 \mathrm{ng} / \mathrm{ml}$ epidermal growth factor for the cultivation of stomach stem cell suspension. They could isolate several cell clones, which show stem cell morphology. After the first passage, various morphologically different cell types were observed in the passaged cells besides epithelial-like cells such as round cells, neuron-like and glial-like cells. To prevent the differentiation of the passaged cells, leukemia inhibitory factor (LIF; $10 \mathrm{ng} / \mathrm{mL}$ ), fibroblast growth factor (FGF; $200 \mathrm{mg} / \mathrm{mL})$, xanthosin $(50 \mathrm{mmol} / \mathrm{L}$ ) and pentagastrin $(0.1 \mathrm{mmol} / \mathrm{L})$ were added in the culture medium. However, all these agents failed to prevent the extensive differentiation of these cells (Yang et al., 2007).

We also tried to establish stomach stem cell line from FACS-sorted GFP-positive cells . We used ES-cell medium containing LIF to grow the GFP-positive cell. But the most GFPpositive cells were not attached to the dish, and also the few number of attached GFPpositive cells lost rapidly their green fluorescence after over night culture. This result suggests that the isolated GFP-positive cells are not able to grow under the used culture conditions.

\subsection{Functional analysis of $V$ sig 1 in chimeric mice}

In an effort to determine the function of X-linked Vsigl gene, we inactivated the mouse gene in embryonic stem cells through homologous recombination. In the conventional knockout construct, 1.7-kb genomic fragment containing exon-1 was deleted and replaced by neomycin-cassette. Only one Vsigl-null ES-clone could be detected and used for generation of chimeric mice. All generated chimera had low chimerism and did not transmit the targeted allele to their offspring. There are two explanations for the low contribution of the Vsig1-null cells in the development of chimera. The Vsigl-deficient cells of the isolated ES-clone may be differentiated during 
ES-culture. Therefore, the differentiated ES cells are not efficiently able to contribute in the development of chimeric embryos. The second explanation may be due to a crucial role of the Vsigl during early development, so that the high contribution of Vsigl-null cells in the embryonic development causes lethality of chimeric mice. Similar phenomena have been observed by targeted disruption of the neural cell adhesion molecule (Ncam) gene. All live-born chimeras derived from $\mathrm{Ncam}^{+/}$have a low level of ES cell contribution, whereas those with high level of contribution have several growth retardation defects in somites and neural tube formation and die between embryonic day 8.5 and 10.5 (Rabinowitz et al., 1996). Immunohistochemical analysis of the stomach from two of our adult chimeric mice revealed the contribution of the Vsigldeficient cells in the development of glandular epithelium. The Vsigl-deficient epithelium locating in the corpus region was morphologically similar to the squamous epithelium, which lines the forestomach. These results demonstrate that the Vsigldeficiency lead to transdifferentiate the glandular epithelium to squamous epithelium.

Several genes have been identified to have a crucial role in transdifferentiation of stomach epithelium. During mouse embryogenesis, the transcription factor GATA-4 is expressed first in primitive endoderm and then in definitive endoderm derivatives including glandular stomach and intestine. The expression of transcription factor GATA-4 in stomach is restricted to glandular epithelium. No expression of GATA-4 could be detected in squamous epithelium. Targeted disruption of GATA-4 leads to early embryonic lethality (Kuo et al., 1997: Molkentin et al., 1997). To explore the role of GATA-4 in development of gastric epithelium, chimeric mice have been generated by introducing $G A T A-4^{-/}$ES cells into blastocyst. Analysis of stomach from chimeric embryo at E18.5 revealed the presence of rare patches of $G A T A-4^{-/-}$epithelium in distal stomach. This heterotypic GATA $-4^{-/}$epithelium had a squamous morphology and did not express markers associated with differentiation of glandular epithelial cell lineages (Jacobsen et al., 2004). Mice deficient in the type-II activin receptors, ActRIIA and ActRIIB, have disrupted development of glandular stomach (Kim et al., 2000). $A c t R I I A^{+/}$and $A c t R^{-/}$embryos exhibit transformation of the distal stomach epithelium from columnar to stratified squamous morphology, a phenotype reminiscent of Vsig chimeras.

The epithelium of skin, oesophagus and forestomach is a multilayered squamous epithelium, while most gastrointestinal tract is lined by monolayer epithelium. Several lines of evidence revealed that the orientation of spindle during asymmetric division of 
stem cells is responsible for the development of mono- or multilayered structures (LeBlone et al., 1966; Smart, 1979; Wright and Alison, 1984; Ferguson, 1988). During the development of multilayered epithelium, the spindle in the progenitor cells is oriented in apico-basal direction, and the resulting daughter cells migrate to apical direction and will be differentiated. In the monolayer epithelium, the orientation of cell division is planar to the basement membrane and the daughter cells migrate up or down the stem cells (Fig.4.4).

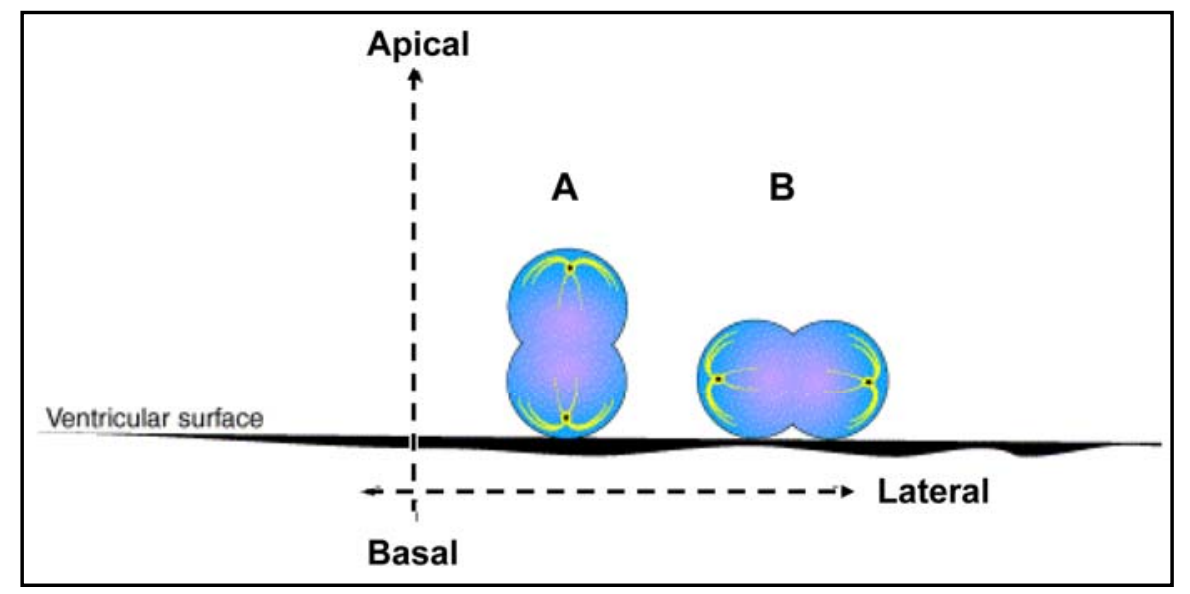

Figure 4.4 Schematic illustration showing orientation of epithelial cell division

(Roegiers and Jan, 2004). In epithelial tissues, the plane of cell division is not random; cytokinesis can be either parallel (A) or perpendicular (B) to the plane of the epithelium, but rarely at an oblique angle. The parallel plane of cell division generates the poly-layered stratified epithelium (skin, oesophagus), whereas perpendicular plane of cell division generates mono-layered glandular epithelium (intestine, glandular stomach).

At embryonic day 11.5, most of the mouse epidermis is single layered and most divisions occur laterally, within the plane of epithelium. During the late stage of development, as the epidermis become multilayered (E15.5), more that $70 \%$ of spindles are oriented perpendicularly to the basement membrane. Perpendicular alignments yield one basal and suprabasal cell, and their temporal appearance during skin development was found to correlate well with stratification (Lechler and Fuchs, 2005). Inactivation of transcription factor p63 in mice leads to transformation of epithelium in skin and oesophagus from multilayer to monolayer (Yang et al., 1999; Mills et al., 1999). Division in p63-null epidermis (E18.5) was lateral to the basement membrane (Lechler 
and Fuchs, 2005). These authors have shown that the localization of polarized proteins in the epithelial cells is responsible for orientation of the spindle axis.

Some of the polarized proteins are associated with adhesion proteins. For example JAM-1, -2, and -3 are associated with polarity proteins PAR-3 and ZO-1 (Ebnet et al., 2003). Based on their observations, deficiency of the VSIG1 in the basolateral membrane of the glandular epithelium may result in the loss of its associated polarity proteins. Therefore, the orientation of the spindle axis is changed from lateral axis to apical-basal axis. The resulting daughter cells migrate then to apical direction, instead the up und down migration, differentiate and form multilayer squamous epithelium.

To overcome the embryonic lethality of chimeric mice due to high level of $V \operatorname{sig} 1^{-} / Y$ ES cell contribution, we generated a $V$ sig $1^{\text {flox }} / Y$ ES cells. In the $V$ sig $1^{\text {flox }}$ allele, the exon- 1 is flanked with two LoxP sites. The Pgk-Neo cassette, which is flanked with frt-elements, was inserted in intron-1. Using the ES cells of two homologous recombinant $V \operatorname{sig} I^{\text {flox }} / Y$ -clones, we generated 46 chimeras. All generated chimeras had low level of $V \operatorname{sig} 1^{\text {flox }} / Y$ cell contribution (chimerism ranged between 1-20\%). This result lead us to suggest that the insertion of lox-P site and frt-flanked Pgk-Neo cassette in promoter and intron-1 of Vsigl gene, respectively, may impair the proper expression of the Vsigl gene. Several lines of evidence revealed that the insertion of Pgk-Neo cassette into an intron region of a gene can impair expression of floxed allele or lead to misexpression of neighbouring genes (Nagy et al., 1998). To avoid such an effect, we deleted the frt-flanked Pgk-Neo cassette in $V \operatorname{sig} 1^{f l o x} / Y$ ES cells by using Flp-recombinase-mediated vector. The generated $V_{\text {sig }} I^{l o x} / Y$-Neo $\Delta$ cells were injected into blastocyst to generate high chimeric mice. Unfortunately, we got also low chimeric mice. Therefore, it is possible that the insertion of the Lox-P sequence into the promoter region may downregulate the gene expression. To avoid such a negative effect of insertion of Lox-P in promoter region, we have generated a construct, in which the exon-3 is flanked with the Lox-P sites.

Breeding of the $V \operatorname{sig} 1^{f l o x} / Y$ male chimeras with wild-type females revealed that 9 of 12 chimeras $(75 \%)$ were infertile over 4 months of breeding. To investigate the reproductive defects in infertile chimeric mice, testis and sperm were isolated from 8 infertile males. 5 chimeric males had significantly smaller testis in comparison to wild type testis. The other three chimeras had testes with normal size. The sperm parameter analysis showed that the infertile chimeras had low quality of sperm parameters, such as reduced number of spermatozoa in cauda epididymis and impaired sperm motility. 
Histological analysis of chimeric testis revealed that the testes of the chimeric mice had a range of unusual seminiferous tubules (about $95 \%$ of all tubules) which show large vacuolization and almost complete loss of spermatogenic cells (Fig. 3.37). Also the damaged tubules contained aggregated cells which did not express spermatogenic markers such as GCNA and Apg-1. Most of the seminiferous tubules contained multilayered pretubular cells.

The infertility of chimeric mice caused by severe germ cell degeneration in seminiferous tubules lead our group to study the expression pattern of Vsigl during testis development. The results of RNA analysis revealed that the Vsig1 transcribes 2.7$\mathrm{kb}$ and $1.5-\mathrm{kb}$ transcripts in testis. The expression of $2.7-\mathrm{kb}$ is restricted to Sertoli cell and $1.5-\mathrm{kb}$ is restricted to haploid spermatid. Immunohistological analysis showed that VSIG1 is localized in the Sertoli-Sertoli and Sertoli-germ cells junctions. This result gives us a suggestion that VSIG1 has a role for spermatogenesis through the interaction between Sertoli-Sertoli and Sertoli-germ cells.

Two unique type of cell-cell adhesion junction (AJs) in seminiferous epithelium are known. Sertoli-Sertoli junctions (Ssj) and Sertoli-Spermatid (Sspj) junctions (Fig 4.5). Inter-Sertoli cell tight junctions compose the blood-testis barrier (BTB), which divides the seminiferous epithelium into two compartments: the spermatogonia containing basal compartment and the immuno-priviliged adluminal compartment.

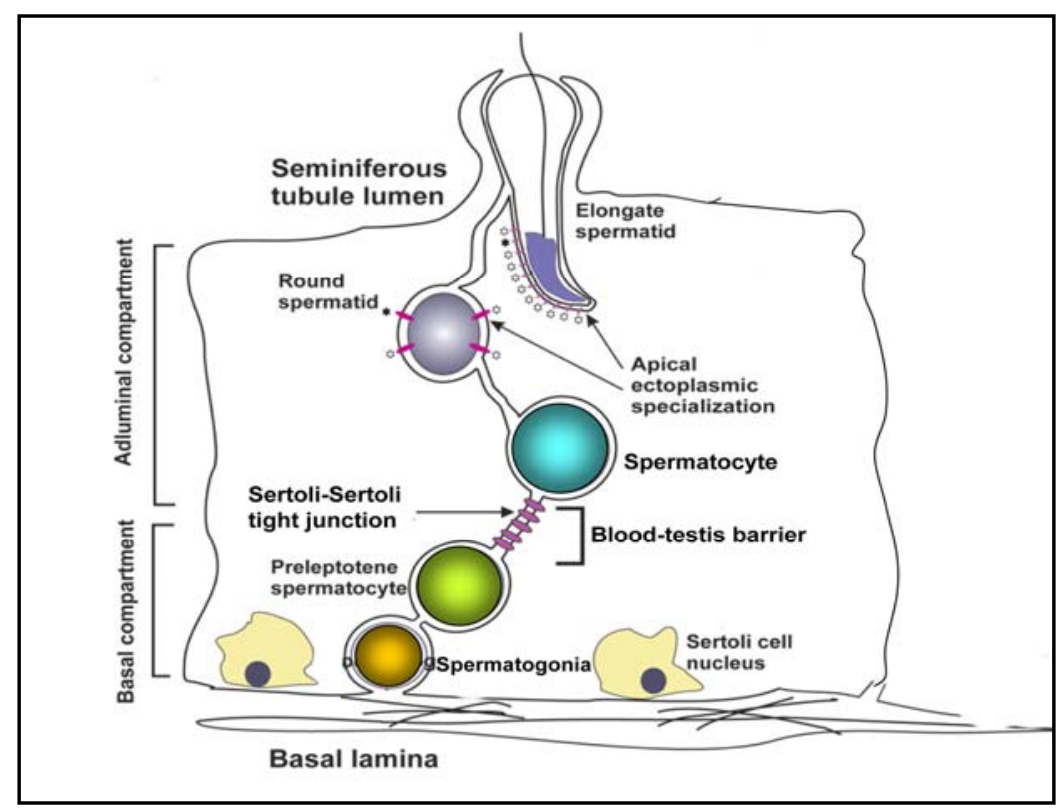

Figure 4.5 Illustration showing the migration of developing germ cells in the seminiferous epithelium of the adult testis (Wang et al., 2007 (modified)). 
Germ cells first have to break through the Sertoli-Sertoli tight junctions at the BTB with minimal disruptions. After the opening of the BTB, the progression of germ cells relies solely on series of transient adherens junctions at the Sertoligerm cell interface.

Cell adhesion molecules of the CTX/JAM and nectin family are located at Sspj and Ssj, and participate in germ cell migration through homophilic and heterophilic interactions. JAM-2 and -3 interact with each other, with JAM-2 coming from the Sertoli cell side and JAM-3 from the spermatid site to form heterotypic interactions (Gliki et al., 2004). Knockout studies have shown that JAM-3 is required for the assembly of the polarity complex in round spermatids and JAM-3 knockout mice are infertile because of lack of mature spermatozoa. JAM-1 is co-localized with occludin-1 at the Ssj of BTB (Xia et al., 2005) and also localized at Sspj. Inactivation of JAM-1 lead to disruption of sperm motility (Shoa et al., 2008). In the absence of nectin-2 and -3, Sspj does not form properly (Mueller et al., 2003; Inagaki et al., 2006). Nectin-2 $2^{-/-}$and Nectin- $3^{-/-}$mice exhibit defective sperm morphogenesis and male infertility.

Immunohistological localization of VSIG1 in testis showed that subcellular localization of Vsig1 is not only restricted to the Sertoli-Sertoli and Sertoli-Spermatid cell junctions, but also between Sertoli-spermatocyte cell junction. Such Sertoli-spermatocyte cell junctions have not been described so far. Therefore, further co-immunolocalization of VSIG1 with adhesion molecules such as occludin, JAM-1, -2, and -3 in seminiferous tubules must be done to prove the exact localization of VSIG1 at cell junctions of testes epithelium.

The presence of Sertoli cell-only seminiferous tubules in testes of the infertile $V$ sigl $1^{\text {flox }} / Y \leftrightarrow \operatorname{Sig}^{+} / Y$ chimeras may contribute to disrupt the tight-junctions between Sertoli-Sertoli cells, which is responsible for blood testes barrier. Disruption of BTB may result in autoimmune orchitis. The infiltration of inflammatory cells may then degenerate the germ cells in seminiferous tubules of the chimera.

\subsection{Perspectives}

Each stage of animal development is determined by the set of genes transcribed specifically at that moment. Identification and characterization of differentially expressing genes and analysis of underlying regulatory mechanisms of these genes for certain 
developmental processes is vital to understand the whole sequences of developmental phenomena in animals.

Till now, a very few number of molecular markers of stomach epithelial cells have been identified. For example, pepsinogen, $\mathrm{H}^{+} / \mathrm{K}^{+}$-ATPase, lectins are well characterized markers for zymogenic, parietal and pit cells, respectively. Nevertheless, all these proteins are markers of certain types of differentiated mature cells and they are not useful for detecting all type of stomach epithelial cells, as well as for analysis of epithelial differentiation of embryonic stomach. Our studies showed that Vsigl is specifically expressed in undifferentiated epithelial cells in a very early stage of stomach (E13.5), and the protein is abundantly detectable further in all types of glandular epithelial cells of stomach during the whole lifespan. Therefore, VSIG1 could be an excellent universal molecular marker of all types of stomach epithelial cells and it can be used for a wide range of studies including overall identification of glandular epithelium, malformations, transdifferention, and epithelial growth of stomach. Especially, the regulatory elements of Vsigl could be perfectly suited for generation of different transgenic mouse models which can be very useful for isolation and characterization of stomach stem cells and gastric tumorigenesis studies.

Functional analysis of Vsigl must be done in detail by several approaches. The failure of several attempts to establish a $\mathrm{V}$ sigl $\mathrm{I}^{-} \mathrm{Y}$ deficient mouse model in the present studies give us suggestion that chimeric mice must be generated by recombinant ES cells produced by homologous recombination event, which does not interfere with the normal function of Vsigl gene. For that purpose, deletion of certain exons, such exon-2 or -3 which locate far away from the gene regulator sequences should be preferable. Once we obtained $V$ sigl $I^{\text {flox }} /$ ${ }^{f l o x}$ and $V \operatorname{sig} I^{f l o x} / Y$ mice, several kind of tissue specific functional analysis would be possible by breeding with different Cre-transgenic mice. For example the $V_{\text {sig }}{ }^{f l o x} / Y-E I I-C r e$ mouse model is very suitable for investigating the role of Vsigl during embryonic development. Also the stomach and testis specific role of Vsigl can be studied by $V_{s i g}{ }^{f l o x} / Y-V s i g 1-C r e$ and $V_{\text {sig }}{ }^{\text {flox }} / Y-A M H-C r e$ (Anti-Müllerian Hormone) mice, respectively.

Our established Vsig1-EGFP transgenic mouse model revealed that stomach stem cells are not localized in every gland and they are localized randomly in one gland of about 20 glands. Also it was shown that the position of stomach stem cells is random, so it can be everywhere in gastric gland from base to pit regions. However, our stomach stem cell studies have several disputable problems mostly concerning on the different patterns of VSIG1 protein distribution and Vsig1 promoter activity. This problem raises a question that whether the $4.5-\mathrm{kb}$ promoter region of Vsigl and SV40 poly-adenylation signal used for Vsig1-EGFP transgenic construct is sufficient for complete expression of 
Vsigl. To solve this problem, it is very important to establish another transgenic mouse line, in which Cre-recombinase is expressed under the control of 4.5-kb Vsigl promoter. This Vsigl-Cre transgenic mouse can be crossed with Rosa-26 indicator mouse line, which has ubiquitous expression of Lac-Z in case of deletion of transcription terminal sequence flanked by lox-P sites. The obtained double transgenic mouse VsiglCre/Rosa-26 will give the opportunity to make lineage tracing analysis of stomach epithelial cells by Lac-Z staining. The results will show whether all the epithelial cells are derived from the GFP-positive stem cells or not. If so, this result will confirm surely that the GFP-positive cells are stomach stem cell.

By using the chimeric mouse wild type $\leftrightarrow$ Vsigl-Cre/Rosa-26, it will be possible to reconfirm that all cells of a gastric unit are clonally derived from one stem cell.

One of the interesting points in the framework of Vsigl studies is the identification of interaction partners of VSIG1. To do that, yeast two hybrid and co-immunoprecipitation experiments must be done. The identification and characterization of VSIG1 interaction partners will help to understand broadly about the precise mechanism of stomach epithelial cell differentiation and epithelial cell polarity. 


\section{Summary}

The aims of this study were to determine expression pattern and subcellular localization of VSIG1, a novel member of the immunoglobulin superfamily, and to analyse the function of the Vsig1 gene.

In order to study the expression of VSIG1 at the protein level and determine the subcellular localization, we have generated polyclonal anti-VSIG1 antibody. Northern and Western blot analysis shows that Vsig1 gene is expressed specifically in stomach and testis. The immunohistochemical analysis showed that VSIG1 is localized on plasma membrane of glandular epithelial cells of stomach, the staining was most intense in the basolateral membrane of the pit cells. Vsigl mRNA and protein were not found in squamous epithelial cells of forestomach. The analysis of Vsig1 expression pattern during the pre- and postnatal developmental stages showed that Vsig1 is expressed initially in E13.5 stomach. The temporal and spatial profile of Vsigl expression suggests a potential role in regulation of cytodifferentiation of stomach epithelium.

To determine the function of Vsig1, a conventional Vsig1 knockout construct has been generated and used for transfection of embryonic stem cells. The $V \operatorname{sig} 1^{-} / Y \leftrightarrow V \operatorname{sig} 1^{+} / Y$ chimeric mice generated by injection of Vsig1-null cells into the blastocyst had low chimerism and did not transmit the targeted allele to their offspring. Analysis of chimeric mice leads us to suggest that a high contribution of Vsig1-null cells in the development of embryos causes lethality of chimeric embryos. Immunohistochemical analysis of the stomachs from two adult chimeric mice revealed that the corpus region of stomach contains Vsig1-deficient epithelial cells. This Vsig1-deficient epithelium was morphologically similar to squamous epithelium and expressed Cytokeratin-5/6 which is the marker of squamous epithelium. These results demonstrate that the Vsig1deficiency leads to transdifferentiate the glandular epithelium to the squamous epithelium.

To overcome the early embryonic lethality of chimeric mice possibly due to highly contributed $V \operatorname{sig}^{\top} / Y$ cells, a conditional targeting vector has been constructed. All chimeric mice had also low chimerism and $75 \%$ of them were infertile. Analysis of sperm parameters from the infertile chimeras revealed that the infertile chimeras had reduced number of spermatozoa in cauda epididymis and impaired sperm 
motility. Histological analysis of the testis from the infertile chimeric mice found a complete degeneration of spermatogenic cells in most of seminiferous tubules. These tubules contained also many vacuoles and aggregated cells accumulating in the lumen. The immunohistochemical analysis with anti-GCNA and anti-Apg1 showed that the altered seminiferous tubules do not have any germ cells.

The expression of the Vsig1 in stomach epithelium of early embryonic development (E13.5) leads us to suggest that the Vsig1 is expressed in stem cells of stomach epithelium. To further determine the expression of Vsig1 in progenitors of stomach epithelium and to perform isolation and cultivation of stomach epithelial stem cell, we have generated Vsig1-EGFP transgenic mice. The Vsig1-EGFP transgenic allele contains the EGFP gene under the control of the 5'-region of the Vsig1 gene. Immunohistological analysis of adult stomach showed that the very few number of GFP-positive cells are distributed as spots in approximately every one of 20 gastric units. Flow cytometric analysis showed that the percentage of GFP-positive cells increased during the prenatal developmental stages and reached to maximum level $(8.26 \%)$ in cellular suspension of stomach from E18.5. After birth, the percentage of GFP-positive cell decreased rapidly to $0.78 \%$ in P90 stomach sample. The FACS-sorted GFP-positive cells did not become attached to the dish and even the few number of attached GFP-positive cells lost rapidly their green fluorescence after 24-hrs. RT-PCR analysis showed that the stomach-derived cultured cells do not express pluripotency markers and early epithelial cell markers.

To study the expression of human VSIG1 protein in gastric cancer, a polyclonal antihuman VSIG1 antibody was produced. Immunohistological analysis with antihumanVSIG1 antibody was performed on the sections of gastric carcinoma representing early, middle and late stages of tumor differentiation. Immunohistological analysis revealed that human VSIG1 protein is strongly expressed in cell clusters containing poorly differentiated compact tumor cells in early stage of gastric carcinoma. In the middle stage of gastric carcinoma, reduced level of VSIG1 expression was observed only in some tumor cells and no expression of VSIG1 was detected in well differentiated tumor cells of late stage of tumorgenesis. 


\section{REFERENCES}

Aoki J, Koike S, Asou H, Ise I, Suwa H, Tanaka T, Miyasaka M, Nomoto A. (1997). Mouse Homolog of Poliovirus Receptor-related Gene 2 Product, mPRR2, Mediates Homophilic Cell Aggregation. Exp. Cell. Res, 235(2): 374-84.

Aubin J, Déry U, Lemieux M, Chailler P, Jeannotte L. (2002). Stomach Regional Specification Requires Hoxa5-Driven Mesenchymalepithelial Signaling. Development, 129: 4075-4087

Aurrand-Lions M. A, Duncan L, Du Pasquier L, Imhof B. A. (2000). Cloning of JAM-2 and JAM-3: an Emerging Junctional Adhesion Molecular Family?. Curr. Top Microbiol. Immunol, 251:91-98

Barbaric I, Miller G, Neil T. (2007). Appearances Can be Deceiving: Phenotypes of Knockout Mice. Brief Funct. Genomic. Proteomic, 6(2): 91-103

Barker N, Van Es J, Kuipers J, Kujala P, Van den Born M, Cozijnsen M, Haegebarth A, Korving J, Begthel H, Peters P. J, Clevers H. (2007). Identification of Stem Cells in Small Intestine and Colon by Marker gene Lgr5. Nature, 449: 1003-1008

Bazzoni G, (2003). The JAM family of Junctional Adhesion Molecules. Curr. Opin. Cell Bio, 15: 525-530

Bei M, Maas R. (1998). FGFs and BMP4 Induce Both Msx1-Independent and Msx1Dependent Signaling Pathways in Early Tooth Development. Development, 125(21): 4325-4333.

Bellusci S, Henderson R, Winnier G, Oikawa T, Hogan B. L. (1996). Evidence from Normal Expression and Targeted Misexpression That Bone Morphogenetic Protein (Bmp-4) Plays a Role in Mouse Embryonic Lung Morphogenesis. Development. 122(6) :1693-1702.

Bjerknes M and Cheng H. (2002). Multipotential Stem Cells in Adult Mouse Gastric Epithelium. Am. J. Physiol. Gastrointest. Liver Physiol, 283: G767-G777

Bitgood MJ, McMahon AP. (1995). Hedgehog and Bmp Genes Are Coexpressed at Many Diverse Sites of Cell-Cell Interaction in the Mouse Embryo. Dev. Biol, 172(1): 126-138

Bradford M. M. (1976). A Rapid and Sensitive Method for the Quantitation of Microgram Quantities of Protein Utilizing the Principle of Protein-dye Binding. Anal. Biochem 72: 248-54 
Bredemeyer A. J, Geahlen J, Weis V, J, Huh W. J, Zinselmeyer H. B, Srivatsan S, Miller M. J, Shaw A. S, Mills J. C. (2009). The Gastric Epithelial Progenitor Cell Niche and Differentiation of the Zymogenic (chief) Cell Lineage. Dev. Bio, 325: 211-224

Brink G. R. (2007). Hedgehog Signaling in Development and Homeostasis of the Gastrointestinal Tract. Physiol. Rev, 87: 1343-1375

Brittan M and Wright N. A. (2002). Gastrointestinal Stem Cells. J. Pathol, 197: 492509

Bryant D. M and Mostov K. E. (2008). From Cells to Organs: Building Polarized Tissue. Nat. Rev. Mol. Cell Bio, 9: 887-901

Carrel L, Cottle A. A, Goglin K. C, Willard H. F. (1999). A First-Generation XInactivation Profile of the Human X Chromosome. Proc. Natl. Acad. Sci. USA, 96(25): 14440-14444.

Carrel L, Willard H. F. (2005). X-inactivation Profile Reveals Extensive Variability in X-Linked Gene Expression in Females. Nature, 434: 400-404

Charchar F. J, Svartman M, El-Mogharbel N, Ventura M, Kirby P, Matarazzo M. R, Ciccodicola A, Rocchi M, D’Esposito M, Graves J. M. (2003). Complex Events in the Evolution of the Human Pseudoautosomal Region 2 (PAR2). Gen. Res, 13: 281-286

Caplan M. J, Seo-Mayer P, Zhang L. (2008). Epithelial Junctions and Polarity: Complexes and Kinases. Curr. Opin. Nephr. Hypert, 17: 506-512

Chrétien I, Marcuz A, Courtet M, Katevuo K, Vainio O, Heath J. K, White S. J, Du Pasquier L. (1998). CTX, a Xenopus Thymocyte Receptor, Defines a Molecular Family Conserved Throughout Vertebrates. Eur. J. Immunol, 12:4094-104.

Cohen C. J, Shieh J. T, Pickles R. J, Okegawa T, Hsieh J. T, Bergelson J. M. (2001). The Coxsackievirus and Adenovirus Receptor is a Transmembrane Component of the Tight Junction. Proc. Natl. Acad. Sci. USA, 98(26):15191-6

Coleman D. L, Kaliss N, Dagg C. P, Russell E. S, Fuller J. L, Staats J, Green M. C. (1966). Biology of the Laboratory Mouse. Dover Publications. inc, New York

Costa G. L and Weiner M. P. (1994). Protocols for Cloning and Analysis of BluntEnded PCR-generated DNA Fragments. PCR Methods Appl, 3: 95-106.

Kroschewski R. (2004). Molecular Mechanisms of Epithelial Polarity: About Shapes, Forces, and Orientation Problems. News. Physiol. Sci, 19: 61-66

Denhardt D. T. (1966). A Membrane-Filter Technique for the Detection of Complementary DNA. Biochem. Biophys. Res. Commun, 23: 641-6. 
D'Esposito M, Ciccodicola A, Gianfrancesco F, Esposito T, Flagiello L, Mazzarella R, Schlessinger D, D'Urso M. (1996). A Synaptobrevin-like Gene in the Xq28 Pseudoautosomal Region Undergoes X-inactivation. Nat. Genet, 13(2): 227-229

Disteche M. C. (1995). Escape from X-inactivation in Human and Mouse. Tren. Gen, 11: $17-22$

Ebnet K, Suzuki A, Ohno S, Vestweber D. (2004) Junctional Adhesion Molecules (JAMs): More Molecules with Dual Functions? J. Cell. Sci, 117: 19-29

El-Alfy M, Leblond C. P, Lee E. R. (1987). Dynamic Histology of the Antral Epithelium in the Mouse Stomach: V. Proliferation Gradient From the Gland Base to the Isthmus at Various Times of Day. The Amer. J. Anat, 178: 65-71

Ellison J, Passage M, Yu L, Yen P, Mohandas T. K, Shapiro L. (1992). Directed Isolation of Human Genes that Escape X Inactivation. Som. Cell. Mol. Gen, 18(3): 259-268

Esposito T, Gianfrancesco F, Ciccodicola A, D'Esposito M, Nagaraja R, Mazzarella R, D'Urso M, Forabosco A. (1997). Escape from X Inactivation of Two New Genes Associated with DXS6974E and DXS7020E. Genomics, 43: 183-190

Etienne-Manneville S. (2008). Polarity Proteins in Migration and Invasion. Oncogene, 27: 6970-6980

Fanning A. S, Mitic L. L, Anderson J. M. (1999). Transmembrane Proteins in the Tight Junction Barrier. J. Am. Soc. Nephrol, 10: 1337-1345

Feinberg A. P, and Vogelstein B. (1983). Technique for Radiolabeling DNA restriction endonuclease fragments to high specific activity. Anal. Biochem,132: 6-13

Fergusson D. J. (1988). An Ultrastructural Study of Mitosis and Cytokinesis in Normal "Resting” Human Breast. Cell. Tiss. Re, 252(3): 581-587

Plenk H. (1932). Der Magen. in Moellendorf, Springer-Verlag, Berlin

Förster C. (2008). Tight Junctions and The Modulation of Barrier Function in Disease. Histochem. Cell Biol, 130: 55-70

Fukamachi H, Mizuno T, Takay S. (1979). Epithelial-Mesenchymal Interactions in Differentiation of Stomach Epithelium in Fetal Mice. Anat. Embryol, 157: 151-160

Fukuda K and Yasugi S. (2005). The Molecular Mechanisms of Stomach Development in Vertebrates. Develop. Growth Differ. 47: 375-382

Fukuda K, Kameda T, Saitoh K, Iba H, Yasugi S. (2003). Down-Regulation of Endodermal Shh is Required for Gland Formation in Chicken Stomach. Mech. Dev, 120(7): 801-809 
Furuse M, Fujita K, Hiiragi T, Fujimoto K, Tsukita S. (1998). Claudin-1 and -2: Novel Integral Membrane Proteins Localizing at Tight Junctions with no Sequence Similarity to Occludin. J. Cell Biol, 141(7): 1539-50

Gershoni J. M, Palade G. E. (1982). Electrophoretic Transfer of Proteins from Sodium Dodecyl Sulfate-Polyacrylamide Gels to a Positively Charged Membrane Filter. Anal. Biochem, 124: 396-405

Gliki G, Ebnet K, Aurrand-Lions M, Imhof B. A, Adams R. H. (2004). Spermatid Differentiation Requires the Assembly of a Cell Polarity Complex Downstream of Junctional Adhesion Molecule-C. Nature, 431: 320-324

Gordon J. I and Hermiston M. L. (1994). Differentiation and Self-Renewal in the Mouse Gastrointestinal Epithelium. Curr. Opin. Cell. Biol, 6(6):795-803

Ikeda W, Kakunaga S, Itoh S, Shingai T, Takekuni K, Satoh K, Inoue Y, Hamaguchi A, Morimoto K, Takeuchi M, Imai T, Takai Y. (2003). Tage4/Nectin-like molecule-5 Heterophilically Trans-Interacts with Cell Adhesion Molecule Nectin-3 and Enhances Cell Migration. J. Biol. Chem, 278(30): 28167-72

Inagaki M, Irie K, Ishizaki H, Tanaka-Okamoto M, Miyoshi J, Takai Y. (2006). Role of Cell Adhesion Molecule Nectin-3 in Spermatid Development. Gen. Cells, 11(9): 1125-32.

Jacobsen C. M, Narita N, Bielinska M, Syder A. J, Gordon J, Wilson D. W. (2002). Genetic Mosaic Analysis Reveals That GATA-4 Is Required for Proper Differentiation of Mouse Gastric Epithelium. Dev. Biol, 241: 34-46

Jacobsen C. M, Mannisto S, Porter-Tinge S, Genova E, Parviainen H, Heikinheimo M, Adameyko I, Tevosian S. G, Wilson D. W. (2005). GATA-4:FOG Interactions Regulate Gastric Epithelial Development in the Mouse. Dev. Dyn, 234: 355-362

Javier R. T, (2008). Cell Polarity Proteins: Common Targets for Tumorigenic Human Viruses. Oncogene, 27: 7031-7046

Jeanes A, Gottardi C. J, Yap A. C. (2008). Cadherins and Cancer: How Does Cadherin Dysfunction Promote Tumor Progression? Oncogene, 27: 6920-6929

Johnstone C. N, Tebbutt N. C, Abud H. E, White S. J, Stenvers K. L, Hall N. E, Cody S. H, Whitehead R. H, Catimel B, Nice E. C, Burgess A. W, Heath J. K. (2004). Characterization of Mouse A33 Antigen, a Definitive Marker for Basolateral Surfaces of Intestinal Epithelial Cells. Am. J. Physiol. Gastroint. Liver. Physiol, 279: 500-510

Judd L.M, Gleeson P. A, Toh B, Van Driel I. R. (1999). Autoimmune Gastritis Results in Disruption of Gastric Epithelial Cell Development. Am. J. Physiol. Gastroint. Liver. Physiol, 277: 209-218

Halaby D.M, Mornon J.P.E. (1998). The Immunoglobulin Superfamily: An Insight on Its Tissular, Species, and Functional Diversity. J. Mol. Evo, 46: 389-400 
Harad H, Suzu S, Hayashi Y, Okada S. (2005) BT-IgSF, a Novel Immunoglobulin Superfamily Protein, Functions as a Cell Adhesion Molecule. J. Cell Phys, 204: 919-926

Held T, Paprotta I, Khulan J, Hemmerlein B, Binder L, Wolf S, Schubert S, Meinhardt A, Engel W, Adham I. (2006). Hspa4l-Deficient Mice Display Increased Incidence of Male Infertility and Hydronephrosis Development. Mol. Cell Biol, 26(21):80998108 .

Hodge R. (1994). Preparation of RNA Gel Blots. Methods. Mol. Biol, 28: 49-54.

Kaestner K. H, Schütz G, Monaghan A. P. (1997). Expression of the Winged Helix Genes fkh-4 and fkh-5 Defines Domains in the Central Nervous System. Mech. Dev, 55: $221-230$

Kang L. I, Wang Y, Suckow A. T, Czymmek K. J, Cooke V. J, Naik U. P, Duncan M. K, (2007). Deletion of JAM-A Causes Morphological Defects in the Corneal Epithelium. The Int. J. Biochem. Cell Bio, 39: 576-585

Karam S. M. and Leblond C. P. (1992). Identifying and Counting Epithelial Cell Types in the "Corpus" of the Mouse Stomach. The Anat. Rec, 232: 231-146

Karam S. M and Leblond C. P. (1993). Dynamics of Epithelial Cells in the Corpus of the Mouse Stomach. The Anat. Rec, 236: 259-279, 280-296, 333-340

Karam S, M and Leblond C. P. (1995). Origin and Migratory Pathways of the Eleven Epithelial Cell Types Present in the Body of the Mouse Stomach. Microscopy Res. Tech, 31: 193-214

Karam S. M. (1998). Cell Lineage Relationship in the Stomach of Normal and Genetically Manipulated Mice. Braz. J. Med. Biol. Res, 31: 271-279

Karam S. M. (1999). Lineage Commitment and Maturation of Epithelial Cells in the Gut. Front. Biosci, 4: 286-298

Karam S. M, Straiton T, Hassan W. M, Leblond C. P. (2003). Defining Epithelial Cell Progenitors in the Human Oxyntic Mucosa. Stem Cells, 21: 322-336

Kim Byeong-Moo, Buchner G, Miletich I, Sharpe P. T, Shivdasani R. A. (2005). The Stomach Mesenchymal Transcription Factor Barx1 Specifies Gastric Epithelial Identity through Inhibition of Transient Wnt Signaling. Dev. Cell, 8: 611-622

Kim S. K, Hebrok M, Li E, Oh S. P, Schrewe H, Harmon E. B, Lee J. S, Melton D. A. (2000). Activin Receptor Patterning of Foregut Organogenesis. Gen. Dev, 14: $1866-1871$

Kitajima I, Kawahara K, Hanyu N, Shin H, Tokioka T, Soejima Y, Tsutsui J, Ozawa M, Shimayama T, Maruyama I. (1996). Enhanced E-cadherin Expression and Increased Calcium-Dependent Cell-Cell Adhesion in Human T-cell Leukemia Virus Type I Tax-expressing PC12 cells. J. Cell Sci, 109: 609-617 
Koike T and Yasugi S. (1999). In-vitro Analysis of Mesenchymal Influences on the Differentiation of Stomach Epithelial Cells of the Chicken Embryo. Differentattion, 65(1): 13-25

Laemmli U. K. (1970). Cleavage of Structural Proteins during the Assembly of the Head of Bacteriophage T4. Nature, 227: 680-5.

Laird P. W, Zijderveld A, Linders K, Rudnicki M. A, Jaenisch R, Berns A. (1991). Simplified Mammalian DNA Isolation Procedure. Nucleic. Acids. Res. 19: 4293.

Laukoetter M. G, Nava P, Nusra A. (2008). Role of the Intestinal Barrier in Inflammatory Bowel Disease. World. J. Gastro, 14(3): 401-407

Lechler T, Fuchs E. (2005). Asymmetric Cell Divisions Promote Stratification and Differentiation of Mammalian skin. Nature, 437(7056): 275-80

Lee E. R, Leblond C. P and Nadler N. J. (1985). Dynamic Histology of the Antral Epithelium in the Mouse Stomach. The Am. J. Anat, 172: 183-185

Lee S, Lee S, Chung T, Kim H, Yoon T, Kwak I, Park S, Cha W, Cho S, Cha K, (2003). Molecular and Cytogenetic Characterization of Two Azoospermic Patients with X-Autosome Translocation. J. Assis. Repr. Gen, 20(9): 385-389

Lee N.P.Y and Cheng C.Y. (2004). Ectoplasmic Specialization, a Testis-Specific CellCell Actin Based Adherens Junction Type: Is This a Potential Target for Male Contraceptive Development? Hum. Repr. Up, 10(4): 349-369

Lopez J. I, Mouw J. K, Weaver V. M. (2008). Biomechanical Regulation of Cell Orientation and Fate. Oncogene, 27: 6981-6993

Lyon M. F. (1962). Sex Chromatin and Gene Action in the Mammalian XChromosome. 135-148

Mangs A. H and Morris B. J. (2007). The Human Pseudoautosomal Region (PAR): Origin, Function and Future. Curr. Genom, 8: 129-136

Mansour S. L, Thomas K. R, Capecchi M. R. (1988). Disruption of the Proto-Oncogene int-2 in Mouse Embryo-Derived Stem Cells: a General Strategy for Targeting Mutations to Non-Selectable Genes. Nature, 336: 348-52.

Miller A. P, Gustashaw K, Wolff D. J, Rider S. H, Monaco A. P, Eble B, Schlessinger D, Gorski J. L, Van Ommen G, Weissenbach J, Willard H. F. (1995). Three Genes that Escape X chromosome Inactivation are Clustered Within a $6 \mathrm{Mb}$ YAC contig and STS map in Xp11.21-p11.22. Hum. Mol. Gen, 4(4): 731-739

Mills A. A, Zheng B, Wang X, Vogel H, Roop D. R, Bradley A. (1999). p63 is a p53 homologue required for limb and epidermal morphogenesis. Nature, 398: 708-713

Mills J. C, Andersson N, Hong C. H, Stappenbeck T. S, Gordon J. I. (2002). Molecular Characterization of Mouse Gastric Epithelial Progenitor Cells. P.N.A.S, 99(23): 14819-14824 
Miyahara M, Nakanishi H, Takahashi K, Satoh-Horikawa K, Tachibana K, Takai Y. (200). Interaction of Nectin with Afadin is Necessary for Its Clustering at CellCell Contact Sites But Not for Its Cis-Dimerization or Trans-Interaction. J. Biol. Chem. 275(1):613-8

Mizuno T and Yasugi S. (1990). Susceptibility of Epithelia to Directive Influences of Mesenchymes During Organogenesis: Uncoupling of Morphogenesis and Cytodifferentiation. Cell. Differ. Dev, 31(3):151-9.

Modlin I. M, Kidd M, Lye K. D, Wright N. A. (2003). Gastric Stem Cells: an Update. Keio. J. Med, 52 (2): 134-137

Mohandas T, Shapiro L. J, Sparkes R. S, Sparkes M. C. (1979). Regional Assignment of the Steroid Sulfatase-X-linked Ichthyosis Locus: Implications for a Noninactivated Region on the Short Arm of Human X chromosome. Proc. Natl. Acad. Sci. USA, 76 (11): 5779-5783

Molkentin J. D, Lin Q, Duncan S. A, Olson E. N. (1997). Requirement of the Transcription Factor GATA4 for Heart Tube Formation and Ventral Morphogenesis. Genes. Dev, 11(8): 1061-72

Mueller S, Rosenquist T. A, Takai Y, Bronson R. A, Wimmer E. (2003). Loss of Nectin-2 at Sertoli-Spermatid Junctions Leads to Male Infertility and Correlates with Severe Spermatozoan Head and Midpiece Malformation, Impaired Binding to the Zona Pellucida, and Oocyte Penetration. Biol. Repr, 69: 1330-1340

Nagy A, Moens C, Ivanyi E, Pawling J, Gertsenstein M, Hadjantonakis AK, Pirity M, Rossant J. (1998). Dissecting the role of N-myc in Development Using a Single Targeting Vector to Generate a Series of Alleles. Curr. Biol, 8(11):661-4

Narita T, Saitoh K, Kameda T, Kuroiwa A, Mizutani M, Koike C, Iba H, Yasugi S. (2000). BMPs Are Necessary for Stomach Gland Formation in the Chicken Embryo: a Study Using Virally Induced BMP-2 and Noggin Expression. Development, 127(5): 981-988

Nasdala I, Wolburg-Buchholz K, Wolburg H, Kuhn A, Ebnet K, Brachtendorf G, Samulowitz U, Kuster B, Engelhard B, Vestweber D, Butz S. A. (2002). Transmembrane Tight Junction Protein Selectively Expressed on Endothelial Cells and Platelets. Biol. Chem, 277: 16294-16303

Nelson W. J. (2003). Adaptation of Core Mechanisms to Generate Cell Polarity. Nature, 422: $766-774$

Nomura S, Esumi H, Job C, Tan S. (1998). Lineage and Clonal Development of Gastric Glands. Dev. Bio, 204(1): 124-35.

Nyeng P, Norgaard G. A, Kobberup S, Jensen J. (2007). FGF10 Signaling Controls Stomach Morphogenesis. Dev Bio, 303: 295-310 
O’Brien L. E, Zegers M. P, Mostov K. E. (2002). Building Epithelial Architecture: Insights from Three-Dimensional Culture Models. Nat. Rev. Mol. Cell Bio, 3: 531537

Ogawa T and Necheles H. (1958). Gastric Secretion in the Mous. Am. J. Physio, 194(2): 303-307

Ozaki-Kuroda K, Nakanishi. H, Ohta H, Tanaka H, Kurihara H, Mueller S, Irie K, Ikeda. W, Sakai T, Wimmer E, Nishimune Y, Takai Y. (2002). Nectin Couples Cell-Cell Adhesion and the Actin Scaffold at Heterotypic Testicular Junctions. Curr. Biol, 12: 1145-1150

Payer B and Lee J. T. (2008). X Chromosome Dosage Compensation: How Mammals Keep the Balance. Annu. Rev. Genet, 42: 733-72

Pierce G. B. (1967). Teratocarcinoma: Model for a Developmental Concept of Cancer Curr. Top. Dev. Biol, 2: 223-246

Qiao X. T, Ziel J. W, McKimpson W, Madison B. B, Todisco A, Merchant J. L, Samuelson L. C, Gumucio D. (2007). Identification of a Multi-Lineage Progenitor in Murine Stomach Epithelium. Gastroenterology, 133(6): 1989-1998

Rabinowitz J. E, Rutishauser U, Magnuson T. (1996). Targeted Mutation of Ncam to Produce a Secreted Molecule Results in a Dominant Embryonic Lethality. Proc. Natl. Acad. Sci. USA, 93(13): 6421-6424

Raven P. H and Johnson G. B. (1993). Biology. Mcgraw Hill Book Co 1-1259

Raschperger E, Engstrom U, Pettersson R. F, Fuxe J. (2004). CLMP, a Novel Member of the CTX Family and a New Component of Epithelial Tight Junctions. J. Biol. Chem, 279: 796-804

Reymond N, Fabre S, Lecocq E, Adelaïde J, Dubreuil P, Lopez M. (2001). Nectin4/PRR4, a New Afadin-associated Member of the Nectin Family that Transinteracts with Nectin1/PRR1 through V Domain Interaction. J. Biol. Chem. 276(46):43205-15

Reinsch S and Karsenti E. (1994). Orientation of Spindle Axis and Distribution of Plasma Membrane Proteins during Cell Division in Polarized MDCKII Cells. J. Cell. Bio, 126(6): 1509-1526

Roegiers F and Jan Y. H. (2004). Asymmetric Cell Division. Curr. Opin. Cell Biol, 16: 195-205

Sakiyama J, Yokouchi Y, Kuroiwa A. (2000). Coordinated Expression of Hoxb Genes and Signaling Molecules During Development of the Chick Respiratory Tract. Dev. Biol, 227(1): 12-27

Saitou M, Ando-Akatsuka Y, Itoh M, Furuse M, Inazawa J, Fujimoto K, Tsukita S. (1997). Mammalian occludin in epithelial cells: its expression and subcellular distribution. Eur. J. Cell Biol, 73(3): 222-31 
Sambrook, P. N, Cohen, M. L, Eisman, J. A, Pocock, N. A, Champion, G. D, Yeates M. G. (1989). Effects of Low Dose Corticosteroids on Bone Mass in Rheumatoid Arthritis: a Longitudinal Study. Ann. Rheum. Dis, 48: 535-8.

Sansonetti P. J, (2004). War and Peace at Mucosal Surfaces. Nature Reviews Immunology, 4: 953-964

Sato T, Irie K, Ooshio T, Ikeda W, Takai Y. (2004). Involvement of Heterophilic trans -Interaction of Necl-5/Tage4/PVR/CD155 with Nectin-3 in Formation of Nectinand Cadherin-Based Adherens Junctions. Genes to Cells, 9: 791-799

Satoh-Horikawa K, Nakanishi H, Takahashi K, Miyahara M, Nishimura M, Tachibana K, Mizoguchi A, Takai Y. (2000). Nectin-3, a New Member of Immunoglobulinlike Cell Adhesion Molecules That Shows Homophilic and Heterophilic Cell-Cell Adhesion Activities. J. Biol. Chem; 275(14): 10291-9

Scanlan M. J, Ritter G, Yin B. T, Williams C, Cohen L. S, Coplan K. A, Fortunato S. A, Frosina D, Lee S, Murray A. E, Chua R, Filonenko V. V, Sato E, Old L. J, Jungbluth A. A. (2006). Glycoprotein A34, a Novel Target for Antibody-Based Cancer Immunotherapy. Can. Immu, 6: 1-6

Shao M, Ghosh A, Cooke G. V, Naik U. P, Martin-DeLeon P. A. (2008). JAM-A is Present in Mammalian Spermatozoa Where it is Essential for Normal Motility. Dev. Bio, 313: 246-255

Schneeberger E. E and Lynch R. D. (2004). The Tight Junction: a Multifunctional Complex. Am.J.Physiol Cell Physiol, 286: 1213-1228

Shirneshan K, Binder S, Böhm D, Wolf S, Sancken U, Meinhardt A, Schmid M, Engel W, Adham I. (2008). Directed Overexpression of Insulin in Leydig Cells Causes a Progressive Loss of Germ Cells. Mol. Cell. Endocrinol, 295(1-2): 79-86

Southern E. M. (1975). Detection of Specific Sequences among DNA Fragments Separated by Gel Electrophoresis. J. Mol. Biol, 98: 503-17.

Spencer-Dene B, Sala F. G, Bellusci S, Gschmeissner S, Stamp G, Dickson C. (2006). Stomach Development is Dependent on Fibroblast Growth Factor 10/Fibroblast Growth Factor Receptor 2b-Mediated Signaling. Gastroenterology, 130(4): 12331244

Spradling A, Drummond-Barbosa D, Kai T. (2001). Stem Cells Find Their Niche. Nature, 414: 98-104

Stevens C. E and Leblond C. P. (1953). Renewal of the Mucous Cells in the Gastric Mucosa of the Rat. Anat. Rec, 115(2): 231-245

Sugimoto M, Akihito Inoko, Takashi Shiromizu, Masanori Nakayama, Peng Zou, Shigenobu Yonemura, Yuko Hayashi, Ichiro Izawa, Mikio Sasoh, Yukitaka Uji, Kozo Kaibuchi, Tohru Kiyono and Masaki Inagaki. (2008). The Keratin-Binding 
Protein Albatross Regulates Polarization of Epithelial Cells. J. Cell. Biol, 183(1): $19-28$

Suzu S, Hayashi Y, Harumi T, Nomaguchi K, Yamada M, Hayasawa H, Motoyoshid K, (2002). Molecular Cloning of a Novel Immunoglobulin Superfamily Gene Preferentially Expressed by Brain and Testis. Biochem. Biophys. Res. Commun, 296: $1215-1221$

Takai Y, Ikeda W, Ogita H, Rikitake Y. (2008). The Immunoglobulin-Like Cell Adhesion Molecule Nectin and Its Associated Protein Afadin, Annu. Rev. Cell Dev. Biol, 24: 309-42

Takahashi K, Nakanishi H, Miyahara M, Mandai K, Satoh K, Satoh A, Nishioka H, Aoki J, Nomoto A, Mizoguchi A, Takai Y. (1999). Nectin/PRR: an Immunoglobulin-like Cell Adhesion Molecule Recruited to Cadherin-based Adherens Junctions through Interaction with Afadin, a PDZ Domain-containing Protein. J. Cell Biol, 145(3):539-49

Takamoto N, You L, Moses K, Chiang C, Zimmer W. E, Schwartz R. Z, DeMayo F. J, Tsai M, Tsai S. Y. (2005). COUP-TFII is Essential for Radial and Anteroposterior Patterning of the Stomach. Development, 132: 2179-2189

Takeichi M. (1995). Morphogenetic roles of classic cadherins.Curr. Opin. Cell Biol, 7(5): 619-27

Tatematsu M, Fukami H, Yamamoto M, Nakanishi H, Masui T, Kusakabe N, Sakakura T. (1994). Clonal Analysis of Glandular Stomach Carcinogenesis in $\mathrm{C} 3 \mathrm{H} / \mathrm{HeN}-$ BALB/c Chimeric Mice Treated with N-methyl-N-nitrosourea.Cancer Lett, 83(12): $37-42$

Thery M, Racine V, Pépin A, Piel M, Chen Y, Sibarita J, Bornens M. (2005). The Extracellular Matrix Guides the Orientation of the Cell Division Axis. Nat. Cell Bio, 7: 947-953

Theodosiou N. A and Tabin C. J. (2003). Wnt Signaling During Development of the Gastrointestinal Tract. Dev. Bio, 259(2): 258-271

Thompson M, Fleming K. A, Evans D. J, Fundele R, Surani M. A, Wright N. A. (1990) Gastric Endocrine Cells Share a Clonal Origin with Other Gut Cell Lineages. Development, 110(2): 477-81

Thomson J. A, Itskovitz-Eldor J, Shapiro S. S, Waknitz M. A, Swiergiel J. J, Marshall V. S, Jones J. M. (1998). Embryonic Stem Cell Lines Derived from Human Blastocysts. Science, 282: 1145 - 1147

Toshimori K, Maekawa M, Ito C, Toyama Y, Suzuki-Toyota F, Saxena D. K. (2006). The Involvement of Immunoglobulin Superfamily Proteins in Spermatogenesis and Sperm-Egg Interaction. Repro. Med. Bio, 5: 87-93

Toyoshima F and Nishida E. (2007). Spindle Orientation in Animal Cell Mitosis: Roles of Integrin in the Control of Spindle Axis. J. Cell. Physio, 213: 407-411 
Tsukita S, Furuse M, Itoh M. (2001). Multifunctional Strands in Tight Junctions. Nat. Rev. Mol. Cell Biol, 2(4): 285-293.

Tucker A. S, Khamis A, Sharpe P. T. (1998). Transformation of Tooth Type Induced by Inhibition of BMP Signaling. Dev. Dyn, 212(4): 533-539

Vogelstein B, Gillespie D. (1979). Preparative and Analytical Purification of DNA from Agarose. Proc Natl Acad Sci U S A, 76: 615-9.

Wakayama T, Koami H, Ariga H, Kobayashi D, Sai Y, Tsuji A, Yamamoto M, Isek S. (2003). Expression and Functional Characterization of the Adhesion Molecule Spermatogenic Immunoglobulin Superfamily in the Mouse Testis. Bio. Repro, 68: 1755-1763

Wang Y and Nathans J. (2007). Tissue/Planar Cell Polarity in Vertebrates: New Insights and New Questions. Development, 134: 647-658

Wang Q.F and Cheng C. (2007). A Seamless Trespass: Germ Cell Migration across the Seminiferous Epithelium during Spermatogenesis. J. Cell Bio, 178: 549-556

Wells J. M, and Melton D. A. (1999). Vertebrate Endoderm Development. An. Rev. Cell Dev. Bio, 15: 393-410

Williams L.A, Martin-Padura, Dejana E, Hogg N, Simmons D. L. (1999). Identification and Characterisation of Human Junctional Adhesion Molecule (JAM). Mol. Immun, 36: $1175-1188$

Witkin S. S, Jeremias J, Bongiovanni A. M, Munoz M. G. (1996). Immune Regulation in the Male Genital Tract. Infec. Dis. Obst. Gyne, 4:131-135

Wodarz A. (2002). Establishing Cell Polarity in Development. Nat. Cell Bio, 4: E39E44

Xia W, Wong C. H, Lee N. P, Lee W. M, Cheng C. Y. (2005). Disruption of SertoliGerm Cell Adhesion Function in the Seminiferous Epithelium of the Rat Testis Can be Limited to Adherens Junctions Without Affecting the Blood-Testis Barrier Integrity: An in vivo Study Using an Androgen Suppression Model. J. Cell Physiol, 205(1): 141-57.

Xia W, Wong E. W. P, Mruk D. D, Cheng C. Y. (2008). TGF- $\beta 3$ and TNF $\alpha$ Perturb Blood-Testis Barrier (BTB) Dynamics by Accelerating the Clathrin-Mediated Endocytosis of Integral Membrane Proteins: A New Concept of BTB Regulation During Spermatogenesis. Dev. Bio, 327: 48-61

Yang A, Schweitzer R, Sun D, Kaghad M, Walker N, Bronson R. T, Tabin C, Sharpe A, Caput D, Crum C, McKeon F. (1999). p63 is Essential for Regenerative Proliferation in Limb, Craniofacial and Epithelial Development. Nature, 398(6729): 714-8 
Yang Y. C, Wang C, Hung H, Chang C, Wu I, Huang Y, Lin T, Tsai J, Chen A, Kuo F, Wang W, Wu D. (2007). Isolation and Characterization of Human Gastric Cell Lines with Stem Cell Phenotypes. J. Gastro. Hepato, 22: 1460-1468

Yasugi S. (1994). Regulation of Pepsinogen Gene Expression in Epithelial Cells of Vertebrate Stomach during Development. J. Dev. Bio, 18: 271-279

Yeaman C, Grindstaff K. K, Nelson W. J. (1999). New Perspectives on Mechanisms Involved in Generating Epithelial Cell Polarity. Physiol. Rev. 79(1): 73-98

Zallen1 J. A. (2007). Planar Polarity and Tissue Morphogenesis. Cell, 129: 1051-1063 


\section{Curriculum Vitae}

\section{Personal details}

$\begin{array}{ll}\text { Name } & \text { Odgerel } \\ \text { Surname } & \text { Oidovsambuu } \\ \text { Family name } & \text { Khunnu } \\ \text { Date of birth } & \text { 08, May, 1980 } \\ \text { Sex } & \text { Male } \\ \text { Marriage status } & \text { Single } \\ \text { Nation/Ethnicity } & \text { Mongolian } \\ \text { Mailing/Home Address } & \text { Theoder-Heuss-Strasse 11/512, Goettingen -37075 } \\ \text { Contact address } & \text { Tel: 01759997080, E-mail: khunnustar@yahoo.co.uk }\end{array}$

\section{$\underline{\text { Education }}$}

Aug, 2005- May, 2009

Doctorate of Philosophy (PhD), Institute of Human

Genetics, Georg-August-Universität Göttingen, Germany

Thesis Topic: "Expression and functional analysis of

Vsig1 gene"

Oct, 2003- June, 2005 Master of Science (MSc), Department for Molecular

Biology and Genetics, National University of Mongolia,

Thesis topic: "Expression analysis of SA7 gene"

Sep, 1998- June, 2003

Bachelor of Science (BSc), Department for Molecular

Biology and Genetics, National University of Mongolia,

Thesis topic: "Expression analysis of murine BIG2 gene"

Sep, 1988- May, 1998 Primary, secondary and high schooling, 40-th school of

Ulaanbaatar

\section{Work experience}

Nov, 2004- July, 2005

Assistant researcher at Institute of Biology, Mongolian

Academy of Sciences, Ulaanbaatar 


\section{ACKNOWLEDGEMENTS}

First, I sincerely and deeply appreciate to Prof. Dr. W. Engel for giving me the chance to study here in the institute. I learned lots of things from him. His help has been very important for my life. It was a great honour to study here under his teaching.

I sincerely thank to my supervisor Prof. Dr. Adham for proofreading the manuscript, his superior support and friendly relationship throughout my study.

I thank PD. Dr. S. Hoyer-Fender for having accepted to be my co-referee in this study. I also thanks to Prof. Dr. M. Mühlenberg and PD. Dr. K. Wesche for accepting to be my examiners.

Special thanks to my lab colleagues and all the co-workers from the "Institute of Human Genetics” for their numerous advices, constant support, and fantastic work atmosphere. 